Tesis Doctoral

\title{
Papel inmunosupresor y citotóxico de la arginasa I y la disponibilidad de L-arginina en el sistema inmune y cáncer
}

Rósula García Navas

Director de tesis:

Faustino Mollinedo García

Centro de Investigación del Cáncer - CSIC

Universidad de Salamanca - Facultad de Medicina

Salamanca, 2014
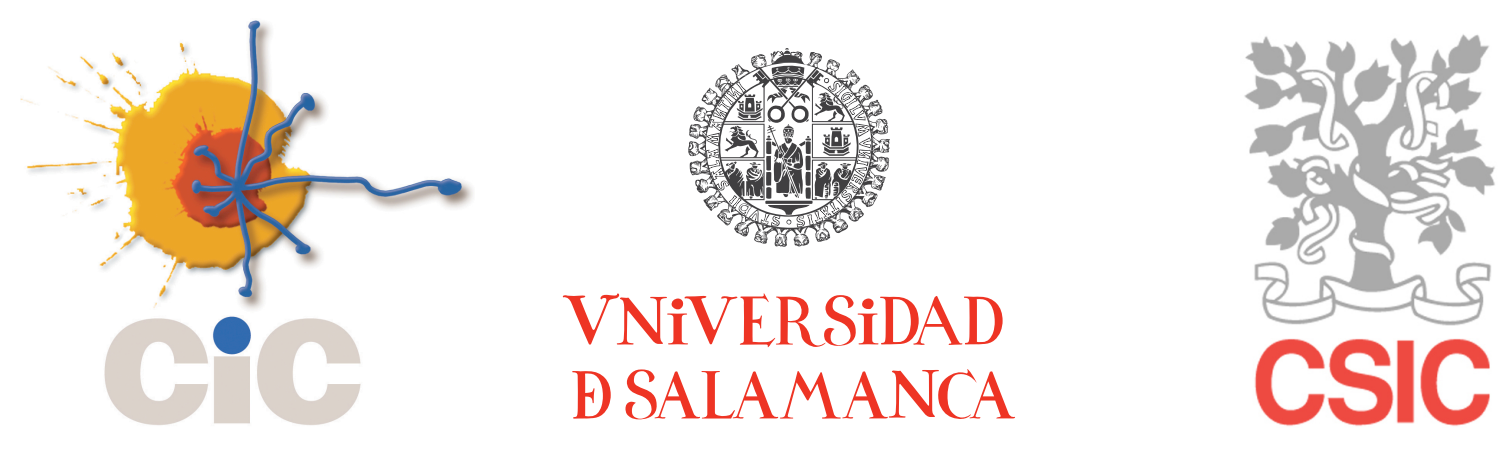

Dr. Faustino Mollinedo García, Profesor de Investigación del Consejo Superior de Investigaciones Científicas (CSIC) y miembro del Instituto de Biología Molecular y Celular del Cáncer de la Universidad de Salamanca, y Dr. Rogelio González Sarmiento, Catedrático de Medicina Molecular de la Universidad de Salamanca y miembro del Instituto de Biología Molecular y Celular del Cáncer de la Universidad de Salamanca (CSIC),

\section{CERTIFICAN:}

Que la memoria "Papel inmunosupresor y citotóxico de la arginasa I y la disponibilidad de L-arginina en el sistema inmune y cáncer” presentado por Rósula García Navas, ha sido realizada bajo su dirección en el Instituto de Biología Molecular y Celular del Cáncer y reúne, a su juicio, originalidad y contenidos suficientes para que sea presentada ante el tribunal correspondiente y optar al grado de Doctor por la Universidad de Salamanca.

Y para que así conste, a efectos legales, expide el presente certificado en Salamanca, a 10 de Diciembre de 2013.

Dr. Faustino Mollinedo García

Director de la tesis
Dr. Rogelio González Sarmiento

Tutor académico 

Aquí y ahora, mi ponto de luz... 



\section{Índice}

$\begin{array}{ll}\text { Abreviaturas } & 1\end{array}$

Introducción $\quad 5$

$\begin{array}{ll}\text { 1. L-Arginina } & 7\end{array}$

$\begin{array}{ll}\text { 1.1. Metabolismo de la arginina } & 7\end{array}$

1.2. Participación de la arginina y la arginasa en el sistema inmune 11

1.3. La ARG y su controvertido papel en cáncer 16

2. Estrés de retículo endoplasmático y la respuesta de proteínas desplegadas $\mathbf{1 8}$

2.1. Vía de IRE1 19

2.2. Vía de PERK 20

2.3. Vía ATF6 21

2.4. Destino celular mediado por la respuesta UPR 22

2.4.1. Mecanismos adaptativos regulados por UPR 22

2.4.2. Estrés de RE crónico y apoptosis $\quad 25$

3. Autofagia 26

3.1. Tipos de autofagia $\quad 26$

3.2. La formación del autofagosoma 28

3.3. Regulación de la autofagia por la vía de mTOR 30

3.3.1. Control de la autofagia por el complejo ULK1-ATG13-FIP200/mTORC1 32

3.3.2. Control de la autofagia por la detección de nutrientes a través de la ruta Rag/mTOR

3.3.3. Control de la autofagia por factores de crecimiento a través de la ruta PI3KC1a/Akt/ TSC/mTORC1

3.3.4. Control de la autofagia mediante sensores de energía a través de la ruta AMPK/ TSC/mTORC1

3.4. Regulación de la autofagia por rutas independientes de mTOR 
3.4.3. Control de la autofagia por la ruta Ca2+/calpaina 37

3.4.4. Control de la autofagia por la ruta JNK1/Beclin-1/PI3KC3 37

\section{Objetivos}

\section{Materiales y Métodos}

1. Cultivos celulares

2. Recuento de células viables mediante Trypan Blue

3. Aislamiento de células sanguíneas

4. Generación de sonicados de neutrófilos

5. Actividad arginasa

6. Ensayos de exocitosis

7. Aislamiento de células endoteliales a partir del cordón umbilical

8. Extracción de RNA

9. Síntesis de cDNA a partir de RNA: transcripción reversa (RT)

10. Amplificación de DNAc mediante la Reacción en Cadena de la Polimerasa (PCR)

11. Expresión y purificación de la proteína de fusión mediante cromatografía de afinidad

12. Análisis de apoptosis y ciclo celular mediante citometría de flujo

13. Análisis de expresión de antígenos en superficie mediante citometría de flujo

14. Electroforesis de proteínas en geles SDS-PAGE, Western blot e inmunodetección

15. Microscopía de fluorescencia

16. Coinmunoprecipitación

17. Proliferación celular

18. Tinción con naranja de acridina

19. Actividad del proteasoma

20. Flujo autofágico

21. Transfección de líneas celulares 
I.1. Expresión de CD3ろ y otros antígenos de membrana en ausencia de L-Arg

I.2. La ausencia de L-Arg induce estrés de retículo en células T

I.3. La ausencia de L-Arg induce autofagia como mecanismo de supervivencia en células T $\quad 71$

I.4. La ausencia de L-Arg induce la regulación negativa de la ruta PI3K-Akt-mTOR-p7oS6K $\quad 76$

I.5. Inhibición de JNK y ERK1/2 bloquea la autofagia inducida por la ausencia de L-Arg en células T

I.6. La autofagia inducida por la ausencia de L-Arg protege a las células T de la apoptosis

I.7. La ruta de señalización de IRE1a en células T humanas es necesaria para la activación de la autofagia inducida por L-Arg

I.8. Ausencia de L-Met y L-Tyr induce estrés de retículo endoplásmico y autofagia como mecanismo de supervivencia en células Jurkat

I.9. El restablecimiento de L-Arg restaura la proliferación celular y la expresión de antígenos e inhibe la autofagia inducida por la deficiencia de L-Arg

II. Participación de la arginasa I en la muerte de células tumorales mediada por neutrófilos

II. 1. La arginasa de neutrófilos induce apoptosis en células tumorales

II. 2. La apoptosis inducida por ARG1 en células tumorales es inhibida por nor-NOHA

II. 3. La liberación de ARG1 por la degranulación de neutrófilos induce apoptosis en células tumorales

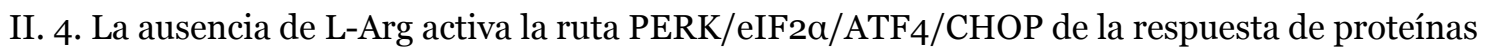
desplegadas

II. 5. La disminución de la L-Arg por la ARG1 de neutrófilos activados, no afecta a células proliferativas no tumorales

Discusión

I. La ausencia de L-Arg en células T humanas induce autofagia como respuesta citoprotectora al estrés del retículo endoplásmico

II. Participación de la arginasa I en la muerte de células tumorales mediada por neutrófilos

Conclusiones 



\section{Abreviaturas}

\begin{tabular}{|c|c|c|c|}
\hline 3-MA & 3-Methyladenine & Atg & Autophagy (related gene) \\
\hline $4 \mathrm{E}-\mathrm{BP} 1$ & $\begin{array}{l}\text { Eukaryotic initiation factor } 4 \mathrm{E} \text { binding } \\
\text { protein } 1\end{array}$ & ATP & Adenosin triphosphate \\
\hline $\mathrm{ADC}$ & Arginine decarboxylase & Bak & Bcl-2 homologous antagonist killer \\
\hline ADI & Arginine deiminase & Bax & $\mathrm{Bcl}-2-$ associated $\mathrm{X}$ protein \\
\hline ADMA & Dimetil-L-arginina asimétrica & $\mathrm{Bcl}-2$ & B-cell lymphoma 2 \\
\hline ADP & Adenosin difosfato & $\mathrm{Bcl}-\mathrm{xl}$ & Bcl-X long \\
\hline AEEM & $\begin{array}{l}\text { Agencia Europea de Evaluación del } \\
\text { Medicamento }\end{array}$ & Beclin-1 & $\begin{array}{l}\text { Coiled-coil, moesin-like BCL2 interacting } \\
\text { protein }\end{array}$ \\
\hline AGAT & L-arginine:glycine amidinotransferase & $\mathrm{BF}$ & Bafilomicina \\
\hline AIR & Autophagy inducing receptor & $\mathrm{BH}$ & Bcl-2 homolgy \\
\hline Akt & $\begin{array}{l}\text { v-akt murine thymoma viral oncogene } \\
\text { homolog } 1\end{array}$ & Bid & $\mathrm{BH} 3$ interacting domain death agonist \\
\hline Ambra1 & $\begin{array}{l}\text { Activating molecule in Beclin-1- regulated } \\
\text { autophagy }\end{array}$ & Bif-1 & Endophilin B1 \\
\hline AMP & Adenosín monofosfato & Bik & $\mathrm{Bcl}-2$ interacting killer \\
\hline $\mathrm{AMC}$ & Autofagia mediada por chaperonas & Bim & Bcl-2 interacting mediator of cell death \\
\hline AMPK & $\begin{array}{l}\text { Adenosin monophophate activated protein } \\
\text { kinase Ams } 1 \alpha \text {-mannosidase }\end{array}$ & BSA & Bovine standard albumin \\
\hline Ape1 & Aminopeptidase I & BSMAP & Brain-specific membrane anchored protein \\
\hline APP & Amyloid beta precursor protein & Calpaina & Calcium-activated neutral proteinase \\
\hline ARG & Arginasa & CCD & Central coiled-coil domain \\
\hline ASL & Argininosuccinate lyase & CCL & Chemokine (C-C motif) ligand \\
\hline ASK1 & Apoptosis signal regulating kinase 1 & $\mathrm{CD}$ & Cluster of differentiation \\
\hline ASS & Argininosuccinate synthase & $\mathrm{cdk}$ & Cyclin-dependent kinase \\
\hline ATF4 & Activating transcription factor 4 & cDNA & Dna complementario \\
\hline ATF6 & Activating transcription factor 6 & $\mathrm{CHOP}$ & $\mathrm{C} / \mathrm{EBP}$ homologous protein \\
\hline cLD & ER-lumenal domain & GRP78/BiP & $78 \mathrm{kDa}$ glucose-regulated protein \\
\hline
\end{tabular}




\begin{tabular}{|c|c|c|c|}
\hline CMA & Chaperone mediated autophagy & GRP94 & $94 \mathrm{kDa}$ glucose-regulated protein \\
\hline CPS-1 & Carbamoyl-phosphate synthase 1 & GST & Glutathione-S-transferase \\
\hline CQ & Cloroquina & HUVEC & Human umbilical vein endothelial cells \\
\hline Cvt & Cytoplasm to the vacuole targeting pathwaty & $\mathrm{IC}_{50}$ & $\begin{array}{l}\text { Concentración que inhibe el } 50 \% \text { de } \\
\text { crecimiento }\end{array}$ \\
\hline DAG & Diacylglycerol & $\mathrm{IC}_{80}$ & $\begin{array}{l}\text { Concentración que inhibe el } 50 \% \text { de } \\
\text { crecimiento }\end{array}$ \\
\hline DAPK & Death-associated protein kinase & ICAM & Intercellular adhesion molecules \\
\hline DDAH & Dimetil-L-arginina-dimetil-amino-hidrolasa & IFN & Interferon \\
\hline Deptor & $\begin{array}{l}\text { DEP-domain containing mTOR-interacting } \\
\text { protein }\end{array}$ & $\operatorname{Ig}$ & Inmunoglobulina \\
\hline Derlin-1 & $\begin{array}{l}\text { Degradation in endoplasmic reticulum } \\
\text { protein 1; }\end{array}$ & $\operatorname{IKK} \beta$ & Inhibitor of nuclear factor $\chi \mathrm{B}$ kinase $\beta$ \\
\hline DMSO & Dimethylsulfoxide & IL & Interleuquina \\
\hline DNA & Desoxyribonucleic acid & IMPasa & Inositol monophosphatase \\
\hline dNTP & Deoxynucleotide triphosphate & IP & Inmunoprecipitación \\
\hline $\operatorname{eIF} 2 \alpha$ & $\begin{array}{l}\text { Eukaryotic translation initiation factor } 2 \\
\text { subunit } 1\end{array}$ & IP3R & inositol 1,4,5-triphosphate receptor \\
\hline Epac & Exchange protein directly activated by cAMP & IPAF & $\begin{array}{l}\text { Interleukin-1beta converting enzyme (ICE) } \\
\text { protease-activating factor Internal ribosome } \\
\text { entry site }\end{array}$ \\
\hline EPT-N & Extracto de proteínas totales de neutrófilos & IPPasa & Inositol polyphosphate 1-phosphatase \\
\hline ERAD & $\begin{array}{l}\text { Endoplasmic-reticulum-associated protein } \\
\text { degradation }\end{array}$ & IRE1 & Inositol-requiring protein 1 \\
\hline FACS & Fluorescence activated cell sorting & IRES & Immunity regulated GTPase \\
\hline FAD & Flavina adenina dinucleótido & ITAM & $\begin{array}{l}\text { Immunoreceptor tyrosine-based activation } \\
\text { motif }\end{array}$ \\
\hline FBS & Foetal bovine serum & JNK & $\mathrm{c}$-Jun $\mathrm{N}$-terminal protein kinase \\
\hline FDA & Food and Drug Administration & $\mathrm{kDa}$ & Kilodalton \\
\hline FIP200 & $\begin{array}{l}\text { Focal adhesion kinase family-interacting } \\
\text { protein of } 200 \mathrm{kDa} \text { Fluorescein } \\
\text { isothiacyanate }\end{array}$ & KEAP1 & kelch-like ECH-associated protein 1 \\
\hline fMLP & Formyl-methionyl-leucyl-phenylalanine & LAMP & Lysosome associated membrane protein \\
\hline FMN & Mononucleótido de flavina & $\mathrm{LB}$ & Luria-Bertani broth \\
\hline FoxO3 & Forkhead box $\mathrm{O} 3$ & LC3 & $\begin{array}{l}\text { Microtubule-associated proteins 1A/1B light } \\
\text { chain } 3\end{array}$ \\
\hline GADD34 & $\begin{array}{l}\text { growth-arrest and DNA-damage-inducible } \\
\text { protein } 34\end{array}$ & LKB1 & Liver Kinase B1 \\
\hline GAP & GTPase-activating protein & MDSCs & Myeloid-derived suppressor cells \\
\hline GCN2 & General control nonrepressed-2 & MEFs & Mouse embryonic fibroblasts \\
\hline GDP & Guanosine diphosphate & mLST8 & Mammalian lethal with SEC13 protein 8 \\
\hline GFP & Green fluorescent protein & mSIN1 & $\begin{array}{l}\text { Mammalian stress-activated mitogen- } \\
\text { activated protein kinase-interacting protein } 1\end{array}$ \\
\hline GRP94 & $94 \mathrm{kDa}$ glucose-regulated protein & mTOR & Mammalian target of rapamycin \\
\hline
\end{tabular}




\begin{tabular}{|c|c|c|c|}
\hline mTORC1 & Mammalian target of rapamycin complex 1 & $\mathrm{RE}$ & Retículo endoplasmático \\
\hline mTORC2 & Mammalian target of rapamycin complex 2 & Rheb & Ras homolog enriched in brain \\
\hline N-fMLP & $\begin{array}{l}\text { Sobrenadante del exocitado de neutrófilos } \\
\text { inducido por fMLP }\end{array}$ & Rictor & Rapamycin-insensitive companion of $\mathrm{mTOR}$ \\
\hline NADP & $\begin{array}{l}\text { Nicotinamide adenine dinucleotide } \\
\text { phosphate }\end{array}$ & RIG-I & Retinoic acid-inducible gene I \\
\hline NFR2 & Nuclear factor erythroid-2-related factor 2 & RIP & Regulated intramembranal proteolysis \\
\hline NO & Nitric oxide & RLH & Retinoic acid-inducible gene I-like helicase \\
\hline NOS & Nitric oxide synthase & RNA & Ribonucleic acid \\
\hline OAT & Ornithine aminotransferase & ROS & Reactive oxygen species \\
\hline ODC & Ornithine decarboxylase & $\mathrm{rpm}$ & Rounds per minute \\
\hline OTC & Ornithine carbamoyltransferase & S6K1 & S6 kinase 1 \\
\hline p53 & P53-upregulated modulator of apoptosis & SDS & Sodium dodecyl sulfate \\
\hline $\mathrm{p} 70 \mathrm{~S} 6 \mathrm{~K}$ & Ribosomal protein S6 kinase-1 & SFB & Suero fetal bovino \\
\hline $\mathrm{pb}$ & Pares de base & siRNA & Small inhibiting RNA \\
\hline PDK1 & Phosphoinositide-dependent kinase 1 & SLC & Solute carrier family \\
\hline PEG & Polietilenglicol & $\begin{array}{l}\text { SMAC/ } \\
\text { DIABLO }\end{array}$ & $\begin{array}{l}\text { Second mitochondria-derived activator of } \\
\text { caspases/direct inhibitor of apoptosis- } \\
\text { binding protein with low pI }\end{array}$ \\
\hline PERK & PKR-like ER kinase & SQSTM1/p62 & Sequestosome-1 \\
\hline $\mathrm{PH}$ & Pleckstrin homology & SRIS & Síndrome de respuesta inflamatoria sistémica \\
\hline PI3K & Phosphatidylinositide 3-kinase & ssRNA & Single stranded ribonucleic acid \\
\hline PI3KC1 & PI3K clase I & STAT & $\begin{array}{l}\text { Signal Transducer and Activator of } \\
\text { Transcription }\end{array}$ \\
\hline PI3KC3 & PI3K clase III & TAN & tumor-associated neutrophils \\
\hline PKB & Protein kinase B & TBS & Tris-buffered saline \\
\hline PKC & Protein kinase $\mathrm{C}$ & TCR & Receptor de células T \\
\hline PLC $\varepsilon$ & Phospholipase C, epsilon 1 & $\mathrm{TE}$ & Tris/EDTA \\
\hline PMA & Phorbol-12-myristate 13-acetate & TFEB & Transcription factor EB \\
\hline PMSF & Phenylmethyl sulphonyl fluoride & TGI & Total Growth Inhibition \\
\hline PP1 & Phospho protein phosphatase 1 & Th & T-helper (cell type) \\
\hline PRAS40 & Proline-rich Akt substrate $40-\mathrm{kDa}$ & TLR & Toll-like receptor \\
\hline Protor & Protein observed with rictor & TNF & Tumour necrosis factor \\
\hline PRR & Pattern recognition receptors & TRIF & $\begin{array}{l}\text { Toll/IL-1 receptor domain-containing } \\
\text { adaptor inducing IFN- } \beta\end{array}$ \\
\hline PS-1 & Presenilin 1 & TRIS & Tris(hydroxymethyl)aminomethan \\
\hline PtdIns3P & Phophatidylinositol-tri-phophate & tRNA & RNA de transferencia \\
\hline PTEN & Phosphatase and tensin homolog & TSC & Tuberous sclerosis complex \\
\hline Rag & Ras-related GTP-binding protein & TSC1/2 & Tuberous sclerosis complex \\
\hline Raptor & Regulatory associated protein of mTOR & $\mathrm{U}$ & Unidades \\
\hline
\end{tabular}


UPR Unfolded protein response

UV Ultraviolet

UVRAG UV-radiation resistance-associated gene protein

VAMP1 Vacuole membrane protein 1

Vps Vacuolar protein sorting

WB Western blot

WM Wortmannin

XBP1 X-box DNA-binding protein 1

XBP1s XBP1 spliced

XBP1u XBP1 unspliced

ZAP70 Zeta-chain (TCR) associated protein kinase $70 \mathrm{kDa}$ 


\section{Introducción}





\section{L-Arginina}

La L-arginina ( $\mathrm{L}-\mathrm{Arg}$ ) es un aminoácido semi-esencial o condicionalmente esencial en algunas etapas del desarrollo. La L-Arg es el portador de nitrógeno más abundante, en parte por que contiene cuatro átomos de nitrógeno en su molécula y por que sirve como precursor para la síntesis del óxido nítrico (NO; nitric oxide), la orinitina, urea, poliaminas, prolina, creatina, agmatina, glutamato y proteínas. Además es un activador alostérico de la $\mathrm{N}$ acetilglutamato sintasa para sintetizar $\mathrm{N}$-acetil glutamato, un cofactor esencial para carbamilfosfato sintasa I. La arginina parece desempeñar otras funciones fisiológicas importantes, como en el mantenimiento de la respuesta inmune. Así mismo, este aminoácido es capaz de estimular la secreción de hormonas como la insulina, glucagon, catecolaminas, prolactina y la hormona del crecimiento ${ }^{1-3}$.

\subsection{Metabolismo de la arginina}

La L-Arg es uno de los aminoácidos mas versátiles y puede tener distintos destinos metabólicos. Posee un papel importante como intermediario en el ciclo de la urea y como precursor de la biosíntesis de la creatinina, agmatina, glutamato, prolina y poliaminas (Figura 1). Por consiguiente, su metabolismo es complejo y se encuentra altamente regulado. Esta complejidad no solo viene dada por la diversidad de enzimas involucradas en su metabolismo, sino también por los patrones específicos de expresión de las enzimas involucradas, dependiendo del tipo celular ${ }^{4,5}$.

La L-Arg es sintetizada a partir de citrulina, por la acción secuencial de dos enzimas citosólicas la ASS (argininosuccinate synthase) y la ASL (argininosuccinate lyase). Esta síntesis es energéticamente costosa para la célula, puesto que cada molécula de argininosuccinato requiere la hidrólisis del ATP a AMP, requiriendo dos equivalentes de ATP. La citrulina puede derivarse de múltiples fuentes: de la L-Arg por la actividad de la NOS (nitric oxide synthase); de la Lornitina procedente del catabolismo de prolina o glutamina/glutamato; o por la hidrolisis de ADMA (dimetiL-Arg asimétrica) por la ruta de la DDAH (dimetiL-Arg-dimetil-aminohidrolasa) (Figura 1). Las células epiteliales del intestino delgado producen citrulina a partir de la glutamina/glutamato y es utilizada por las células del riñón para producir L-Arg y devolverla a la circulación ${ }^{6}$. Otros tipos celulares además de las células renales pueden producir citrulina ya que poseen los genes implicados en la ruta. Sin embargo, los niveles de expresión de los mismos son significativamente más bajos. Estudios recientes han demostrado que la 
producción de L-Arg también puede ser inducida por citoquinas y otros agentes, a través de la ruta de la iNOS ${ }^{7}$.

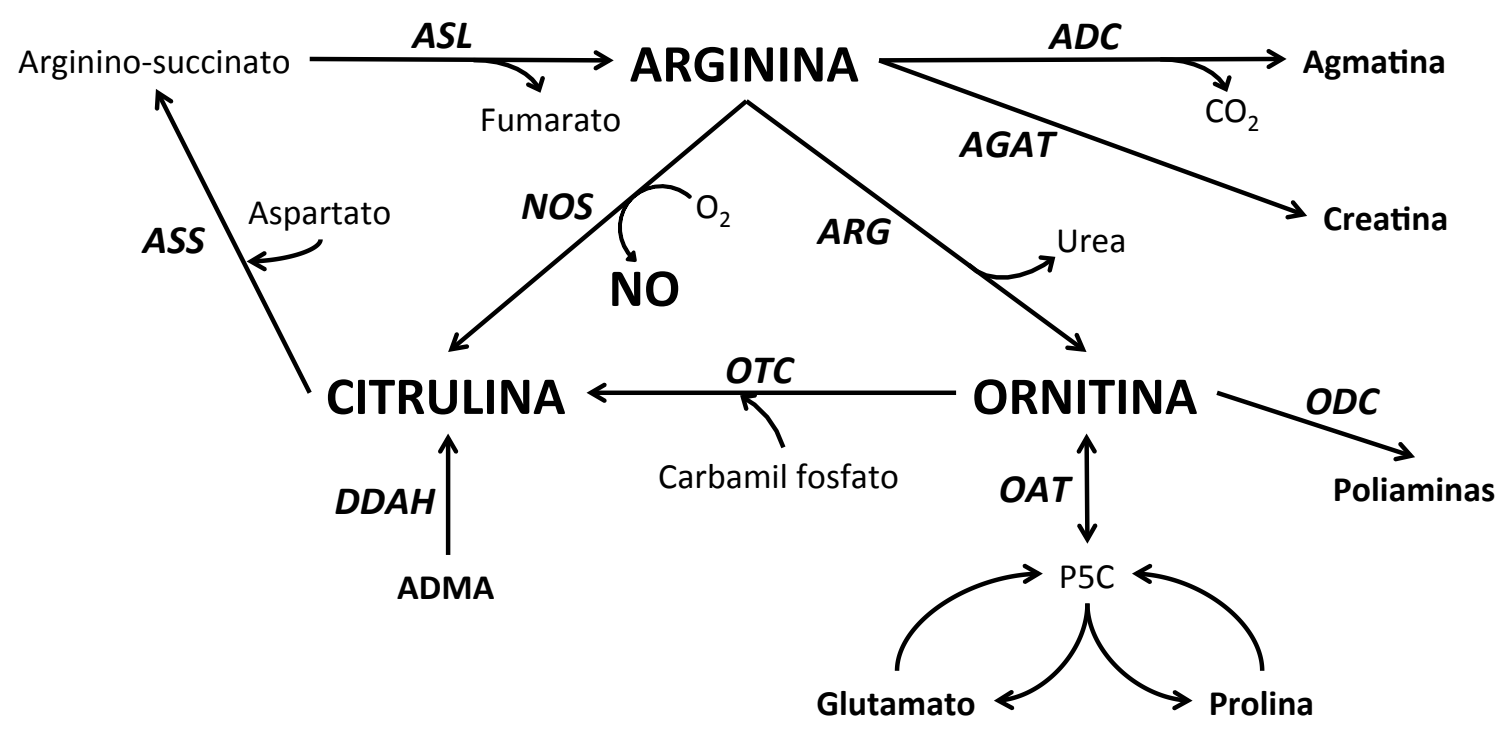

Figura 1. Origen metabólico y destinos de la L-Arg, citrulina y ornitina. Sólo las enzimas que participan directamente en la producción o utilización de estos aminoácidos están señaladas. Abreviaciones: ADC, arginina decarboxilasa; ADMA, asimetric-dimetiL-Arg; DDAH, dimetiL-Arg dimetil-amino-hidrolasa; AGAT, arginina:glicina amidinotransferasa; ARG, arginasa; NOS, oxido nítrico sintasa; ASL, argininosuccinato liasa; ASS, argininosuccinateo sintetasa; OAT, ornitina aminotransferasa; ODC, ornitina decarboxilasa; OTC, ornitina transcarbamilasa; P5C, L- $\Delta$ 1-pirrolina-5-carboxilato. El P5C se encuentra en equilibrio químico con el L-glutamato--semialdehido vía una reacción espontánea no enzimática ${ }^{9}$.

La L-Arg puede ser catabolizada en células de mamíferos por cuatro enzimas: la arginasa (ARG), la NOS, la AGAT (L-arginine:glycine amidinotransferase) y la ADC (arginine decarboxylase $)^{8,9}$ (Figura 1). En mamíferos se han identificado dos isoformas de la ARG, ARG1 y la ARG2. Estas isoformas comparten un 54\% de identidad de secuencia (Figura 2) y difieren en su distribución tisular, subcelular, reactividad cruzada inmunológica y función fisiológica. La ARG1 es un componente importante del ciclo de la urea y se encuentra localizada en el citosol de hepatocitos y eritrocitos, y en gránulos de neutrófilos y macrófagos. La ARG2 esta localizada en las mitocondrias de varios tipos celulares, incluyendo células renales, neuronas y macrófagos ${ }^{10-14}$. La ARG2 se expresa constitutivamente y juega un papel importante en la síntesis de L-prolina, debido a su proximidad a la OAT (ornithine aminotransferase) también localizada en la mitocondria ${ }^{15,16}$.

La L-Arg es el precursor inmediato de la urea. La urea se forma a lo largo de una secuencia de cinco reacciones en el hígado, de las cuales cuatro forman un ciclo. En la mitocondria, la enzima mitocondrial CPS-1 (carbamoyl-phosphate synthase 1) cataliza la condensación amonio y bicarbonato para formar carbamoil fosfato, quien proporciona uno de 

MSLRGSLSRLLQTRVHSILKKSVHSVAVIGAPFSQGQKRKGVEHGPAAIREAGLMKRLSS :. : : : : : ******:******.**:.:*:***:::*..

43 QECDVKDYGDLPFADIPNDSPFQ-IVKNPRSVGKASEQLAGKVAEVKKNGRISLVLGGDH 61 LGCHLKDFGDLSFTPVPKDDLYNNLIVNPRSVGLANQELAEVVSRAVSDGYSCVTLGGDH

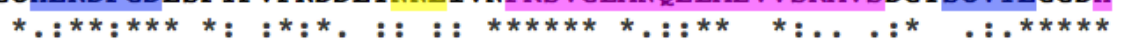

102 SLAIGSISGHARVHPDLGVIWVDAHTDINTPLTTTSGNLHGQPVSFLLKELKGKIPDVPG 121 SLAIGTISGHARHCPDLCVVWVDAHADINTPLTTSSGNLHGQPVSFLLRELQDKVPQLPG $* * * * *: * * * * * * \quad * * * *: * * * * *: * * * * * * * *: * * * * * * * * * * * * *: * *: *: *:: * *$

162 FSWVTPCISAKDIVYIGLRDVDPGEHYILKTLGIKYFSMTEVDRLGIGKVMEETLSYLLG

181 FSWIKPCISSASIVYIGLRDVDPPEHFILKNYDIQYFSMRDIDRLGIQKVMERTFDLLIG $* * *: . * * * *: . * * * * * * * * * * * * *: * * * . \quad *: * * * *:: * * * * * * * * * . *: . *$ : $;$

222 RKKRPIHLSFDVDGLDPSFTPATGTPVVGGLTYREGLYITEEIYKTGLLSGLDIMEVNPS

241 KRQRPIHLSFDIDAFDPTLAPATGTPVVGGLTYREGMY IAEEIHNTGLLSALDLVEVNPQ $::: * * * * * * * *: * .: * *::: * * * * * * * * * * * * * * * *: * *: * * *:: * * * * * . * *:: * * * *$.

282 LGKTPEEVTRTVNTAVAITLACFGLAREGNHKPIDYLNPPK-------------

301 LATSEEEAKTTANLAVDVIASSFGQTREGGH IVYDQLPTPSSPDESENQARVRI *.: : **..****: : :**:**** ***.

42 ARGI 1

60 ARGI2

101 ARGI 1

120 ARGI2

161 ARGI 1

180 ARGI2

221 ARGI 1

240 ARGI 2

281 ARGI 1

300 ARGI2

322 ARGI1

354 ARGI2

Figura 2. Alíneamiento de las arginasas 1 y 2 humanas. Las secuencias de aminoácidos de las arginasas 1 (ARGI1P05089) y 2 (ARGI2-P7854) humanas, fueron alíneadas con el software Clustal Omega, disponible en: www.uniprot.org. Las ARG1 y ARG2 presentan un 53,67\% de identidad, donde comparten 91 posiciones. Los residuos en azul corresponden a laminas beta de la estructura secundaria de la proteína, los residuos en rojo hélices alfa y los residuos en amarillos a los giros. (*) indica posición conservada; (:) indica que la conservación entre los grupos es altamente similar, valor de matriz Gonnet PAM250 > 0.5; (.) indica que la conservación entre los grupos es poco similar, valor de matriz Gonnet PAM250 0.5

los dos átomos de nitrógeno de la urea. Esta reacción es irreversible y requiere la hidrólisis de 2 ATP. En los eucariotas la carbamoil fosfato sintetasa II es citosólica, usa glutamina como donador de nitrógeno y esta involucrada en la síntesis de pirimidinas. El grupo carbamoil del carbamoil fosfato es transferido a la L-ornitina formando L-citrulina. Esto ocurre dentro de la mitocondria gracias a la OTC (ornitbine carbamoyltransferase). La L-citrulina en el citosol se condensa con el aspartato, produciendo argininsuccinato; el aspartato proporciona el segundo átomo de nitrógeno de la urea. La ASS, responsable de la reacción, requiere de dos enlaces de alta energía del ATP. El argininsuccinato se convierte en arginina al liberar fumarato, con la participación de la ASL. En el ciclo de Krebs el fumarato se transforma en oxalacetato, el cual por transaminación se convierte nuevamente en aspartato. Por último la ARG1 hidroliza a la LArg con lo que se restaura la L-ornitina y liberando urea. La urea es excretada a través de la orina y la L-ornitina es trasladada a la mitocondria, para que nuevamente reaccione con el carbamoil fosfato y el ciclo continúe ${ }^{17}$ (Figura 3).

Como responsable de la producción de L-ornitina, la ARG1 participa en varias vías metabólicas importantes. La L-ornitina puede ser metabolizada a poliaminas (putrescina, espermidina, espermina) a través de la ODC (ornithine decarboxylase). Las poliaminas son 


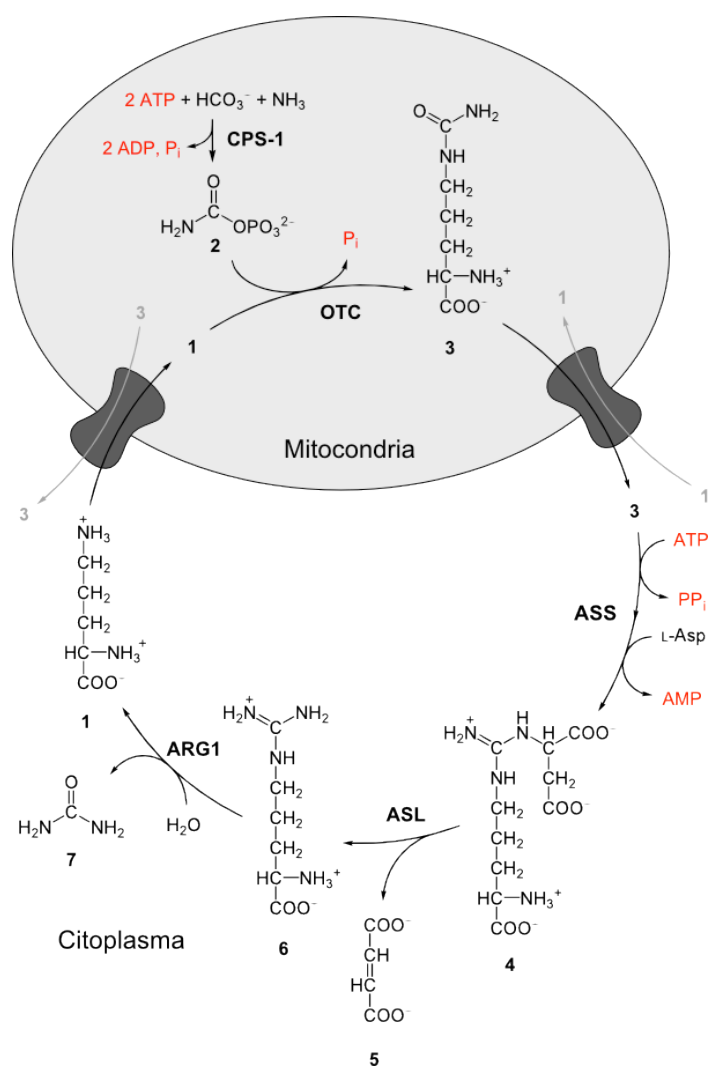

Figura 3. Ciclo de la urea. El ciclo de la urea consta de dos reacciones mitocondriales y cuatro citoplasmáticas El primer grupo amino que ingresa al ciclo proviene del amoníaco libre intramitocondrial. El amoníaco producido en las mitocondrias, se utiliza junto con el bicarbonato, para producir carbamoilfosfato (2), reacción dependiente de ATP y catalizada por la CPS-1. El carbamoil-fosfato cede su grupo carbamoilo a la L-ornitina (1), para formar L-citrulina (3) y liberar Pi, reacción catalizada por la OTC. La Lcitrulina se libera al citoplasma. El segundo grupo amino procedente del aspartato (L-Asp) se condensa con la L-citrulina para formar argininosuccinato (4). Reacción catalizada por la ASS citoplasmática. ASS ATP y produce como intermediario de la reacción citrulil-AMP. El argininosuccinato se hidroliza por la ASL, para formar L-Arg (6) libre y fumarato (7). El fumarato ingresa en el ciclo de Krebs y la L-Arg libre se hidroliza en el citoplasma, por la ARG 1 citoplasmática para formar urea (7) y L-ornitina. La ornitina puede ser transportada a la mitocondria para iniciar otra vuelta del ciclo de la urea.

pequeñas moléculas catiónicas que participan en varias funciones celulares fundamentales como la proliferación celular y el transporte celular de membrana. La L-ornitina participa en la síntesis de L-prolina a través de la OAT. La L-prolina es un aminoácido esencial para diversas estructuras protéicas, como la hélice del colágeno ${ }^{18}$. La asociación de la ARG con el sistema inmune fue descubierta hace mas de 30 años cuando Kung y colaboradores demostraron que agotamiento de L-Arg por la ARG de macrófagos provocaba deficiencias en la producción de anticuerpos en linfocitos murinos ${ }^{19}$.

La L-Arg sirve como sustrato para la NOS en la producción de NO (nitric oxide) y otros intermediarios del nitrógeno ${ }^{8}$. La expresión de NOS está relacionada con distintos procesos infecciosos y con el funcionamiento del sistema inmune. La L-Arg es el sustrato único para la producción de NO por todas las isoformas de la NOS, por lo que, la regulación de la disponibilidad de la arginina controla la producción de NO. La enzima NOS requiere la presencia de calmodulina y de los cofatores (6R)-5,6,7,8-tetrahidrobioterin (BH4), hierroprotoporfirina IX (hemo), flavina adenina dinucleótido (FAD) y mononucleótido de flavina (FMN) para su plena actividad. Hasta la fecha se han descrito tres isoformas de la NOS, que son los productos de diferentes genes. Estas isoformas presentan un 50\% de identidad, pero difieren en su localización celular, regulación, propiedades catalíticas y sensibilidad a los 
inhibidores. NOS1 (nNOS) se expresa en el tejido neuronal; NOS2 (iNOS) es una isoforma inducible, que está presente en varios tipos celulares del sistema inmune; NOS3 (eNOS) se encuentra en células endoteliales ${ }^{5}$. Las enzimas NOS comparten dos dominios funcionales, un dominio oxigenasa amino terminal y un dominio reductasa carboxilo terminal. Los electrones donados por la conversión de NADPH a NADP se transfieren al dominio oxigenasa a través de una cadena redox que involucra los transportadores de electrones FAD y FMN. El dominio oxigenasa utiliza a su vez los cofactores hemo y BH4 para catalizar la reacción entre el oxígeno $\left(\mathrm{O}_{2}\right)$ y L-Arg, lo que genera L-citrulina y NO (Figura 1). La presencia de calmodulina es necesaria para la transferencia electrónica efectiva ${ }^{20,21}$.

La AGAT, interviene en el primer paso de la síntesis de la creatina, catalizando la transferencia de un grupo amino de la L-Arg a la glicina, para producir L-ornitina y glicociamina. El catabolismo de L-Arg a través de AGAT esta determinado por los niveles de creatina en la dieta. La creatina se encuentra en altas concentraciones en los músculos esqueléticos, el corazón, espermatozoides y células fotorreceptoras. En periodos de actividad de alta en células musculares y del sistema nervioso, la creatina actúa como tampón en el cambio de ADP/ATP22.

La ADC es la enzima que cataliza la síntesis de agmatina a partir de L-Arg, liberando $\mathrm{CO}_{2}$. En mamíferos, la ADC se encuentra en la membrana mitocondrial, y su actividad puede estar condicionada por los niveles de $\mathrm{Ca}^{2+}$ en la mitocondria. La importancia biológica de la ADC viene dada por la participación de la agmatina en procesos como la respuesta inflamatoria, la proliferación celular, la neurotransmisión y en la regulación de las funciones renales y gástricas ${ }^{23}$.

\subsection{Participación de la arginina y la arginasa en el sistema inmune}

Desde su descubrimiento, la L-Arg es un aminoácido importante en la modulación de muchas funciones metabólicas, representa la mayor fuente de urea en el organismo, es necesaria para la síntesis del colágeno en la cicatrización de las heridas, modifica la inducción y desarrollo de tumores malignos a través de sus efectos sobre el sistema inmune, tiene capacidad de estimular la respuesta del timo, además favorece la liberación de diferentes hormonas, como la hormona del crecimiento, la insulina, el glucagon, la somatostatina, las catecolaminas, la aldosterona y la vasopresina ${ }^{24}$. El uso de arginina como inmunonutriente puede mejorar la respuesta de las células $\mathrm{T}$ y aumentar la fagocitosis. En pacientes operados de 
cáncer, suplementos de arginina, aumentan la respuesta de los linfocitos $\mathrm{T}$ a fitohemaglutinina y concavalina A, e incrementan el número de células T-CD4. La arginina modula la respuesta inflamatoria e inmunológica. A pesar que se ha evidenciado una mejoría clínica en pacientes quirúrgicos, el beneficio para pacientes en unidades de cuidado crítico con respuesta sistémica inflamatoria, sepsis o falla orgánica es menos claro ${ }^{25}$.

Estudios clínicos han descrito que la ingesta de arginina previene daños en el timo después de cirugías mayores, además de incrementar el número de células $\mathrm{T}$ circulantes $^{26}$. La suplementación dietética con L-Arg en adultos y en modelos animales mejora la inmunocompetencia, aumentando la producción de oxido nítrico, la fagocitosis en neutrófilos y la adhesión en células polimorfonucleares ${ }^{1,27-29}$. A pesar de que en pacientes con diversos traumatismos, quemados y quirúrgicos no sépticos se ha demostrado la utilidad de la administración de L-Arg, en pacientes críticamente enfermos no quirúrgicos, con choque séptico o fallo miltiorgánico puede resultar en un aumento de la mortalidad ${ }^{30-34}$. El destino metabólico de la L-Arg en el sistema inmune está determinado por el estado de activación de las células $\mathrm{T}$ y el patrón de expresión de citoquinas en el proceso inflamatorio. Por ejemplo, la L-Arg mediante su catabolismo puede intervenir en el síndrome de respuesta inflamatoria sistémica (SRIS) a través de dos mecanismos básicos: (i) la producción de $\mathrm{NO}$ en los macrófagos por la ruta inducible 4 ; (ii) y la utilización de L-Arg por parte de las células T para su activación y proliferación ${ }^{35}$.

En células mieloides murinas (macrófagos, células dendríticas y granulocitos) el destino metabólico de la L-Arg viene dada por la acción de citoquinas. Las citoquinas del tipo $\mathrm{T}_{\mathrm{H}} 1$ inducen la expresión de iNOS, mientras que las del tipo $\mathrm{T}_{\mathrm{H}} 2$, como IL-4, IL-10 e IL-13, inducen la expresión de ARG136-38. El metabolismo de la L-Arg en macrófagos se ha utilizado como un parámetro importante para discriminar entre la activación clásica y la alternativa. El IFN- $\gamma$, una citoquina del tipo $\mathrm{T}_{\mathrm{H}} 1$, induce la activación clásica de los macrófagos incrementando la liberación de NO por medio de la actividad de NOS2 e inhibe la secreción de IL-4 ó IL-10 que modulan la actividad de la ARG1. La activación alternativa de los macrófagos es regulada por citoquinas del tipo $\mathrm{T}_{\mathrm{H}} 2$ como IL-4, IL-10 e IL-13, las cuales inhiben la actividad de NOS2 e inducen la síntesis de ARG139. Kung y colaboradores observaron que en cultivos de leucocitos murinos, la adición de macrófagos peritoneales que sobre-expresan arginasa, suprimía la generación de linfocitos citotóxicos, posiblemente por el agotamiento de la L-Arg en el medio de cultivo ${ }^{19}$. La primera evidencia de la participación de la ARG1 en la respuesta citotóxica de los macrófagos murinos fue en 1978, donde se reportó que 
macrófagos activados con LPS inhibían la proliferación y el aumento de la muerte celular en varias líneas tumorales de diferentes especies (rata, raton, hamster y humans), que se restablecía añadiendo arginina a los cultivos ${ }^{40}$.

En contraste con el amplio conocimiento sobre el metabolismo de la L-Arg y la ARG1 en el sistema inmune murino, el papel de la ARG1 en la regulación del sistema inmune humano no esta del todo esclarecido y su importancia comienza a despertar el interés de muchos grupos de investigación.

La expresión de la ARG1 se encuentra altamente inducida en enfermedades que implican el mal funcionamiento del sistema inmune como la glomerulonefritis, en la epidermis de pacientes con psoriasis hiperproliferativa, en pacientes con distintas formas de artritis, en el suero de pacientes con asma crónica, en monocitos activados de pacientes con enfermedades autoinmunes y en células mononucleares de pacientes con tuberculosis pulmonar activa. Todas ellas humanas en las que el sistema inmune juega un papel fundamental como ${ }^{41-46}$.

En células del sistema inmune la expresión de la ARG1 juega un papel importante en la regulación de infecciones, por ejemplo en macrófagos la ARG1 participa en la regulación de las infecciones por esquistosomiasis y leishmaniosis ${ }^{47,48}$. En neutrófilos humanos, la ARG1 se expresa constitutivamente y se almacena en gránulos intracelulares. La ARG1 en neutrófilos parece intervenir en un mecanismo antimicrobiano novedoso, independiente de oxígeno. Cuando los gránulos azurófilos se fusionan con los fagosomas, la ARG1 agota la L-Arg disponible, impidiendo la duplicación de microorganismos como Candida albicans. A diferencia de la ARG1 de neutrófilos murinos, la expresión de la ARG1 humana no es modulada por estímulos pro ó anti-inflamatorios ${ }^{13}$.

Otras células involucradas en la respuesta inmune como las células T, se ven afectadas por la disponibilidad de L-Arg o la actividad de la ARG1. La disminución de la L-Arg, regula la cadena $\zeta$ del receptor de células $\mathrm{T}$ (TCR; $T$ cell receptor), afectando su activación y proliferación ${ }^{35,49-52}$.

En la mitad de los años 80, los avances en la biología de las células T proporcionaron la base para comprender los eventos moleculares que se producen en la activación de estas células. Entre estos mecanismos se descubrieron los elementos que forman parte del receptor de antígeno de células $\mathrm{T}$ y los mecanismos de transducción de señales tras la estimulación por antígenos $^{53}$. El TCR está formado por dos cadenas polimórficas $(\alpha \beta$ ó $\gamma \delta)$ que le confieren la especificidad por los antígenos y forman el sitio de unión al antígeno presentado en el 
complejo mayor de histocompatibilidad. Las cadenas polimórficas $(\alpha \beta$ ó $\gamma \delta$ ) son cadenas variables y glicosiladas que se asocian entre sí por un puente disulfuro. Estas cadenas están unidas covalentemente al complejo $\mathrm{CD} 3$, formado por las cadenas $\gamma, \delta, \varepsilon$ y $\zeta$. Las cadenas $\mathrm{CD} 3 \gamma, \mathrm{CD} 3 \delta$ y $\mathrm{CD} 3 \varepsilon$, se encuentran unidas entre sí por uniones no covalentes ${ }^{54}$. La cadena CD3 $\zeta$ se asocia al complejo TCR, en forma de homodímeros $\zeta \xi$ (en el $90 \%$ de los complejos TCR/CD3) ó formando heterodímeros con otras cadenas de su misma familia como $\eta$, derivada de un procesamiento alternativo del mRNA de la cadena $\zeta^{55}$ (Figura 4).

Las cadenas CD3 son las responsables de transducir las señales de reconocimiento antigénico al interior celular, y de regular los niveles de expresión del receptor en la superficie celular. Las cadenas $\mathrm{CD} 3 \gamma, \mathrm{CD} 3 \delta$ y $\mathrm{CD} 3 \varepsilon$ constan de una región extracelular grande con un dominio inmunoglobulina, una región transmembrana y un dominio intracelular pequeño con un dominio ITAM (immunoreceptor tyrosine-based activation motif). Sin embargo, la cadena CD3\} posee un corto dominio extracelular, una región transmembrana y una región intracelular grande que contiene tres dominios ITAM. Los dominios ITAM son secuencias conservadas YxxLx6-8YxxL que contienen residuos tirosina $(Y)$ separados entre sí por 18 aminoácidos y son la diana para la fosforilación mediada por tirosina quinasas asociadas al receptor ${ }^{56}$.

La asociación del TCR con los ligandos adecuados tiene como consecuencia una rápida fosforilación de estos residuos y de proteínas tirosina quinasas asociadas a ellos como la familia Syk dando lugar a la señalización intracelular ${ }^{57}$. Cuando la cadena zeta del CD3 se fosforila se une a ZAP70 (zeta-chain (TCR) associated protein kinase 70kDa), que permite la fosforilación y la activación de la p56lck quinasa. ZAP70 inicia la transducción de señales intracelulares resultando en la activación de la PKC (protein kinase C), la movilización del calcio y la regulación de los genes cruciales para la función de las células $\mathrm{T}$ efectoras ${ }^{58}$ (Figura 4). Cualquier regulación negativa tanto de las cadenas del TCR como del CD3 ocasionaría graves consecuencias en la activación de la respuesta inmune, ya que la señalización intracelular no se estaría llevando a cabo correctamente.

Durante la ultima década, la expresión de ARG y el agotamiento de L-Arg ha demostrado ser una poderosa ruta inmunosupresora en mamíferos ${ }^{39}$. Ochoa y colaboradores, estudiaron el efecto de la disminución de la concentración extracelular de L-Arg en células T humanas. La ausencia de L-Arg induce la regulación negativa de la cadena CD3 $\zeta$ del complejo TCR/CD3, un componente crítico en la señalización y activación de células $\mathrm{T}^{51}$. La carencia de L-Arg induce un arresto en la fase G0-G1 del ciclo celular de las células T, asociado a una 


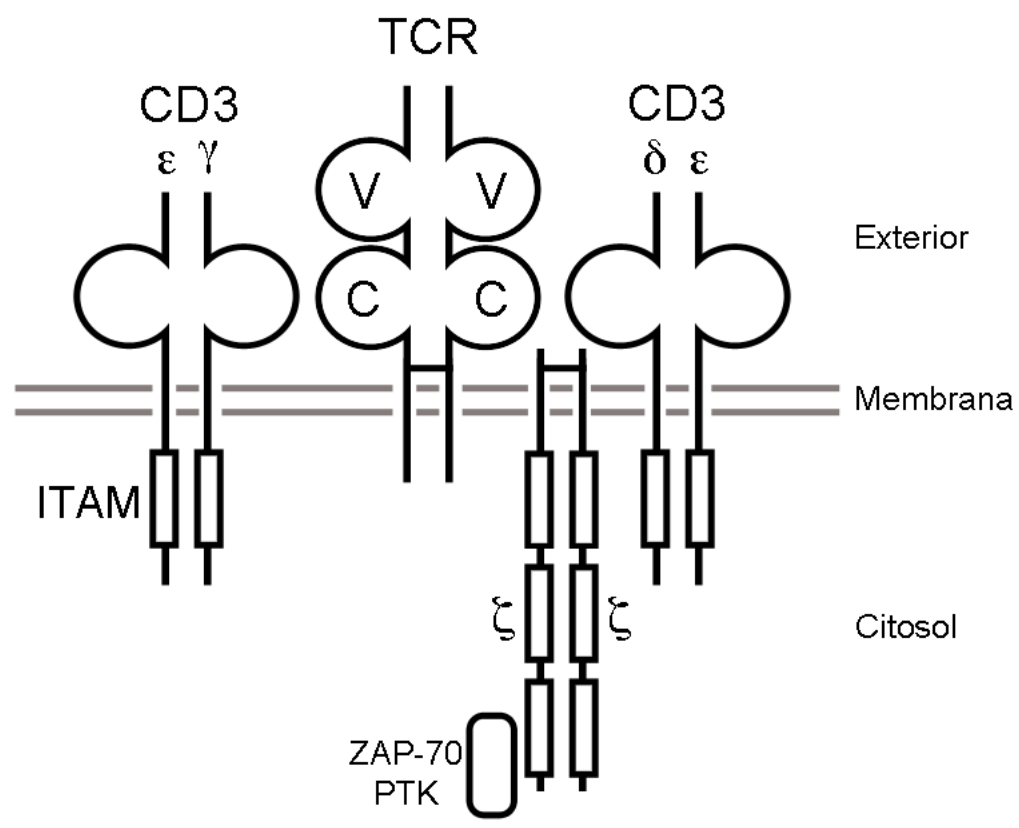

Figura 4. Representación esquemática del complejo TCR/CD3 de células T. El TCR es un complejo protéico multimérico que consiste en un heterodimero clonotípico a y $\beta$. Estas cadenas son muy semejantes a las inmunoglobinas y tienen, al igual que éstas, un dominio constante $(\mathrm{C})$ y un dominio variable $(\mathrm{V})$, el cual se encuentra en la región apical de la porción extracelular. El complejo CD3 está compuesto por tres monomeros denominados $\gamma, \delta$ y $\varepsilon$ unidos por enlaces no covalentes. El CD3 tiene una importante porción intracelular llamada $\zeta \zeta$ que es la responsable de transmitir las señales resultantes de la unión TCR:MCH-antígeno. La porción intracelular de las cadenas GD3ろ posee tres zonas fosforilables denominadas ITAM (Inmunoreceptor Tyrosine-based Activation Motif) encargadas de la transducción de señales. La quinasa ZAP-70 PTK se une a la región ITAM de la cadena CD3ろ y colabora en la cascada de señalización generada por la activación de los linfocitos $\mathrm{T}^{57}$.

regulación negativa de la ciclina D3 y la cdk4 (cyclin-dependent kinase $)^{59}$. En humanos, la inmunosupresión asociada a la disminución de la $\mathrm{CD} 3 \zeta$ es un evento recurrente en pacientes con cáncer, autoinmunidad o infecciones crónicas ${ }^{60}$.

Durante el embarazo se requiere una regulación compleja de las funciones de las células T para asegurar la tolerancia materno-fetal. En mujeres embarazadas la actividad arginasa en sangre periférica y en la placenta es elevada, esta actividad disminuye los niveles de L-Arg en el microambiente fetal y aumenta la producción de poliaminas necesarias para el desarrollo embrionario. Además, la disminución local de los niveles de L-Arg, amortigua la invasión de células T por la regulación negativa de la $\mathrm{CD} 3 \zeta^{61}$.

La ARG1 también es expresada constitutivamente en los eritrocitos ${ }^{11}$ y es liberada al medio extracelular por hemólisis. En los concentrados de hematíes, la ruptura de los eritrocitos aumenta con el tiempo de almacenamiento. Este evento permite la liberación de la ARG, la cual disminuye los niveles de la L-Arg en el suero de pacientes transfundidos causando inmunodepresión ${ }^{62,63}$. 
La perdida de la cadena $\mathrm{CD} 3 \zeta$ es el único mecanismo dirigido por la actividad de la ARG que tiene relevancia comprobada en la función de células T. Sin embargo, el mecanismo mediante el cual la deficiencia de L-Arg afecta la expresión del CD3 $\zeta$, no esta completamente definido y requiere estudios más profundos.

\subsection{La ARG y su controvertido papel en cáncer}

La proliferación de las células tumorales no solo depende de su capacidad para adaptarse y utilizar los recursos disponibles, también influyen las características fenotípicas de las células mieloides que se infiltran en el tejido tumoral. Los leucocitos que interaccionan con el tumor pueden promover la destrucción, así como también la proliferación y la metástasis ${ }^{64}$.

En ratones portadores de tumores se ha descrito una población heterogénea de células mieloides en diferentes estados de desarrollo asociadas al tumor. Esta población se caracteriza por la expresión de CD11b, una integrina que funciona como receptor del complemento (C3bi), del fibrinógeno, o del factor de coagulación $\mathrm{X}, \mathrm{y}$ Gr-1, marcador de neutrófilos diferenciados. Estas células se denominan células supresoras derivadas de la línea mieloide (MDSCs: myeloid-derived suppressor cells). Existe una gran variedad de células inmunosupresoras que pueden estar asociadas al microambiente tumoral. Sin embargo, las células MDSCs se encuentran en la mayoría de los pacientes con cáncer. El recuento celular de MDSCs aumenta hasta diez veces en sangre de pacientes con cáncer en comparación con los individuos sanos ${ }^{65}$. La acumulación y activación de las células MDSCs se ha asociado con la disminución de la cadena $\mathrm{CD} 3 \zeta$ en células $\mathrm{T}$ efectoras, por la acción de la ARG166. Otros estudios han demostrado que la progresión del cáncer se puede retardar eliminando las células MDSCs ${ }^{67,68}$. En conjunto, estos resultados sugieren que los efectos supresores de MDSCs juegan un papel importante en la supervivencia del tumor, ayudándolo a escapar de la inmunovigilancia por la acción de la ARG1. Sin embargo, para una aproximación terapéutica, es necesario entender con mayor profundidad las vías que pueden mitigar los efectos supresores de las células MDSCs.

Además de las MDSCs otras células del sistema inmune que se han relacionado con la progresión del cáncer son los neutrófilos. Tradicionalmente los neutrófilos han sido catalogados como precursores de la inflamación aguda y crónica, pero estudios recientes en neutrófilos asociados a tumores (TAN; tumor-associated neutrophils) revelan que pueden jugar un papel importante en la biología del cáncer. Los TAN constituyen una de las mayores poblaciones celulares que infiltran el tumor, en muchos tipos de cáncer ${ }^{69}$. Los TAN poseen 
diferencias marcadas en su transcriptómica, con respecto a los neutrófilos circulantes y a la fracción granulocítica de las células $\mathrm{MDSCs}^{70}$. Existen dos fenotipos de TAN, el antitumoral (N1) y el pro-tumorigénico (N2). El fenotipo N1 expresan altos niveles de FAS, TNFa, ICAM-1, ROS y bajos niveles de ARG1. El Fenotipo N2 produce altos niveles de las citoquinas pro-inflamatorias CCL2 y CCL5, además de suprimir la respuesta inmune antitumoral por la secreción de ARG1 ${ }^{69}$. Los neutrófilos son una población celular poco apreciada en la biología del cáncer, y sus funciones necesitan una mejor caracterización con vista a desarrollar estrategias terapéuticas, en donde el sistema inmune sea el actor principal.

A pesar de las propiedades inmunosupresoras de la ARG1, existen tumores auxótrofos para L-Arg. Cuando son cultivados en ausencia de L-Arg, desarrollan un arresto en la fase $G_{0} /$ $\mathrm{G}_{1}$ del ciclo celular y la posterior muerte celular por apoptosis ${ }^{71,72}$. Una fracción grande de los carcinoma hepatocelulares, melanomas, carcinomas de células renales, mesoteliomas, carcinomas pancreáticos y algunos cánceres de pulmón de células pequeñas poseen defectos en el ciclo de la urea, por lo que son auxótrofos para la L-Arg. Mientras que células no malignas pueden entrar en inactividad permaneciendo en la fase $\mathrm{G}_{0}$ del ciclo celular durante semanas, las células tumorales desarrollan defectos en el ciclo celular, inhibición de la síntesis de proteínas y muerte celular ${ }^{71,73}$. Para estos tumores el diseño de estrategias que interfieran en el metabolismo de la L-Arg puede ser una terapia adecuada de tratamiento. Por ejemplo, ADI (arginine deiminase) cataboliza la L-Arg para producir citrulina y amonio. La ADI-PEG-20, una enzima recombinante de Mycoplasma arginini unida covalentemente a polietilenglicol (PEG), fue aprobada como droga huérfana para el tratamiento del carcinoma hepatocelular y del melanoma metastásico por la Food and Drug Administration (FDA) de Estados Unidos en marzo de 1999 y por la Agencia Europea de Evaluación del Medicamento (AEEM) en julio de $2005^{74,75}$. En ensayos clínicos con ADI-PEG20 un 21\% de los pacientes con carcinoma hepatocelular, se observó una estabilización de la enfermedad y una inhibición del crecimiento tumoral tras 2 años de tratamiento. En el caso del melanoma, más del 50\% de los pacientes que recibieron dosis mayores de $160 \mathrm{U} / \mathrm{m}^{2}$ experimentaron una regresión parcial de las lesiones. $\mathrm{La}$ eficacia de la ADI-PEG20 en ensayos de fase I/II muestra que potencialmente el agotamiento de L-Arg podría ser utilizado como un agente anti-tumoral eficaz. Sin embargo, efectos secundarios como el elevado nivel de amoníaco, la inmunogenicidad de la proteína microbiana ADI y la inestabilidad de la dosis biológica óptima, hacen que los ensayos clínicos no sean todo lo prometedor que se esperaba ${ }^{76}$. Actualmente se están llevando a cabo ensayos clínicos en fase III con ADI-PEG20 (Polaris Group) para carcinoma hepatocelular y en fase I para melanomas metastásicos y linfomas, además se esta estudiando la posibilidad de extender su utilización en 
cáncer de próstata, leucemia, sarcoma y cáncer de páncreas. En comparación con la quimioterapia tradicional, las terapias basadas en la restricción de aminoácidos presentan ciertas ventajas en cuanto a la alta especificidad por las células malignas y la baja toxicidad para los pacientes. Sin duda, el avance en la investigación de este tipo de terapias, facilitará la búsqueda de tratamientos efectivos para combatir el cáncer.

El punto común de estas terapias es la deficiencia de la L-Arg y el incremento de los niveles de urea por el aumento de la actividad arginasa. Tanto la deficiencia de aminoácidos como el incremento de los niveles de urea pueden alterar la traducción de varios mRNA a través de rutas metabólicas que involucran a las quinasas GCN2 (general control nonrepressed-2) y mTOR (mammalian target of rapamycin), además de inducir la acumulación de proteínas desplegadas en el retículo endoplásmico (RE) iniciando rutas de señalización para la adaptación ${ }^{77}$. Cuando la concentración intracelular de aminoácidos disminuye, aumenta la cantidad de tRNA no cargados, lo cual activa a GCN2. La quinasa GCN2 se une a los tRNA no cargados, fosforilando el residuo serina 51 de la sub-unidad $\alpha$ del eIF2 $\alpha$ (enkaryotic translation initiation factor 2 subunit 1), interrumpiendo la síntesis de proteínas ${ }^{78}$. La interrupción de la traducción, la acumulación de proteínas desplegadas en el RE y la inhibición de la ruta de mTOR puede inducir la respuesta de proteínas desplegadas o la autofagia para suplir las necesidades nutricionales ${ }^{79}$. Sin embargo, se desconoce cual de estas rutas se encuentra activada en las células T en ausencia de L-Arg.

\section{Estrés de retículo endoplasmático y la respuesta de proteínas desplegadas}

El retículo endoplasmático (RE) es un orgánulo celular constituido por un sistema membranoso que lleva a cabo funciones muy importantes a nivel celular como la síntesis, el plegamiento y la maduración de proteínas, el almacenamiento de $\mathrm{Ca}^{2+}$ y la biosíntesis de $\operatorname{lípidos}^{80}$. Estímulos fisiológicos, farmacológicos y patológicos pueden alterar la homeostasis del RE y afectar la capacidad de plegamiento proteico. Señales de estrés que afecten al RE, pueden provocar una acumulación de proteínas mal plegadas, perjudicando la supervivencia celular. Cuando se pierde la capacidad de plegar y secretar proteínas eficientemente, se dice que se está bajo estrés de RE, y se activan rutas de transducción de señales conocidas como la respuesta a proteínas desplegadas (UPR; unfolded protein response) ${ }^{81}$. 
La respuesta UPR tiene una fase adaptativa que desencadena tres tipos de respuestas citoprotectoras: i) un aumento en la expresión de chaperonas del RE como GRP78/BiP para mejorar el plegamiento proteico; ii) una disminución de la traducción para reducir la afluencia de proteínas hacia el RE; y iii) la degradación de proteínas mal plegadas en el proteasoma mediante el sistema ERAD (endoplasmic-reticulum-associated protein degradation) o la autofagia. Estas respuestas limitan la carga proteica y reducen el estrés de RE. Si el estrés de RE es excesivo o prolongado, la célula activa mecanismos de muerte celular programada (apoptosis), algunos de los cuales derivan del propio $\mathrm{RE}^{82,83}$. En células de mamífero, la respuesta UPR está compuesta por tres vías de señalización, con sensores ubicados en la membrana del RE: PERK (PKR-like ER kinase), IRE1 (inositol-requiring protein 1 $\alpha$ ) y ATF6 (activating transcription factor 6 ). Cada una de estas proteínas transmembrana tiene un dominio luminal en el RE, el cual se asocia con la proteína GRP78/BiP; un dominio transmembrana, mediante el cual están ancladas a la membrana del RE; y un dominio citosólico funcional. En condiciones de reposo, los tres sensores se encuentran asociados a la chaperona GRP78/BiP. Cuando las condiciones celulares promueven el estrés de RE, la chaperona GRP78/BiP se disocia de los sensores de estrés y se une a las proteínas insuficientemente glicosiladas, mal plegadas o no ensambladas, iniciando de la respuesta $\mathrm{UPR}^{84}$ (Figura 5) .

A continuación detallaremos brevemente la participación de las rutas PERK, IRE1 y ATF6, en la respuesta UPR, tanto en mecanismos de supervivencia como en la muerte por apoptosis.

\subsection{Vía de IRE1}

La ruta de IRE1 es la vía más conservada de la respuesta UPR ${ }^{85}$. En mamíferos se encuentran dos genes que codifican para la proteína IRE1: IRE1 $\alpha$ e IRE1 $\beta$. IRE1 $\alpha$ se expresa ubícuamente, mientras que la expresión de IRE1 $\beta$ está limitada al epitelio intestinal. La proteína IRE1 $\alpha$ tiene un dominio amino-terminal en el lumen del RE una región transmembrana, y un dominio carboxi-terminal citoplasmático, que contiene las actividades catalíticas endoribonucleasa y serina-treonina quinasa ${ }^{86}$. El mecanismo mediante el cual IRE1 $\alpha$ detecta la acumulación de proteínas desplegadas en el RE, ha sido ampliamente debatido. En levaduras IRE1 $\alpha$ puede unirse a las proteínas mal plegadas por medio de cLD (ER-lumenal domain). Esta interacción promueve su homodimerización y autofosforilación, iniciando la 
respuesta UPR ${ }^{87}$. No obstante, en mamíferos, la activación IRE1 $\alpha$ depende de la disociación de GRP78/BiP y no de su unión directa de proteínas mal plegadas ${ }^{88}$. Una vez activado, IRE1 se homodimeriza y autofosforila, activando sus funciones quinasa y endoribonucleasa. La activación de la función endoribonucleasa de IRE1 induce el splicing alternativo del mRNA de XBP1 (X-box DNA-binding protein 1), un proceso en el que una secuencia de 26 nucleóticos del mRNA de XBP1 se escinde produciéndose un cambio en el marco de lectura en la traducción. El mecanismo de splicing del mRNA de XBP1 es completamente distinto al splicing convencional de mRNA. El splicing convencional se da en el núcleo y depende del spliceosoma mientras que el splicing del mRNA de XBP1 tiene lugar en el citoplasma y es independiente de spliceosoma ${ }^{89}$. A diferencia de la proteína XBP1 no procesada (XBP1u, unspliced XBP1), que se degrada rápidamente, la proteína procesada (XBP1s, spliced XBP1) codifica un factor de transcripción con un potente dominio de transactivación. La proteína XBP1s activa genes que aumentan la capacidad de plegamiento y la degradación de proteínas del RE, mediante la activación de ERAD $^{90}$. XBP1s, también modula la síntesis de fosfolípidos, los cuales son requeridos para la expansión de la membrana del RE bajo condiciones de estrés ${ }^{90}$ (Figura 5A).

\subsection{Vía de PERK}

Tras la disociación de GRP78/BiP, la proteína de membrana PERK se homodimeriza y autofosforila, activando su actividad quinasa. Inicialmente, PERK fosforila la Ser ${ }^{51}$ de eIF2 $\alpha$, lo que conlleva a la rápida atenuación de la traducción de mRNA, reduciendo la afluencia de nuevas proteínas hacia el RE, y disminuyendo la síntesis de ciclina D1, con el fin de dirigir una parada del ciclo celular ${ }^{91}$. La fosforilación de eIF2 $\alpha$ potencia la traducción preferencial de algunos mRNAs como los de: ATF4 (activating transcription factor 4), GRP94 (94 kDa glucoseregulated protein) y GRP78/BiP 92 . La expresión del factor de transcripción ATF4 controla la expresión de genes involucrados en el transporte y metabolismo de aminoácidos, en el equilibrio redox, en el plegamiento proteico y la autofagia. Cuando el estrés de RE es persistente, ATF4 activa un factor proapoptótico llamado CHOP (C/EBP homologous protein). El factor de transcripción CHOP estimula la expresión de la proteína GADD34 growth-arrest and DNA-damage-inducible protein 34), la cual forma un complejo con PP1 (phospho protein phosphatase 1) y desfosforila eIF $2 \alpha^{93}$. La proteína GADD34 promueve la recuperación de la transcripción, ayudando a las células a recuperar sus funciones normales ${ }^{94}$. La activación de CHOP también causa la regulación negativa de proteínas anti-apoptóticas mitocondriales como Bcl-2, la liberación de calcio del RE y la muerte celular por apoptosis ${ }^{95}$ (Figura 5B). Otro factor de 


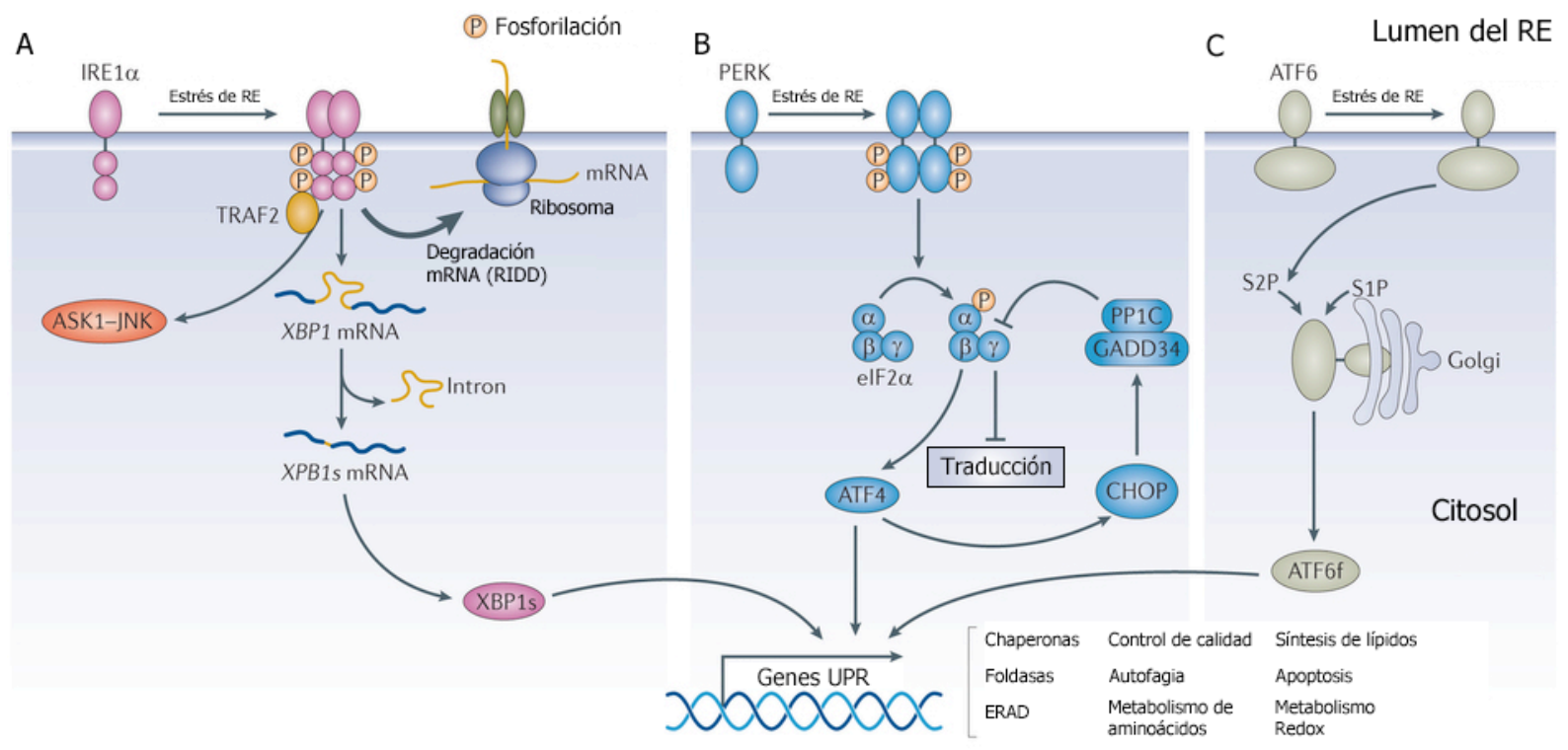

Figura 5. La respuesta de proteínas mal plegadas (UPR). El estrés de RE induce una respuesta adaptativa conocida como UPR. Existen tres vías principales de señalización UPR: IRE1a, PERK y ATF6. Estas proteínas transmembrana del RE transmiten señales desde el citosol hacia el núcleo para restaurar la capacidad de plegado de proteínas del RE a través de varias rutas. A) La actividad RNAsa de IRE1a, procesa el mRNA de XBP1 dando lugar al mRNA XBP1s. El XBP1s se transloca al núcleo para activar la transcripcción de genes relacionados con el plegado de proteínas, ERAD, proteínas involucradas en el control de calidad del RE y para la biogénesis de organelos. IREla también activa a la vía JNK-ASK1 a través de la proteína adaptadora TRAF2. B) La activación de PERK atenúa la síntesis general de proteínas a través de la fosforilación de eIF2a. La fosforilación de eIF2a permite la traducción selectiva del factor de transcripción ATF4, el cual induce la expresión de genes involucrados en el metabolismo redox, metabolismo de aminoácidos, autofagia y apoptosis. ATF4 controla la expresión de componentesco-cultivadas pro-apoptóticos como GADD34 y GHOP. GADD34 se une a la proteína PP1G para desfosforilar eIF2a. G) En condiciones basales ATF6 se encuentra en la membrana del RE y codifica un factor de transcripción bZIP en su dominio citosólico. En condiciones de estrés de RE, ATF6 se transloca al aparato de Golgi donde es procesado por las proteasas S1P y S2P, liberando el dominio citoplasmático ATF6f. ATF6f regula la transcripción de genes UPR como XBP1, GHOP, chaperonas y proteínas involucradas en la secreción ${ }^{102}$.

transcripción regulado por PERK es NRF2 (nuclear factor erythroid-2-related factor 2). Bajo condiciones normales, NRF2 se encuentra en estado de reposo por su interacción con KEAP1 (kelch-like ECH-associated protein 1). Tras la fosforilación de PERK, NRF2 es liberado por KEAP1 y se dirige al núcleo donde activa la transcripción de genes que codifican para proteínas anti-oxidantes. Esta activación de NRF2 por PERK es un mecanismo adaptativo importante, ya que células deficientes de NRF2 mueren por apoptosis ante estrés de retículo 96,97 .

\subsection{Vía ATF6}

En mamíferos, existen dos isoformas de ATF6: ATF6 $\alpha$ y ATF6 $\beta$. Aunque ambas son expresadas ubícuamente, ATF6 $\alpha$ es un activador transcripcional más potente que ATF6 $\beta$. ATF6 posee un dominio N-terminal citoplasmático que contiene un motivo básico de 
cremallera de leucina, esencial para su unión al DNA y para la formación de dímeros ${ }^{98}$. El factor de transcripción ATF6 se encuentra anclado al RE y tiene un peso molecular de $90 \mathrm{kDa}$. Posee dos secuencias de localización al Golgi (GLS, Golgi localization sequences), que en condición de reposo se encuentran ocupadas por GRP78/BiP. Cuando GRP78/BiP se disocia de ATF6 por la acumulación de proteínas desplegadas en el RE, la proteína ATF6 se transloca a Golgi, en donde su mitad C-terminal es escindida por la proteasa S1P mientras que la mitad N-terminal anclada en la membrana es escindida por la proteasa S2P (Figura 5C). La proteólisis secuencial por las proteasas S1P y S2P es un proceso denominado RIP (regulated intramembranal proteolysis $^{99}$. La proteólisis RIP libera el dominio citosólico N-terminal de ATF6, de $50 \mathrm{kDa}$. Este fragmento se dirige al núcleo y activa genes involucrados en la degradación ERAD, la biosíntesis de lípidos, la expansión del RE y el plegamiento proteico ${ }^{100}$. ATF6 activa directamente la expresión de XBP1, CHOP y chaperonas del RE (tales como GRP78/BiP). La activación de la expresión de XBP1 por parte de ATF6 es muy importante para la supervivencia celular durante el estrés de $\mathrm{RE}^{101}$ (Figura 5C).

\subsection{Destino celular mediado por la respuesta UPR}

La respuesta UPR en mamíferos esta involucrada en una dinámica y flexible red de señalización que responde a un amplio rango de estados metabólicos. Bajo condiciones de estrés de RE, la activación de UPR reduce la acumulación de proteínas desplegadas a través de varios mecanismos de supervivencia como la expansión de la membrana del RE, la síntesis selectiva de componentes del plegado y transporte de proteínas hacia el RE. Sin embargo, cuando el estrés no es mitigado y no se recupera la homeostasis del RE, la respuesta UPR inicia rutas de señalización que conducen a la muerte celular por apoptosis ${ }^{102}$ (Figura 6).

\subsubsection{Mecanismos adaptativos regulados por UPR}

En mamíferos, existen dos vías temporalmente distintas en la respuesta celular al estrés RE (Figura 6). Una reacción inmediata, es la activación de PERK que inhibe la traducción general proteínas a través de la fosforilación de eIF2 $\alpha$, y la degradación selectiva de mRNA que codifican para ciertas proteínas localizadas en el RE a través del complejo RIDD ${ }^{103,104}$. El factor de transcripción ATF4 controla la expresión de genes involucrados en la supervivencia, el balance redox, el metabolismo de aminoácidos, el plegado de proteínas y la autofagia ${ }^{93,105}$. 
Cuando los intermediarios del plegado o del ensamblaje de proteínas exponen sus superficies hidrofóbicas, cisteínas no pareadas o glicanos inmaduros, las chaperonas residentes del RE ó las oxidoreductasas, interactuan con ellas, dirigiéndolas al Golgi o reteniendolas en el ER. Estas chaperonas son parte del sistema de calidad primario del RE. Cuando existe una acumulación de proteínas desplegadas, el sistema de calidad del RE actúa mediante el reconocimiento de una secuencia específica, dirigiendo las proteínas reconocidas al citosol para su degradación, aliviando la carga del RE y restableciendo la homeostasis ${ }^{106-108}$. El splicing alternativo de XBP1 induce la regulación positiva de genes ERAD. Una de estas proteínas es EDEM1 (ER degradation-enhancing alpha-mannosidase-like 1), un regulador estrés-inducible encargado de la eliminación de glicoproteínas. En condiciones de reposo, el nivel intracelular de la proteína EDEM1 permanece bajo. Cuando se activa la ruta IRE1, XBP1s induce la expresión de EDEM1 para acelerar la maquinaria ERAD ${ }^{109}$. La principal función de ERAD es eliminar las proteínas desplegadas del lumen del RE, que podrían generar agregados tóxicos para la célula. Las proteínas que no alcanzan su conformación nativa son retro-translocadas hacia el citoplasma por la maquinaria ERAD, poli-ubiquitinadas por ubiquitin-ligasas E3 específicas y degradadas mediante el proteasoma ${ }^{110}$.

El proceso mediante el cual las proteínas desplegadas son transportadas hacia el citoplasma aún no está totalmente definido. Sin embargo, se han descrito una serie de proteínas cuya función es indispensable para la retro-translocación de las proteínas desplegadas del RE hacia el citoplasma. Una de estas proteínas es Sec61, un translocon bi-direccional ubicado en la membrana del RE. La proteína Sec61 forma un complejo heterotrimerico en forma de rosquilla, que consta de las subunidades $\operatorname{Sec} 61 \alpha$, Sec61 $\beta$ y Sec61 $\gamma^{111}$. La proteína Derlin-1 constituye otro posible candidato para la formación del canal. Derlin-1 posee la capacidad de formar oligómeros a través de la membrana del RE junto con otras proteínas adaptadoras, pudiendo funcionar como un canal para la retro-translocación durante el ERAD ${ }^{112}$. Los complejos proteicos AAATPasa y ubiquitin ligasa E3 Hrd1/Synoviolina, además de las proteínas p97 y Herp, pueden unirse a Derlin-1 formando un complejo retrotranslocón que permite el traspaso de las proteínas desde el RE al citoplasma para su degradación por el sistema ubiquitina-proteasoma ${ }^{113}$.

El proteasoma es el sistema más importante de degradación de proteínas. El sistema ubiquitina-proteasoma es un proceso de degradación en el cual las proteínas que han sido marcadas a través de la poli-ubiquitinación, son degradadas por un complejo proteico denominado proteasoma 26S. La ubiquitinación es un proceso de modificación post- 


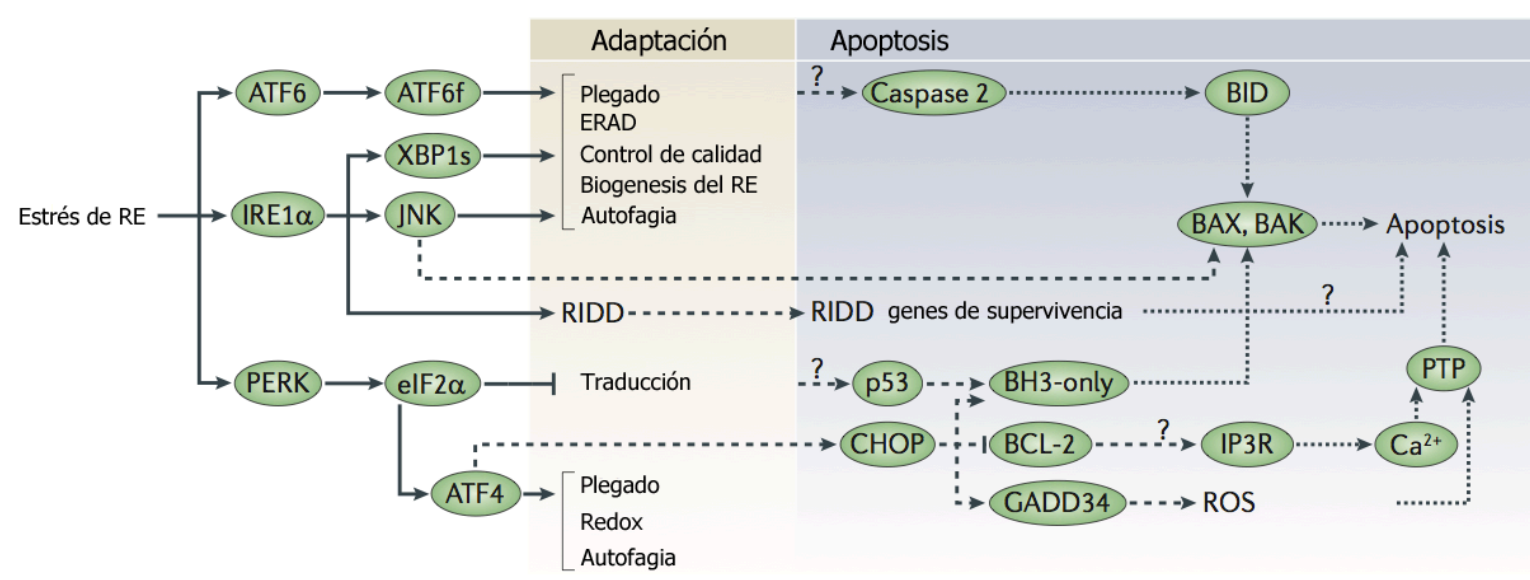

Tiempo e exposición al estrés de RE

Figura 6. Destino celular mediado por la respuesta UPR. Una respuesta temprana de la ruta UPR es la atenuación de la traducción por la fosforilación de eIF2a a través de PERK, degradación de mRNA que codifica para los mediadores del plegado de proteínas a través de la degradación dependiente de IRE1 (RIDD), y la activación de la autofagia a través de la ruta IREla/JNK. En una segunda oleada de eventos, los factores transcripcionales ATF6f, XBP1s y ATF4 inducen una respuesta adaptativa para el restablecimiento de las funciones del RE y para mantener la supervivencia celular. Cuando las señales de estrés de RE son persistentes, se induce apoptosis para eliminar las células con daños irreversibles. La estimulación sostenida de la vía PERK regula positivamente la transcripción de CHOP, el cual regula negativamente la proteína anti-apoptótica Bcl-2, induciendo la expresión de proteínas BH3-only y GADD34. CHOP, ATF4 y p53, también inducen la expresión de proteínas BH3-only. La proteína GADD34 induce la generación de ROS y una arresto en el ciclo celular. La alteración de la homeostasis del calcio por la activación de IP3R, además de la producción de ROS, puede contribuir a la apertura del poro mitocondrial (PTP) induciendo apoptosis. Las caspasa-2 también puede participar en la apoptosis mediada por estrés de RE, mediante el procesamiento de la proteína BH3-only BID, la cual activa a BAK y BAX. Las flechas discontinuas ejemplifican los pasos de transición entre la fase adaptativa y la apoptosis. Las flechas punteadas indican los eventos que intervienen en la apoptosis. El signo de interrogación indica que el mecanismo responsable del paso representado no esta del todo esclarecido ${ }^{102}$.

traduccional, en la que una proteína de $8,5 \mathrm{kDa}$ denominada ubiquitina, se une covalentemente a una proteína. La ubiquitinación es un proceso secuencial y reversible que requiere de varias enzimas clasificadas en E1 activadoras, E2 conjugadoras y E3 ligasas. Las enzimas E1 activan la ubiquitina utilizando una molécula de ATP, dando como resultado un enlace tioester entre el grupo carboxilo terminal de la ubiquitina y un residuo de cisteína en la enzima E1 activadora. La segunda etapa en el proceso de ubiquitinación requiere la transferencia de la ubiquitina desde la enzima E1 hacia la E2, para esto la ubiquitina ya activada se une a la enzima conjugadora E2, formando un nuevo enlace tioester entre ellas. Finalmente la ubiquitina es unida covalentemente a un residuo de lisina de la proteína específica, mediante la acción de una ubiquitin ligasa E3 $3^{114-117}$.

La homeostasis del RE es crucial para la supervivencia celular. Esta homeostasis puede ser alterada por una variedad de condiciones fisiológicas como el incremento de la maquinaria de secreción, deficiencias nutricionales y condiciones patológicas como la acumulación de proteínas desplegadas en el RE. Mientras que las proteínas desplegadas son inicialmente 
degradadas por la vía proteasomal, sí el daño en el RE es demasiado grave como para restablecer sus funciones, se inician varias vías de señalización que conducen a la apoptosis y la autofagia $^{118}$.

\subsubsection{Estrés de RE crónico y apoptosis}

Procesos fisiológicos que requieren una alta tasa de síntesis proteica y secreción, deben mantener un balance entre los programas adaptativos y de muerte celular de la respuesta UPR. Cuando el estrés de RE no se resuelve correctamente, las células afectadas mueren por apoptosis activando una serie de vías complementarias (Figura 6) ${ }^{119}$.

Algunos estudios sugieren que las caspasas-12, 4 y 7 las cuales son trasocadas al RE durante la apoptosis, pueden ser las responsables de iniciar el proceso muerte celular programada ${ }^{120-122}$. Fibroblastos embrionales de ratón (MEFs; Mouse embryonic fibroblasts) deficientes en APAF-1 (apoptotic protease activating factor 1) muestran resistencia a agentes que inducen estrés de RE, como la tunicamicina ó el DTT. En MEFs normales, bajo condiciones de estrés de RE, la proteína BAX (Bcl-2-associated $X$ protein) se transloca a la mitocondria, liberando citocromo $c$. Además, la proteína APAF-1 procesa a la caspasa-12 iniciando la apoptosis. Estos resultados sugieren que APAF-1 y la ruta mitocondrial son componentes importantes de la apoptosis inducida por estrés de $\mathrm{RE}^{123}$.

La muerte celular bajo estrés de RE, requiere de la activación de rutas apoptóticas mitocondriales reguladas por la familia de proteínas Bcl-2 (B-cell lymphoma 2) ${ }^{124}$. En esta ruta, la activación conformacional del multidominio apoptótico BAX/BAK es el paso clave para disparar la activación de caspasas. La exposición prolongada a estrés de RE conduce a la activación de la transcripción y de modificaciones post-traduccionales de proteínas BH3-only, iniciando la activación conformacional downstream de BAX y BAK (Bcl-2 homologous antagonist killer). Las proteínas $\mathrm{BH} 3$-only inducen la homo-oligomerización intermembrana de BAX y BAK, y la posterior permeabilización de la membrana mitocondrial externa, dando lugar a la liberación del citocromo $c$ y el ensamblaje del apoptosoma ${ }^{125}$. Aunque las proteínas BH3-only, PUMA, NOXA, BID y BIM, se han visto implicadas en la apoptosis inducida por el estrés de ER, los mecanismos exactos por medio de los cuales la respuesta UPR interviene en la señalización de estos componentes para iniciar la apoptosis siguen sin esclarecerse ${ }^{126}$.

La transcripción del C/EBP-homologo (CHOP) es de unos de los elementos claves de la ruta pro-apoptótica iniciada por la respuesta $\mathrm{UPR}^{91,127}$. El factor de transcripción CHOP 
promueve la regulación positiva de BIM y la regulación negativa de $\mathrm{Bcl}-2$, contribuyendo a la inducción de apoptosis ${ }^{95}$. Además, CHOP, ATF4 y p53 regulan la expresión de PUMA y NOXA bajo condiciones crónicas de estrés de RE ${ }^{128-130}$. Sin embargo, el mecanismo mediante el cual las señales de estrés de RE pueden inducir la activación de p53 no esta del todo esclarecido $^{131}$. Se han descrito otros mecanismos complementarios capaces de inducir la muerte celular por estrés de RE, incluyendo la activación de la caspasa-4, la escisión de BID por la caspasa-2, la escisión de BAP31 por la caspasa-8 y la liberación de calcio de la mitocondria ${ }^{132-135}$. Bajo ciertas condiciones, la activación de IRE1 puede desencadenar apoptosis, mediante el reclutamiento de la proteína adaptadora TRAF2. Este reclutamiento activa a la quinasa reguladora de la apoptosis ASK1 (apoptosis signal regulating kinase 1) y a su sustrato downstream JNK (c-Jun N-terminal kinase). La fosforilación de JNK en respuesta a la activación de IRE1 es una señal pro-apoptótica importante, probablemente por la regulación negativa de las proteínas de la familia Bcl-2, así como también la degradación de mRNAs que codifican para los mediadores del plegado de proteínas a través de la degradación dependiente de IRE1 (RIDD) $)^{136,137}$.

\section{Autofagia}

La homeostasis celular requiere de un delicado balance entre la síntesis y degradación de macromoléculas (proteínas, lípidos, DNA, RNA, segundos mensajeros, etc). La degradación de proteínas puede llevarse a cabo a través de dos vías principales: la proteasomal y la autofágica $^{138}$. La autofagia, es un proceso evolutivamente conservado y es el responsable no solo de la degradación de proteínas (como fue inicialmente descrita) sino también del reciclaje y degradación de orgánulos y material citoplasmático ${ }^{139-141}$. En levaduras, por ejemplo, la privación de nutrientes induce la regulación positiva de la autofagia, degradando proteínas no relevantes para el reciclaje de aminoácidos, necesarios para la síntesis de proteínas $^{142}$.

\subsection{Tipos de autofagia}

La autofagia puede clasificarse en tres tipos diferentes según el material intracelular que se degrada. Estos tres tipos son, la macroautofagia, la microautofagia y la autofagia mediada por chaperonas (AMC) (Figura 7) ${ }^{143}$. 
La macroautofagia involucra un reordenamiento de membranas, y a diferencia de la degradación proteasomal, este mecanismo implica la fusión de estructuras vacuolares con los lisosomas. La macroautofagia se inicia con la formación del fagoforo, también llamado membrana de aislamiento. Esta membrana puede secuestrar componentes citosólicos de manera selectiva o no selectiva, formando una vacuola con los componentes secuestrados, que luego se fusionará con los lisosomas ${ }^{144}$. Desde el descubrimiento de la autofagia en la década de 1950, se ha intentado descubrir el origen de la membrana del fagoforo. Se ha planteado que la formación del fagoforo implica un mecanismo de ensamblaje de novo o que la membrana podría provenir del RE o del aparato de Golgi. Recientemente nuevas evidencias indican que tanto el RE como las mitocondrias pueden proporcionar la membrana del fagoforo, revelando la complejidad de la puesta en marcha de la autofagia en células de mamíferos ${ }^{145}$. El autofagosoma es una estructura membranosa que mide entre 300 y $900 \mathrm{~nm}$, y que se fusiona con el lisosoma liberando el contenido intravesicular para su degradación por las proteasas lisosomales. El resultado es la liberación de moléculas al citosol para la resíntesis de diferentes componentes celulares (Figura 7A) ${ }^{146-148}$.

La AMC es la única ruta de la autofagia que permite la degradación selectiva de proteínas solubles en los lisosomas. En contraste con las otras formas de la autofagia, la AMC no requiere la formación de vesículas o cambios importantes en la membrana lisosomal. En su lugar, las proteínas diana cruzan directamente la membrana lisosomal para alcanzar el lumen, donde son degradadas rápidamente. Las proteínas que serán degradadas por la AMC son reconocidas por el motivo KFERQ-like, y son transportadas hacia la membrana lisosomal por un complejo de chaperonas formado por Hsc70 y sus cochaperonas. Una vez en la membrana lisosomal, la proteína interactúa con LAMP- 2A (lysosome-associated membrane protein 2), y se transloca a través de la membrana hacia el lumen lisosomal ${ }^{149}$ (Figura $7 \mathrm{~B}$ ).

La microautofagia es un proceso de degradación lisosomal no selectivo, que implica la inmersión directa de la carga citoplasmática en el lisosomas (mamíferos) o en la vacuola (plantas y hongos). La microautofagia de sustratos solubles puede ser inducida por el agotamiento de nitrógeno o por la acción de la rapamicina a través de vías de señalización complejas. Entre sus funciones principales destacan el mantenimiento del tamaño de organelos, la homeostasis de la membrana y la supervivencia celular bajo restricción de nitrógeno (Figura $7 C)^{150}$. 


\subsection{La formación del autofagosoma}

La autofagia es un mecanismo altamente conservado desde levaduras hasta mamíferos, donde las proteínas relacionadas con la autofagia (Atg) son las que orquestan la iniciación, elongación, maduración y fusión del autofagosoma ${ }^{151}$. Existen dos sistemas de conjugación de ubiquitina que intervienen en la formación del autofagosoma (Figura 8).

En un primer paso, el extremo C-terminal de Atg12 se activa por acción de Atg7 (E1like), formando el intermediario Atg12-Atg7. Posteriormente, la proteína Atg12 es transferida a Atg10 para formar el complejo Atg12-Atg10. El C-terminal de Atg12 se une covalentemente a la lisina 130 del Atg5. Este nuevo complejo (Atg12-Atg5) se une en forma no covalente a la proteína homologa de levaduras Atg16L ${ }^{152}$. El complejo Atg12/Atg5/Atg16L reside mayoritariamente en el citosol, aunque una pequeña fracción se ubica en la membrana del autofagosoma. En el proceso de elongación la distribución del complejo Atg12/Atg5/Atg16L es asimétrica, asociándose en gran parte a la membrana externa. Finalmente, este complejo se disocia de la membrana al completarse la formación del autofagosoma ${ }^{153}$ (Figura 8).

La proteína LC3 (microtubule-associated proteins 1A/1B light chain 3A) en mamíferos, ó Atg8 en levaduras, experimenta algunas modificaciones post-traduccionales antes de unirse a la membrana del autofagosoma. Inmediatamente después de su síntesis se eliminan 22 aminoácidos en ratas, y 5 aminoácidos en humanos, correspondientes al C-terminal. Este procesamiento es catalizado por la proteína Atg4. La forma procesada, LC3-I, reside principalmente en el citosol y conserva un residuo de glicina en el C-terminal. Tras la activación por la proteína Atg7, la cual funciona también como una enzima activadora de Atg12, el LC3-I es transferido a una enzima E2 del sistema de ubiquitinación, homóloga a Atg3 y se conjuga conjuga con fosfatidiletolamina. El producto final, llamado LC3-II, se asocia al precursor de la membrana y a diferencia del complejo Atg12-Atg5/Atg16L, permanece unido a la membrana interna después de completar la formación del autofagosoma y es degradado por la fusión con el lisosoma (Figura 8). La proteína LC3-II que se encuentra en la parte citosólica de la membrana del autolisosoma, es delipidada por la proteína Atg4 y reciclado ${ }^{154-156}$ (Figura 8). El sequestosoma 1 (SQSTM1) es una proteína de unión a ubiquitina que participa en el estrés oxidativo y en la autofagia. El SQSTM1 forma agregados de proteínas que pueden ser degradados a través del autofagosoma, gracias su interacción con LC3 en la membrana del autofagosoma. La degradación lisosomal de los autofagosomas conduce a una disminución de los niveles del LC3-II y del SQSTM1 como parte del flujo autofágico ${ }^{157-159}$. 


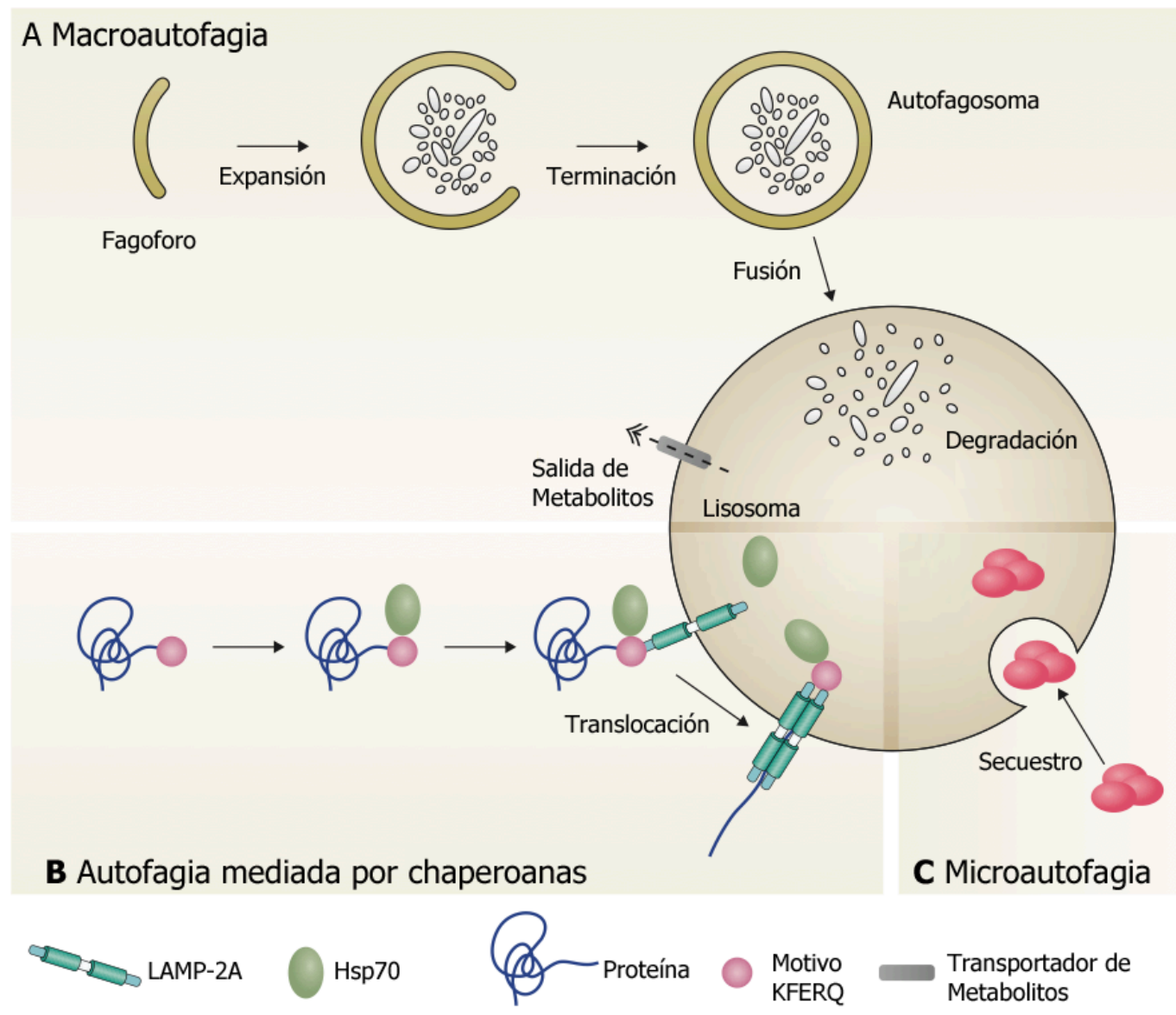

Figura 7. Diferentes tipos de autofagia. A) Macroautofagia, se caracteriza por secuestrar las estructuras blanco en una doble membrana vesicular llamada autofagosoma. La formación del autofagosoma comienza con la expansión y cierre del fagoforo, para luego exponer su contenido en el lumen del lisosoma para su degradación y posterior reciclaje. B) En la autofagia mediada por chaperonas, la chaperona Hsc70 reconoce las proteínas con el motivo KFERQ-like para asociarlas posteriormente con la proteína de la membrana lisosomal LAMP-2A, induciendo su oligomerización. Este evento transloca las proteínas específicas al lumen del lisosoma donde serán degragadas. G) La microautofagia implica el reclutamiento de componentes que se encuentran en la proximidad del lisosoma, y su posterior invaginación y degradación ${ }^{146}$.

Existen distintas clases de PI3K (phosphatidylinositide 3-kinase) que regulan la autofagia en células de mamíferos. La actividad de la PI3K clase III (PI3KC3), es esencial para para la biogénesis del autofagosoma, mientras que la inhibición de la PI3K clase I (PI3KC1) puede estimular la autofagia a través de la ruta de $\mathrm{mTOR}^{160}$. La quinasa $\mathrm{hVps} 34$ fosforila el fosfatidilinositol para formar fosfatidilinositol 3 fosfato (PtdIns3P) el cual posibilita la síntesis del autofagosoma. La quinasa hVps34, forma parte del macro-complejo iniciador de la autofagia que incluye a Beclin-1/Atg6 y Atg14L. La actividad de hVps34 se incrementa cuando interacciona con Beclin-1, el cual posee varios patrones de unión que dirigen la formación del autofagosoma ${ }^{161}$. Cuando Beclin-1 interactúa con Atg14L, Ambra1 (activating molecule in Beclin-1regulated autophagy), UVRAG (UV irradiation resistance-associated gene) y Bif-1 (endophilin B1), regula positivamente la autofagia. Mientras que su interacción con Rubicon, proteínas anti- 
apoptóticas Bcl-2-BCL-X y la proteína pro-apoptótica Bim, regula negativamente la autofagia $^{162}$. La GTPasa Rab5, también se une a este macro-complejo, activando hVps34 para inducir autofagia ${ }^{163}$. El macro-complejo ULK1-ATG13-FIP200 también interviene en la biogénesis del autofagosoma y los mecanismos implicados en su regulación los describiremos más adelante. La proteína Atg9, localizada en la red trans-Golgi, es la encargada de la elongación del fagoforo para la formación del autofagosoma ${ }^{164}$. Los autofagosomas en primer lugar se fusionan con los endosomas tardíos para formar los amfisomas, los cuales se fusionaran con los lisosomas formando los autolisosomas. Estos eventos de fusión son mediados por los complejos Rab7/HOPS (bomotypic fusion and vacuoles protein sorting), ESCRTs (endosomal sorting complexes required for transport), SNARE (N-ethylmaleimide-sensitive factor-attachment protein receptors) y la clase C de proteínas Vps. En la formación del amfisoma, la unión entre las membranas vesiculares es dirigida por el complejo GTPasa Rab7 y su efector/activador HOPS. Los complejos ESCRT y SNARE regulan la formación del amfisoma y la maduración del autofagosoma ${ }^{165,166}$ (Figura 8).

Aunque los mecanismos implicados en la formación y regulación del autofagosoma están relativamente bien caracterizados, se conoce mucho menos acerca de la organización general de la ruta y en que medida los diversos elementos funcionales se comunican entre sí. Un análisis proteómico de células humanas en condiciones basales de autofagia ha puesto de manifiesto la complejidad de las interacciones, revelando una red de 751 interacciones entre 409 candidatos, con una amplia conectividad entre las subredes. Muchos de los nuevos componentes de la red de interacción, están involucrados en el tráfico de vesículas, fosforilación de lípidos y proteínas y la ubiquitinación ${ }^{167}$.

\subsection{Regulación de la autofagia por la vía de mTOR}

La proteína quinasa mTOR es uno de los sensores más importantes en la regulación de la respuesta celular a la disminución o ausencia de nutrientes. mTOR es una serina/treonina quinasa que forma parte de dos complejos proteicos: mTORC1 y mTORC2168. El complejo mTORC1 está constituido por Raptor (regulatory-associated protein of mTOR), PRAS40 (proline-rich Akt substrate of $40 \mathrm{kDa}$ ), mLST8 (mammalian lethal with SEC13 protein 8) y Deptor (DEP-domain containing mTOR-interacting protein). El complejo mTORC2 esta constituido por Rictor (rapamycininsensitive companion of $m$ TOR), Protor (protein observed with rictor), mSIN1 (mammalian stressactivated mitogen-activated protein kinase-interacting protein 1), mLST8 y Deptor. En este complejo 


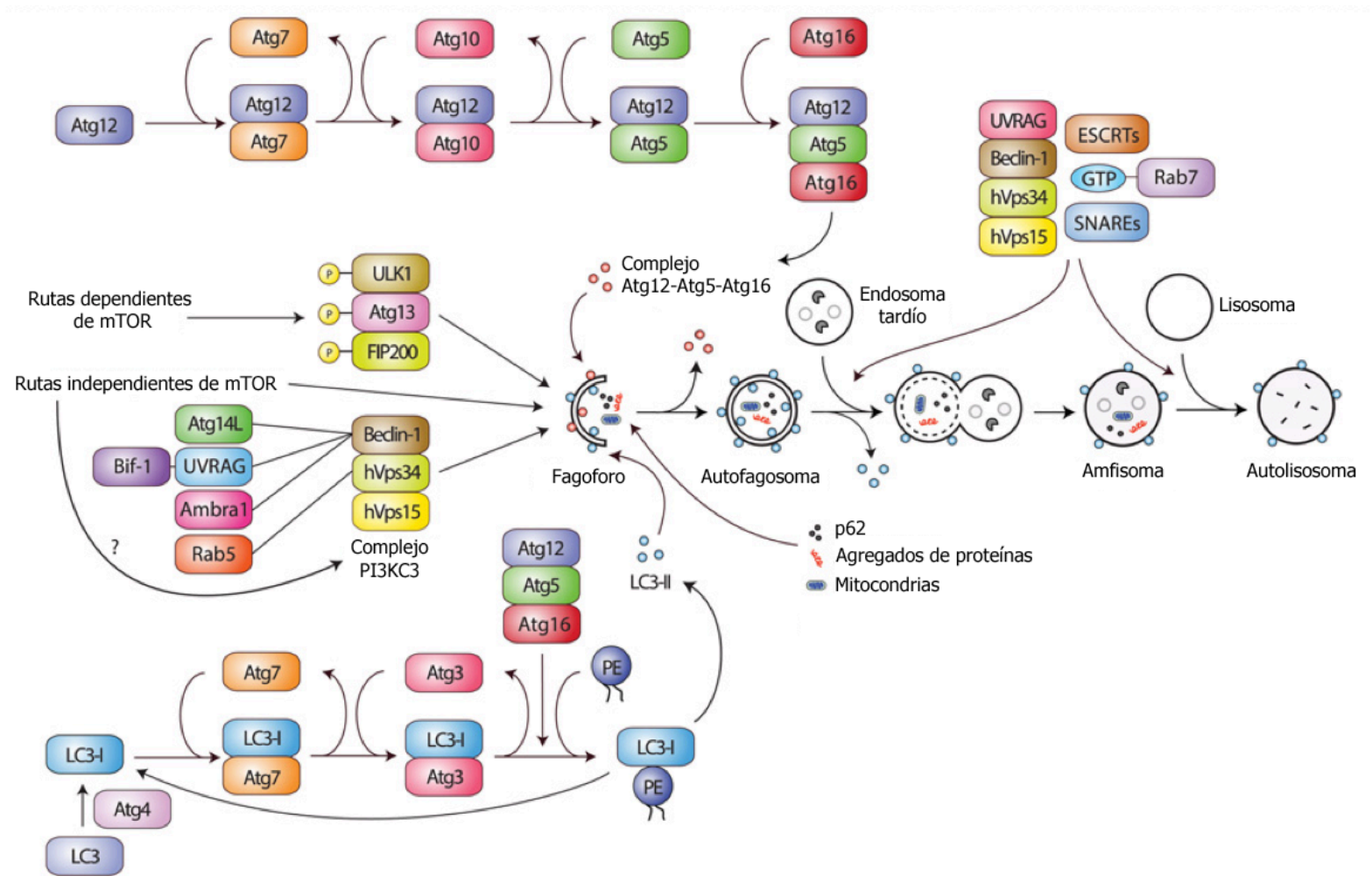

Figura 8. La ruta de la autofagia en mamíferos y la maquinaria reguladora. La autofagia es iniciada por la formación del fagoforo en el citoplasma, el cual engulle componentes citoplasmáticos para formar el autofagosoma. Los autofagosomas se fusionan con los endosomas tardíos para formar el amfisoma que se fusiona con los lisosomas. La vesicula donde los componentes citoplasmáticos son degradados se denomina autolisoma. La autofagia es controlada por vías dependientes e independientes de mTOR. El complejo ULK1-Atg13-FIP200 controla la autofagia por mecanismos downstream de mTOR. El complejo PI3KC3 formado por Beclin-1/hVsp34/hVsp15, controla la formación del autofagosoma por rutas independientes de mTOR. Proteínas que interactuan con Beclin-1 como Atg14L, UVRAG, Bif-1, Ambra-1 ó Rab5 en su interacción con $\mathrm{hVsp34}$, modulan positivamente este proceso. La elongación del fagoforo implica dos sistemas de conjugación de ubiquitina. La conjugación de Atg5-Atg12 se realiza a través de Atg7 (E1) y Atg10 (E2), mientras que en la conjugación de LC3-PE intervienen Atg7 (E1) y Atg3 (E2). El conjugado Atg5-Atg12 forma un complejo con Atg16: Atg5Atg12.Atg16, el cual ejerce su actividad E3 a través de la conjugación de LC3-PE (LC3-II). LC3-II es un marcador específico de los autofagosomas que es degradado en el autolisosoma, así como también puede der delipidado y reciclado a través de Atg4 173 .

mTOR tiene un papel importante en la regulación de la autofagia ya que su actividad quinasa es muy sensible a la disminución de nutrientes, nitrógeno, ATP o a la rapamicina. Al contrario que en el complejo mTORC1, la actividad de mTor en mTORC2 no se ve inhibida por la rapamicina ${ }^{169,170}$. Durante periodos de inanición, se inhibe la actividad de mTORC1 y se induce la autofagia para reciclar componentes celulares como una fuente de energía. La inhibición de mTOR y la inducción de autofagia se asocia con la reducción de la fosforilación de dos efectores downstream mTOR, p70 ${ }^{\mathrm{S} 6 \mathrm{~K}}$ (ribosomal protein 56 kinase-1) y 4E-BP1 (translation initiation factor 4E-binding protein-1) en $\mathrm{Thr}^{389} / \mathrm{Thr}^{421} / \mathrm{Ser}^{424} \mathrm{y} \mathrm{Thr}^{37} / \mathrm{Thr}^{46}$ respectivamente ${ }^{171}$.

A continuación describiremos brevemente los mecanismos que controlan la autofagia, vinculados a mTOR. Estos eventos se encuentran resumidos en la Figura 9. 


\subsubsection{Control de la autofagia por el complejo ULK1-ATG13-FIP200/mTORC1}

En condiciones de abundancia de nutrientes mTOR inhibe la autofagia mediante la unión directa con el complejo ULK1-ATG13-FIP200, inactivando por fosforilación la actividad de las quinasas Atg13 y ULK1. En condiciones de inanición o en el tratamiento con rapamicina, mTOR se disocia de este complejo, conduciendo a la desfosforilación y activación de la quinasa ULK1. ULK1 fosforila a Atg13, a FIP200 y a si misma, disparando el inicio de la autofagia ${ }^{172}$. Diversas señales como la incorporación de aminoácidos, factores de crecimiento, una alta tasa de recambio ATP/AMP activan mTORC1 e inhiben la autofagia ${ }^{173}$.

\subsubsection{Control de la autofagia por la detección de nutrientes a través de la ruta Rag/ mTOR}

Los aminoácidos son necesarios para la activación de mTOR. Sin embargo, el mecanismo mediante el cual mTOR detecta los niveles intracelulares de aminoácidos no estaba del todo esclarecido. Estudios recientes han demostrado que la absorción celular de Lglutamina y su posterior secreción en presencia de los aminoácidos esenciales es el paso limitante que activa mTOR. La absorción de L-glutamina es regulada por el transportador de aminoácidos SLC1A5. La inactivación de SLC1A5 inhibe el crecimiento celular y activa autofagia. El transportador bidireccional SLC7A5/SLC3A2, regula el transporte de L-leucina y aminoácidos esenciales hacia el interior celular y la secreción simultánea de L-glutamina fuera de las células. Los niveles intracelulares de L-glutamina modulan la actividad de los transportadores SLC1A5 y SLC7A5/SLC3A2, proporcionando un interruptor para la absorción de aminoácidos no esenciales y regulando la señalización de mTORC1 ${ }^{174-176}$ (Figura $9)$.

La GTPasa Rag (Ras-related GTP-binding protein), existe como un heterodímero entre RagA ó RagB unido a RagC ó RagD. Las GTPasas Rag junto con Regulator y la v-ATPasa forman un complejo ubicado en la superficie de los lisosomas, que se encarga de dirigir la señalización de mTOR cuando la concentración de aminoácidos varia. Cuando la concentración de aminoácidos es baja, las GTPasas Rag permanecen en un estado inactivo, donde el complejo RagA/B se encuentra unido a GDP y el complejo RagC/D a GTP. En presencia de aminoácidos, las GTPasas Rag cambian a su conformación activa donde el complejo RagA/B se encuentra unido a GTP y el complejo RagC/D a GDP. El heterodímero activo de Rag interactúa físicamente con Raptor, secuestrando y activando mTORC1 en la 
superficie de los lisosomas, regulando negativamente la autofagia ${ }^{175}$. El reclutamiento de mTORC1 en la superficie lisosomal, promueve su interacción con TFEB (transcription factor $E B)$, fosforilándolo e inactivándolo. Cuando hay deficiencias nutricionales, mTORC1 libera a TFEB, el cual se dirige al núcleo, activando la expresión de genes relacionados con las vías de degradación lisosomal y la autofagia ${ }^{173}$ (Figura 7).

Bajos niveles de glucosa, también promueven la traslocación de mTORC1 hacia el citoplasma. Cuando se restablecen los niveles de glucosa se observa una recolocalización de mTORC1 en la superficie lisosomal. Sin embargo, en células que expresan Rag constitutivamente activo, mTORC1 se localiza en la superficie lisosomal independientemente de las concentraciones de glucosa. La v-ATPasa lisosomal regula la interacción de Regulator en la superficie del lisosoma como respuesta a la disponibilidad de aminoácidos o glucosa. Las GTPasas Rag constituyen un sensor de nutrientes multi-entrada, en el que los aminoácidos y glucosa convergen, de una manera v-ATPasa dependiente, upstream mTORC1 ${ }^{177}$ (Figura 9).

\subsubsection{Control de la autofagia por factores de crecimiento a través de la ruta PI3KC1 a/Akt/TSC/mTORC1}

La mayor cascada de señalización encargada de la regulación de mTORC1 es la ruta PI3KC1a (Figura 9) ${ }^{160}$. La unión de factores de crecimiento, insulina, integrinas, proteínas GPCRs (G-protein-coupled receptors) u oncogenes tipo Ras, a sus respectivos receptores de membrana activan el complejo PI3KC1a. El complejo PI3KC1a cataliza la conversión de PtdIns(4,5) $P_{2}$ a PtdIns (3,4,5) $P_{3}$. El PtdIns $(3,4,5) P_{3}$ se une a proteínas con dominio PH (pleckstrin homology) como la serina/treonina quinasa PDK1 (phosphoinositide-dependent kinase 1) y Akt ( $v$-akt murine thymoma viral oncogene homolog 1), activando y translocando ambas proteínas a la membrana plasmática. Esta activación inhibe la autofagia. El supresor de tumores PTEN (phosphatase and tensin homologue deleted from chromosome 10), antagoniza con PI3KC1a desfosforilando PtdIns $(4,5) P_{2}$ y PtdIns(3,4,5) $P_{3}$, evitando de este modo la activación de Akt y de PDK1, activando así la autofagia ${ }^{178,179}$.

La activación de Akt también activa al complejo mTORC1 a través de la vía TSC/Rheb. El complejo TSC1/2 (tuberous sclerosis complex) es una GAP (GTPase-activating protein) que inhibe la función de Rheb mediante la unión de GDP. La activación de Akt induce la fosforilación del TSC2 inhibiendo su actividad GAP sobre Rheb y la formación del complejo TSC1/2, permitiendo que Rheb se una directamente a mTORC1 activándolo180,181. 
El factor de transcripción FoxO3 (forkhead box) en su conformación activa, promueve la autofagia mediante la transcripción de genes como LC3, Bnip3 (Bcl-2/adenovirus E1B 19 kDainteracting protein 3), Vps34 y ULK1. La activación de Akt induce la fosforilación y consecuente inactivación del factor de transcripción FoxO3, impidiendo su translocación al núcleo ${ }^{182}$.

\subsubsection{Control de la autofagia mediante sensores de energía a través de la ruta AMPK/TSC/mTORC1}

Durante periodos de estrés metabólico, la activación de la autofagia es esencial para la viabilidad celular. En células de mamíferos, la reducción de los niveles de ATP son detectados por la quinasa AMPK (5'-AMP-activated protein kinase). AMPK se activa a través de la quinasa upstream LKB1 (Liver Kinase B1), cuando la proporción ATP/AMP disminuye. Esta activación induce la fosforilación y activación de TSC1/2, el cual inhibe la actividad de mTORC1 a través de Rheb ${ }^{183}$. La activación de la autofagia por la regulación negativa de mTOR resulta en una elevada producción de ATP gracias al reciclaje de nutrientes. Adicionalmente, la vía LKB1AMPK fosforila y activa $\mathrm{p} 27^{\mathrm{kip} 1}$, un inhibidor de $\mathrm{cdk}$ (cyclin-dependent kinase) que induce un arresto en el ciclo celular, esencial para prevenir la muerte celular y favorecer la supervivencia en respuesta a estrés bioenergético producido por la privación de nutrientes ${ }^{184}$ (Figura 9).

El estrés nitrosativo mediado por el NO inhibe la síntesis del autofagosoma. El NO inhibe a la quinasa IKK $\beta$ (inbibitor of nuclear factor $\varkappa B$ kinase $\beta$ ), lo que conlleva a una caída en la actividad de AMPK y TSC1/2, y a una activación de mTORC1 ${ }^{185}$. La activación de IKK $\beta$, fosforila AMPK y JNK1 para estimular la autofagia en un proceso independiente del factor nuclear NF- $x B^{186}$. El p53 citoplásmico inhibe la autofagia posiblemente a través de la vía AMPK/TSC/mTORC1. Cuando se detectan bajos niveles de glucosa, p53 se activa a través de la fosforilación mediada por AMPK, inhibiendo la actividad de mTORC1 ${ }^{187}$. La quinasa AMPK interviene en la autofagia inducida por hipoxia. Durante la hipoxia, la respiración mitocondrial se deteriora, produciendo una disminución de la proporción de ATP:AMP, la cual es detectada por AMPK. La activación de AMPK resulta en la inhibición de mTORC1 a través de TSC2 ${ }^{188}$. 


\subsection{Regulación de la autofagia por rutas independientes de mTOR}

Además de la regulación de la autofagia por mTORC1 y las diversas rutas de señalización up y downstream que inciden en él, se han descrito varias rutas de señalización de la autofagia independientes de mTORC1 susceptibles a perturbaciones químicas (Figura 10).

\subsubsection{Control de la autofagia por la ruta de señalización del inositol}

Esta ruta es estimulada por la PLC (phospholipase C), la cual hidroliza el PtdIns(4,5) $P_{2}$ para formar Ins $(1,4,5) P_{3}$ y $\mathrm{DAG}$ (diacylglycerol). El Ins $(1,4,5) P_{3}$ funciona como segundo mensajero y se une a su receptor (IP3R) en el RE, liberando el $\mathrm{Ca}^{2+}$ desde almacenes intracelulares, principalmente del RE al citoplasma. El poro conductor del IP3R comprende sólo el 5\% del total del receptor y se sitúa en el extremo C-terminal de la proteína, mientras que el sitio de unión a ligando $\operatorname{Ins}(1,4,5) P_{3}$ se encuentra entre los aminoácidos 226-578 del extremo amino terminal ${ }^{189}$. El Ins $(1,4,5) P_{3}$ es degradado por una 5'-fosfatasa y la IPPasa (inositol polyphosphate 1-phosphatase) para formar Ins $P$, el cual es hidrolizado por IMPasa (inositol monophosphatase) en inositol libre requerido para la señalización de esta ruta ${ }^{190}$. Concentraciones intracelulares elevadas de $\operatorname{Ins}(1,4,5) P_{3}$ inhiben la síntesis del autofagosoma ${ }^{191}$. Agentes que disminuyen el inositol, como las drogas de estabilización del humor como el litio, la carbamazepina o ácido valproico, inducen autofagia y facilitan la eliminación de sustratos autofagicos sin inhibir la actividad de mTORC1. La rapamicina tampoco afecta los niveles de inositol, sugiriendo que el control de la autofagia por el Ins $(1,4,5) P_{3}$ y mTOR esta mediada por dos rutas independientes. El litio actúa inactivando la IMPasa, y disminuyendo en consecuencia los niveles intracelulares del inositol ${ }^{192}$ (Figura 10).

\subsubsection{Control de la autofagia por la ruta cAMP/Epac/PLCE}

La autofagia es regulada por el segundo mensajero cAMP. El incremento de los niveles intracelulares del cAMP inhibe la autofagia. La inhibición de la actividad de la adenilato-ciclasa con $2^{\prime} 5^{\prime} \mathrm{dd} A$ induce autofagia y aumenta la degradación del contenido autofagosomal por una ruta independiente de mTORC1, mientras incrementos en los niveles de cAMP, inhiben la autofagia. La clonidina y la rilmenidine, drogas agonistas del receptor de imidazol-1 (I1R), inducen autofagia por una ruta independiente de mTOR, reduciendo los niveles de cAMP ${ }^{193}$. 


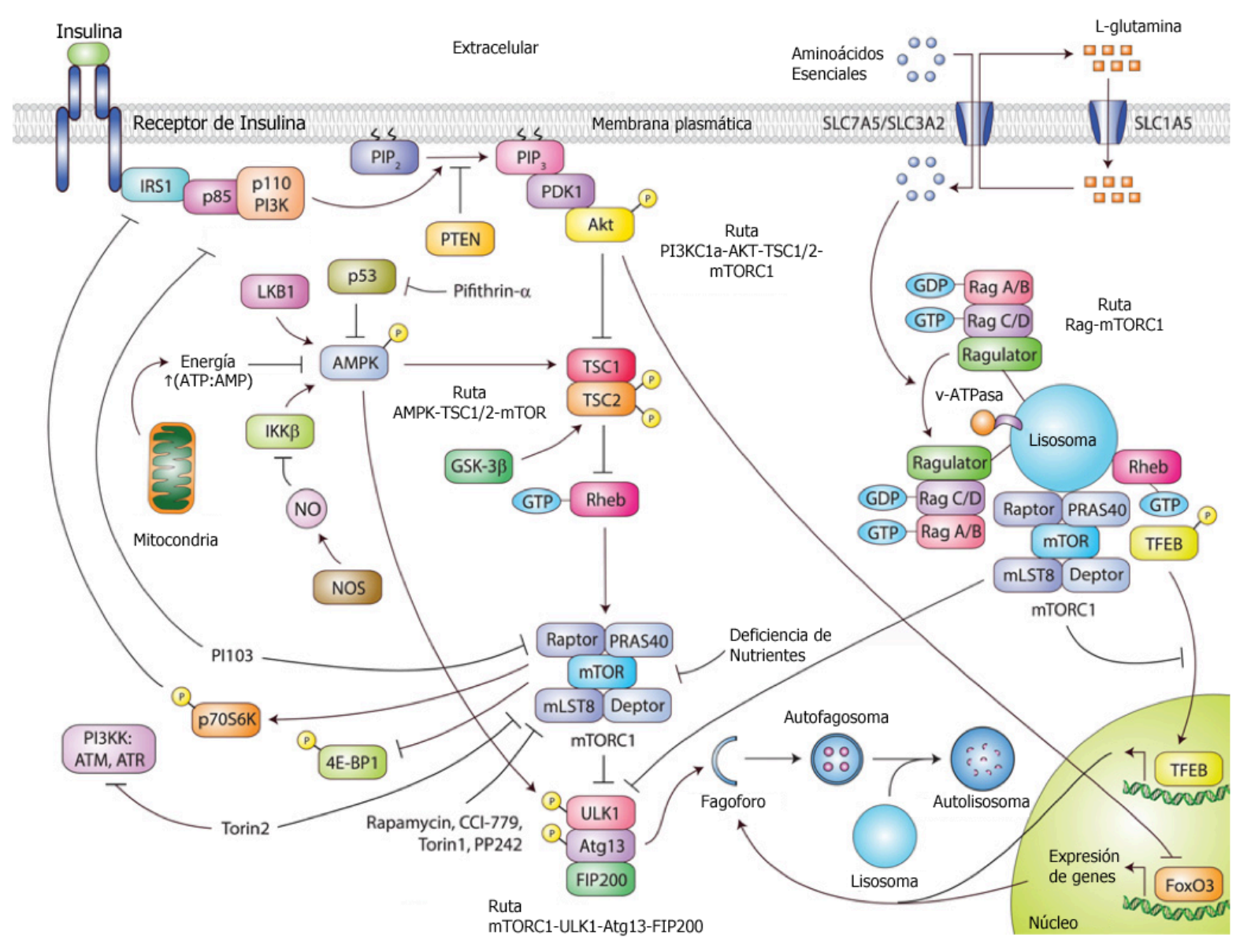

Figura 9. Regulación de la autofagia por rutas dependientes de mTORC1. Diversas señales como factores de crecimiento, disponibilidad de aminoácidos, condiciones de estrés y el estatus energético pueden activar mTORG1, el cual regula negativamente la autofagia. La insulina y los factores de crecimiento actúan a través de la ruta PI3KCla/Akt/TSG/ mTORC1. La unión a sus respectivos receptores de membrana activa PI3KCla y Akt, resultando en la inhibición de TSG1/2 y permitiendo que Rheb active a mTORG1 inhibiendo la autofagia. La activación de p70 ${ }^{\mathrm{S} 6 \mathrm{~K}}$ por mTORG1 también ejerce un bucle de retroalimentación inhibiendo IRS1 (insulin receptor susbstrate 1). Además la activación de Akt inhibe la transcripción de genes relacionados con la autofagia por FoxO3. La afluencia de aminoácidos a través de sus transportadores de membrana activa la GTPasa Rag (ruta Rag/mTORC1), la cual se une a la proteína residente en el lisosoma Regulator y recluta a mTORC1 activandolo e inhibiendo la autofagia. La activación de mTORG1 en la superficie del lisosoma impide la translocación de TFEB al núcleo, previniendo la transcripción de genes relacionados con la autofagia y la vía lisosomal. El estatus energético y distintas señales de estrés modulan la autofagia a través de la ruta AMPK/TSG/mTORG1. Una proporción elevada de ATP:AMP, NO o la activación del p53 citoplasmático, inhiben AMPK lo cual evita la activación de TSC1/2, permitiendo la activación de mTORG1 a través de Rheb. El complejo ULK1-Atg13-FIP200 regula la síntesis del autofagosoma downstream mTORG1. La inhibición de mTORG1 y PI3KK con Torin2, ó la inhibición de PI3KCla y mTORC1 con PI103, activan la autofagia ${ }^{173}$.

Es probable que la regulación de autofagia a través de los niveles intracelulares de Ins $(1,4,5) P_{3}$ se deba a la liberación de calcio desde el retículo endoplasmático (ER), a través de IP3R. Los niveles citosólicos elevados de calcio activan las calpaínas, las cuales activan receptores acoplados a proteínas $G(\mathrm{G} \alpha \mathrm{s})$, aumentando la actividad de la adenilil-ciclasa (AD), influyendo directamente en los niveles de cAMP $^{194}$. Niveles intracelulares elevados de cAMP inhiben la autofagia, mediada a través de Epac (exchange protein directly activated by cAMP). La 
activación de Epac activa a su vez Rap2B, una proteína $G$ de la familia Ras, que induce la hidrólisis de PtdIns $(4,5) P_{2}$ a Ins $(1,4,5) P_{3}$ a través de PLC $\varepsilon^{191}$ (Figura 8).

\subsubsection{Control de la autofagia por la ruta $\mathrm{Ca}^{2+} /$ calpaina}

La autofagia es regulada por los niveles intracelulares de $\mathrm{Ca}^{2+}$. Estudios en hepatocitos de rata demostraron que un incremento del $\mathrm{Ca}^{2+}$ citosólico inhibe la autofagia ${ }^{195}$. Subsecuentes estudios han encontrado que elevados niveles de $\mathrm{Ca}^{2+}$ citosólico tiene efectos complejos en la regulación de la autofagia, tanto en la formación del autofagosoma como en la fusión del autofagosomas con el lisosoma. Tratamientos con thapsigargin inhibidor de la $\mathrm{Ca}^{2+} /$ $\mathrm{Mg}^{2+}$ ATPasa del RE, ó ionomicina, un ionoforo de $\mathrm{Ca}^{2+}$, bloquea el flujo autofágico y retarda la degradación del contenido de los autofagosomas ${ }^{196}$. Antagonistas de los canales L-type $\mathrm{Ca}^{2+}$, el canal $\mathrm{K}^{+}$ATP abridor minoxidil y el activador Gi de la señalización por clonidina, inducen la autofagia. Estos fármacos actúan por una ruta independiente mTOR, en la cual el cAMP regula los niveles de IP3, influyendo en la actividad de las calpainas y activando a su vez la proteína Gs $\alpha$. La proteína Gs $\alpha$ regula los niveles de cAMP a través de la activación de la adenilato ciclasa (AD). Un incremento en los niveles citosólicos de $\mathrm{Ca}^{2+}$ activa las calpainas 1 y 2 (calciumactivated neutral proteinase). La inhibición farmacológica de las calpainas con calpastatin y calpeptin, o por silenciamiento genético, incrementa el flujo autofágico, sin perturbación de mTORC1. Por el contrario, la activación de las calpainas por la apertura de los canales de $\mathrm{Ca}^{2+}$, o la sobre-expresión de la calpaina 2 constitutivamente activa, inhiben la formación del autofagosoma ${ }^{193}$.

\subsubsection{Control de la autofagia por la ruta JNK 1 / Beclin-1 / PI3KC3}

Beclin-1 es una proteína de $60 \mathrm{kDa}$ fundamental para la activación y tiene diversos patrones de unión que regulan la autofagia. La modificación post-traduccional de Beclin-1 junto con su asociación a otras proteínas da lugar a distintos complejos PI3KC3, que regulan la autofagia. Dentro de las proteínas capaces de asociarse a Beclin-1 se encuentran hVps34, UVRAG, AMBRA1, Bif-1, Rubicon, IP3R, ATG14L/Barkor y Bcl-2 ${ }^{162}$. La síntesis de los autofagosomas requiere de la actividad de PI3CK3, la cual aumenta mediante la interacción de Beclin-1 con hVps34197. Los complejos Beclin-1-UVRAG y Beclin-1-ATG14L intervienen en la regulación de los primeros pasos de la autofagia, activando la formación de los autofagosomas. 


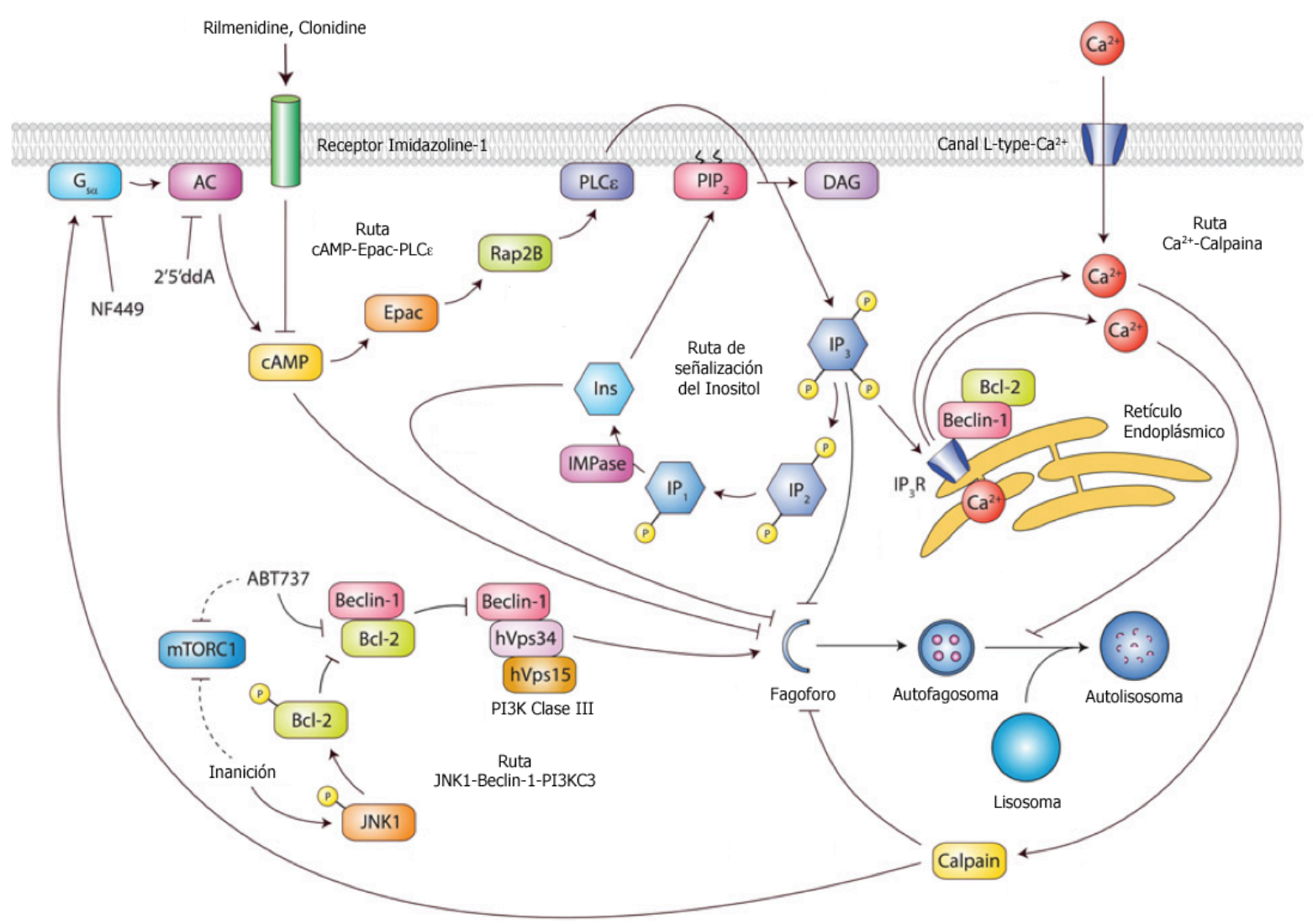

Figura 10. Regulación de la autofagia por rutas independientes de mTORC1. Varias cascadas de señalización como cAMP/Epac/PLC $\varepsilon, \mathrm{Ca}^{2+} /$ calpaina y del inositol (Ins) regulan la autofagia de manera independiente de mTORC1. La activación de la adenilato-ciclasa (AD) aumenta los niveles de cAMP, activando Epac y Rap2B. Esta activación permite que PLC $\varepsilon$ hidrolice el PtdIns $(4,5) P_{2}\left(\mathrm{PIP}_{2}\right)$ para producir $\operatorname{Ins}(1,4,5) P_{3}\left(\mathrm{IP}_{3}\right)$, el cual inhibe la autofagia. $\mathrm{El} \mathrm{IP}_{3}$ se une al IP 3 R del $\mathrm{RE}$, liberando el $\mathrm{Ca}^{2+}$ e impidiendo la maduración del autofagosoma y la fusión con el lisosoma. El aumento del $\mathrm{Ca}^{2+}$ citosólico, tanto por la liberación de los reservorios del RE como por la incorporación de $\mathrm{Ca}^{2+}$ a través del canal L-type$\mathrm{Ca}^{2+}$ resultan en la activación de las calpainas y la inhibición de la autofagia. Las calpainas activan a Gsa, aumentando la actividad de AD y generando cAMP. La unión de Bcl-2 a Beclin-1 inhibe la autofagia, mientras que el inhibidor selectivo de Bcl-2 ABT737 induce la autofagia. La deficiencia de nutrientes o la inanición, induce la fosforilación de JNK1, el cual fosforila a Bcl-2 e inhibe la formación del complejo Bcl-2/Beclin-1. El Beclin-1 libre forma un complejo con hVps34 iniciando la formación del autofagosoma. El complejo PI3KC3 comprende las proteínas Beclin-1/hVsp34/hVps15 y regula la síntesis del autofagosoma, posiblemente en una ruta independiente de mTORC1, pero los mecanismos específicos que regulan esa vía no están del todo esclarecidos ${ }^{173}$.

Sin embargo, se ha observado que la interacción de UVRAG con la proteína Rubicon, inhibe la autofagia impidiendo la maduración de los autofagosomas ${ }^{198}$. La proteína AMBRA1 se asocia al complejo PI3KC3 que posee la proteína ATG14L, actuando como un modulador positivo de la autofagia ${ }^{199}$. Bcl-2 es hasta la fecha la única proteína que inhibe la autofagia al asociarse directamente a Beclin-1. La interacción de Bcl-2 con Beclin-1 impide el ensamblaje del complejo Beclin-1-hVps34, e inhibe la autofagia. Por este motivo, ambas proteínas están sometidas a distintas modificaciones post-traduccionales que regulan su interacción ${ }^{200}$. La fosforilación de Bcl-2 en los residuos $\operatorname{Thr}^{69}, \operatorname{Ser}^{70} \mathrm{y} \mathrm{Ser}^{87}$ por JNK1 (c-Jun N-terminal kinase 1), en ausencia de nutrientes, permite su disociación de Beclin-1 y la consiguiente activación de la 
autofagia, por la formación del complejo Beclin-1/hVsp34. La deficiencia de nutrientes también inhibe mTORC1, pero la expresión de JNK1 constitutivamente activa no perturba la actividad de mTORC1. La rapamicina, por otra parte, no afecta la fosforilación de Bcl-2 por JNK1, sugiriendo que la regulación de la autofagia por las rutas JNK1/Beclin-1/PI3KC3 y mTOR son posiblemente independientes ${ }^{173}$. La mono-ubiquitinación de Bcl-2 por la ubiquitina quinasa E3 Parkina estabiliza la unión de Bcl-2 con Beclin-1, aumenta la vida media de Bcl-2 y disminuye la activación de la autofagia, sugiriendo que la mono-ubiquitinación de Bcl-2 inhibiría la autofagia al aumentar la cantidad de Bcl-2 disponible para unirse a Beclin-1201 (Figura 10). 



\section{Objetivos}

La disponibilidad de arginina es un factor importante para la evolución de la respuesta inmune, y para el desarrollo y proliferación de algunos tumores. Se conoce que en ausencia de arginina, las células $\mathrm{T}$ pierden la expresión de la cadena $\mathrm{CD} 3 \zeta$ y pueden mantenerse en un estado senescente sin que se inicie un proceso apoptótico. Sin embargo, no se conocen en detalle las alteraciones que llevan a la disfuncionalidad de las células $\mathrm{T}$ en ausencia de arginina. Por lo tanto, en el presente trabajo de Tesis intentaremos establecer una relación entre la función de las células T, los neutrófilos y el cáncer, utilizando la actividad arginasa como pieza importante en la regulación de los niveles de arginina libre en el medio extracelular. Para la consecución de este objetivo principal nos planteamos los siguientes objetivos específicos:

1. Estudiar los mecanismos involucrados en la supervivencia de células $\mathrm{T}$ en ausencia de arginina.

2. Identificar los mecanismos responsables de la regulación negativa de la cadena CD3 $\zeta$ de células $\mathrm{T}$ en ausencia de arginina.

3. Determinar el efecto de la arginasa I de neutrófilos humanos y su exocitosis en la proliferación y muerte de células tumorales. 

Materiales y Métodos 



\section{Cultivos celulares}

Las líneas celulares humanas utilizadas se describen en la Tabla 1:

Tabla 1. Descripción de las líneas celulares utilizadas en este estudio.

\begin{tabular}{|c|c|c|c|}
\hline Línea Celular & Tipo celular & $\mathbf{N}^{\circ}$ de Pase (ATCC) & No Células/pocillo (96) \\
\hline A549/ATCC & Cáncer de pulmón no microcítico & 3 & 3000 \\
\hline EKVX & Cáncer de pulmón no microcítico & 3 & 6500 \\
\hline HOP-62 & Cáncer de pulmón no microcítico & 4 & 3500 \\
\hline HOP-92 & Cáncer de pulmón no microcítico & 5 & 3500 \\
\hline $\mathrm{NCl}-\mathrm{H} 226$ & Cáncer de pulmón no microcítico & 4 & 3000 \\
\hline $\mathrm{NCl}-\mathrm{H} 23$ & Cáncer de pulmón no microcítico & 4 & 5500 \\
\hline $\mathrm{NCl}-\mathrm{H} 322 \mathrm{M}$ & Cáncer de pulmón no microcítico & 5 & 3000 \\
\hline $\mathrm{NCl}-\mathrm{H} 460$ & Cáncer de pulmón no microcítico & 4 & 2500 \\
\hline $\mathrm{NCl}-\mathrm{H} 522$ & Cáncer de pulmón no microcítico & 4 & 4000 \\
\hline COLO 205 & Colon & 4 & 3000 \\
\hline HCC-2998 & Colon & 7 & 3500 \\
\hline HCT-116 & Colon & 3 & 3000 \\
\hline HCT-15 & Colon & 3 & 3000 \\
\hline HT-29 & Colon & 4 & 3500 \\
\hline KM12 & Colon & 4 & 6000 \\
\hline SW-620 & Colon & 6 & 3000 \\
\hline HeLa & Cuello uterino & 23 & 1500 \\
\hline HEP-G2 & Hígado & 34 & 2300 \\
\hline CCRF-CEM & Leucemia & 13 & 15000 \\
\hline HL-60(TB) & Leucemia & 8 & 6000 \\
\hline Jurkat & Leucemia & 32 & 5000 \\
\hline K-562 & Leucemia & 7 & 3000 \\
\hline MOLT-4 & Leucemia & 3 & 5000 \\
\hline RPMI-8226 & Leucemia & 7 & 3500 \\
\hline SR & Leucemia & 6 & 6000 \\
\hline BT-549 & Mama & 4 & 3000 \\
\hline HS 578T & Mama & 5 & 3000 \\
\hline MCF7 & Mama & 4 & 3500 \\
\hline MDA-MB-231 & Mama & 5 & 4000 \\
\hline MDA-MB-468 & Mama & 4 & 3000 \\
\hline T-47D & Mama & 4 & 4000 \\
\hline LOX IMVI & Melanoma & 4 & 3000 \\
\hline M14 & Melanoma & 3 & 4000 \\
\hline MALME-3M & Melanoma & 6 & 3500 \\
\hline MDA-MB-435 & Melanoma & 3 & 5000 \\
\hline SK-MEL-2 & Melanoma & 6 & 4000 \\
\hline
\end{tabular}




\begin{tabular}{|c|c|c|c|}
\hline Línea Celular & Tipo celular & $N^{\circ}$ de Pase (ATCC) & $N^{\circ}$ Células/pocillo (96) \\
\hline SK-MEL-28 & Melanoma & 4 & 4500 \\
\hline SK-MEL-5 & Melanoma & 5 & 4500 \\
\hline UACC-257 & Melanoma & 5 & 3000 \\
\hline UACC-62 & Melanoma & 5 & 3000 \\
\hline IGR-OV1 & Ovario & 3 & 3500 \\
\hline $\mathrm{NCl} / \mathrm{ADR}-\mathrm{RES}$ & Ovario & 3 & 6000 \\
\hline OVCAR-3 & Ovario & 7 & 5000 \\
\hline OVCAR-4 & Ovario & 5 & 5000 \\
\hline OVCAR-5 & Ovario & 6 & 3000 \\
\hline OVCAR-8 & Ovario & 3 & 4000 \\
\hline SK-OV-3 & Ovario & 6 & 4000 \\
\hline BxPC-3 & Páncreas & 48 & 4500 \\
\hline MIA-PaCa-2 & Páncreas & 40 & 1000 \\
\hline PANC-1 & Páncreas & 57 & 4500 \\
\hline DU-145 & Próstata & 5 & 2500 \\
\hline PC-3 & Próstata & 4 & 3000 \\
\hline $786-0$ & Renal & 7 & 2500 \\
\hline A498 & Renal & 34 & 4000 \\
\hline $\mathrm{ACHN}$ & Renal & 4 & 5500 \\
\hline CAKI-1 & Renal & 4 & 6000 \\
\hline RXF 393 & Renal & 6 & 3000 \\
\hline SN12C & Renal & 4 & 3500 \\
\hline TK-10 & Renal & 5 & 4000 \\
\hline UO-31 & Renal & 5 & 3500 \\
\hline SF-268 & Sistema Nervioso Central & 4 & 4000 \\
\hline SF-295 & Sistema Nervioso Central & 3 & 3500 \\
\hline SF-539 & Sistema Nervioso Central & 3 & 3500 \\
\hline SNB-19 & Sistema Nervioso Central & 5 & 4000 \\
\hline SNB-75 & Sistema Nervioso Central & 3 & 3000 \\
\hline T98G & Sistema Nervioso Central & 4 & 4000 \\
\hline U251 & Sistema Nervioso Central & 5 & 3000 \\
\hline
\end{tabular}

Los cultivos primarios utilizados fueron los siguientes:

- HUVEC, procedentes de células endoteliales de la vena del cordón umbilical humano.

- Células T, procedentes de sangre periférica humana.

- Neutrófilos, procedentes de sangre periférica humana.

El cultivo de células se realizó a $37^{\circ} \mathrm{C}$ en atmósfera humidificada y $5 \%$ de $\mathrm{CO}_{2}$, en medio de cultivo RPMI-1640 ó DMEM (HeLa) suplementado con 10\% de suero fetal bovino 
(SFB) inactivado por calor $\left(56^{\circ} \mathrm{C}, 45 \mathrm{~min}\right), 2 \mathrm{mM}$ de L-glutamina, $100 \mathrm{U} / \mathrm{ml}$ de penicilina y 100 $\mu \mathrm{g} / \mathrm{ml}$ de estreptomicina (GIBCO BRL, Life Technologies, Gaithersburg, MD, USA). Además se utilizó RPMI-1640 sin arginina de GIBCO BRL suplementado con $\mathrm{MnCl}_{2}$ a una concentración de $4 \mu \mathrm{M}, 5 \%$ suero fetal bovino dializado $(<10 \mathrm{kDa})$ (Sigma, St. Louis, MO, USA) descomplementarizado por calor $\left(56^{\circ} \mathrm{C}, 45 \mathrm{~min}\right), 2 \mathrm{mM}$ de L-glutamina, $100 \mathrm{U} / \mathrm{ml}$ de penicilina y $100 \mu \mathrm{g} / \mathrm{ml}$ de estreptomicina (GIBCO BRL, Life Technologies, Gaithersburg, MD, USA).

\section{Recuento de células viables mediante Trypan Blue}

La reactividad del Trypan Blue se basa en el hecho de que el cromóforo está cargado negativamente y no interacciona con la célula a menos que la membrana esté dañada. Por lo tanto, todas las células que excluyen el colorante son viables. Para realizar el conteo de células viables, se tomó $0,5 \mathrm{ml}$ de una suspensión celular a la cual se añadió 0,1 $\mathrm{ml}$ de Trypan Blue al 0,4\%, se homogeneizo y se dejó a temperatura ambiente por 5 min. Bajo el microscopio y utilizando una cámara de Neubauer se procedió a contar las células viables no teñidas. El porcentaje de células viables se calculó como sigue:

$\% \mathrm{n}^{\circ}$ Células viables $=\left[\left(\mathrm{n}^{\circ}\right.\right.$ células viables $) /\left(\mathrm{n}^{\mathrm{o}}\right.$ células viables $+\mathrm{n}^{\mathrm{o}}$ células no viables $\left.) \times 100\right]$

\section{Aislamiento de células sanguíneas}

Las células sanguíneas fueron aisladas a partir de sangre periférica humana por sedimentación con dextran al 6\% en PBS, para eliminar el exceso de eritrocitos. La solución que contiene las células sanguíneas fue centrifugada durante 8 min a $1200 \mathrm{rpm}$. El pellet celular fue resuspendido en PBS en una proporción 1:1 con respecto al gradiente de densidad FicollPaque. La resuspención celular fue dispensada encima del gradiente y centrifugada a $1500 \mathrm{rpm}$ durante $45 \mathrm{~min}$. Las células mononucleares se obtuvieron de la interfase formada entre el gradiente y el PBS. Se realizaron dos lavados con PBS y se resuspendieron en RPMI-1640 (10\% SFB, $2 \mathrm{mM}$ de L-glutamina, $100 \mathrm{U} / \mathrm{ml}$ de penicilina y $100 \mu \mathrm{g} / \mathrm{ml}$ de estreptomicina). La preparación de células T esta formada típicamente por 65-71\% CD3+, 27-29\% CD19+, y $<0.4 \%$ CD14+. Con la finalidad de purificar las células T, las células no adherentes se lavaron con PBS y se pasaron dos veces a través de una columna de lana de nylon para disminuir las células $\mathrm{B}$ y monocitos residuales como se ha descrito previamente ${ }^{202}$. Estas células fueron 
incubadas toda la noche a $37^{\circ} \mathrm{C}$ en atmósfera humidificada y $5 \%$ de $\mathrm{CO}_{2}$. Después de la incubación se recogieron las células no adherentes (células T) que fueron posteriormente lavadas con PBS y resuspendidas en medio RPMI-1640 (10\% SFB, 2 mM de L-glutamina, 100 $\mathrm{U} / \mathrm{ml}$ de penicilina y $100 \mu \mathrm{g} / \mathrm{ml}$ de estreptomicina). La proliferación de las células $\mathrm{T}$ fue inducida mediante la incubación durante cuatro días con $0,5 \mu \mathrm{g} / \mathrm{ml}$ PHA, que activa la proliferación primaria y la expresión del receptor de interleuquina-2 (IL-2), seguido de un día de tratamiento con 0,5 $\mathrm{g} / \mathrm{ml}$ PHA y $50 \mathrm{U} / \mathrm{ml}$ (IL-2) en RPMI-1640 (10\% SFB, $2 \mathrm{mM}$ de Lglutamina, $100 \mathrm{U} / \mathrm{ml}$ de penicilina y $100 \mu \mathrm{g} / \mathrm{ml}$ de estreptomicina). Las células T resultantes fueron CD25+ en mas del 80\%. Las células polimorfonucleares fueron aisladas del pellet celular resultante del gradiente de Ficoll-Paque, los eritrocitos residuales fueron eliminados por choque osmótico mediante la resuspención del pellet celular en $8 \mathrm{ml}$ PBS y $24 \mathrm{ml}$ de agua destilada durante $1 \mathrm{~min} 15 \mathrm{seg}$. La isotonicidad se restableció mediante la adición de $1 \mathrm{ml}$ de cloruro de sodio $5 \mathrm{M}$. Las células fueron centrifugadas a $800 \mathrm{~g}$ durante $7 \mathrm{~min}$.

\section{Generación de sonicados de neutrófilos}

Los neutrófilos purificados de sangre periférica humana fueron resuspendidos en PBS (4 x $10^{7}$ células $/ \mathrm{ml}$ ) y sonicados durante $3 \mathrm{~min}$ (80 amplitud) en un Sonicador Ultrasonic Processor XL (Misonix, Inc. New Highway, Farmingdale, NY), y centrifugados a $20000 \mathrm{~g}$ durante 30 min a $4^{\circ} \mathrm{C}$. El sobrenadante fue filtrado $(0.2 \mu \mathrm{m})$ y se midió la concentración de proteínas del extracto, mediante la solución comercial Kit Protein Assay (BioRad, Richmond, CA, USA). La concentración de proteínas totales de cada muestra se determinó mediante la interpolación de las absorbancias obtenidas en una curva patrón realizada con concentraciones conocidas de BSA (Sigma).

\section{Actividad arginasa}

Para medir la actividad arginasa de los sonicados de neutrófilos se utilizaron $40 \mu \mathrm{l}$, a los cuales se agregó $10 \mu \mathrm{l}$ de $10 \mathrm{mM} \mathrm{MnCl}_{2}$; la enzima fue activada calentando la reacción a $56^{\circ} \mathrm{C}$ durante 10 min. La hidrólisis de arginina fue medida mediante la conversión de L-Arg a urea, para lo cual se añadió $50 \mu \mathrm{l}$ de L-Arg $0,5 \mathrm{M}\left(\mathrm{pH}\right.$ 9.7) y se incubó a $37^{\circ} \mathrm{C}$ de 15 a $120 \mathrm{~min}$. La reacción fue detenida con $400 \mu \mathrm{l}$ de $\mathrm{H}_{2} \mathrm{O}$ (64\%), H3PO4 (27\%) y $\mathrm{H}_{2} \mathrm{SO}_{4}(9 \%)$ (7/3/1, v/v/v). La concentración de urea fue medida a $540 \mathrm{~nm}$ tras la adición de $20 \mu \mathrm{l}$ de $\alpha$ - 
isonitrosopropiophenone de $6 \%$ (disuelto en 100\% etanol) seguido de calentamiento a $95^{\circ} \mathrm{C}$ durante $30 \mathrm{~min}$. Una unidad de actividad enzimática se define como la cantidad de enzima necesaria para catalizar la formación de $1 \mu \mathrm{mol}$ de urea $/ \mathrm{min}$.

\section{Ensayos de exocitosis}

Neutrófilos aislados de sangre periférica humana $\left(1 \times 10^{7}\right.$ células $)$ fueron estimulados con phorbol-12-myristate 13-acetate (PMA; 2,5 $\mu \mathrm{g} / \mathrm{ml}$, Sigma), formyl-methionyl-leucylphenylalanine (fMLP; $100 \mathrm{nM}$, Sigma) y factor de necrosis tumoral $\alpha$ (rhTNF- $\alpha ; 10 \mathrm{ng} / \mathrm{mL}$. Promega, Madison, WI, USA) durante 15 min a $37^{\circ} \mathrm{C}$ y posteriormente se centrifugaron, recogiéndose los sobrenadantes. Adicionalmente, otras muestras de neutrófilos se mantuvieron en hielo y a $37^{\circ} \mathrm{C}$ sin estímulo como controles negativos. Las proteínas de los gránulos fueron analizadas por Western blot.

\section{Aislamiento de células endoteliales a partir del cordón umbilical}

Se utilizó el medio de cultivo RPMI-1640 (con L-glutamina a $2 \mathrm{mM}$ ) suplementado con suero fetal bovino (al 10\% para el mantenimiento ó 20-30\% en los primeros pasos de aislamiento), $100 \mathrm{U} / \mathrm{mL}$ de penicilina y $50 \mu \mathrm{g} / \mathrm{mL}$ de gentamicina. Se preparó colagenasa A a una concentración de 22 U/100 mL en buffer de Hanks-Wallace (NaCl: 136,89 mM; KCl: 5,36 $\mathrm{mM} ; \mathrm{KH}_{2} \mathrm{PO}_{4}$ : 0,44 mM; $\mathrm{MgSO}_{4} \cdot 7 \mathrm{H}_{2} \mathrm{O}: 0,81 \mathrm{mM} ; \mathrm{Na}_{2} \mathrm{HPO}_{4} \cdot 12 \mathrm{H} 2 \mathrm{O}: 0,41 \mathrm{mM} ; \mathrm{CaCl}_{2} \cdot 2 \mathrm{H}_{2} \mathrm{O}$ : 1,7 mM; $\mathrm{NaHCO}_{3}: 11,6 \mathrm{mM}$; glucosa: 5,55 mM). Esta solución se mantuvo en agitación y oscuridad durante 10 min a temperatura ambiente. Esta solución fue esterilizada por filtración, primero con filtros de $0.45 \mu \mathrm{m}$ y posteriormente de $0,22 \mu \mathrm{m}$. El cordón umbilical, de al menos $20 \mathrm{~cm}$, fue separado de la placenta proveniente de una embarazada con controles prenatales normales y con un parto natural en condiciones asépticas. Las muestras fueron transportadas en medio RPMI-1640 y procesadas en un tiempo inferior a 3 horas tras su obtención. El procesamiento de las muestras se realizó en condiciones de esterilidad bajo campana de flujo laminar. Se utilizaron pinzas para cerrar los extremos del cordón umbilical, dejando aproximadamente $0,5 \mathrm{~cm}$ de tejido, entre los extremos y las pinzas. El tejido sobrante fue retirado con la ayuda de un bisturí. Se identificó la vena umbilical la cual fue canalizada y obturada en un extremo. La vena fue perfundida con 50-60 ml de PBS, con una jeringa de 50 $\mathrm{ml}$ para lavar los restos de sangre. Después de los lavados, se obturó el otro extremo del 
cordón, y el aire contenido en la vena se succionó con una jeringa de $20 \mathrm{ml}$. Posteriormente, se introdujeron de 10 a $20 \mathrm{ml}$ de colagenasa en la vena. El cordón fue incubado a $37^{\circ} \mathrm{C}$ durante 30 min. Una vez finalizado el tiempo de incubación, se realizó un masaje suave para facilitar el desprendimiento de las células endoteliales del lecho vascular tratado con colagenasa. Seguidamente se perfundió la vena por un extremo con $20 \mathrm{ml}$ de RPMI-1640 suplementado con $20 \%$ SFB y se recogió la solución resultante en tubos de centrifuga de $50 \mathrm{ml}$ (BD Laboratories, Los Angeles, CA, USA). La solución que contenía las células HUVEC, se centrifugó durante 5 min a $1500 \mathrm{rpm}$. El sobrenadante fue descartado y las células HUVEC se resuspendieron en $5 \mathrm{ml}$ de medio de cultivo fresco RPMI+SFB 20\%. Las placas o flasks utilizados para el cultivo de las células HUVEC se pretrataron con gelatina al 2\% (peso/ volumen en PBS) 2 horas antes de hacer el pase. Las células se mantuvieron en condiciones estándares de cultivo a $37^{\circ} \mathrm{C}$ con $5 \%$ de $\mathrm{CO}_{2}$. Para estimular el crecimiento y proliferación, las células HUVEC fueron estimuladas con factor de crecimiento de células endoteliales (ECGF) a $200 \mathrm{~g} / \mathrm{ml}$ y heparina sódica a $10 \mathrm{mg} / \mathrm{ml}$.

\section{Extracción de RNA}

Para la extracción y purificación de RNA se utilizó el método desarrollado por Chomczynski y Sacchi ${ }^{203}$, con el que se consigue la lisis celular manteniendo la integridad del RNA. Este método consiste en utilizar una mezcla de fenol ácido e isotiocianato de guanidinio, que puede adquirirse de forma comercial con el nombre de TRIZOL ${ }^{\circledR}$ (Invitrogen, San Diego, CA, USA). Por cada 5-10 × $10^{6}$ de células, se añadió $1 \mathrm{ml}$ del reactivo TRIZOL®. Una vez homogeneizada la mezcla, se incubó la misma durante 5 min a temperatura ambiente. Para favorecer la separación de fases se añadieron $200 \mu \mathrm{l}$ de cloroformo, y tras una agitación vigorosa y una incubación de 2-3 min a temperatura ambiente, se procedió a la centrifugación de las muestras a $12000 \mathrm{x}$ g durante $15 \mathrm{~min}$ a $4^{\circ} \mathrm{C}$. Finalizada la centrifugación, la mezcla quedó separada en una fase inferior de fenol-cloroformo, una interfase, y una fase superior acuosa en la que se encontraba el RNA. Una vez transferida la fase acuosa a un tubo limpio, se precipitó

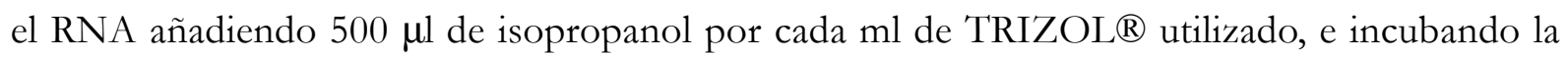
mezcla a $-20^{\circ} \mathrm{C}$ durante $90 \mathrm{~min}$ o durante toda la noche. A continuación se realizó una centrifugación de $15 \mathrm{~min}$ a $4^{\circ} \mathrm{C}$ a 12000 x g, tras la que se eliminó el sobrenadante y se lavó el sedimento con $1 \mathrm{ml}$ de etanol al 75\% por cada $\mathrm{ml}$ de TRIZOL $®$ utilizado en la fase de homogenización. Por último, una vez seco, el precipitado se resuspendió en agua tratada con DEPC $\left(0,1 \%\right.$ dietil pirocarbonato) libre de RNAasas, y se incubó $10 \mathrm{~min}$ a $65^{\circ} \mathrm{C}$ hasta su 
completa disolución. La cuantificación y la determinación del grado de pureza del RNA extraído se llevó a cabo mediante electroforesis en geles al 1\% de agarosa con formaldehído al $7 \%$, y posterior tinción con bromuro de etidio y visualización en transiluminador de luz ultravioleta; y mediante análisis de absorbancia de luz ultravioleta (UV) a 260 y $280 \mathrm{~nm}$ en un espectrofotómetro BioRad Smartspec 3000 (BioRad, Richmond, CA, USA). Se consideró que la pureza de las muestras era óptima cuando la proporción A260/A280 fue de $2 \pm$ 0,05. La concentración de RNA se determinó con la siguiente formula:

[RNA] $\mu \mathrm{g} / \mathrm{ml}=$ A260 $\mathrm{x}$ factor de dilución x 44,19 (coeficiente de extinción del RNA)

\section{Síntesis de cDNA a partir de RNA: transcripción reversa (RT)}

Se utilizaron $5 \mu \mathrm{g}$ de RNA para transcribir a DNA complementario (cDNA) mediante la reacción llevada a cabo por la enzima transcriptasa reversa SuperScripTM III (Invitrogen, San Diego, CA, USA) en los siguientes pasos:

1. Desnaturalización: incubación durante 5 min a $65^{\circ} \mathrm{C}$, seguida de al menos $1 \mathrm{~min}$ en hielo, de $5 \mu \mathrm{g}$ RNA, $50 \mathrm{ng}$ hexámeros y $1 \mu \mathrm{l}$ de una mezcla $10 \mathrm{mM}$ de desoxinucleótidos trifosfato (dNTPs) en un volumen final de $10 \mu \mathrm{l}$.

2. Anillamiento: incubación durante $10 \mathrm{~min}$ a $25^{\circ} \mathrm{C}$ de la mezcla del paso anterior junto con $40 \mathrm{mM}$ Tris- $\mathrm{HCl}$ (pH 8,4), $100 \mathrm{mM} \mathrm{KCl,} 10 \mathrm{mM} \mathrm{MgCL2,} 20 \mathrm{mM}$ DTT, 40 U RNasaOUT TM, y 200 U SuperScript $^{\mathrm{TM}}$ III RT en un volumen final de $10 \mu l$.

3. Síntesis de cDNA: incubación de 50 min a $50^{\circ} \mathrm{C}$.

4. Fin de la reacción: la reacción de síntesis se detuvo con una incubación de 5 min a $85^{\circ} \mathrm{C}$, y a continuación se procedió a la eliminación del RNA sin transcribir mediante el tratamiento de la mezcla final con RNAasa $\mathrm{H}$ durante 20 $\min$ a $37^{\circ} \mathrm{C}$.

5. $\quad$ El cDNA una vez sintetizado se mantuvo a $-20^{\circ} \mathrm{C}$ hasta ser utilizado. 


\section{Amplificación de DNAc mediante la Reacción en Cadena de la Polimerasa (PCR)}

El cDNA se amplificó de manera semicuantitativa mediante la reacción en cadena de la polimerasa (PCR). Para ello, detuvimos la reacción en su fase exponencial (30 ciclos aproximadamente), y comparamos la cantidad de cDNA amplificado del gen en estudio con la de un gen utilizado como control interno ( $\beta$-actina). Se mezclaron $250 \mathrm{ng}$ cDNA, 10 pmol de cada cebador, 0,2 mM de cada dNTP, $10 \mathrm{mM}$ Tris- $\mathrm{HCl}$ (pH 8,3), $50 \mathrm{mM} \mathrm{KCl,} \mathrm{1,5} \mathrm{mM} \mathrm{MgCl2} \mathrm{y}$ 2,5 U de la DNA polimerasa de (ECOTAQ/BIOTAQ) (Barcelona, España) en un volumen final de $25 \mu \mathrm{l}$. La mezcla se introdujo en un termociclador Perkin Elmer GeneAmp PCR System 9600 (Perkin Elmer, Massachusetts, USA), y se sometió a los siguientes pasos:

5.1. Desnaturalización inicial: $95^{\circ} \mathrm{C}, 5 \mathrm{~min}$.

5.2. Amplificación: 30 ciclos con las siguientes fases:

5.2.1. Desnaturalización: $95^{\circ} \mathrm{C}, 30 \mathrm{seg}$.

5.2.2. Anillamiento: $30 \mathrm{seg}$ a la temperatura de anillamiento específica para cada par de cebadores utilizado.

5.2.3. Extensión: $72^{\circ} \mathrm{C}, 90 \mathrm{seg}$.

5.3. Extensión final: $72^{\circ} \mathrm{C}, 15 \mathrm{~min}$.

El análisis de los productos de PCR se realizó mediante electroforesis en geles de agarosa al 2\% (p/v) en tampón TBE (45 mM Tris, $45 \mathrm{mM}$ ácido bórico, $1 \mathrm{mM}$ EDTA) y mediante tinción con bromuro de etidio. Las bandas correspondientes a los fragmentos amplificados fueron visualizadas en un transiluminador de luz ultravioleta, y sus tamaños fueron determinados por comparación con el marcador de peso molecular $\phi X 174 / \mathrm{Hae}$ III (Promega, Madison, WI, USA). Los cebadores utilizados junto con sus correspondientes temperaturas de anillamiento se detallan en la Tabla 2. 


\section{Expresión y purificación de la proteína de fusión mediante cromatografía de afinidad}

Para la amplificación por PCR de la arginasa I de neutrófilos se utilizaron cebadores flanqueados con los sitios de restricción para las enzimas EcoRI y XhoI (Tabla 2), este fragmento fue directamente clonado en el vector pCR 2.1 del kit TA Cloning (Life Technologies S.A., Madrid, España) siguiendo las instrucciones del fabricante. El DNA fue secuenciado a partir de 5 clones independientes mediante ABI PRISM ${ }^{\circledR} 3100$ Avant Genetic Analyzer (Applied Biosystems, Carlsbad, CA, USA). La subclonación se llevó a cabo utilizando los sitios de restricción en el vector pGEX-4T1 (Pharmacia Biotech, Piscataway, NJ, USA) para obtener la proteína recombinante ARG1 unida en su $\mathrm{N}$ terminal a GST. Bacterias E. coli BL21DE3, transformadas con el plásmido pGEX-4T1-ARG1, fueron cultivadas en medio Luria-Bertani (LB) $(0,5 \%$ extracto levadura, $1 \% \mathrm{NaCl}, 1 \%$ triptona) con $100 \mu \mathrm{g} / \mathrm{ml}$ de ampicilina en agitación constante a $37^{\circ} \mathrm{C}$ hasta alcanzar una densidad óptica correspondiente a DO600 = 0,5 - 0,8. La expresión de la proteína de fusión GST-ARG1 se indujo a gran escala adicionando 0,1 $\mathrm{mM}$ de IPTG al caldo de cultivo. Transcurridas $4 \mathrm{~h}$, las bacterias fueron recolectadas mediante centrifugación a $5000 \mathrm{rpm}, 15 \mathrm{~min} 4^{\circ} \mathrm{C}$ con un rotor JA-14 en una centrífuga AvantiTM LE-80K (Beckman Instruments, Palo Alto, CA, USA). El sedimento obtenido fue resuspendido en $5 \mathrm{ml}$ de PBS frío, suplementado con 0,5 mM PMSF, $1 \mu \mathrm{g} / \mathrm{ml}$ aprotinina, $1 \mu \mathrm{g} / \mathrm{ml}$ leupeptina y 0,1 mM EDTA, y sometido a 4 ciclos de ultrasonidos de 30 seg cada uno. Al lisado bacteriano resultante se le adicionaron $0,5 \mathrm{ml}$ de Triton X-100 al 10\%, y tras una breve agitación, se centrifugó a $14000 \mathrm{rpm} \mathrm{4}{ }^{\circ} \mathrm{C}, 10 \mathrm{~min}$. El sobrenadante fue mezclado con $200 \mu \mathrm{l}$ de una suspensión de bolas de resina Glutathione Sepharose (Glutathione Sepharose 4B beads, Amersham Biosciences, Uppsala, Suecia), e incubado $12 \mathrm{~h}$ a $4^{\circ} \mathrm{C}$ en rotación constante. Finalmente, las bolas fueron sedimentadas por centrifugación a $2000 \mathrm{rpm}$, 10 min, lavadas tres veces con PBS frío al 0,1\% de Tritón X-100, y equilibradas con tampón de dilución (20 mM HEPES, (pH 7,7), 0,1 mM EDTA, 2,5 mM MgCl $2,0,05 \%$ Triton X-100, $20 \mathrm{mM} \beta$-glicerofosfato, 0,1 $\mathrm{mM} \mathrm{Na}_{3} \mathrm{VO}_{4}, 0,5 \mathrm{mM}$ PMSF, $1 \mu \mathrm{g} / \mathrm{ml}$ aprotinina, $1 \mu \mathrm{g} / \mathrm{ml}$ leupeptina). Para liberar la proteína sobrexpresada de la resina de Glutathione Sepharose se preparó el tampón de elución (50 mM Tris- $\mathrm{HCl}, 10 \mathrm{mM}$ glutathione reducido) y se incubó $1 \mathrm{ml}$ de este tampón por cada $1 \mathrm{ml}$ de preparado (tampón de dilución + resina + proteína) durante 10 min a temperatura ambiente. Las resina era sedimentada y el sobrenadante contenía la proteína de fusión. 
Tabla 2. Cebadores utilizados en los ensayos de PCR. Esta tabla indica el nombre de los genes amplificados por PCR, el número de acceso en la base de datos del NCBI, la secuencia de los cebadores utilizados, la temperatura de anillamiento (TA) y el tamaño del fragmento esperado.

\begin{tabular}{|c|c|c|c|c|}
\hline Gen & $\mathrm{N}^{\circ}$ Acceso & Cebadores & $\operatorname{TA}\left({ }^{\circ} \mathrm{C}\right)$ & $\begin{array}{l}\text { Fragmento } \\
(\mathrm{pb})\end{array}$ \\
\hline ARG1 & NM_000045 & $\begin{array}{l}5 \\
\text { TAGAATTCATGAGCGCCAAGTCCAG } \\
\text { A -3' } \\
5 \\
\text { TTCTCGAGCTTAGGTGGGTTAAGGT } \\
\text { A-3' }\end{array}$ & 58,5 & 952 \\
\hline XBP1 & $\begin{array}{l}\text { NM_001079 } \\
539\end{array}$ & $\begin{array}{l}\text { 5'- CCTTGTAGTTGAGAACCAGG -3' } \\
\text { 5'- GGGGCTTGGTATATATGTGG -3' }\end{array}$ & 56,5 & 440 \\
\hline $\begin{array}{ll}\beta & - \\
\text { actin }\end{array}$ & X00351 & $\begin{array}{l}\text { 5'- CTGTCTGGCGGCACCACCAT -3' } \\
\text { 5'- GCAACTAAGTCATAGTCCGC -3' }\end{array}$ & 56,0 & 256 \\
\hline
\end{tabular}

\section{Análisis de apoptosis y ciclo celular mediante citometría de flujo}

Un total de $5 \times 10^{5}$ células fueron centrifugadas e incubadas toda la noche en $1 \mathrm{ml}$ de etanol al $70 \%$ en $\mathrm{H}_{2} \mathrm{O}$ (v/v) a $4{ }^{\circ} \mathrm{C}$. Una vez fijadas, las células se lavaron tres veces con PBS y se incubaron durante $1 \mathrm{~h}$ en oscuridad a temperatura ambiente con $1 \mathrm{mg} / \mathrm{ml}$ de RNAsa A y 20 $\mu \mathrm{g} / \mathrm{ml}$ de ioduro de propidio. La proporción de células en cada fase del ciclo celular se determinó por medio de un citómetro de flujo FACScalibur (BD, San Jose, CA, USA). Para analizar el fenotipo asociado a muerte celular con la externalización de fosfatidilserina en la cara externa de la membrana plasmática se utilizó el kit de AnexinaV/ioduro de propidio (Clontech, Mountain View, CA, USA). Las células se centrifugaron y lavaron con $1 \mathrm{ml}$ de 1x Binding Buffer para posteriomente ser resuspendidas en $200 \mu \mathrm{l}$ 1x Binding buffer. Se añadió AnexinaV a una concentración final de $1 \mu \mathrm{g} / \mathrm{ml}$ e ioduro de propidio (IP) a $50 \mu \mathrm{g} / \mathrm{ml}$. Las células marcadas fueron incubadas 15 min a temperatura ambiente y protegidas de la luz. A continuación se lavaron las células con PBS 1x para eliminar el exceso de compuesto. 1 x $10^{4}$ células, fueron adquiridas con el software Cell Quest y analizadas con el software Flowjo en el citómetro de flujo FACScan (BD), con los filtros FITC (excitación $\lambda 494 \mathrm{~nm}$ y emisión $\lambda 520$ $\mathrm{nm})$ y rodamina (excitación $\lambda 540 \mathrm{~nm}$ y emisión $\lambda 570 \mathrm{~nm}$ ). Las células viables fueron aquellas negativas para anexina $\mathrm{V}$ e IP. 


\section{Análisis de expresión de antígenos en superficie mediante citometría de flujo}

Para el análisis de la expresión de proteínas en la cara externa de la membrana plasmática, 1 × $10^{6}$ células fueron centrifugadas, lavadas con PBS e incubadas durante $1 \mathrm{~h} \mathrm{a} 4^{\circ} \mathrm{C}$ con los anticuerpos primarios, cuya dilución y tipo se detallan en la Tabla 3. El sobrenadante del mieloma P3X63, cedido gentilmente por el Dr. F. Sánchez-Madrid (Hospital de La Princesa, Madrid, España), fue utilizado como control negativo. A continuación, tras un lavado con PBS se procedió a la incubación de las células durante $1 \mathrm{~h} \mathrm{a} 4^{\circ} \mathrm{C}$ con el correspondiente anticuerpo secundario conjugado con isotiocianato de fluoresceína (FITC, Dako, Glostrup, Dinamarca), a una dilución de 1:100 en PBS. Finalmente, tras un último lavado con PBS, las células fueron fijadas con 1,5\% (v/v) de formaldehído en PBS, y se procedió a la cuantificación de su fluorescencia en un citómetro de flujo FACScalibur (Becton Dickinson). Para el análisis de los resultados obtenidos se seleccionaron 10000 células por relación tamaño/complejidad, y el porcentaje de células positivas se estimó utilizando como control negativo células incubadas con el sobrenadante del hibridoma P3X63, siguiendo las mismas condiciones experimentales que las descritas para el resto de muestras. Para el análisis de la expresión de proteínas en la cara interna de la membrana plasmática, 1 × $10^{6}$ células fueron centrifugadas a $1200 \mathrm{rpm}$ durante 5 min, lavadas con PBS y luego permeabilizadas y fijadas mediante el kit FIX \& PREM® Cell Fixation and Permeabilization de Invitrogen (Invitrogen, San Diego, CA, USA). Con el software Cell Quest y analizadas con el software FlowJo en el citómetro de flujo FACScan (Becton Dickinson)

\section{Electroforesis de proteínas en geles SDS-PAGE, Western blot e inmunodetección}

Se utilizaron un total de 5-10 × $10^{6}$ células las cuales fueron lisadas en $60 \mu \mathrm{l}$ del tampón de lisis (25 mM HEPES ( $\mathrm{pH}$ 7,7), 0,3 M NaCl, 1,5 mM MgCl $2,0,2 \mathrm{mM}$ EDTA, 0,1\% Triton $\mathrm{X}-100,20 \mathrm{mM} \beta$-glicerofosfato, 0,1 mM ortovanadato sódico), suplementado con inhibidores de proteasas (1 mM PMSF, $20 \mu \mathrm{g} / \mathrm{ml}$ aprotinina, $20 \mu \mathrm{g} / \mathrm{ml}$ leupeptina). Tras una agitación vigorosa y la posterior incubación en hielo durante $20 \mathrm{~min}$, las proteínas solubilizadas se obtuvieron por centrifugación a $13000 \mathrm{rpm}, 20 \mathrm{~min}, 4^{\circ} \mathrm{C}$. La medida de la concentración proteica se realizó mediante el método de Bradford ${ }^{204}$, método colorimétrico basado en la 
reacción del colorante azul de Coomassie G-250 al unirse a proteínas. Se utilizó la solución comercial Kit Protein Assay (BioRad, Richmond, CA, USA), y la cantidad de proteínas totales de cada muestra se determinó mediante la interpolación de las absorbancias obtenidas en una curva patrón realizada con concentraciones conocidas de BSA (Sigma). Un total de 40-70 $\mu \mathrm{g}$ de proteínas fueron desnaturalizados mediante una incubación de 5 min a $95^{\circ} \mathrm{C}$ en tampón Laemmli (2\% SDS, 10\% glicerol, $140 \mathrm{mM} \beta$-mercaptoetanol, $60 \mathrm{mM}$ Tris-HCl (pH 6.8), 0,01\% azul de bromofenol), y sometidas a electroforesis en geles de poliacrilamida con SDS (dodecilsulfato sódico) (SDS-PAGE).

Una vez separadas en función de su peso molecular, las proteínas fueron transferidas a membranas de nitrocelulosa (Amersham Biosciences, Buckinghamshire, Reino Unido) utilizando como tampón de transferencia $25 \mathrm{mM}$ Tris, $192 \mathrm{mM}$ glicina, 20\% (v/v) metanol. Tras eliminar los restos de metanol mediante un lavado con tampón TBST (50 mM Tris-HCl, pH 8.0, $150 \mathrm{mM} \mathrm{NaCl}, 0.1 \%$ Tween-20), las membranas fueron incubadas con Rojo Ponçeau (Sigma) para evaluar la transferencia y la igual carga de todos los pocillos. A continuación, las membranas fueron bloqueadas con leche desnatada al 5\% (p/v) en TBST durante 60 min a temperatura ambiente y agitación, y posteriormente incubadas durante $1 \mathrm{~h}$ a temperatura ambiente, o toda la noche a $4^{\circ} \mathrm{C}$, con los anticuerpos primarios que se detallan en la Tabla 3 . Tras el exhaustivo lavado de las membranas, se procedió a la incubación con los correspondientes anticuerpos secundarios conjugados a peroxidasa de rábano (HRP), durante $1 \mathrm{~h}$ a temperatura ambiente en agitación, y a su posterior lavado en TBST.

Finalmente, las membranas se incubaron durante un minuto con el sustrato de ECL (enhanced chemiluminescence) de inmunodetección en filtro (Amersham Biosciences), y el peso molecular de las proteínas en estudio se calculó utilizando marcadores estándar de peso molecular conocido (Kaleidoscope Prestained Standards, BioRad). En algunos casos las membranas fueron reutilizadas. Para conseguir eliminar los anticuerpos ya unidos, se sumergieron las membranas en una solución que contenía, $100 \mathrm{mM} \beta$-mercaptoetanol, 2\% SDS, 62,5 mM Tris- $\mathrm{HCl}$ pH 6.2 durante 30 min a $56^{\circ} \mathrm{C}$ con agitación ocasional, y tras el posterior lavado con TBST, las membranas fueron bloqueadas con leche al 5\%, y se continuó con las incubaciones con los anticuerpos correspondientes. 
Tabla 3. Anticuerpos primarios. Esta tabla indica el nombre de cada anticuerpo, casa comercial de la cual proviene y dilución utilizada en cada tipo de ensayo: Western blot (WB), citometría de flujo (CF) inmunofluorescencia (IF), inmunoprecipitación (IP). Dependiendo del isotipo del cual provengan se indican con una $(r)$ los anticuerpos monoclonales hechos en ratón, (c) los policlonales hechos en conejo y (ca) los policlonales hechos en cabra.

\begin{tabular}{|c|c|c|}
\hline Nombre del Anticuerpo & Casa comercial & Dilución \\
\hline Anti-Akt (c) & Santa Cruz Biotechnology & 1:500 (WB) \\
\hline Anti-ATF4 (c) & Abcam plc & 1:500 (WB) \\
\hline Anti-ATG12 (r) & Sigma-Aldrich & 1:1000 (WB) \\
\hline Anti-ATG7 (r) & Sigma-Aldrich & 1:1000 (WB) \\
\hline Anti-Bap31 (ca) & Santa Cruz Biotechnology & 1:500 (WB) \\
\hline Anti-Bcl-2 (r) & BD Pharmingen & 1:250 (WB) \\
\hline Anti-Beclin 1 (c) & Cell Signaling & 1:1000 (WB); 1:200 (IP) \\
\hline Anti-Caspasa 3 (c) & BD Pharmingen & 1:500 (WB) \\
\hline Anti-Caspasa 4 (ca) & Santa Cruz Biotechnology & 1:1000 (WB) \\
\hline Anti-Caspasa 8 (r) & Cell Signaling & 1:1000 (WB) \\
\hline Anti-CD11a (r) & BD Pharmingen & $1: 100(\mathrm{CF})$ \\
\hline Anti-CD2 (r) & BD Pharmingen & 1:100 (CF) \\
\hline Anti-CD3e (r) & BD Pharmingen & 1:1000 (WB); 1:100 (CF) \\
\hline Anti-CD3ל (r) & BD Pharmingen & $1: 100(\mathrm{CF})$ \\
\hline Anti-CD45 (r) & BD Pharmingen & $1: 100(\mathrm{CF})$ \\
\hline Anti-CD5 (r) & BD Pharmingen & $1: 100(\mathrm{CF})$ \\
\hline Anti-CHOP (r) & Cell Signaling & 1:1000 (WB) \\
\hline Anti-EDEM1(c) & Sigma-Aldrich & 1:500 (WB) \\
\hline Anti-eIF2 $\alpha(c)$ & Cell Signaling & 1:1000 (WB) \\
\hline Anti-ERK1/2 (r) & Santa Cruz Biotechnology & 1:1000 (WB) \\
\hline Anti-fosfo-Akt (c) & Cell Signaling & 1:1000 (WB) \\
\hline Anti-fosfo-Bcl-2 (r) & Cell Signaling & 1:1000 (WB) \\
\hline Anti-fosfo-eIF2 $\alpha$ (c) & Cell Signaling & 1:1000 (WB) \\
\hline Anti-fosfo-ERK1/2 (r) & Santa Cruz Biotechnology & 1:1000 (WB) \\
\hline Anti-fosfo-PERK (c) & Santa Cruz Biotechnology & 1:1000 (WB) \\
\hline Anti-fosfo-GCN2 (c) & Cell Signaling & 1:1000 (WB) \\
\hline Anti-fosfo-mTOR (c) & Cell Signaling & 1:1000 (WB) \\
\hline Anti-fosfo-p70S6K (c) & Cell Signaling & 1:1000 (WB) \\
\hline Anti-fosfo-SAPK/JNK (c) & Cell Signaling & 1:1000 (WB) \\
\hline Anti-GRP78/BiP (c) & Santa Cruz Biotechnology & 1:500 (WB) \\
\hline
\end{tabular}




\begin{tabular}{|l|l|l|}
\hline Nombre del Anticuerpo & Casa comercial & Dilución \\
\hline Anti-IREa $(c)$ & Sigma-Aldrich & $1: 500(\mathrm{WB})$ \\
\hline Anti-LC3B (c) & Cell Signaling & $1: 1000(\mathrm{WB}) ; 1: 200(\mathrm{IF})$ \\
\hline Anti-p70S6K (r) & Cell Signaling & $1: 1000(\mathrm{WB})$ \\
\hline Anti-PARP $(\mathrm{r})$ & BD Pharmingen & $1: 500(\mathrm{WB})$ \\
\hline Anti-PERK $(\mathrm{ca})$ & Santa Cruz Biotechnology & $1: 1000(\mathrm{WB})$ \\
\hline Anti-SAPK/JNK (c) & Cell Signaling & $1: 1000(\mathrm{WB})$ \\
\hline Anti-SQSTM1/p62 (c) & Cell Signaling & $1: 1000(\mathrm{WB})$ \\
\hline Anti- $\beta$-actina $(r)$ & Sigma-Aldrich & $1: 5000(\mathrm{WB})$ \\
\hline
\end{tabular}

\section{Microscopía de fluorescencia}

Para detectar la expresión de LC3, indicador de la formación de los autofagosomas ${ }^{155}$, se utilizaron $2-4 \times 10^{5}$ células y fueron centrifugadas a $1500 \mathrm{rpm}$ durante 5 min y lavadas dos veces con PBS. Fueron resuspendidas en $100 \mu \mathrm{l}$ de PBS, expandidas en un portaobjetos con poli-lisina y colocadas en un bloque a $37^{\circ} \mathrm{C}$ para evaporar el exceso de PBS tratando de causar el menor daño posible a las células. Estos portaobjetos fueron sumergidos en una solución de p-formaldehído al 3,7\% en PBS, durante 20 min a temperatura ambiente. A continuación, las células fueron lavadas con PBS frío varias veces y permeabilizadas con Triton X-100 al 0,1\% en PBS durante 10 min a temperatura ambiente. Para bloquear los sitios de aldehídos libres, las células fueron bloqueadas con glicina $10 \mathrm{mM}$ durante $10 \mathrm{~min}$ a temperatura ambiente. Los portaobjetos se bloquearon con 1\% BSA en PBS durante 30 min a temperatura ambiente y luego se incubaron con el anticuerpo primario correspondiente, durante $1 \mathrm{~h}$ a temperatura ambiente. Tras varios lavados con PBS, se incubaron con el anticuerpo secundario específico FITC (verde). Finalmente, se montaron los cubreobjetos sobre los portaobjetos utilizando la solución SlowFade Light Antifade Kit (Molecular Probes) para sellarlos. La localización subcelular se analizó mediante microscopía confocal utilizando un microscopio confocal LEICA SP5. Las imágenes así adquiridas se analizaron con el programa LAS AF Lite.

\section{Coinmunoprecipitación}

Un total de $2 \times 10^{7}$ células fueron incubadas 30 min en hielo con $200 \mu \mathrm{l}$ de tampón de lisis (30 mM Tris- $\mathrm{HCl},(\mathrm{pH} 7,5), 1 \%$ Triton X-100, 10\% glicerol, $150 \mathrm{mM} \mathrm{NaCl}, 2 \mathrm{mM}$ 
$\mathrm{Na}_{3} \mathrm{VO}_{4}, 2 \mu \mathrm{g} / \mathrm{ml}$ aprotinina, $2 \mu \mathrm{g} / \mathrm{ml}$ leupeptina, $2 \mathrm{mM}$ PMSF) y posteriormente centrifugadas a $12000 \mathrm{rpm}, 20 \mathrm{~min}, 4^{\circ} \mathrm{C}$. Con la finalidad de eliminar toda posible unión inespecífica, el sobrenadante resultante se incubó durante $4 \mathrm{~h}$ a $4^{\circ} \mathrm{C}$, en rotación constante con $300 \mu \mathrm{l}$ de una solución de bolas de proteína A-sepharosa al 20\% en tampón de lisis. La proteína A de Staphylococcus aureus, se une a la región Fc de las inmunoglobulinas a través de interacciones con la cadena pesada; dado que sólo la región Fc está implicada en la interacción, la región Fab se encuentra disponible para unirse a su correspondiente antígeno. $2 \mu \mathrm{l}$ del anticuerpo policlonal de conejo anti-Beclin 1 (Cell Signaling Biotechnology) fueron incubados durante $2 \mathrm{~h} \mathrm{a} 4^{\circ} \mathrm{C}$ en constante rotación con $200 \mu \mathrm{l}$ de bolas de proteína A-sepharosa al 20\% en tampón de lisis. Tras dos lavados con tampón de lisis, las bolas con el anticuerpo anti-Beclin 1 unido fueron incubadas $2-3 \mathrm{~h}$ en rotación a $4^{\circ} \mathrm{C}$ con los extractos celulares. El complejo bolas-anticuerpo-antígeno fue sedimentado mediante centrifugación a $12000 \mathrm{rpm}$, lavado 5 veces con tampón de lisis, y finalmente resuspendido en 15-20 $\mu$ l de tampón Laemmli dos veces concentrado e incubado durante 5 min a $95^{\circ} \mathrm{C}$. Tras la eliminación de las bolas por sedimentación, las muestras fueron sometidas a SDS-PAGE y posterior Western-blot utilizando el anticuerpo monoclonal anti-26-kDa Bcl-2 (BD Biosciences), y como control de la cantidad de proteína cargada, el mismo anticuerpo utilizado para inmunoprecipitarla. Como control negativo, los extractos celulares fueron simultáneamente inmunoprecipitados con el sobrenadante del mieloma P3X63, y procesados en paralelo y de forma similar a la anteriormente descrita.

\section{Proliferación celular}

El Kit de proliferación celular XTT (Cell Proliferation Kit II-XTT. ROCHE) es un ensayo colorimétrico no radioactivo que cuantifíca la proliferación celular, viabilidad y citotoxicidad. Este ensayo se basa en la conversión de la sal de tetrazolium XTT en presencia de un reactivo de acoplamiento de electrones, que produce formazan. Esta conversión solo ocurre en células viables. Las células son cultivadas en $100 \mu \mathrm{l}$ de medio de cultivo en placas de 96 pocillos, a una densidad celular adecuada para evitar el sobrecrecimiento y dependiendo de cada tipo celular como se describe en la Tabla 1. Después de colocar los tratamientos, se cultivan las células durante 72 horas. Pasado el tiempo del tratamiento, se coloca el reactivo siguiendo las instrucciones del fabricante. La absorbancia es medida a 490 y $690 \mathrm{~nm}$ en un lector de placas. 


\section{Tinción con naranja de acridina}

La tinción de células con naranja de acridina se ha llevado a cabo según las instrucciones del fabricante (Acridine Orange Staining Solution - Life Technologies). En células teñidas con naranja de acridina, el citoplasma y nucléolo emiten fluorescencia verde y rojo tenue, mientras que los compartimientos ácidos emiten una fluorescencia de color rojo brillante. La intensidad de la fluorescencia roja es proporcional al grado de acidez ${ }^{205}$. La solución de naranja de acridina se agregó a las células en cultivo a una concentración final de 2,5 $\mathrm{mg} / \mathrm{ml}$, después de $10 \mathrm{~min}$ las células fueron centrifugadas a $1200 \mathrm{rpm}$ durante $8 \mathrm{~min}$ y lavadas dos veces con PBS. Las células fueron analizadas por citometría de flujo en FACSCalibur (Becton Dickinson) usando el software FlowJo.

\section{Actividad del proteasoma}

La actividad del proteasoma fue cuantificada mediante el kit 20S Proteasome Activity Assay (Chemicon, Darmstadt, Alemania). El ensayo se basa en la detección del fluoróforo 7amino-4-metilcumarina (AMC) después de la escisión del sustrato marcado LLVY-AMC. La actividad de la subunidad $20 \mathrm{~S}$ del proteasoma fue cuantificada por triplicado incubando $20 \mu \mathrm{g}$ de lisado proteico de cada cultivo celular con el sustrato marcado LLVY-AMC a $37^{\circ} \mathrm{C}$ durante 60 min. El AMC liberado por la actividad del proteasoma se cuantificó usando un lector de placas (ULTRA Evolution; XFLUOR4 Versión V4.50). La curva estándar se realizó con diluciones seriadas de AMC. La actividad del proteasoma fue confirmada utilizando el inhibidor del proteasoma lactacystin $(10 \mu \mathrm{M})$ para descartar cualquier degradación del AMC que no sea por la actividad del proteasoma.

\section{Flujo autofágico}

El flujo autofágico fue determinado por citometría de flujo ${ }^{206}$. Las células $\mathrm{T}$ y las células Jurkat EGFP-LC3 fueron centrifugadas a $1200 \mathrm{rpm}$ y lavadas con PBS. De cada muestra se tomaron dos alícuotas, una de las cuales fue lavada con PBS al 0,05\% de saponina durante 5 min con agitación. Las células $\mathrm{T}$ fueron incubadas con el anticuerpo monoclonal anti-LC3 a una dilución 1:100 durante 30 min, lavadas con PBS e incubadas con un anticuerpo secundario conjugado con Cy2 (Jackson ImmunoResearch Laboratories) a una dilución 1:100 
por 30 min. Las muestras fueron analizadas por citometría de flujo utilizando el citómetro FACSCalibur (Becton Dickinson). En cada muestra, se analizaron 30.000 eventos. Los datos fueron analizados con el software Flowjo.

\section{Transfección de líneas celulares}

Las células Jurkat fueron cultivadas en placas de 24 pocillos en medio OptiMEM® a una concentración de $1 \times 10^{5}$ células/ml para la transfección del plásmido que contenía el gen reportero EGFP-LC3 y 1 × $10^{7}$ células/ml para el silenciamiento de los genes BECN1 (L-010552-00-0005) y ATG7 (L-010552-00-0005) de Dharmacon (SMARTpool), GCN2 (sc-45644) de Santa Cruz Biotechnology y IRE1 $\alpha$ (RI11837) de AbGent. Para cada pocillo de células, se diluyeron $5 \mu \mathrm{g}$ de DNA del EGFP-LC3 y $50 \mathrm{nM}$ de cada siRNA en $25 \mu \mathrm{l}$ de medio de OptiMEM® (Invitrogen). A continuación, se diluyó $1 \mu$ le Lipofectamine $^{\mathrm{TM}} 2000$ (Invitrogen) en $25 \mu \mathrm{l}$ de OptiMEM ${ }^{\circledR}$, durante 5 min a temperatura ambiente, después del tiempo de incubación se añadió la dilución del DNA y del siRNA a la Lipofectamine ${ }^{\text {TM }}$ y se incubó durante $30 \mathrm{~min}$. La mezcla se añadió a cada pocillo y se dejo incubar durante $4 \mathrm{~h}$. Transcurrido el tiempo las células fueron centrifugadas $800 \mathrm{rpm}$ durante $8 \mathrm{~min}$ y resuspendidas en $1 \mathrm{ml}$ de medio OptiMEM ${ }^{\circledR}$ y se dejaron a $37^{\circ} \mathrm{C}$ durante toda la noche. Las células transfectadas con EGFP-LC3 fueron seleccionadas con $1 \mathrm{mg} / \mathrm{ml}$ de geneticina (G418SIGMA). 



\section{Resultados}





\section{La ausencia de $L$-Arg en células $T$ humanas induce autofagia como respuesta citoprotectora al estrés del retículo endoplásmico}

\section{I.1. Expresión de CD3 $\zeta$ y otros antígenos de membrana en ausencia de L- Arg}

L-Arg es un aminoácido semi-esencial que juega un papel importante en la respuesta inmune $^{39}$. La L-Arg puede ser metabolizado por la óxido nítrico sintasa (iNOS) para producción de óxido nítrico, o por la Arginasa I ó II (ARG1 ó ARG2) para la producción de urea y L-ornitina. La L-ornitina es utilizada como sustrato en la ruta de producción de poliaminas, importantes componentes de la proliferación celular ${ }^{48}$. La L-Arg es necesaria para la expresión del receptor de células T (TCR) encargado de la transducción de señales que intervienen en la producción de citoquinas, supervivencia celular, proliferación y diferenciación celular $^{207}$. La deficiencia de L-Arg disminuye la expresión de la cadena zeta (CD3̧) del TCR afectando a la participación de las células $T$ en la respuesta inmune $44,51,208$. Sin embargo, el mecanismo mediante el cual la ausencia de L-Arg inhibe la función de las células T en la respuesta inmune e induce la bajada de expresión del CD3ל no está del todo esclarecido.

La deficiencia de L-Arg así como de otros aminoácidos puede ser detectada por sensores celulares altamente sensibles a las necesidades nutricionales. La quinasa GCN2 es un sensor específico de la deficiencia de aminoácidos en células de mamíferos. Bajo condiciones de restricción de aminoácidos, GCN2 fosforila el factor de iniciación eucariótico 2 en la subunidad $\alpha$ (eIF2 $\alpha)$, resultando en la inhibición general de la síntesis de proteínas ${ }^{209}$. Para conocer si la ausencia de L-Arg activaba la ruta de señalización de GCN2, se cultivaron células T activadas así como la línea celular Jurkat, en medio con y sin L-Arg durante 48 horas. Jurkat es una línea celular inmortalizada de células $\mathrm{T}$ aislada de un paciente con leucemia linfoide ampliamente utilizada para el estudio de células $\mathrm{T}^{210,211}$. Nuestros resultados indican que la ausencia de L-Arg induce la fosforilación de GCN2 y eIF2 $\alpha$ tanto en células T activadas como en células Jurkat (Figura I-1). La fosforilación de eIF2 $\alpha$ da como resultado la inducción de ATF4 ${ }^{127}$. ATF4 promueve la expresión de genes que codifican para la biosíntesis de aminoácidos y genes involucrados en la autofagia, como ATG12 ${ }^{212}$. La ausencia de L-Arg 
indujo la expresión de ATF4 a partir de las 9 horas de cultivo, así como la expresión ATG12. La proteina GRP78 es la chaperona encargada de regular el plegamiento de proteínas en el RE e iniciar la señalización de la respuesta UPR ${ }^{213}$. Observamos que la ausencia de L-Arg induce la bajada de expresión de la proteína GRP78 en células Jurkat, pero no en células T activadas (Figura I-1).

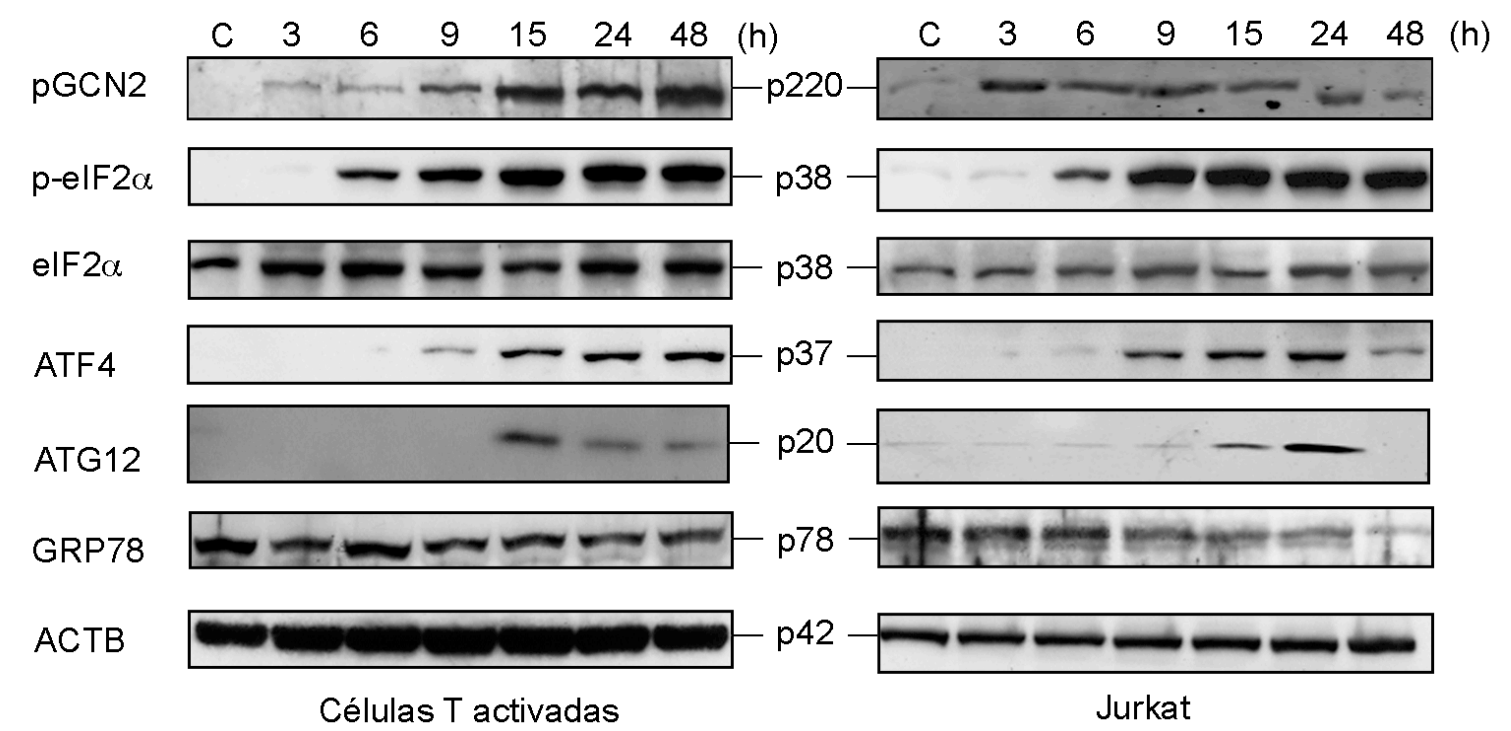

Figura I-1. La ausencia de L-Arg induce la activación de las rutas GCN2 y eIF2a. Células T activadas y células Jurkat fueron cultivadas en medio con $(\mathrm{C})$ y sin L-Arg durante 48 horas. Los extractos de proteínas totales fueron analizados mediante Western blot para identificar las proteínas indicadas con anticuerpos específicos. Se ha utilizado $\beta$-actina (ACTB) como control de carga. Los datos corresponden a un ensayo representativo de al menos tres experimentos independientes.

La fosforilación del eIF2 $\alpha$ es un indicador de la inhibición de la expresión de proteínas. Ante determinadas condiciones, la inhibición de la expresión de proteínas permite que se adopten nuevos programas de expresión génica, como para el transporte, degradación y plegado de proteínas ${ }^{214}$. Teniendo en cuenta que la ausencia de L-Arg induce la fosforilación de eIF2 $\alpha$ en células T, la bajada de expresión observada para la cadena CD3 $\zeta$ podría también extenderse a otras proteínas de membrana importantes para la activación y proliferación de las células T. Mediante citometría de flujo se cuantificó la expresión de las proteínas de membrana $\mathrm{CD} 2, \mathrm{CD} 3 \varepsilon, \mathrm{CD} 5, \mathrm{CD} 11 \mathrm{~A}, \mathrm{CD} 45$ y CD $3 \zeta$ involucradas en adhesión, proliferación celular y transducción de señales. Nuestros resultados revelaron que existe una disminución en la expresión de las proteínas estudiadas a partir de las $6 \mathrm{~h}$ de tratamiento sin L-Arg, en ambos tipos celulares (Fig. I-2). Estas observaciones concuerdan con la inhibición general de la expresión de proteínas, inducida por la fosforilación de eIF2 $\alpha$ (Fig. I-1). 

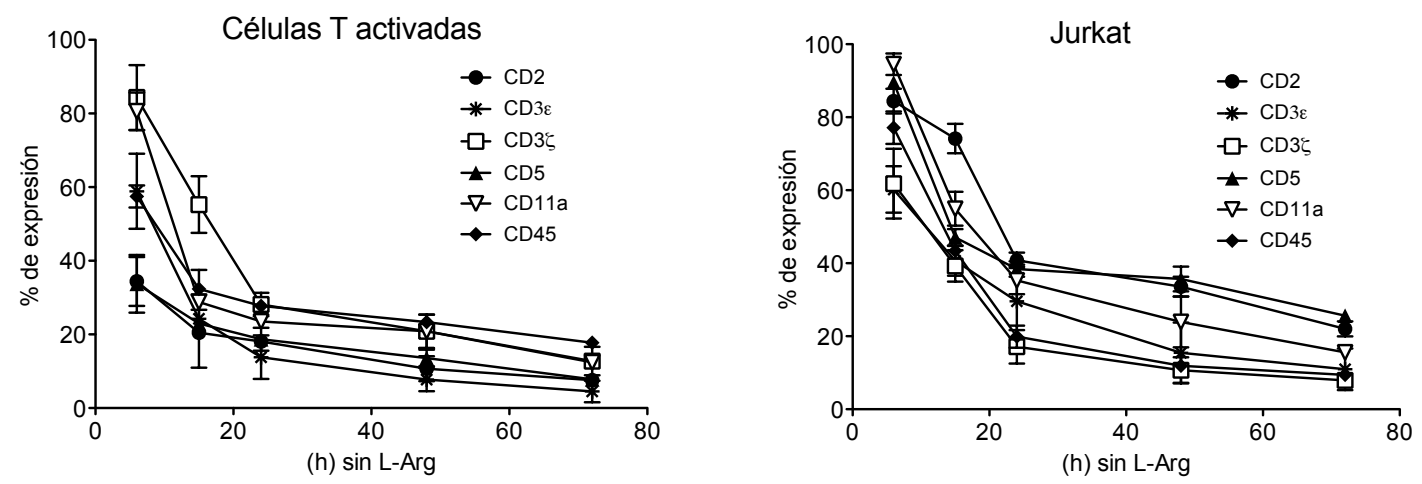

Figura I-2. La ausencia de L-Arg regula negativamente la expresión de CD3ろ y otros antígenos de membrana en células $\mathrm{T}$ activadas y células Jurkat. Por citometría de flujo se comparó el porcentaje de expresión de las proteínas de membrana indicadas en células cultivadas en medio sin L-Arg con respecto a las células cultivadas en presencia de L-Arg. Los datos corresponden a la media \pm SD de tres experimentos independientes.

La ausencia de L-Arg en células T también afecta la expresión de otras proteínas como las ciclinas $\mathrm{D} 3$ y cdk4, induciendo en consecuencia una parada en $\mathrm{G}_{0} / \mathrm{G}_{1}{ }^{59}$. Sin embargo, no se ha determinado sí la restricción prolongada de L-Arg y la parada en $\mathrm{G}_{0} / \mathrm{G}_{1}$ desencadenan mecanismos de muerte celular programada. Para determinar el efecto de L-Arg sobre la apoptosis y la proliferación celular, cultivamos células T activadas y células Jurkat en presencia y ausencia de L-Arg. No observamos un aumento significativo en la degradación del DNA (Figura I-3), pero sí una disminución en la proliferación celular a partir de las 36 h (Figura I-4).

Nuestros resultados indican que la ausencia de L-Arg puede inducir la actividad quinasa de GCN2, disminuyendo la expresión de proteínas importantes en la señalización, activación y proliferación de células T. Sin embargo, no observamos un aumento significativo en la muerte celular, lo que sugiere que la ausencia de L-Arg puede desencadenar rutas de señalización que favorezcan la adaptación y supervivencia a las nuevas condiciones metabólicas.

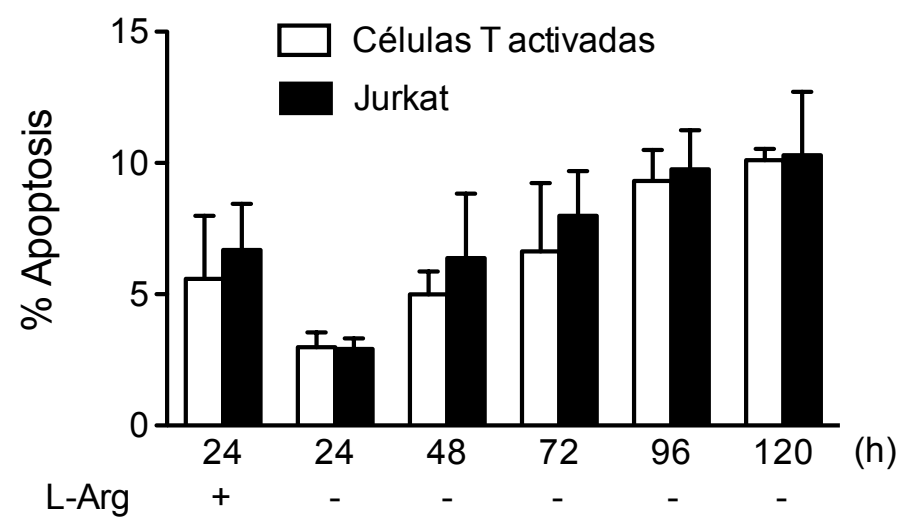

Figura I-3. La ausencia de L-Arg induce un ligero aumento en la apoptosis. Células $\mathrm{T}$ activadas y células Jurkat fueron cultivadas en medio sin L-Arg durante los tiempos indicados. El control $(\mathrm{C})$ representa células cultivadas en medio completo durante 120 horas. Mediante citometría de flujo se cuantificó las poblaciones celulares con fragmentación de DNA. Los datos corresponden a la media \pm SD de al menos tres experimentos independientes. 

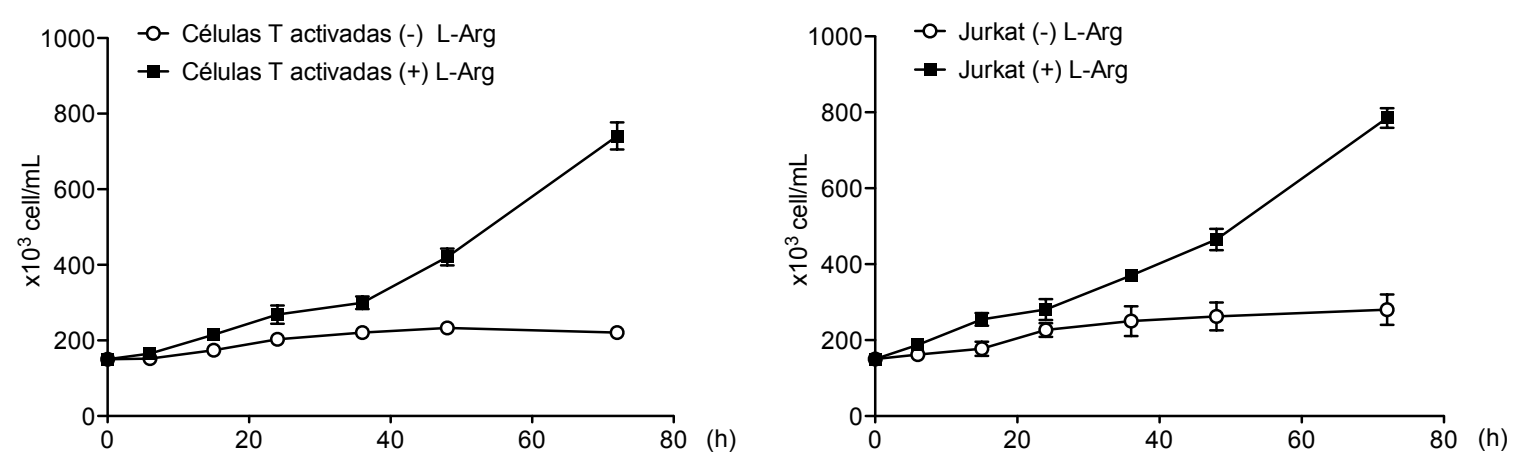

Figura I-4. La ausencia de L-Arg detiene la proliferación celular. Células T activadas y células Jurkat fueron cultivadas en medio con y sin L-Arg partiendo de un cultivo inicial de $150 \times 10^{3}$ células $/ \mathrm{ml}$. Se determinó la concentración celular de cada cultivo en los tiempos indicados mediante el recuento de células con Trypan blue. Los datos corresponden a la media \pm SD de al menos tres experimentos independientes.

\section{I.2. La ausencia de L-Arg induce estrés de retículo en células T}

Condiciones de estrés celular como la carencia de glucosa o aminoácidos, hipoxia, infecciones virales, o la perturbación del flujo de calcio a través de la membrana plasmática causan la acumulación de proteínas desplegadas en el RE, lo cual promueve la activación de la respuesta de proteínas desplegadas $(\mathrm{UPR})^{80}$. La función de la respuesta UPR es recuperar el funcionamiento normal del RE, para ello la respuesta UPR detiene la traducción de proteínas y activa la expresión de genes que aumentan la capacidad de plegado de proteínas en el RE. Además, la UPR induce la expresión de proteínas asociadas a la degradación ERAD, maquinaria encargada de eliminar las proteínas desplegadas del $\mathrm{RE}^{215}$. Cuando los mecanismos adaptativos de la respuesta UPR no logran restablecer las funciones del RE, la ruta UPR conduce a la muerte celular por apoptosis ${ }^{83,216}$. Como describimos anteriormente, la ausencia de un sólo aminoácido, en este caso la L-Arg, es capaz de activar señales de estrés como la fosforilación de eIF2 $\alpha$. Existen cuatro quinasas capaces de fosforilar eIF2 $\alpha$ dependiendo de las señales de estrés celular. La quinasa GCN2 se activa por restricción de aminoácidos ${ }^{78}$, la quinasa PERK se activa por la acumulación de proteínas desplegadas en el $\mathrm{RE}^{217}$, la quinasa PKR se activa por la acumulación de RNA de doble cadena ${ }^{218}$, y la quinasa HRI se activa cuando hay niveles bajos del grupo hemo ${ }^{219}$. Detectamos que la ausencia de L-Arg induce la fosforilación de GCN2 (Figura I-1). Sin embargo, queríamos determinar si la fosforilación de eIF2 $\alpha$ puede indicar que la ausencia de L-Arg genera la acumulación de proteínas desplegadas en el RE dando lugar a una respuesta del tipo UPR. 
La respuesta UPR es un complejo programa de señalización celular mediado por tres quinasas: IRE1 $\alpha$, PERK y ATF6 ${ }^{95}$. Para determinar si algunas de estas rutas se activaba en ausencia L-Arg, se cultivaron las células T activadas y las célula Jurkat en medio con y sin LArg. La activación de PERK puede detectarse por su auto-fosforilación y la activación de ATF6 por su procesamiento a través de las proteasas S1P y S2P, dando lugar a un dominio citosólico N-terminal de $50 \mathrm{kDa}$ (p50ATF6) ${ }^{98}$. Sin embargo, la activación de estas rutas no fue detectada cuando se cultivaton las células T en ausencia de L-Arg.

La tercera ruta de señalización UPR viene dada por la activación de IRE1 $\alpha$. La quinasa IRE1 $\alpha$ se activa a través de su dominio RNasa que elimina una secuencia de 26 nucleotidos del RNA inmaduro de XBP1 denominado XBP1s, dando lugar a un RNA maduro XBP1s. Dentro de esta secuencia de nucleotidos de 26-pb, existe un sitio de restricción para la enzima Pst 1 que permite diferenciar XBP1u y XBP1s ${ }^{220,221}$. Para detectar la activación de IRE1 $\alpha$, las células T fueron cultivadas con y sin L-Arg. Mediante RT-PCR se amplificó el cDNA correspondiente al gen XBP1. Este cDNA se analizó mediante restricción enzimática con PstI. Para el XBP1u se esperaban dos fragmentos de 294 y $146 \mathrm{pb}$, mientras que para la forma madura XBP1s se esperaba sólo una banda de 414 pb (Figura I-5). Se observó coexistencia tanto de la forma XBP1 $u$ como de XBP1s en las células T activadas a partir de las 6 horas de cultivo en medio sin L-Arg y a partir de las 15 horas para las celular Jurkat. A las 48 horas de cultivo, tanto las células $\mathrm{T}$ activadas como las células Jurkat, presentaron solo la forma madura XBP1s. Estos datos sugieren que la ausencia de L-Arg induce la acumulación de proteínas desplegadas, resultando en la activación de la vía IRE1 $\alpha$ de la respuesta UPR.

El factor de transcripción XBP1s es un potente activador de genes que codifican para la expresión de chaperonas y proteínas como EDEM1, integrantes de la maquinaria ERAD ${ }^{222}$. Debido a la fuerte inducción de XBP1s observada en ausencia de L-Arg, quisimos evaluar la expresión de EDEM1 en las células T cultivadas en ausencia de L-Arg. La expresión de la proteína EDEM1 está modulada por señales de estrés celular y su función es participar en la degradación de glicoproteínas del $\mathrm{RE}^{109,223}$. Observamos que el agotamiento de L-Arg induce una regulación positiva de la proteína EDEM1 en ambos tipos celulares. Sin embargo, en células Jurkat la expresión de EDEM1 cae a partir de las 24 horas de cultivo (Figura I-6). La expresión de EDEM1 coincide con la aparición de la forma XBP1s, lo que sugiere que la deficiencia de L-Arg induce la activación de señales UPR a través de IRE1 $\alpha$ iniciando una señalización downstream, en la cual participa EDEM1. 


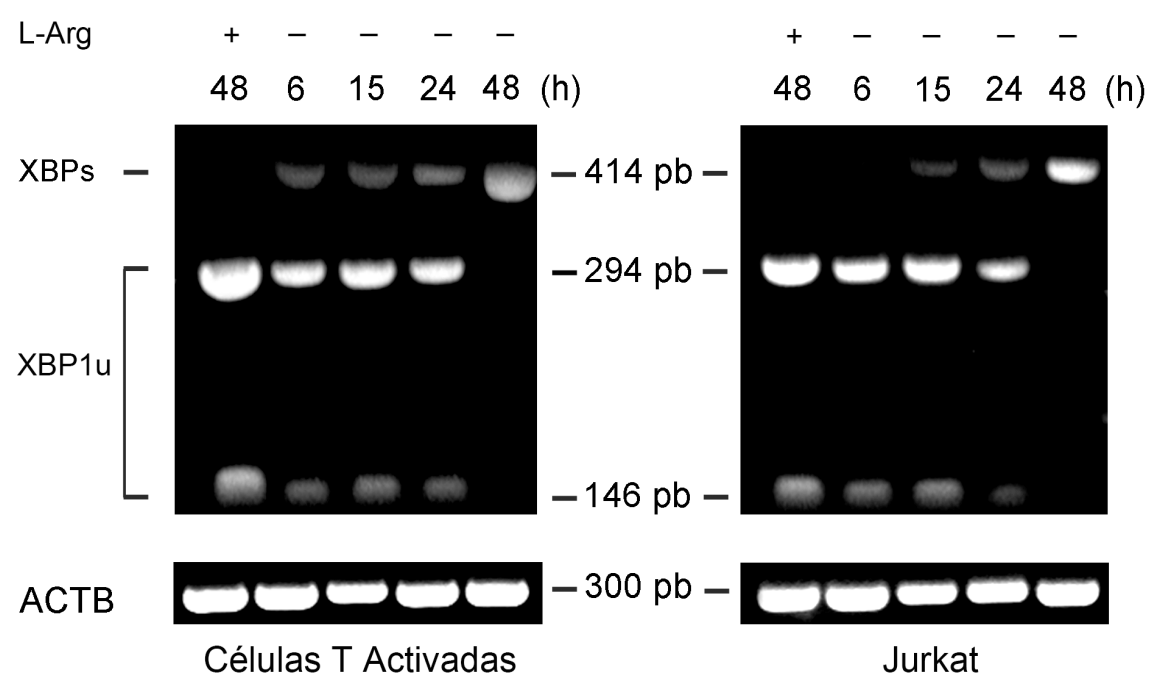

Figura I-5. La ausencia de L-Arg induce splicing de XBP1 en células T activadas y células Jurkat. Células T activadas y células Jurkat fueron cultivadas en medio con y sin L-Arg. En los tiempos indicados se extrajo el RNA total y se sintetizó el cDNA. Se utilizaron cebadores específicos para el gen XBP1 y los fragmentos de PCR resultantes fueron digeridos con la enzima de restricción PstI. Sólo el cDNA correspondiente al XBP1s mRNA no posee el sitio de corte para la enzima PstI, debido a la perdida de un intrón de 26 pb en respuesta a estrés de retículo. Se ha utilizado $\beta$-actina (ACTB) como control de carga. Los datos corresponden a un ensayo representativo de al menos tres experimentos independientes.

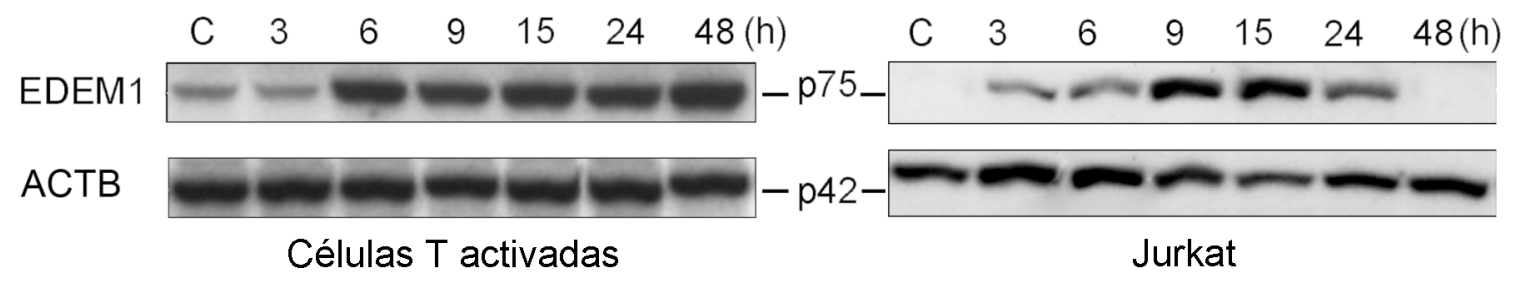

Figura I-6. La ausencia de L-Arg induce la expresión de EDEM1 en células T activadas y células Jurkat. Células T activadas y células Jurkat fueron cultivadas en medio con $(\mathbf{C})$ y sin L-Arg. En los tiempos indicados se realizó un extracto de proteínas totales para analizar mediante Western blot la expresión de EDEM1. Se ha utilizado anti-ACTB como control de carga. Las imágenes del Western blot corresponden a un ensayo representativo de al menos tres experimentos independientes.

La ausencia de L-Arg induce la activación de la quinasa IRE1 $\alpha$, posiblemente por la acumulación de proteínas desplegadas en el RE. Sin embaro, no se observa un aumento significativo de la muerte celular después de las 72 horas de cultivo sin L-Arg (Figura I-3). A partir de estos resultados suponemos que la respuesta UPR activa rutas de degradación proteínas como mecanismo de supervivencia. La respuesta UPR puede activar dos vías principales para la degradación de proteínas, la vía proteasomal y la autofagia ${ }^{224}$. Se quiso determinar si la actividad del proteasoma 20 S intervenía como mecanismo de estabilización del RE en respuesta a la acumulación de proteínas desplegadas. Para este ensayo utilizamos lisados de proteínas totales de células $\mathrm{T}$ y células Jurkat cultivadas en medio con y sin L-Arg durante 
48 horas. Utilizamos en paralelo Lactacystin, un inhibidor irreversible de la hidrólisis de proteínas por el proteasoma, para determinar si la actividad observada se debía exclusivamente a la degradación proteasomal225. La actividad del proteasoma se incrementó después de las 3-6 $\mathrm{h}$ de cultivo en medio sin L-Arg seguido por una disminución gradual de la actividad en ambos tipos celulares. Esta actividad fue inhibida por Lactacystin (Figura I-7A). La activación de las células T depende de la disponibilidad de L-Arg, efecto que se correlaciona con la expresión de la cadena $\zeta$ del complejo TCR/CD $3^{60}$. Observaciones previas sugieren que la degradación de la $\mathrm{CD} 3 \zeta$ puede efectuarse tanto por vía lisosomal, como por la vía proteasomal226,227. Para investigar que ruta de degradación interviene en la regulación negativa de la cadena $\mathrm{CD} 3 \zeta$ en ausencia de L-Arg, utilizamos inhibidores del proteasoma (PS-341 y Lactacystin), además de inhibidores de la vía lisosomal (Bafilomicina A - BF y Cloroquina - CQ). Observamos que en ausencia de L-Arg, la vía proteasomal, y no la lisosomal, es la responsable de la degradación de cadena $\mathrm{CD} 3 \zeta$ en células $\mathrm{T}$ (Figura I-7B y C).

El estrés de RE inhibe la formación de puentes disulfuro y la glicosilación de proteínas, bloquea el transporte del RE al aparato de Golgi y desregula el tráfico de $\mathrm{Ca}^{2+}$. Células sometidas a estrés de RE persistente pueden activar rutas apoptóticas entre las 20-48 horas del inicio de las condiciones de estrés ${ }^{228}$. Transcurridas 72 horas en medio sin L-Arg, las células T no muestran un elevado porcentaje de muerte celular (Figura I-3). Sin embargo, a las 48 h aún se puede detectar la forma madura del XBP1 (Figura I-5), indicando que la ruta IRE1 $\alpha$ sigue activa y el estrés de RE persiste a pesar de que la actividad del proteasoma disminuye continuamente a partir de las $6 \mathrm{~h}$. Por lo tanto, quisimos determinar si la autofagia intervenía en el restablecimiento de las funciones del RE, una vez que disminuye la actividad del proteasoma.

\section{I.3. La ausencia de L-Arg induce autofagia como mecanismo de supervivencia en células $T$}

La autofagia es uno de los mecanismos principales de degradación intracelular. La autofagia se activa en respuesta a entornos adversos, tales como la restricción de nutrientes y/o factores de crecimiento $^{229}$. Diversos estudios han demostrado que células sometidas a estrés de RE pueden inducir autofagia como mecanismo de supervivencia y adaptación ${ }^{230,231}$. La autofagia se caracteriza por la formación de autofagosomas y su posterior fusión con lisosomas para digerir moléculas complejas y liberar ácidos grasos, aminoácidos, azúcares y demás 
A
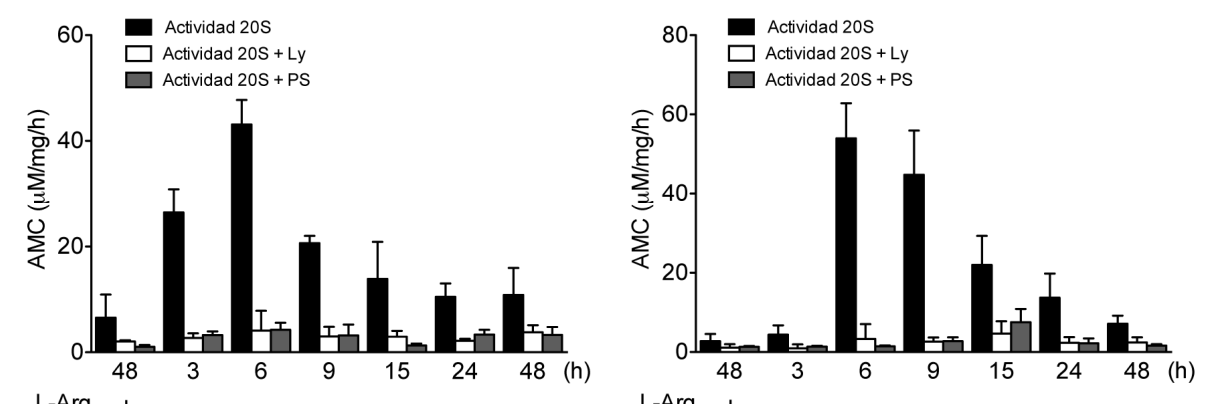

B
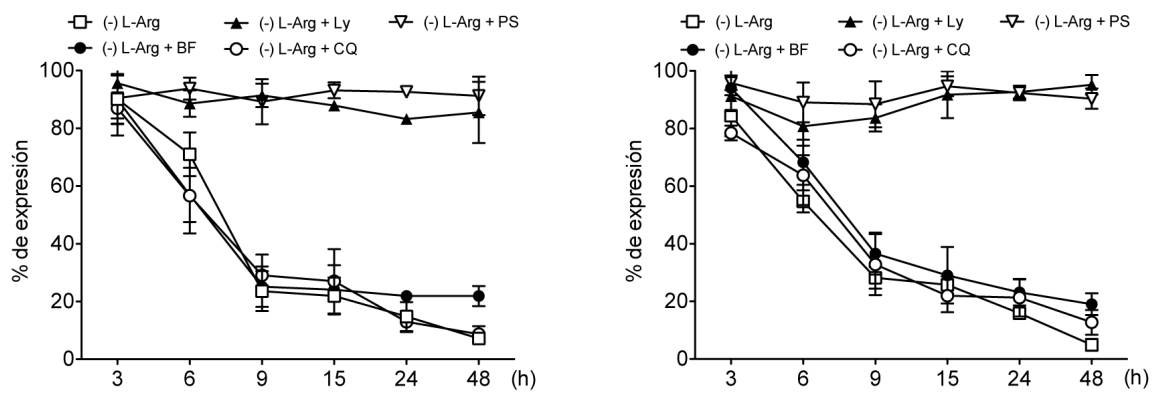

C
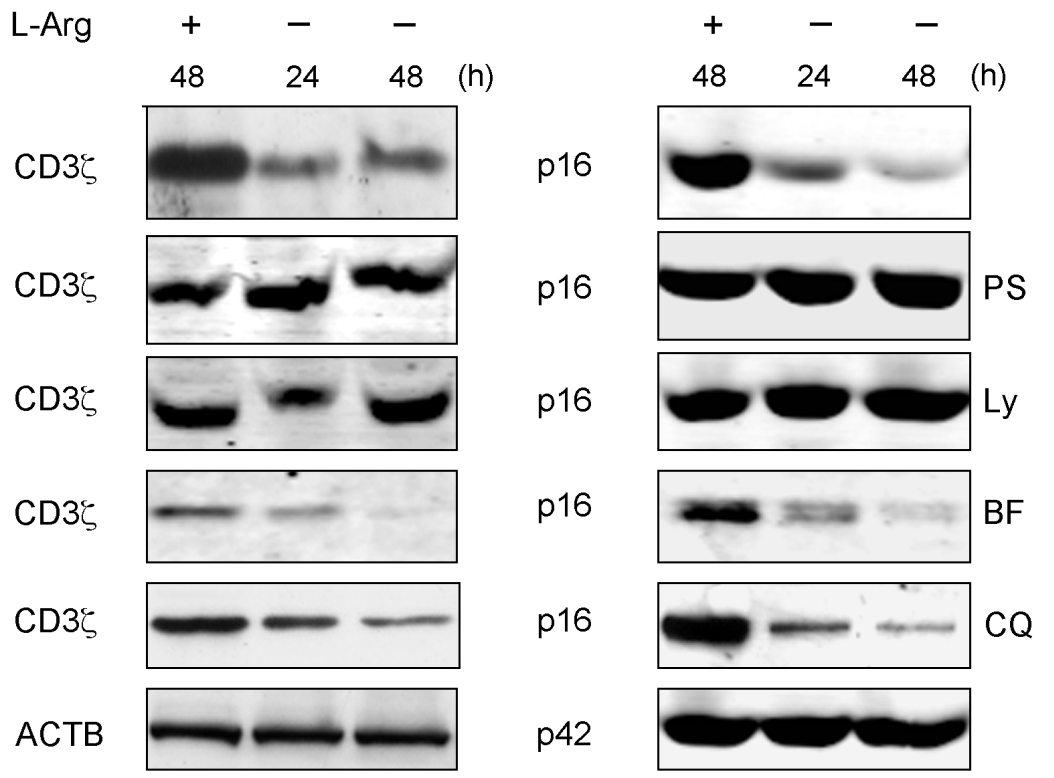

Células $\mathrm{T}$ activadas

\section{Jurkat}

Figura I-7. La ausencia de L-Arg aumenta la actividad del proteasoma $20 \mathrm{~S}$ en células $\mathrm{T}$ activadas y células Jurkat. Células T activadas y células Jurkat fueron cultivadas en medio con y sin L-Arg en presencia o ausencia de los inhibidores de la degradación proteasomal (Ly; Lactacystin, PS; PS-341) y lisosomal (BF; Bafilomicina y CQ; Cloroquina) (A y B). En los tiempos indicados se determinó la actividad del proteasoma 20S (A) también se evaluó la expresión del CD3孔 mediante citometría de flujo (B) y Western blot $(\mathrm{C})$. La actividad del proteasoma $20 \mathrm{~S}$ viene dada en $\mu \mathrm{M}$ de AMC (7-amino-4metilcumarina) detectado, por mg de proteína utilizado, por hora. Los datos de la actividad 20S y la cuantificación del CD33 por citometría de flujo corresponden a la media \pm SD de al menos tres experimentos independientes. Se ha utilizado anti-ACTB como control de carga. Las imágenes de Western blot corresponden a un ensayo representativo de al menos tres experimentos independientes. 
nutrientes necesarios para el funcionamiento celular ${ }^{143}$. Un incremento en la cantidad de los lisosomas podría asociarse a un proceso autofágico ${ }^{232}$. El compuesto naranja de acridina (NA) es una base débil fluorescente que se acumula en espacios ácidos, tales como los autofagolisosomas y lisosomas. Estos espacios ácidos se denominan orgánulos vesiculares ácidos (OVA). Debido a sus propiedades metacromáticas, el compuesto NA se utiliza comúnmente en microscopía de fluorescencia y citometría de flujo para el análisis de la fisiología celular ${ }^{233,234}$. El gradiente de protones existente en los lisosomas resulta en una acumulación de la NA dentro de estos orgánulos. En el interior de los lisosomas la NA forma agregados capaces de emitir fluorescencia en el espectro del rojo ${ }^{235}$. Después de cultivar las células con o sin L-Arg, se realizó la tinción con NA y se cuantificó mediante citometría de flujo el incremento de fluorescencia roja (Figura I-8). Se observó que la fluorescencia aumentaba con el tiempo de cultivo en medio sin L-Arg en células T activadas y células Jurkat, lo que puede relacionarse con la formación de vacuolas ácidas y el inicio de un proceso autofágico. Sin embargo, es necesario estudiar marcadores específicos de la autofagia para asegurar la implicación directa de este proceso en la respuesta inducida por la ausencia de LArg en células T.

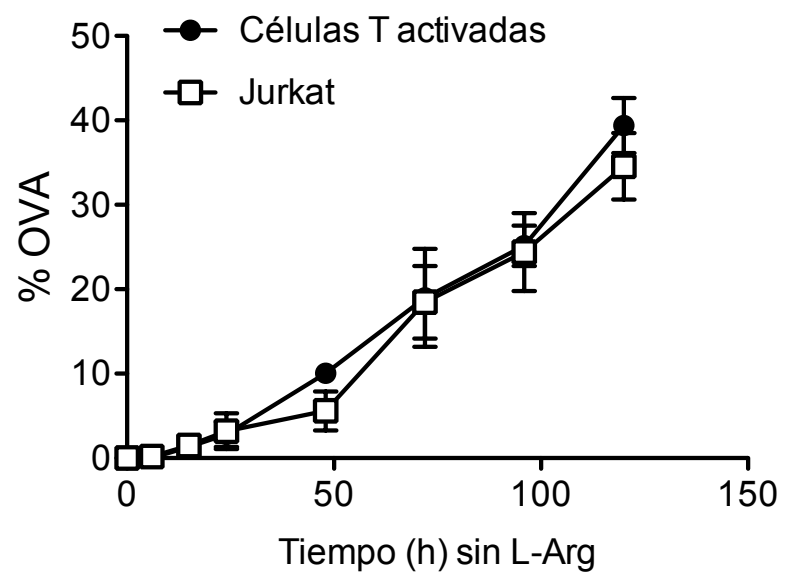

Figura I-8. La ausencia de L-Arg promueve la formación de organelos vesiculares ácidos (OVA) en células $\mathrm{T}$ activadas y células Jurkat. Células $\mathrm{T}$ activadas y células Jurkat fueron cultivadas en medio con y sin L-Arg y analizadas mediante citometría de flujo. La formación de OVA se representa como el porcentaje de células donde se observa incremento de fluorescencia roja. Los resultados representados corresponden a la media \pm SD de al menos tres experimentos independientes.

Uno de los marcadores de la formación del autofagosoma es el LC3. El LC3 es una proteína asociada a microtubulos encargada de regular la interacción entre los microtubulos y componentes del citoesqueleto. Durante la autofagia, la forma citosólica de LC3 (LC3-I) se conjuga con fosfatidiletanolamina (PE) para formar el conjugado LC3-PE ó LC3-II, que se recluta en la membrana de los autofagosomas ${ }^{155}$. Cuando se forman los autolisosomas, el LC3II que se encuentra en la cara interna de la membrana del autolisosoma se degradada ${ }^{154}$. Los cambios en la localización celular del LC3 son utilizados para detectar la activación de la 
autofagia por microscopía de fluorescencia, por citometría de flujo y por Western $\operatorname{blot}^{236}$. Con el fin de evaluar si el aumento de los OVA se correspondía con la formación de autofagosomas, se procedió a analizar mediante microscopía confocal células cultivadas en medio con y sin L-Arg durante 48 horas. Tanto las células T activadas como las células Jurkat presentaban una transición desde el patrón citoplasmático difuso del LC3 al patrón punteado característico de la formación de los autofagosomas (Figura I-9). Estos resultados sugieren que la ausencia de L-Arg promueve la activación de la autofagia en células T.

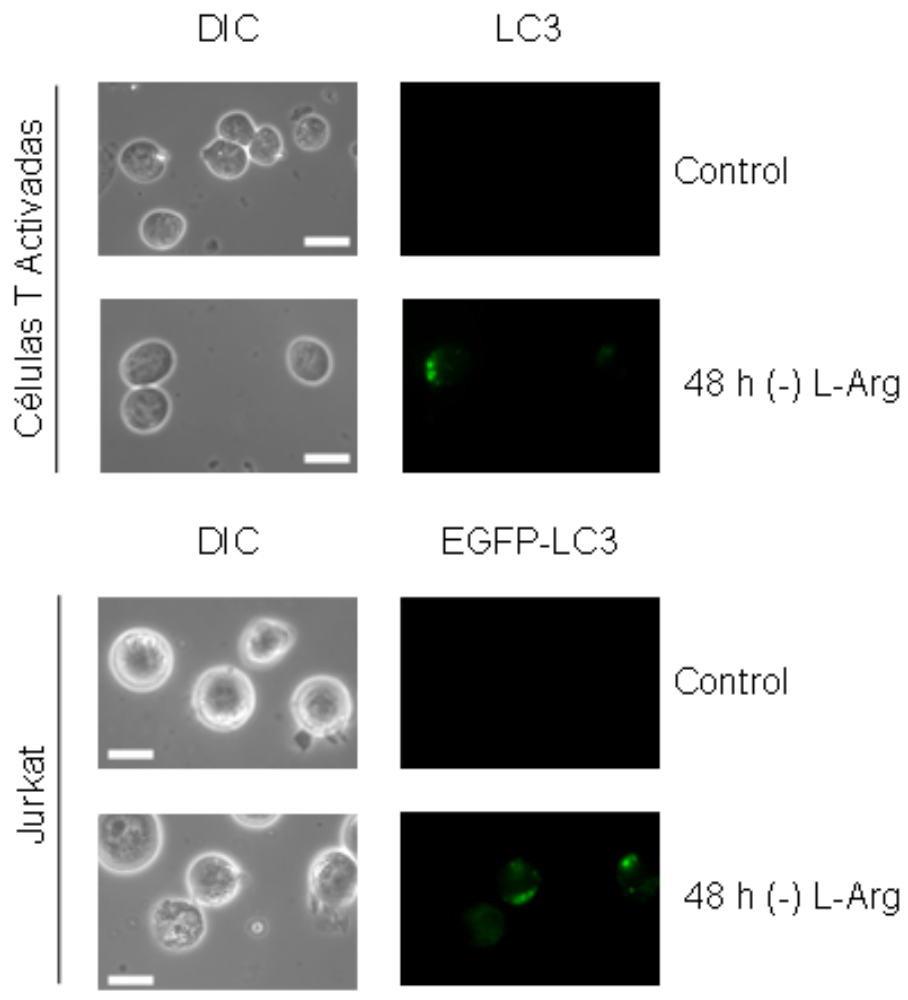

Figura I-9. La ausencia de L-Arg promueve la formación de autofagosomas en células T activadas y células Jurkat. Ambos tipos celulares fueron cultivados en medio con (Control) y sin L-Arg, y analizados mediante microscopía confocal. Para las células $\mathrm{T}$ activadas, se utilizó el anticuerpo anti-LC3, con un secundario conjugado con Cy2. Mientras que la línea celular Jurkat fue transfectada con un plásmido EGFP-LC3. Las imágenes corresponden a un ensayo representativo de al menos tres experimentos independientes..

El término flujo autofágico se utiliza para designar el proceso dinámico entre la síntesis de autofagosoma, la entrega de sustratos autofágicos a los lisosomas, y la degradación de estos sustratos dentro del autolisosoma. El flujo autofágico es el indicador más fiable de la autofagia, y puede determinarse mediante la disminución de los niveles del LC3-II y del sequestosoma 1 (SQSTM1/p62), en comparación con la acumulación inducida por inhibidores de la degradación lisosomal. El SQSTM1/p62 es un armazón proteico de proteínas ubiquitinadas que se une directamente al LC3 para degradar los agregados poliubiquitinados a través de la autofagia $^{237}$. Quisimos determinar si la ausencia de L-Arg, promovía la degradación de LC3-II y de SQSTM1/p62 como parte del flujo autofágico. En células cultivadas en ausencia de L- 
Arg, observamos la conversión de LC3-I a LC3-II a partir de las 24 horas de cultivo en células T, y partir de las 15 horas en células jurkat. También se detectó una disminución de la proteína SQSTM1/p62 a partir de las 24 horas de cultivo en ausencia de L-Arg para ambos tipos celulares (Figura I-10A). Para corroborar estos resultados se analizó el flujo autofágico por citometría de flujo. Las células fueron lavadas con saponina $(0,05 \%)$ para eliminar la fluorescencia correspondiente al LC3-I citoplasmático, permitiendo captar solo la fluorescencia del LC3-II que se encuentra unido a los autofagosomas ${ }^{206}$. La cloroquina (CQ) se utilizó para inhibir la fusión de los autofagosomas con los lisosomas y medir la acumulación del LC3-II. Se observó un aumento de la fluorescencia entre las 24 y 48 horas en ambos tipos celulares seguido de una disminución continua hasta las $120 \mathrm{~h}$ de cultivo (Figura I-10B). Estos resultados indican una degradación de la proteína LC3-II por la vía lisosomal, confirmando la participación de la autofagia en la supervivencia de las células T ante la ausencia de L-Arg.

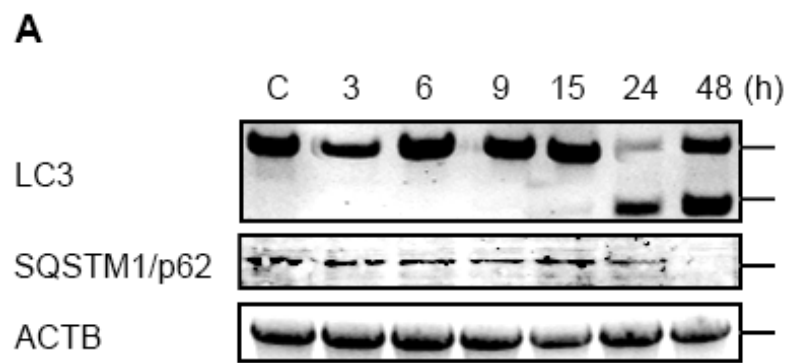

Células T activadas

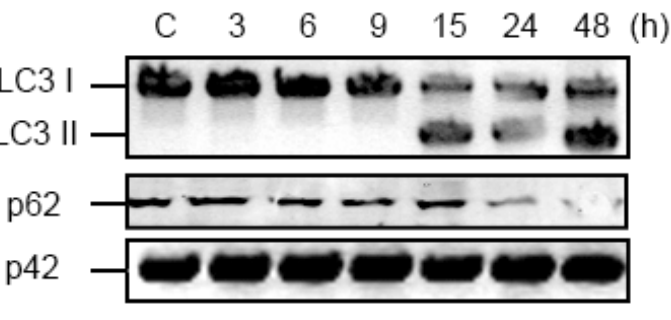

Jurkat

B

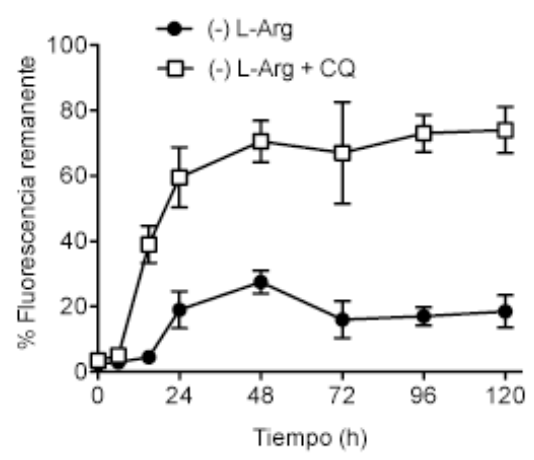

Células T activadas

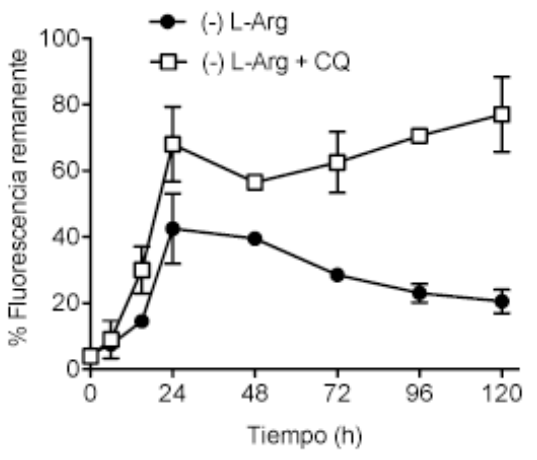

Jurkat

Figura I-10. La ausencia de L-Arg induce autofagia en células T activadas y células Jurkat. (A) Las células fueron cultivadas en medio con $(\mathrm{C})$ y sin L-Arg, se realizaron extractos de proteínas totales en los tiempos indicados, y fueron analizados mediante Western blot utilizando anticuerpos específicos para las proteínas indicadas. Se ha utilizado ACTB como control de carga. Los datos corresponden a un ensayo representativo de al menos tres experimentos independientes. (B) Para medir el flujo autofágico las células fueron cultivadas en medio sin L-Arg en presencia o ausencia de Cloroquina $(\mathrm{CQ}, 10 \mu \mathrm{M})$. Las células T activadas fueron inmunoteñidas con anti-LC3 y un secundario conjugado con Cy2, mientras que las células Jurkat fueron transfectadas con un plásmido GFP-LC3. Las células fueron analizadas por citometría de flujo. Los datos se presentan como porcentaje de fluorescencia total tras el lavado con saponina $(0,05 \%)$. Los datos corresponden a la media \pm SD de al menos tres experimentos independientes. 


\section{I.4. La ausencia de L-Arg induce la regulación negativa de la ruta PI3K-Akt- mTOR-p70 $0^{\text {S6K }}$}

Existen dos rutas encargadas de regular la autofagia ante la disminución de nutrientes, las cascadas de señalización de PI3K-Akt-mTOR-p70 ${ }^{\mathrm{S} 6 \mathrm{~K}}$ y Ras-Raf1-MEK1/2-ERK1/2141,238. La activación de ambas rutas tienen un efecto antagónico con respecto a la regulación de la autofagia. La activación de PI3K-Akt-mTOR-p70 $56 \mathrm{~K}$ inhibe la autofagia, mientras que la activación de Ras-Raf1-MEK1/2-ERK1/2 la induce ${ }^{168}$. Quisimos estudiar la participación de ambas rutas en la autofagia inducida por la ausencia de L-Arg en células T. Observamos que los niveles basales de fosforilación de Akt, mTOR y su sustrato $\mathrm{p} 70^{\mathrm{S} 6 \mathrm{~K}}$ disminuyen a partir de las 15 h de cultivo en medio sin L-Arg (Figura I-11). La inactivación por desfosforilación de la ruta Akt/mTOR, concuerda con el inicio de la formación de los autofagosomas (Figura I-9 y II-10). Adicionalmente, observamos un aumento en la fosforilación de ERK1/2 a partir de las $6 \mathrm{~h}$ para ambos tipos celulares (Figura I-11). Podemos inferir que la ausencia de L-Arg induce la inhibición de la ruta AKT/mTOR y la activación por fosforilación de la ruta ERK1/2 favoreciéndose así la formación de los autofagosomas.

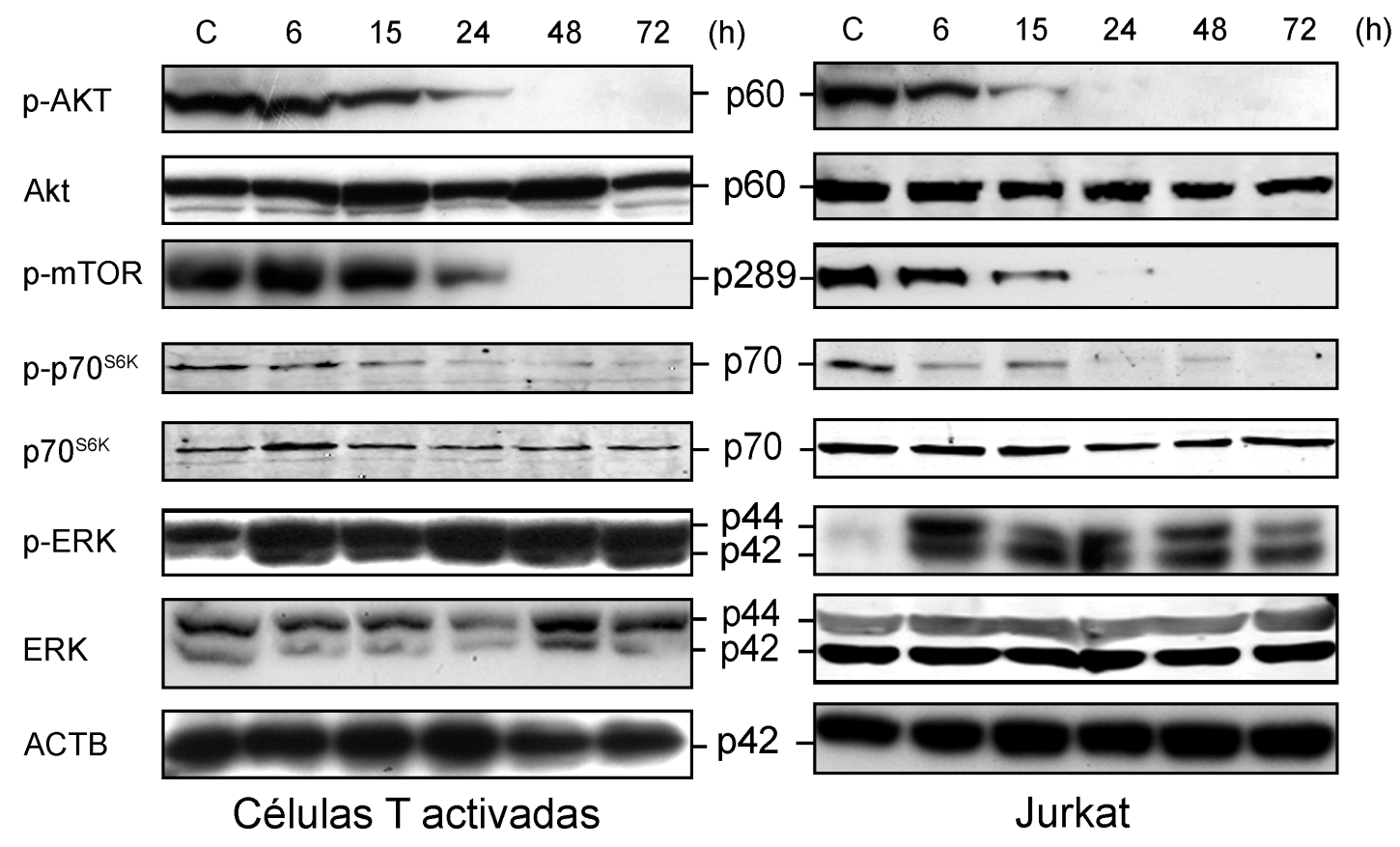

Figura I-11. Efecto de la ausencia de L-Arg en las vías de señalización AKT1/mTOR y ERK1/2 en células T. Las células fueron cultivadas en medio con $(\mathrm{C})$ y sin L-Arg. En los tiempos indicados se realizaron extractos de proteínas totales, los cuales fueron analizados mediante Western blot utilizando anticuerpos específicos para las proteínas indicadas. Se utilizó ACTB como control de carga. Los datos corresponden a un ensayo representativo de al menos tres experimentos independientes. 


\section{I.5. Inhibición de JNK y ERK1/2 bloquea la autofagia inducida por la ausencia de $L$-Arg en células $T$}

Como observamos en la Figura I-5, el splicing del mRNA de XBP1 indica la activación de IRE1 $\alpha$, evento que se mantiene hasta las $48 \mathrm{~h}$ de cultivo. La activación prolongada de IRE1 $\alpha$ induce la fosforilación de la quinasa estrés-inducible JNK (c-Jun N-terminal kinase $)^{239}$. En un proceso autofágico la forma fosforilada de JNK ( $\mathrm{p}-\mathrm{JNK}$ ) fosforila a la proteína antiapoptotica Bcl-2, disociando el complejo Bcl-2/Beclin-1. La liberación de la proteína Beclin-1 es importante para la formación del autofagosoma y la posterior activación del flujo autofágico $^{162,240}$. Quisimos determinar si la activación de IRE1 $\alpha$ en células T mediada por la ausencia de L-Arg inducía la fosforilación de JNK y la disociación del complejo Bcl-2/ Beclin-1. Tanto en células T activadas como en células Jurkat se observó una fosforilación temprana de JNK, acompañada de la fosforilación consecutiva de Bcl-2 (Figura I-12A). Esta fosforilación concuerda con la liberación del complejo Bcl-2/Beclin-1 (Figura I-12B). Estos resultados sugieren que JNK está implicada en la activación de la autofagia mediada por la ausencia de L-Arg en células T.

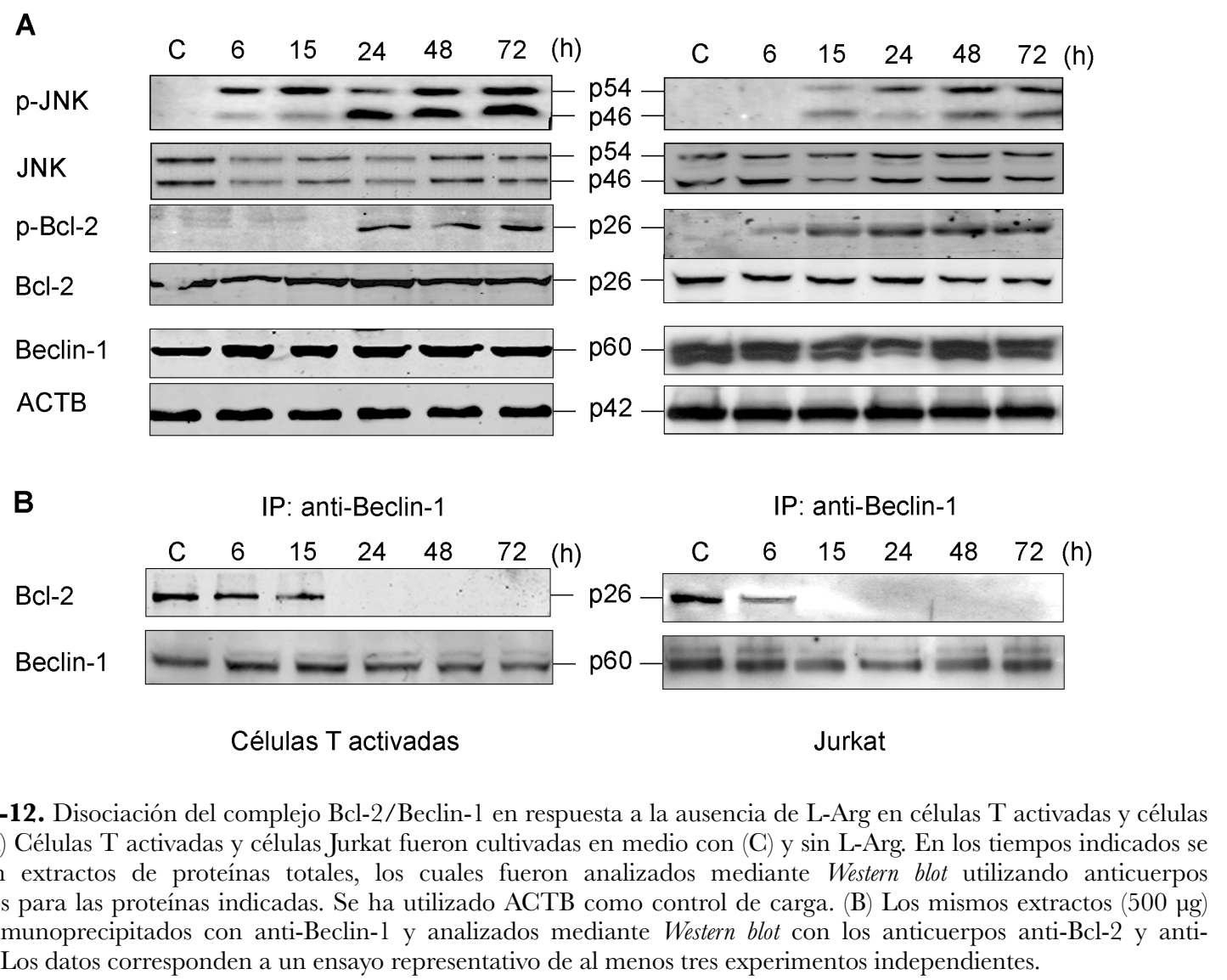

Figura I-12. Disociación del complejo Bcl-2/Beclin-1 en respuesta a la ausencia de L-Arg en células T activadas y células Jurkat. (A) Células T activadas y células Jurkat fueron cultivadas en medio con (G) y sin L-Arg. En los tiempos indicados se realizaron extractos de proteínas totales, los cuales fueron analizados mediante Western blot utilizando anticuerpos específicos para las proteínas indicadas. Se ha utilizado ACTB como control de carga. (B) Los mismos extractos (500 $\mu$ g) fueron inmunoprecipitados con anti-Beclin-1 y analizados mediante Western blot con los anticuerpos anti-Bcl-2 y antiBeclin-1. Los datos corresponden a un ensayo representativo de al menos tres experimentos independientes. 
Para determinar la importancia de JNK y ERK1/2 en la autofagia mediada por la ausencia de L-Arg, las células fueron tratadas previamente con SP600125 (inhibidor específico de JNK) y U0126 (inhibidor de la ruta Raf/MEK/ERK) durante 1 hora. Ambos inhibidores fueron capaces de inhibir el flujo autofágico tanto en células T activadas como en células Jurkat (Figura I-13A). Además, la inhibición del flujo autofágico inducido por SP600125 y U0126 resultó en la muerte celular apoptótica, cuantificada por el aumento de células anexina-V positivas en ambos tipos celulares (Figura I-13B). Nuestros resultados indican que la activación de las rutas JNK y ERK son importantes para el inicio de la autofagia y la supervivencia celular.

Debido a que la respuesta de las células T activadas y las células Jurkat ante la ausencia de L-Arg es similar, los siguientes experimentos se realizaron utilizando solamente la línea celular Jurkat, ya que estas ofrecen una mejor manipulación genética y un mayor facilidad de mantenimiento en cultivo.
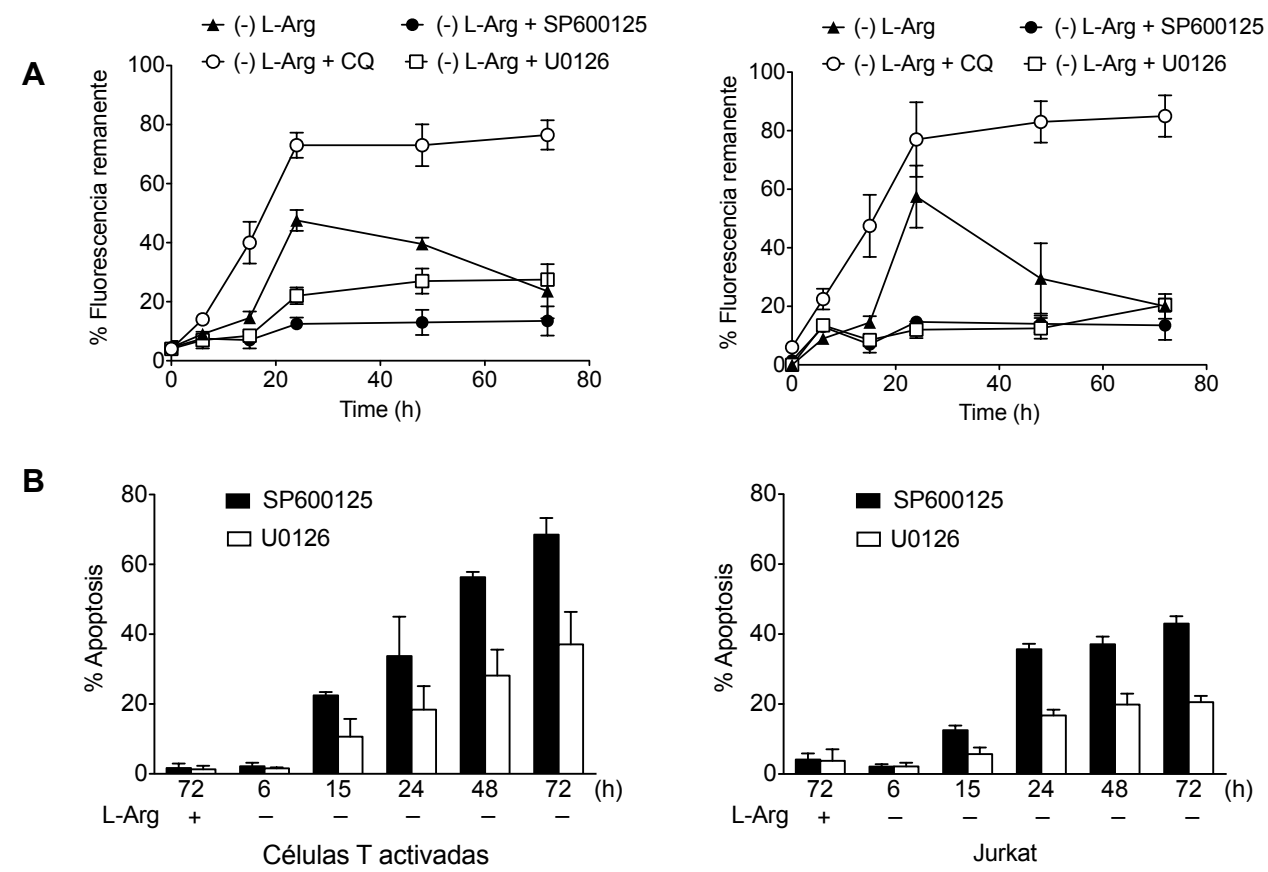

Figura I-13. Inhibidores de JNK y ERK1/2 inhiben el flujo autofágico en células T activadas y células Jurkat induciendo apoptosis. Células T activadas y células Jurkat fueron cultivadas en medio con L-Arg y con el inhibidor de JNK (SP600125, $10 \mu \mathrm{M})$ y el inhibidor de ERK1/2 (U0126, $10 \mu \mathrm{M})$ durante 1 hora, luego las células fueron lavadas y resuspendidas en medio sin L-Arg, con los inhibidores SP600125 y U0126. (A) Para medir el flujo autofágico las células fueron posteriormente cultivadas en presencia o ausencia de CQ $(10 \mu \mathrm{M})$. Las células T activadas fueron inmunoteñidas con anti-LC3, mientras que las células Jurkat fueron transfectadas con un plásmido GFP-LC3. Las células fueron analizadas por citometría de flujo. Los datos se presentan como porcentaje de fluorescencia después del lavado con saponina (0,05\%). Los datos del porcentaje de fluorescencia corresponden a la media \pm SD de al menos tres experimentos independientes. (B) Para medir la muerte celular las células fueron analizadas por citometría de flujo mediante la tinción de Anexina-V, en comparación con el control a las $72 \mathrm{~h}$ en medio con L-Arg. Los datos corresponden a la media \pm SD de al menos tres experimentos independientes. 


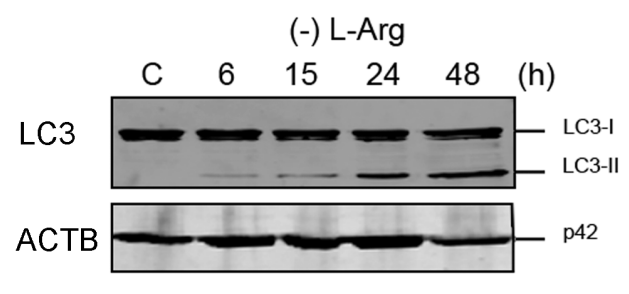

(-) L-Arg + CQ

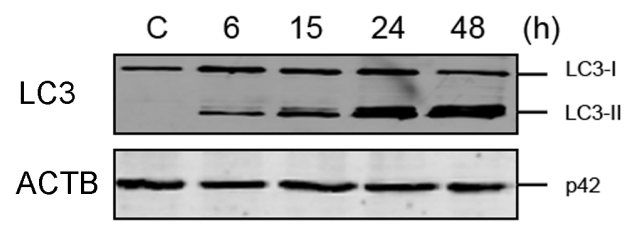

(-) L-Arg + SP600125

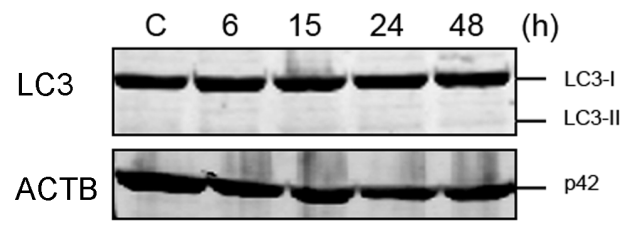

(-) L-Arg + U0126

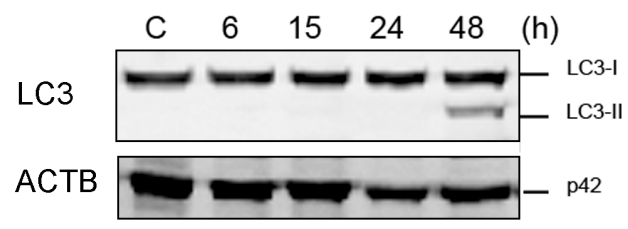

Figura I-14 Inhibidores de JNK y ERK1/2 inhiben el flujo autofágico en células Jurkat limitando la formación de LC3II. Células Jurkat fueron cultivadas en medio con L-Arg y con el inhibidor de JNK (SP600125, $10 \mu \mathrm{M}$ ) y el inhibidor de ERK1/2 (U0126, $10 \mu \mathrm{M}$ ) durante 1 hora, luego las células fueron lavadas y resuspendidas en medio sin L-Arg, con los inhibidores SP600125 y U0126. Para observar la formación de LC3-II, se utilizaron extractos de proteínas totales y se analizaron por Western blot utilizando los anticuerpos específicos para las proteínas indicadas. Se utilizaron las células Jurkat cultivadas en medio sin L-Arg y con el inhibidor del la formación del autofagolisosoma $(\mathrm{CQ}, 10 \mu \mathrm{M})$, como controles del flujo autofágico. Se ha utilizado ACTB como control de carga. Los datos corresponden a un ensayo representativo de al menos tres experimentos independientes.

Quisimos analizar el efecto de la inhibición de JNK y ERK1/2 en la conversión de LC3-I a LC3-II en ausencia de L-Arg. Nuestros resultados mostraron que la preincubación con SP600125 impedía la formación de LC3-II (Figura I-14), mientras que el inhibidor U0126 no parecía tener un efecto tan marcado en cuanto a la formación de LC3-II (Figura I-14). Así pues, nuestros resultados indican que la inhibición en la ruta JNK tiene un efecto directo en la formación de los autofagosomas, mientras que la inhibición de la ruta ERK permite en menor grado la formación de LC3-II, aunque no se refleja directamente en el flujo autofágico.

\section{I.6. La autofagia inducida por la ausencia de L-Arg protege a las células T de la apoptosis}

Hemos observado que la ausencia de L-Arg induce la activación de señales de estrés del RE como la fosforilación de eIF2 $\alpha$ (Figura I-1) y el procesamiento de XBP1 (Figura I-5). Estas rutas promueven mecanismos de supervivencia, como la activación del proteasoma (Figura I-7) y de la autofagia (Figura I-10). Además, la inhibición de las rutas JNK y ERK inducen muerte celular por apoptosis (Figura I-13). Así pues, quisimos determinar si inhibidores específicos de la formación de los autofagosomas como 3-metiladenina (3-MA) y wortmanina (WM), ambos 
inhibidores de PI3K; así como inhibidores de la fusión del autofagosoma con los lisosomas como cloroquina (CQ) y bafilomicina A1, eran capaces de inducir muerte celular.

Se detectó un aumento en la población de células positivas para anexina-V (Figura I-15A), además de la activación de la caspasa-3 y la escisión de su sustrato PARP1 (Figura I-15B) para todos los inhibidores. El bloqueo de las etapas iniciales de la autofagia (3-MA ó WM) inhibió el procesamiento de LC3-I a LC3-II. Mientras que la inhibición tardía de la autofagia (CQ o BF) indujo la acumulación de LC3-II (Figura I-15B). Quisimos determinar si la ausencia de L-Arg en células Jurkat era capaz de activar marcadores de la apoptosis dirigida por la respuesta UPR como CHOP, caspasa-4, caspasa-8 y la escisión de su sustrato Bap31241. Observamos que tanto la inhibición inicial (3-MA o WM), como la tardía (CQ o BF) de la autofagia inducen la regulación positiva de CHOP, la activación de caspasa-4, caspasa-8 y la escisión de Bap31. Todos estos datos indican que, independientemente de la fase en la que se inhiba la autofagia, las células Jurkat desarrollan muerte celular apoptótica posiblemente por la señalización UPR.

A

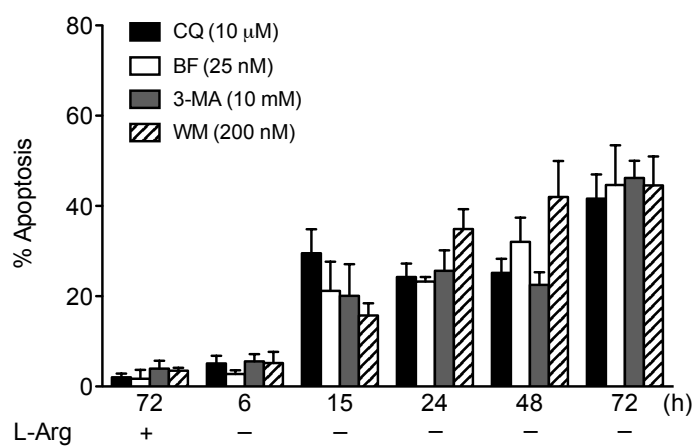

Figura I-15. La inhibición farmacológica de la autofagia en células Jurkat induce apoptosis. (A) Las células fueron pretratadas durante $1 \mathrm{~h}$ con inhibidores indicados en medio con L-Arg. Transcurrido el pretratamiento se cultivaron en medio sin L-Arg con los inhibidores durante $72 \mathrm{~h}$. Se ha utilizado como control $(\mathrm{C})$ células Jurkat cultivadas con L-Arg y los inhibidores por $72 \mathrm{~h}$. En los tiempos indicados las células se tiñeron con anexina V. Se determinaron las poblaciones Anexina V-positivas por citometría de flujo, representando el porcentaje de la apoptosis. Los datos se representan como medias $\pm \mathrm{SD}$ de 3 experimentos independientes. (B) Las células tratadas con los respectivos inhibidores se analizaron por Western blot para determinar la expresión de CHOP, LC3, la activación de caspasa-3, caspasa-4 y caspasa-8, así como para la escisión de PARP y BAP31. Las células Jurkat identificadas como control (C), se incubaron durante $72 \mathrm{~h}$ en medio sin L-Arg en ausencia de los inhibidores. Los datos corresponden a un ensayo representativo de al menos tres experimentos independientes. Se utilizó ACTB como control de carga. 
Otra aproximación experimental para inhibir directamente la autofagia consiste en bloquear la expresión de genes claves en el proceso de formación de los autofagosomas como Beclin-1 y ATG $7^{147}$. Utilizando RNA de interferencia (siRNA) se silenciaron transitoriamente los genes Beclin-1 y ATG7 (Figura I-16 A y B). El silenciamiento de estos genes fue capaz de bloquear el flujo autofágico y la formación de LC3-II en células Jurkat transfectadas con el plásmido EGFP-LC3 y cultivadas en medio sin L-Arg (Figura I-16C y E). Así mismo la inhibición de la autofagia por el silenciamiento de Beclin-1 y ATG7 indujo una respuesta del tipo apoptótica caracterizada por el aumento de células positivas para anexina-V (Figura I-16D) y de la expresión de CHOP, además de la activación de caspasa-3 y la escisión de su sustrato PARP1 (Figura I-16E). Estos datos confirman los resultados obtenidos con la inhibición farmacológica (Figura I-15) e indican que la autofagia contribuye a la supervivencia celular después del estrés de retículo causado por la ausencia de L-Arg.

A
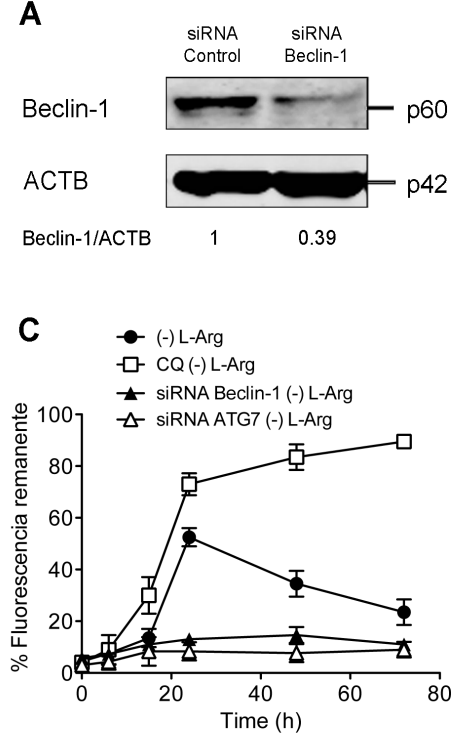

E

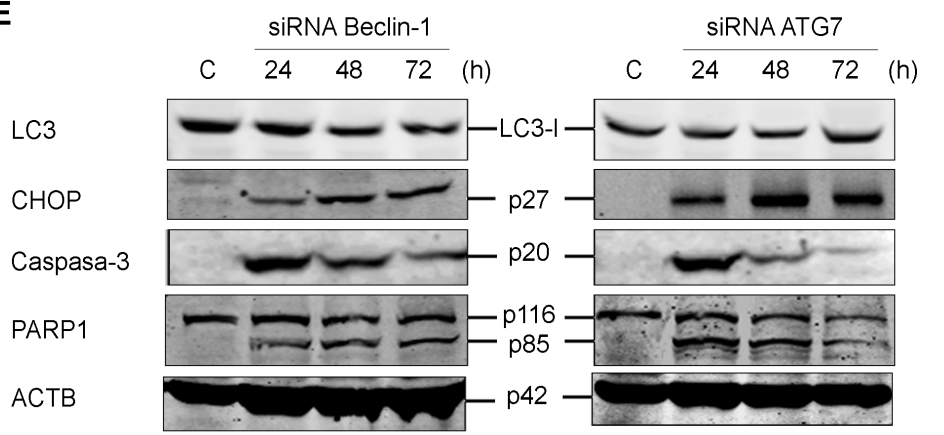

B

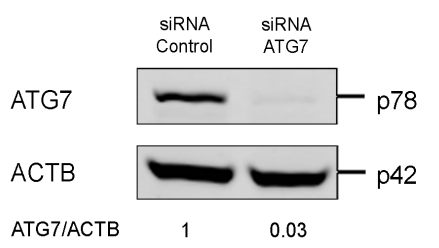

D

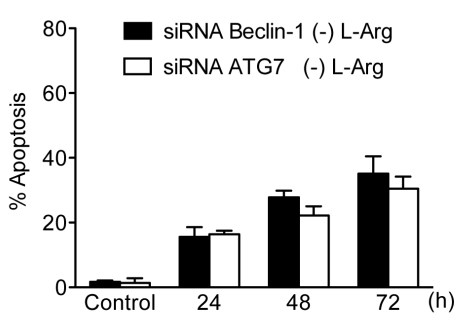

Figura I-16. La inhibición genética de la autofagia en células Jurkat induce apoptosis en ausencia de LArg. (A y B) Células Jurkat fueron transfectadas transitoriamente con siRNA control y específico para Beclin-1 y ATG7. (C) Para evaluar el flujo autofágico, se utilizaron células Jurkat-EGFP-LC3 transfectadas transitoriamente con siRNA específicos para Beclin-1 y ATG7. A las $24 \mathrm{~h}$ después de la transfección, las células se incubaron en medio sin L-Arg y se analizó el flujo autofágico por citometría de flujo. Los datos se representan como el porcentaje de fluorescencia remanente después del lavado con saponina $(0,05 \%)$. (D) La muerte celular se analizó mediante citometría de flujo por tinción con anexina $\mathrm{V}$, cultivando las células $24 \mathrm{~h}$ después de la transfección en medio con y sin L-Arg durante $72 \mathrm{~h}$. (E) Mediante Western blot se analizó la expresión de las proteínas LC3, CHOP, caspasa 3 y PARP1. Se utilizó ACTB como control de carga en A, B y E. Los datos mostrados corresponden a la media $\pm \mathrm{SD}$ de al menos tres repeticiones $\left(\mathrm{C}_{\text {y }} \mathrm{D}\right)$, ó un experimento representativo de tres ensayos independientes (A, B y E). 


\section{I.7. La ruta de señalización de IRE1 $\alpha$ en células $T$ humanas es necesaria para la activación de la autofagia inducida por L-Arg}

En células de mamíferos, IRE1 $\alpha$, PERK y ATF6 son los sensores encargados de detectar la presencia de proteínas desplegadas en el lumen del RE y activar los mecanismos necesarios para restablecer las funciones del RE. Después de la inducción de estrés de RE la ruta que se activa más rápidamente es la dirigida por la quinasa PERK. La quinasa residente del retículo endoplásmico PERK fosforila al factor de transcripción eIF2 $\alpha$ para inhibir la síntesis de nuevas proteínas para prevenir su flujo al lumen del $\mathrm{RE}^{242}$. Sin embargo, nuestros experimentos revelan que el estrés de retículo inducido por la ausencia de L-Arg en células T no implica la activación de PERK, pero sí la activación de IRE1 $\alpha$ (Figura I-5) y la fosforilación de eIF2 $\alpha$ mediada por GCN2 (Figura I-1). Por estos motivos quisimos evaluar la importancia de ambas rutas en la autofagia inducida por la deficiencia de L-Arg en células Jurkat.

Las células Jurkat fueron transfectadas con siRNA control y específico para el silenciamiento de los genes IRE1 $\alpha$ y GCN2. Después de la transfección, las células fueron cultivadas en medio con y sin L-Arg durante 24 horas. El silenciamiento de IRE1 $\alpha$ (Figura I-17A) resultó en la inhibición de la fosforilación de JNK y Bcl-2, la formación de LC3-II y la no degradación de SQSTM1/p62 (Figura I-17C). El silenciamiento de IRE1 $\alpha$ también inhibió el splicing de XBP1 (Figura I-17E). En contraste, el silenciamiento de GCN2 (Figura I-17B) no afectó a la formación de los autofagosomas ni al flujo autofágico, ya que observamos la formación de LC3-II y la degradación de SQSTM1/p62 (Figura I-17D). Cuando las células Jurkat se cultivaron en medio sin L-Arg, la fosforilación PERK apenas fue detectada. Sin embargo, en las células con el silenciamiento de GCN2 observamos una potente fosforilación de PERK (Figura I-17D). Estos datos indican que PERK podría actuar como una ruta alternativa a GCN2 en la activación de eIF2 $\alpha$. Además, la regulación negativa de IRE1 $\alpha$, pero no de GCN2, induce un aumento de la muerte celular por apoptosis (Figura I-17F). En conjunto nuestros resultados sugieren que la ruta IRE1 $\alpha$ es esencial para contrarrestar el estrés de retículo inducido por la ausencia de L-Arg, ya que IRE1 $\alpha$ es necesaria en los pasos iniciales de la autofagia, como lo es la activación de JNK y la consecuente escisión del complejo Bcl-2/ Beclin-1 por la fosforilación de Bcl-2. 
A

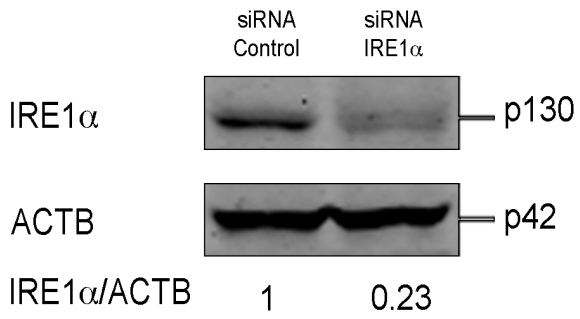

C

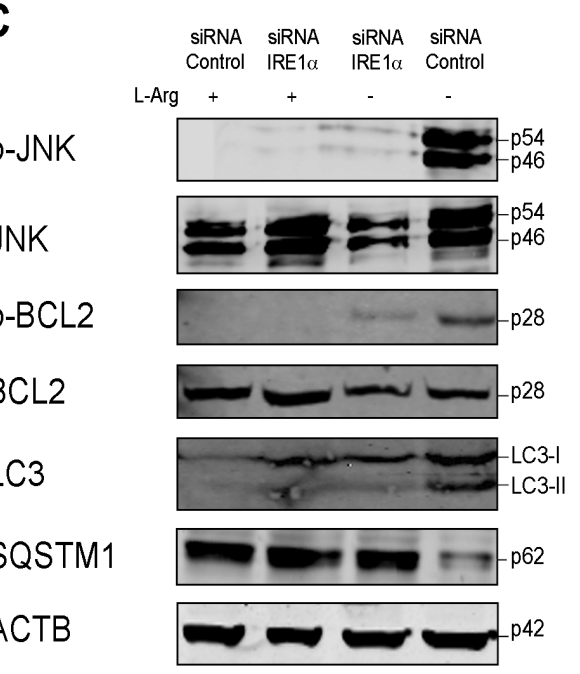

E

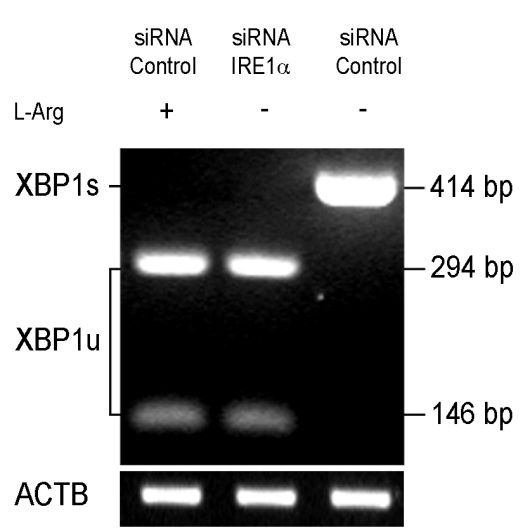

B
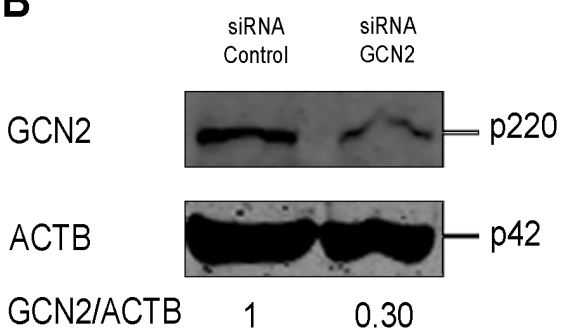

D

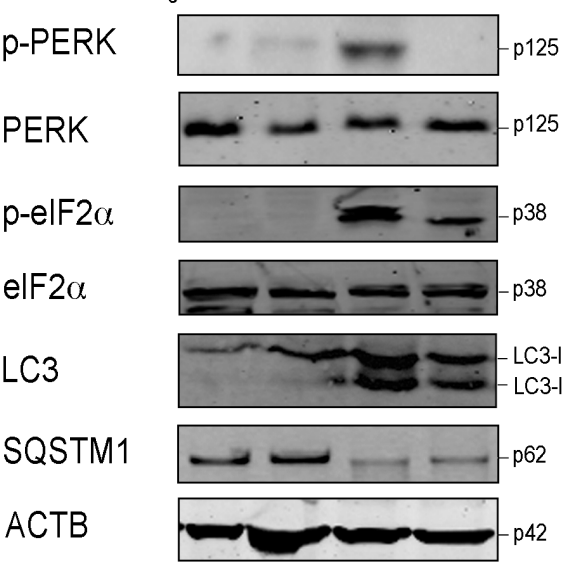

p-elF $2 \alpha$

elF2 $\alpha$

LC3

SQSTM1

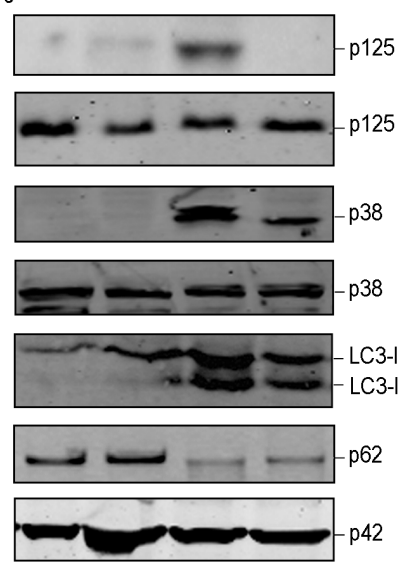
L-Arg +

F

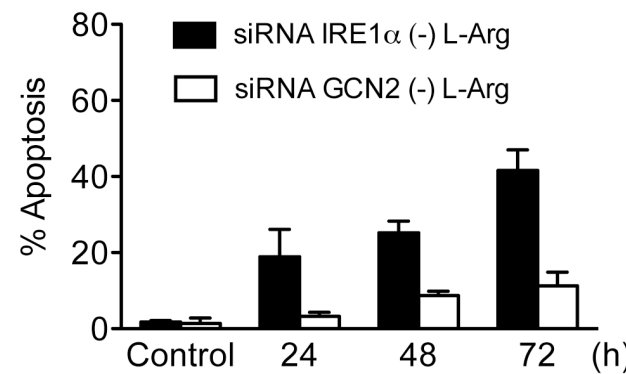

Figura I-17. El silenciamiento de IRE1 a pero no el de GCN2, inhibe la autofagia inducida por la ausencia de L-Arg en las células Jurkat induciendo apoptosis. (A y B) Células Jurkat fueron transfectadas transitoriamente con $50 \mathrm{nM}$ de siRNA control y específicos para IRE1a y GCN2. El silenciamiento fue verificado por Western blot respectivamente. (C y D) Las células Jurkat transfectadas fueron cultivadas con o sin L-Arg durante $24 \mathrm{~h}$, y analizadas por Western blot para verificar la expresión de las proteínas indicadas. Se utilizó ACTB como control de carga. (E) 24 horas después de la transfección se amplificó por PCR el gen XBP1, los fragmentos de PCR fueron digeridos con la enzima de restricción PstI. Sólo el cDNA correspondiente al XBP1s mRNA no posee el sitio de corte para la enzima PstI, debido a la pérdida de un intron de $26 \mathrm{pb}$ en respuesta a estrés de retículo. Los datos corresponden a un ensayo representativo de al menos tres experimentos independientes. Se indican las posiciones de los productos de amplificación de XBPlu y XBP1s. La expresión de ACTB se utilizó como control de carga. (F) 24 h después de la transfección, las células se incubaron en medio con y sin L-Arg durante $72 \mathrm{~h}$ y mediante citometría de flujo se cuantificó el porcentaje de células apoptóticas Los datos mostrados corresponden a la media \pm SD de tres experimentos $(F)$ o experimentos representativos de tres ensayos realizados (A-E). 


\section{I.8. Ausencia de L-Met y L-Tyr induce estrés de retículo endoplásmico y autofagia como mecanismo de supervivencia en células Jurkat}

La autofagia es una importante vía catabólica intracelular que participa en diversos eventos biológicos incluyendo deficiencia de aminoácidos y proteínas, recambio de orgánulos, desarrollo, envejecimiento, infección por patógenos y muerte celular. La proteolisis mediada por la autofagia es el único mecanismo regulado directamente por requerimientos nutricionales $^{243}$. Quisimos determinar el efecto de otros aminoácidos en la inducción de autofagia en células T. Cultivamos células Jurkat EGFP-LC3 en medio con carencia de un aminoácido cada vez, durante 48 horas. A las 24 y 48 horas, se evaluó el flujo autofágico mediante citometría de flujo antes y después del lavado con saponina al 0,05\%. Observamos que además de la falta de L-Arg, la ausencia de los aminoácidos L-His, L-Leu, L-Met, L-Phe, LTrp y L-Tyr también inducían significativamente la formación y posterior degradación de LC3II (Figura I-18) indicando que al igual que la ausencia de L-Arg, la falta de estos aminoácidos es capaz de inducir autofagia.

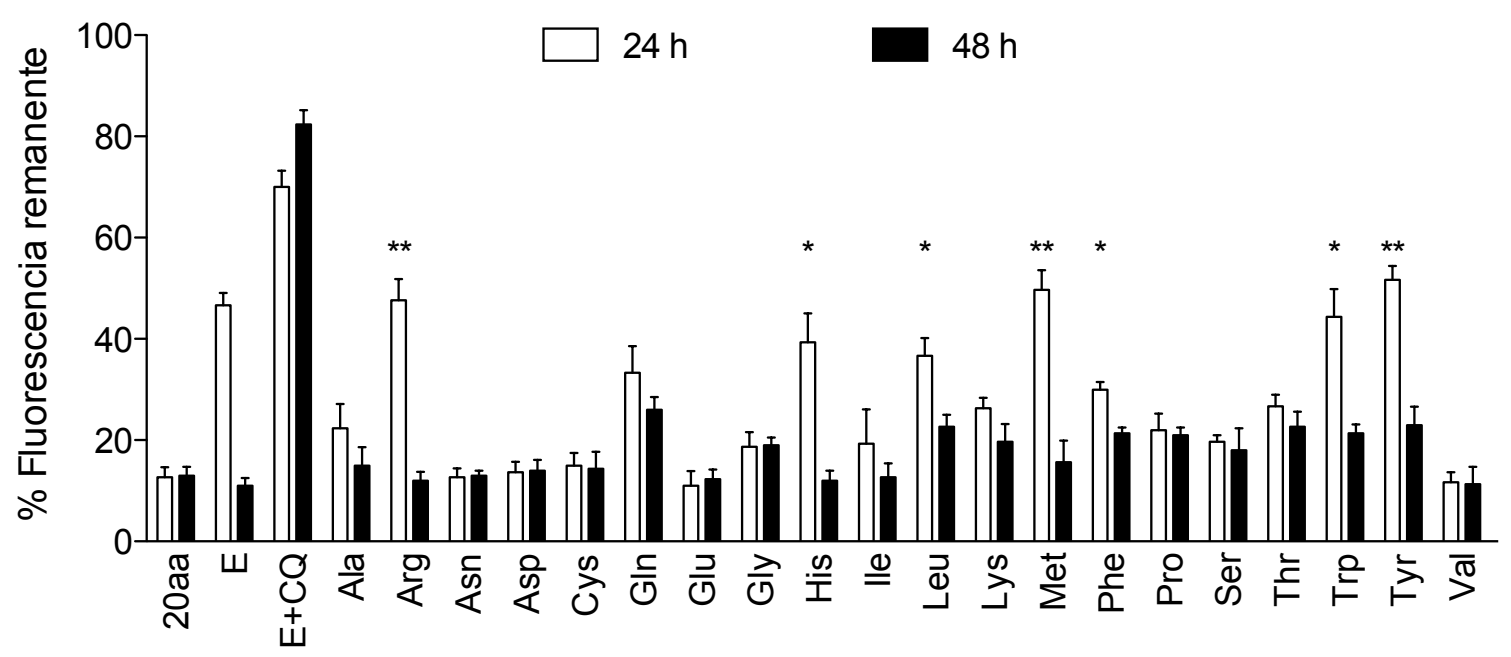

Figura I-18. La ausencia de L-His, L-Leu, L-Met, L-Phe, L-Trp y L-Tyr induce autofagia en células Jurkat. Para medir el flujo autofágico las células Jurkat transfectadas con el plásmido GFP-LC3 fueron cultivadas en medio completo (20aa), en medio sin aminoácidos $(\mathrm{E})$, en medio sin aminoácidos y Cloroquina $(10 \mu \mathrm{M})(\mathrm{E}+\mathrm{CQ})$ y en medios donde faltaba sólo el aminoácido indicado. Las células fueron analizadas por citometría de flujo. Los datos se presentan como porcentaje de fluorescencia total después del lavado con saponina. Los datos del porcentaje de fluorescencia corresponden a la media \pm SD de al menos tres experimentos independientes. En los aminoácidos indicados con asterisco se observa diferencia significativa en la disminución de la fluorescencia entre las $24 \mathrm{~h}$ y las $48 \mathrm{~h}$ con respecto al medio completo. * $\mathrm{p}<0,05 ; * * \mathrm{p}$ $<0,01$ 
Posteriormente, estudiamos si la ausencia de estos aminoácidos tenía la capacidad de inducir la actividad de IRE1 $\alpha$. Se cultivaron las células en medio sin los respectivos aminoácidos. A las 24 horas de cultivo se extrajo el RNA y se amplificó el cDNA correspondiente al gen XBP1 mediante RT-PCR. Los productos de PCR fueron analizados por restricción enzimática con la enzima PstI. Solamente la ausencia de L-Arg, L-Met y L-Tyr inducía el splicing de XBP1 (Figura I-19). Esto sugiere que la capacidad de inducir estrés de RE y autofagia no es una respuesta general a la restricción de cualquier aminoácido y que las células tienen una capacidad diferencial para desencadenar este tipo de respuesta.

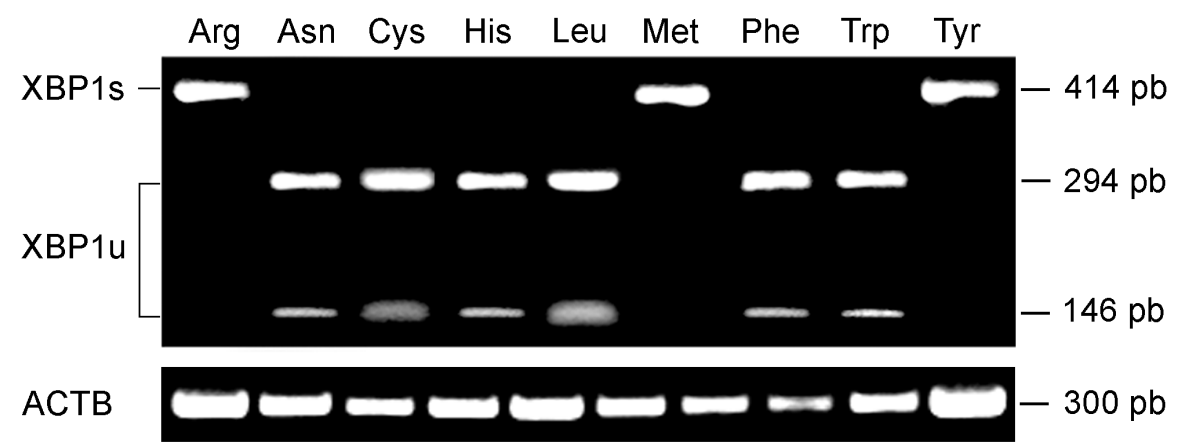

Figura I-19. Ausencia de L-Met y L-Tyr induce splicing de $X B P 1$ en células Jurkat. Células Jurkat fueron cultivadas en medio con y sin L-Arg. Se utilizaron cebadores específicos para el gen XBP1 y los fragmentos de PCR resultantes fueron digeridos con la enzima de restricción PstI. Sólo el cDNA correspondiente al XBP1s mRNA no posee el sitio de corte para la enzima $P s t \mathrm{I}$, debido a la perdida de un intrón de 26 pb en respuesta a estrés de retículo. Los datos corresponden a un ensayo representativo de al menos tres experimentos independientes.

\section{I.9. El restablecimiento de L-Arg restaura la proliferación celular y la expresión de antígenos e inhibe la autofagia inducida por la deficiencia de}

\section{L-Arg}

Con la finalidad de evaluar si los efectos observados en las células Jurkat por la ausencia de L-Arg eran reversibles, se cultivaron las células durante 72 horas en medio sin LArg. Después de las 72 horas de cultivo, las células fueron resuspendidas en medio RPMI-1640 completo. Posteriormente, evaluamos la expresión de los antígenos de membrana, el ciclo y la proliferación celular y la autofagia. Observamos que después de 96 horas en medio completo, las células Jurkat recuperan la expresión de los antígenos de membrana (Figura I-20A), así como el perfil de distribución ciclo celular (Figura I-20B), y su capacidad de proliferación (Figura I-20C). Además, observamos una disminución del patrón punteado del LC3-II característico de la formación de los autofagosomas (Figura I-20D), y de la conversión de LC3- 
I a LC3-II por Western blot (Figura I-20E). Estos resultados indican que la autofagia inducida por la ausencia de L-Arg es un proceso reversible que no induce apoptosis en células T.

A

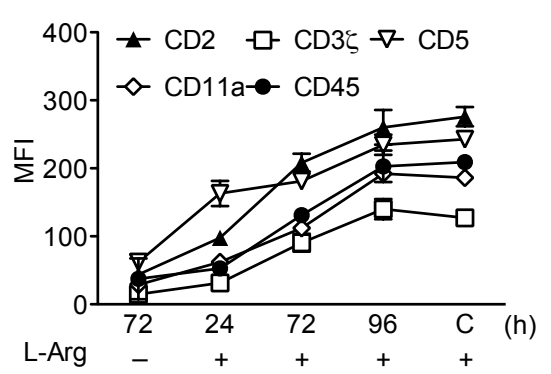

C

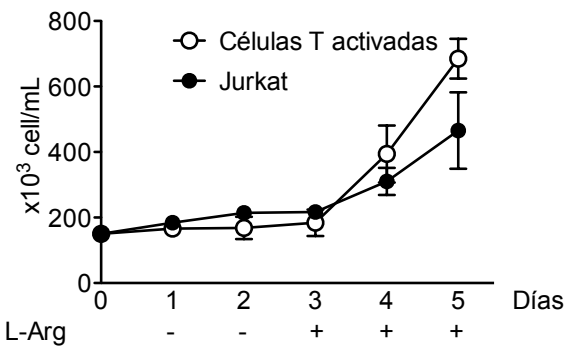

E

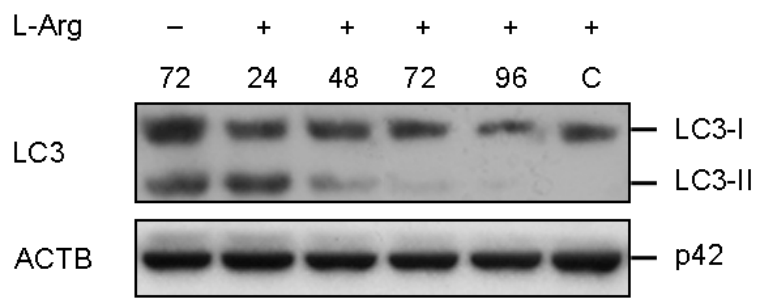

B

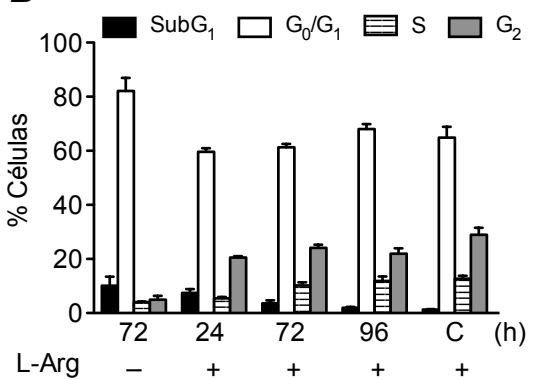

D
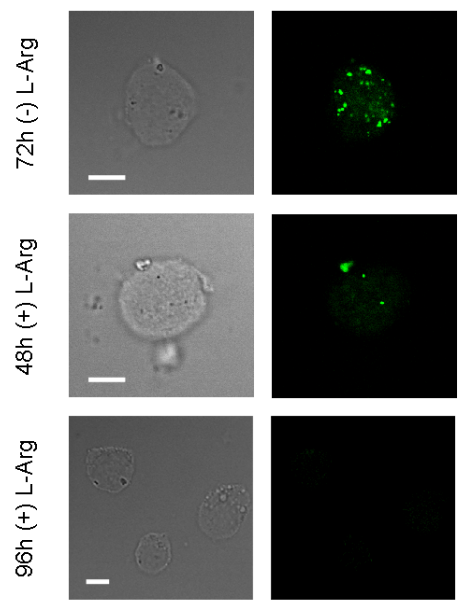

高

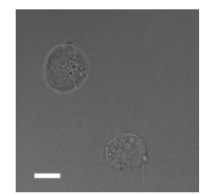

DIC

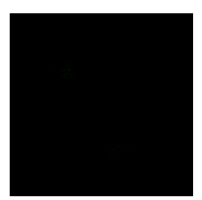

LC3

Figura I-20. La restitución de L-Arg restaura la expresión de antígenos de la membrana, el perfil del ciclo celular y la proliferación celular. (A, B) Células Jurkat incubadas en medio sin L-Arg durante $72 \mathrm{~h}$ fueron resuspendidas en medio con L-Arg y cultivadas durante los tiempos indicados. La expresión de los antígenos de membrana se restableció a las 96 h de cultivo, al igual que el ciclo celular. (C) Para examinar la proliferación se determinó la concentración celular de cada cultivo en los tiempos indicados mediante el recuento de células con Trypan blue. La formación de los autofagosomas se determinó por microscopía confocal utilizando células Jurkat-EGFP-LC3 (D), y por Western blot a través de la conversión de LC3-I a LC3-II (E). La barra de escala: $10 \mu \mathrm{m}$. Los datos mostrados en A-G corresponden a las medias \pm SD de tres experimentos independientes. Los datos mostrados en D y E son representativos de tres experimentos realizados. 


\section{Participación de la arginasa I en la muerte de células tumorales mediada por neutrófilos}

\section{1. La arginasa de neutrófilos induce apoptosis en células tumorales}

Las células tumorales suelen poseer modificaciones importantes en el metabolismo de macromoleculas como carbohidratos, lípidos, ácidos nucleicos y aminoácidos para satisfacer sus demandas energéticas durante la proliferación celular ${ }^{244}$. La dependencia de fuentes exógenas de aminoácidos esenciales y no esenciales es una de las modificaciones metabólicas más comunes en neoplasias malignas ${ }^{245}$. Ciertos tipos de cáncer como la leucemia linfoblástica aguda, el linfoma no-Hodgkin y el cáncer de ovario no pueden sintetizar la L-asparagina y dependen de su absorción para la proliferación celular $246-248$. Los neuroblastomas humanos, algunos tipos de hepatomas y cáncer de pulmón dependen de los niveles extracelulares de Lmetionina para el crecimiento celular ${ }^{249}$. Algunos tipos de melanomas y cáncer de próstata dependen de la incorporación de L-tirosina y L-fenilalanina para la proliferación celular ${ }^{245,250}$. La proliferación en la mayoría de los hepatomas depende de la incorporación de L-glutamina y L-leucina ${ }^{251,252}$. Además, ciertas leucemias, una fracción considerable de melanomas metastásicos, carcinomas hepatocelulares y pancreáticos muestran auxotrofía para la LArg $71,253-257$. Conociendo las deficiencias metabólicas en cuanto a la disponibilidad de aminoácidos para algunos tipos tumorales, se han planteado estrategias terapéuticas en donde se utilizan enzimas que degradan aminoácidos necesarios para la proliferación de las células tumorales. El caso más conocido de este tipo de terapia es la utilización de asparaginasa en el tratamiento de la leucemia linfoblástica aguda infantil ${ }^{246}$. Dada la importancia de la disponibilidad de L-Arg para la activación y proliferación de células $\mathrm{T}$ y de algunos tipos tumorales, quisimos estudiar si la degradación de L-Arg mediante la enzima ARG1 podía actuar como agente potenciador de la apoptosis en células tumorales.

Los neutrófilos humanos expresan constitutivamente grandes cantidades de ARG1 y pueden utilizarla como mecanismo antifúngico ${ }^{13}$. Los neutrófilos comprenden la población más abundante de leucocitos en sangre, representando un $\sim 60 \%$ de todos los leucocitos circulantes. Son las primeras células en reclutarse en los focos de infección fagocitando microorganismos y liberando moléculas efectoras. Muchos tumores surgen de sitios de infección o inflamación crónica persistente que contienen un número elevado de leucocitos y factores que estimulan la proliferación celular, la supervivencia, la migración, la remodelación 
de la matriz extracelular y la neovascularización ${ }^{258,259}$. Sin embargo, un tipo de neutrófilos asociado a tumores (denominado N1) pueden favorecer la respuesta inmune contra el tumor, limitar la proliferación celular e inducir apoptosis en las células tumorales ${ }^{70}$.

Para determinar como afecta la actividad de la enzima ARG1 de neutrófilos a la proliferación de células tumorales, generamos la proteína recombinante de neutrófilos GSTARG1. La proteína resultante posee un peso aproximado de $66 \mathrm{kDa}$ (Figura II-1A). Se comparó la especificidad del anticuerpo policlonal anti-ARG1, cedido por el Dr. M. Munder (Universidad de Heidelberg, Alemania) contra la proteína nativa de los neutrófilos así como contra la recombinante y no observamos diferencias significativas (Figura II-1B).

A

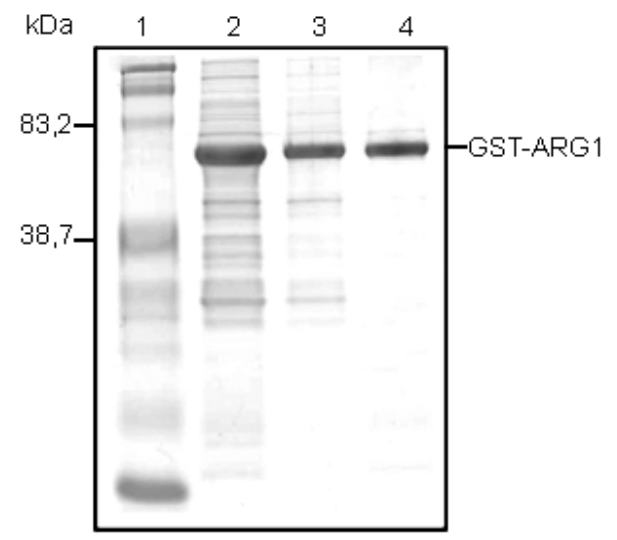

B

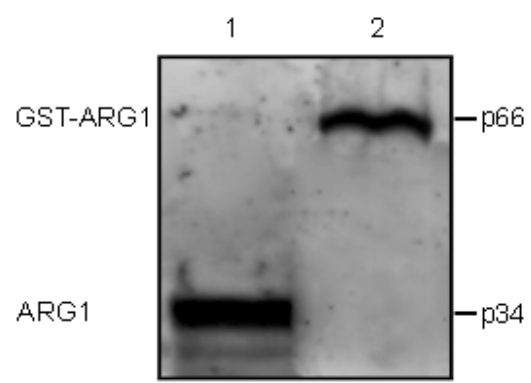

Figura II-1. La proteína recombinante de neutrófilos GST-ARG1 es reconocida por el anticuerpo policlonal. (A) Mediante PCR se amplificó el gen correspondiente a la proteína de neutrófilos ARG1, el producto fue clonado y sobreexpresado en E.coli. Por SDS-PAGE se verificó la purificación de la proteína GST-ARG1 (66kDa). Carril 1: Marcador de peso molecular; Carril 2: extracto total de proteínas; Carril 3: primera purificación con esferas de glutationsefarosa B; Carril 4: segunda purificación con esferas de glutation-sefarosa B. (B) Por Western blot se verificó la capacidad del anticuerpo policlonal anti-ARG1 para reconocer tanto a la proteína nativa procedente de extractos celulares de neutrófilos (Carril 1, $30 \mu \mathrm{g}$ proteínas totales) como a la proteína recombinante GST-ARG1 (Carril 2, $5 \mu \mathrm{g}$ de la segunda purificación). Los datos corresponden a un ensayo representativo de al menos tres experimentos independientes.

Evaluamos la actividad in vitro de la enzima recombinante GST-ARG1, midiendo la producción de urea a partir de L-Arg. Comparamos la actividad de la GST-ARG1 con respecto a la ARG1 presente en extractos de proteínas totales de neutrófilos (EPT-N). La actividad arginasa se determinó como se describe en materiales y métodos, utilizando $45 \mu \mathrm{g}$ del extracto proteínas totales de neutrófilos y $10 \mu \mathrm{g}$ de la proteína GST-ARG1. Observamos que la capacidad de la proteína recombinante GST-ARG1 para producir urea a partir de L-Arg no se veía afectada por la cola de GST (Figura II-2). 


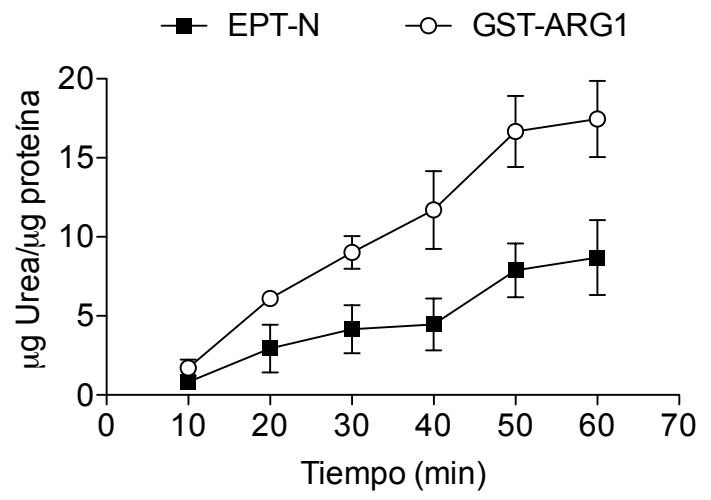

Figura II-2. Actividad arginasa de la proteína recombinante de neutrófilos GSTARG1 y la ARG1 presente en extractos de proteínas totales de neutrófilos (EPT-N). Se cuantificó los $\mu \mathrm{g}$ de urea producidos por $\mu \mathrm{g}$ de proteína cada diez min hasta un total de 60 min para ambos extractos protéicos. Los datos corresponden a la media $\pm \mathrm{SD}$ de tres experimentos independientes.

Quisimos evaluar el efecto de la enzima ARG1 de neutrófilos en la proliferación y muerte celular de líneas de diferentes tipos tumorales humanas como HeLa (cuello uterino), HEP-G2 (hígado), SF268 y T98G (sistema nervioso central). Con esta finalidad realizamos una curva dosis-respuesta de GST-ARG1 partiendo de una actividad de $1000 \mathrm{mU} / \mathrm{ml}$, haciendo diluciones seriadas 1:2 hasta 1,95 mU/ml. Para todas las líneas celulares estudiadas observamos una disminución en la proliferación celular al co-cultivarlas con la enzima recombinante GSTARG1 (Figura II-3A). A partir de los resultados anteriores, seleccionamos la dosis de $300 \mathrm{mU} /$ ml de GST-ARG1 para determinar el porcentaje de apoptosis ya que a esta concentración observamos una disminución de la proliferación celular en todas las líneas analizadas. Las células fueron cultivadas durante 24 horas en presencia o ausencia de GST-ARG1 y se analizaron por citometría de flujo las células positivas para anexina-V. Observamos que a las 24 h de cultivo todas las líneas tratadas con GST-ARG1 presentaban más de un 20\% de células apoptóticas en comparación con el control (Figura II-3B). Nuestros resultados sugieren que las líneas celulares estudiadas son sensibles al agotamiento de L-Arg por la GST-ARG1, lo que resulta en la muerte celular por apoptosis.

Con el fin de determinar qué tipos tumorales son más sensibles a la actividad arginasa determinamos la actividad de la enzima GST-ARG1 necesaria para inhibir el 50\% del crecimiento $\left(\mathrm{IC}_{50}\right)$ en tres líneas celulares de cáncer de páncreas y en el panel de 60 líneas celulares del Instituto Nacional del Cáncer de EEUU (NCI-60). El panel NCI-60 es ampliamente utilizado en el desarrollo de nuevos fármacos con acción antitumoral y comprende 60 líneas tumorales humanas de leucemia, melanoma, cáncer de pulmón, colon, cerebro, ovario, mama, próstata y riñón ${ }^{260}$. Realizamos una curva dosis respuesta partiendo de una actividad de $1000 \mathrm{mU} / \mathrm{ml}$ con diluciones seriadas 1:2 hasta 1,95 mU/ml. Los experimentos fueron realizados por triplicado experimental en dos ensayos independientes y la proliferación 
A

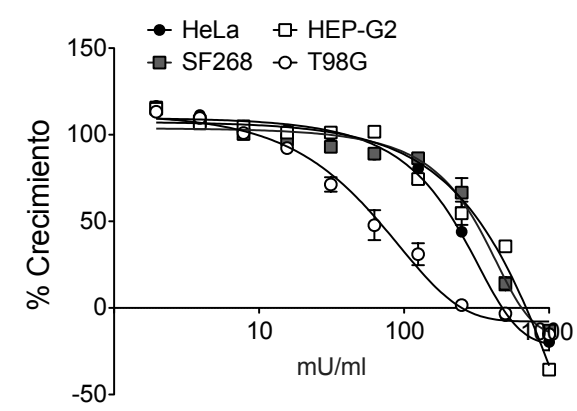

B

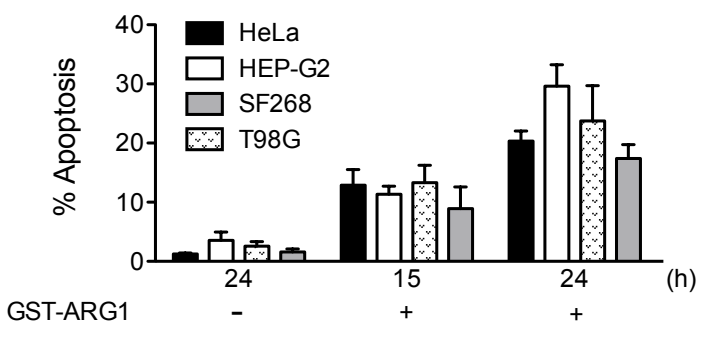

Figura II-3. Efecto de la actividad arginasa de la GST-ARG1 sobre la proliferación y muerte celular de líneas tumorales. (A) Se realizó una curva dosis respuesta para la GST-ARG1 durante 72 horas, la proliferación celular fue determinada utilizando el kit XTT. (B) Para determinar la muerte celular las células fueron cultivadas en presencia o ausencia de 300 $\mathrm{mU} / \mathrm{ml}$ de GST-ARGl durante 24 horas. El porcentaje de células apoptóticas fue determinado por citometría de flujo. Los datos corresponden a la media \pm SD de tres experimentos independientes.

celular se determinó con el kit XTT a tiempo final de 72h. Los valores de $\mathrm{IC}_{50}$ obtenidos para cada subpanel se muestran en la Figura II-4. De los resultados obtenidos podemos observar que existen diferencias marcadas en la sensibilidad de los distintos tipos celulares al agotamiento de L-Arg por la actividad de la enzima GST-ARG1. En las líneas celulares de ovario, pulmón y páncreas más del 50\% de las líneas testadas presentan un $\mathrm{IC}_{50}$ menor de 400 $\mathrm{mU} / \mathrm{ml}$ indicando que son altamente sensibles a la deficiencia de L-Arg. En las líneas de mama se observa una disminución marcada en la proliferación celular a partir de las $500 \mathrm{mU} / \mathrm{ml}$ de GST-ARG1, siendo la línea MCF-7 la más sensible al agotamiento de L-Arg. Las líneas de cáncer de riñón y de piel presentan un perfil más heterogéneo en cuanto a la sensibilidad a la ausencia de L-Arg, con líneas muy sensibles (786-O y SK-MEL-5) y líneas muy resistentes (ACHN y SK-MEL-2). En las líneas celulares de colon, próstata y del sistema nervioso central (SNC) se observa una disminución de la proliferación menos evidente, donde sólo dos líneas celulares de cada subpanel poseía un IC 50 por debajo de las $500 \mathrm{mU} / \mathrm{ml}$. Las líneas celulares de leucemia parecen ser las menos sensibles al agotamiento de L-Arg ya que no se observó una disminución de la proliferación en ninguna de líneas celulares testadas.

A partir de estos resultados y utilizando la curva dosis respuesta de las líneas celulares más sensibles a la actividad arginasa de cada tipo tumoral, se determinó el $\mathrm{IC}_{80}$ (actividad que inhibe el $80 \%$ del crecimiento) y el TGI (Total Growth Inbibition) (Tabla II-1). Estas concentraciones se utilizaron para evaluar el efecto del agotamiento de L-Arg en la muerte celular por apoptosis. Las células fueron cultivadas durante 24 horas utilizando la 
concentración equivalente al IC 80 (Tabla II-1) tanto para GST-ARG1 como para la ARG1 presente en EPT-N.

Después del tratamiento con ambas enzimas las células fueron analizadas por citometría de flujo para cuantificar el aumento de poblaciones anexina- $V$ positivas. Observamos que tanto el EPT-N como la GST-ARG1 eran capaces de inducir apoptosis en todas las líneas celulares evaluadas (Figura II-5).
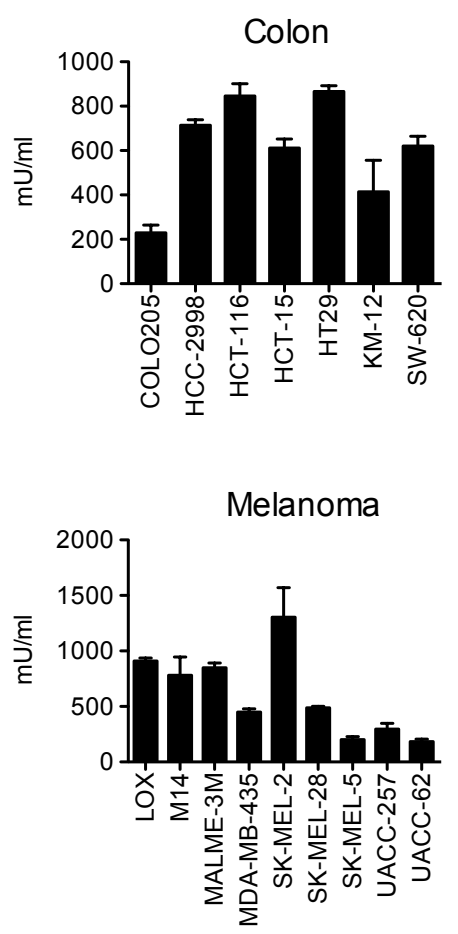

Renal

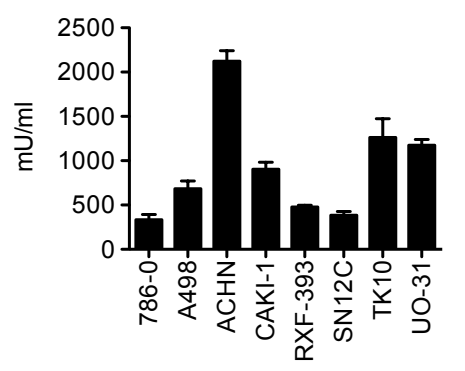

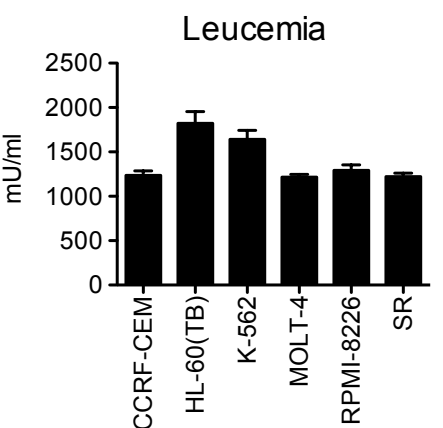

Ovario

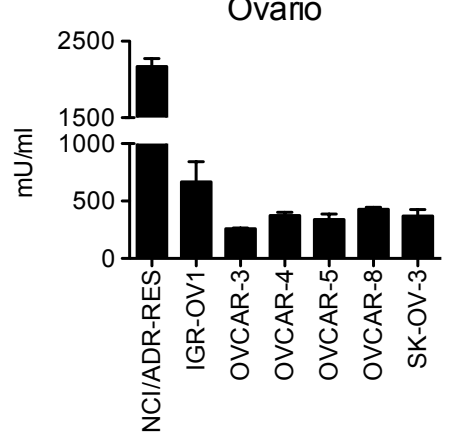

Próstata

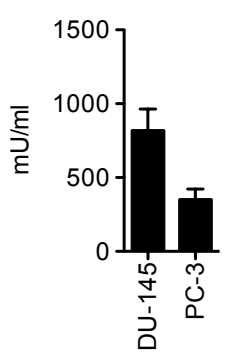

Páncreas

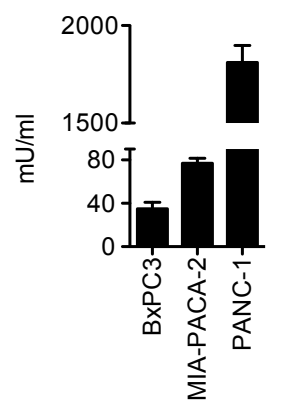

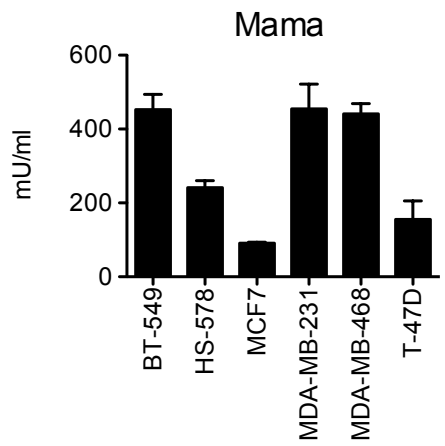

Pulmón

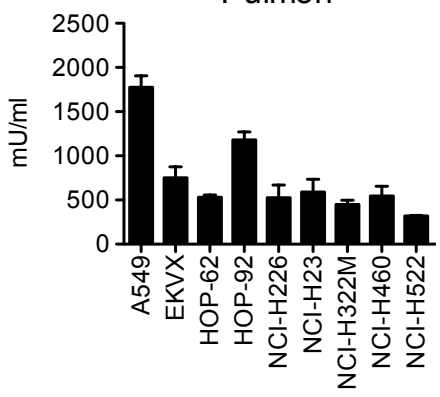

SNC

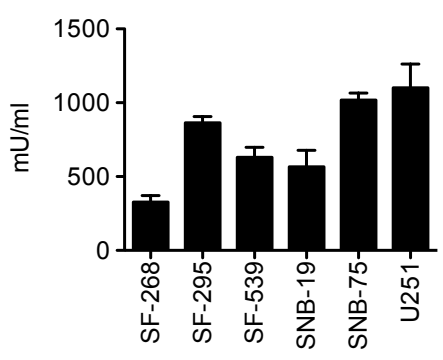

Figura II-4. Determinación del IC50 de GST-ARG1 en líneas celulares tumorales. Las líneas celulares señaladas fueron cultivadas con diferentes concentraciones de GST-ARG1. Después de 72 horas se determinó la proliferación celular con el kit XTT. Los datos corresponden a la media $\pm \mathrm{SD}$ de los valores de $\mathrm{IC}_{50}$ obtenidos para cada línea celular en dos experimentos independientes realizados en triplicado experimental. (SNC: Sistema Nervioso Central). 
Tabla II-1. Determinación del $\mathrm{IC}_{80}$ y TGI para la GST-ARG1 sobre las líneas celulares más sensibles al agotamiento de L-Arg.

\begin{tabular}{|l|c|c|}
\hline Línea Celular & IC $_{80}(\mathrm{mU} / \mathrm{ml})$ & TGI (mU/ml) \\
\hline COLO205 & 477 & 691,7 \\
\hline MCF7 & 163,5 & 200,4 \\
\hline SK-MEL-5 & 378,2 & 619,4 \\
\hline NCI-H522 & 469 & 686,9 \\
\hline OVCAR-3 & 493,6 & 724,1 \\
\hline PC3 & 494,3 & 732,2 \\
\hline 786-O & 473,4 & 714,5 \\
\hline SF268 & 471,4 & 758,3 \\
\hline BxPC3 & 84,9 & 104,6 \\
\hline HeLa & 373,2 & 476,1 \\
\hline
\end{tabular}

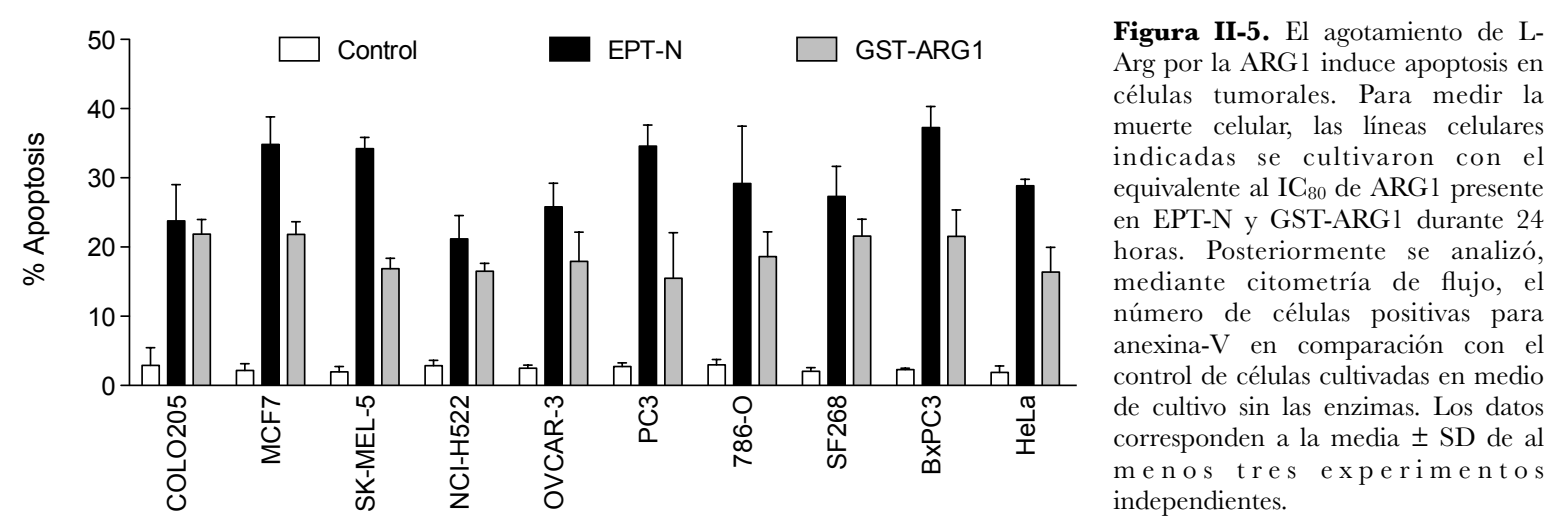

\section{2. La apoptosis inducida por ARG1 en células tumorales es inhibida por nor-NOHA}

Nuestros resultados indican que la disminución de la L-Arg por la enzima de neutrófilos ARG1 es capaz de inducir apoptosis en líneas celulares de distintos tipos tumorales. Sin embargo, un extracto de proteínas totales de neutrófilos posee componentes como ácido hipocloroso, proteasas y especies reactivas de oxígeno que pueden contribuir a la muerte celular $^{69,261}$. Por lo tanto quisimos determinar la importancia de la ARG1 en la muerte inducida por el EPT-N en las líneas celulares más sensibles a la actividad arginasa de cada tipo tumoral. Para ello, utilizamos un potente inhibidor reversible de ARG1 (nor-NOHA) ${ }^{262}$. Las líneas celulares fueron cultivadas durante 24 horas con EPT-N al $\mathrm{IC}_{80}$ de la actividad arginasa calculada para cada línea celular, en presencia o ausencia de nor-NOHA, y se calculó el 
porcentaje de apoptosis. El inhibidor de la enzima ARG1 nor-NOHA provocó la disminución de la apoptosis en todas las líneas celulares evaluadas (Figula II-7). Este resultado indica que la actividad de la ARG1 es el principal componente de la muerte mediada por EPT-N.

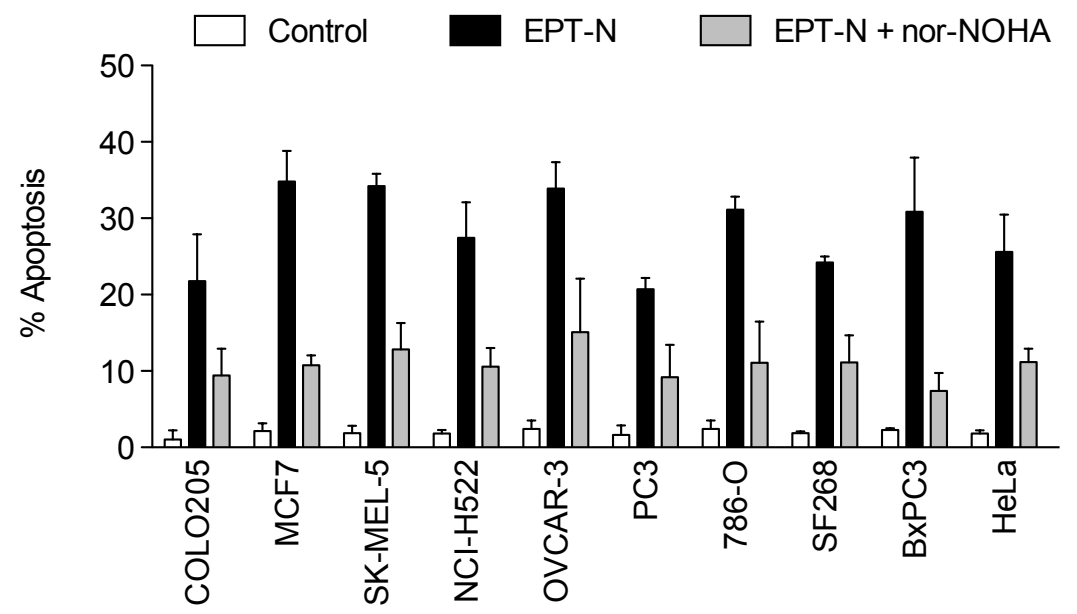

Figura II-7. La apoptosis inducida por EPT-N es inhibida parcialmente por nor-NOHA. Las líneas celulares indicadas se cultivaron con el equivalente al $\mathrm{IC}_{80}$ de ARG1 presente en EPT-N en presencia o ausencia del inhibidor nor-NOHA $(50 \mu \mathrm{M})$ durante 24 horas. Posteriormente fueron analizadas por citometría de flujo mediante la tinción de Anexina-V en comparación con el control de células. Los datos corresponden a la media \pm SD de al menos tres experimentos independientes.

\section{3. La liberación de ARG1 por la degranulación de neutrófilos induce apoptosis en células tumorales}

La utilización de EPT-N no es una estrategia fisiológica apropiada para implementar una herramienta terapéutica en el tratamiento del cáncer. Un mecanismo eficiente podría ser utilizar la propiedad de los neutrófilos para regular la liberación de la enzima ARG1 mediante exocitosis. Los neutrófilos contienen al menos cuatro tipos diferentes de gránulos: gránulos primarios o azurófilos; gránulos secundarios o específicos; gránulos terciarios y las vesículas secretoras. La exocitosis de gránulos y vesículas secretoras juega un papel importante en la mayoría de las funciones de los neutrófilos activados y en la destrucción temprana de los microorganismos fagocitados. Los gránulos de los neutrófilos contienen una multitud de sustancias antimicrobianas y potencialmente citotóxicas que se liberan al fagosoma o al exterior de la célula tras la consiguiente degranulación ${ }^{263-265}$. Una degranulación excesiva es una característica común de muchos trastornos inflamatorios, tales como episodios de asma, lesión pulmonar aguda, la artritis reumatoide y el choque séptico. Para atenuar la respuesta inflamatoria neutrofílica, una estrategia terapéutica eficaz sería aquella dirigida a la regulación de la degranulación de neutrófilos. El conocimiento de las vías de señalización que controlan la movilización de gránulos puede ser útil no solo en la búsqueda de dianas para la intervención 
farmacológica de la degranulación, sino también para regular la colaboración de los neutrófilos en procesos inflamatorios o invasivos, como el cáncer, sin afectar el tejido circundante ${ }^{266-269}$.

Partiendo de esta idea, realizamos estudios de exocitosis en neutrófilos utilizando diferentes moléculas que favorecen la degranulación. De este modo quisimos determinar cual es el estímulo capaz de liberar la mayor cantidad de ARG1 por exocitosis. Como activadores de la movilización de gránulos utilizamos fMLP, PMA y TNFa. Mediante Western blot detectamos la secreción de la enzima ARG1 (Figura II-8A) y determinamos el porcentaje de ARG1 liberado con cada estímulo, en comparación con la cantidad de ARG1 contenida en la fracción de neutrófilos en reposo (Figura II-8B). Observamos que el fMLP fue la molécula que generó una mayor liberación de ARG1.

A

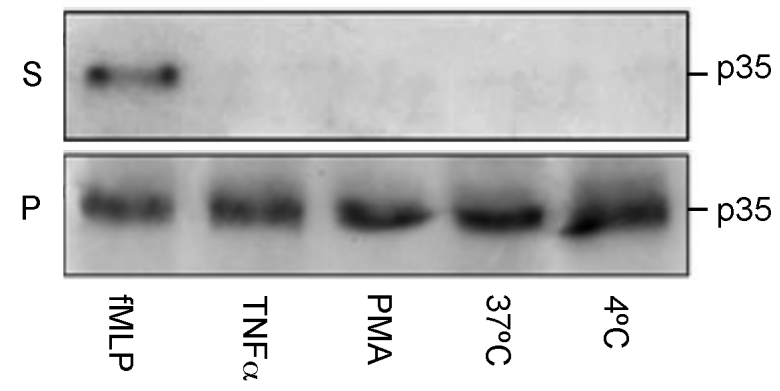

B

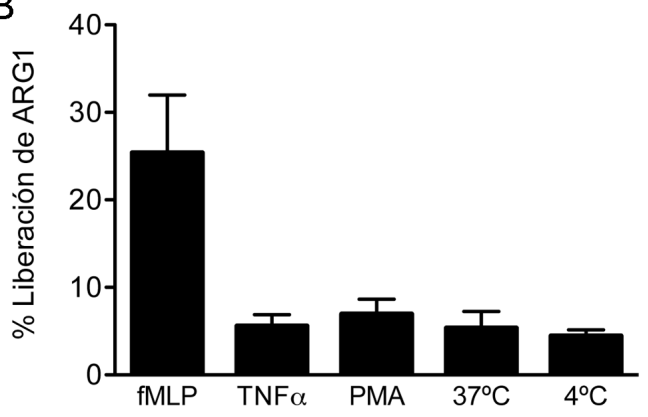

Figura II-8. ARG1 es secretada en neutrófilos activados. (A) 1 × $10^{7}$ neutrófilos fueron incubados durante 15 min a $37^{\circ} \mathrm{C}$ en presencia o ausencia de 2,5 $\mathrm{g} / \mathrm{ml}$ de PMA, $100 \mathrm{nM}$ fMLP ó $50 \mathrm{ng} / \mathrm{ml}$ TNF. El sobrenadante (S) contiene las proteínas liberadas al exterior tras la movilización de gránulos. Mientras que el pellet $(\mathrm{P})$ corresponde al total de células estimuladas. Los datos corresponden a un experimento representativo de al menos tres repeticiones. (B) Se determinó el porcentaje de ARG1 liberada, mediante la comparación de la actividad arginasa presente en el sobrenadante de neutrófilos estimulados, con la sumatoria de la actividad arginasa presente en el pellet celular y el sobrenadante. Los datos corresponden a la media $\pm \mathrm{SD}$ de al menos tres experimentos independientes.

En base a estos resultados quisimos determinar si la activación de neutrófilos con fMLP podría inducir apoptosis en las líneas celulares MCF7, SK-MEL-5, SF-268, BxPC3 y HeLa. Adicionalmente, quisimos determinar la capacidad del inhibidor nor-NOHA para disminuir la posible muerte celular provocada por la liberación de ARG1. Estimulamos 1 x $10^{7}$ neutrófilos de sangre periférica con fMLP. El sobrenadante (N-fMLP) fue cocultivado con las líneas celulares indicadas durante 24 horas en presencia o ausencia del inhibidor nor-NOHA (Figura II-9). Observamos que en todas las líneas celulares evaluadas, el N-fMLP podía inducir hasta un 25\% de apoptosis en sólo 24 horas de tratamiento. Además, observamos que el inhibidor nor-NOHA era capaz de disminuir significativamente la muerte celular por apoptosis (Figura II-9). Nuestros resultados indican que la activación de neutrófilos por el fMLP puede 
ser un mecanismo eficiente para inducir apoptosis en células tumorales, siendo la ARG1 parte importante en este proceso.

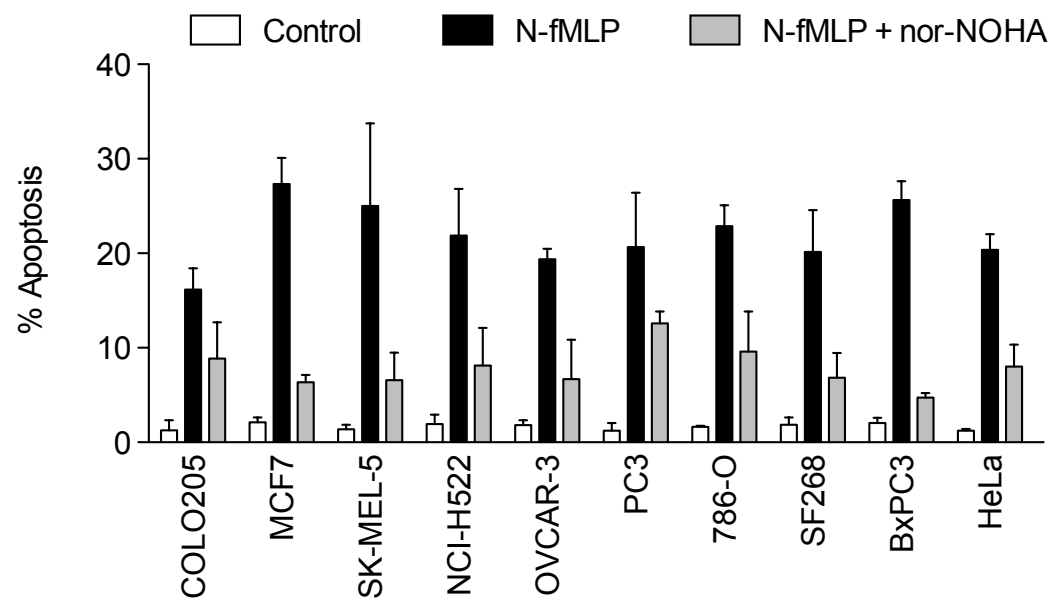

Figura II-9. Neutrófilos activados inducen apoptosis en células tumorales. Un total de $1 \times 10^{7}$ neutrófilos fueron estimulados con 100 nM de fMLP, el sobrenadante fue cocultivado con cada línea celular en presencia o ausencia del inhibidor nor-NOHA $(50 \mu \mathrm{M})$ durante 24 horas. Se cuantificó el porcentaje de apoptosis por citometría de flujo mediante la tinción de Anexina- $\mathrm{V}$, en comparación con el control de células incubadas con el sobrenadante de los neutrófilos en reposo. Los datos corresponden a la media $\pm \mathrm{SD}$ de al menos tres experimentos independientes.

\section{4. La ausencia de L-Arg activa la ruta PERK/eIF2 $\alpha$ /ATF4/CHOP de la respuesta de proteínas desplegadas}

En el capitulo anterior observamos que la ausencia de L-Arg induce autofagia como mecanismo de supervivencia al estrés de RE. Sin embargo, la degradación de L-Arg a través de la enzima ARG1 de neutrófilos induce apoptosis a las 24 horas de cultivo. Se conoce que las señales UPR tienen como prioridad el restablecimiento de las funciones del RE y la supervivencia celular. Sin embargo, cuando el daño en el RE es muy grande se induce apoptosis ${ }^{134,228,270}$. Cualquiera de las tres rutas mediadoras de la respuesta UPR (IRE1 $\alpha$, ATF6 y PERK) podría inducir apoptosis. Por lo tanto, quisimos determinar si la muerte celular inducida por la enzima ARG1 de neutrófilos era consecuencia de la activación de la respuesta UPR por estrés de RE. La línea celular HeLa fue cultivada en presencia o ausencia del sobrenadante de neutrófilos activados por fMLP (N-fMLP). A diferentes tiempos analizamos la expresión de proteínas involucradas en las diferentes rutas de señalización de la respuesta UPR.

En primer lugar pudimos detectar la fosforilación temprana de PERK y del factor de transcripción eIF2 $\alpha$, característicos de la respuesta $\mathrm{UPR}^{271}$. También observamos la regulación positiva del factor de transcripción ATF4 y de su gen diana CHOP (Figura II-10A). Estas dos 
proteínas se encuentran involucradas en la cascada de señalización de PERK/eIF2 $\alpha$ y en la apoptosis mediada por estrés de $\mathrm{RE}^{272}$. El incremento en la expresión de CHOP se considera un indicador de la muerte celular por apoptosis frente a señales de estrés de RE ${ }^{95}$. El factor de transcripción CHOP induce la activación de la cascada apoptótica DR5/caspasa-8 ${ }^{273}$. Dado que nuestros resultados muestran una regulación positiva de CHOP tras el agotamiento de LArg quisimos estudiar si la ruta de la caspasa-8 estaba activada. Observamos que el tratamiento con N-fMLP induce el procesamiento de la caspasa-8 a su forma activa (p20) tras un periodo de incubación de 6 horas. Además la caspasa- 8 podía procesar a la proteína de membrana del RE Bap31 a su forma activa p20 (Figura II-10A). Otro componente de la muerte celular apoptótica inducida por el estrés de RE es la caspasa-4. En células HeLa tratadas con N-fMLP pudimos observar el procesamiento de la caspasa-4 a su forma activa p20 (Figura II-10A). La chaperona residente del RE GRP78 es un componente importante de la respuesta UPR y bajo condiciones prolongadas de estrés de RE, puede incrementar su expresión hasta 20 veces ${ }^{274,275}$. Sin embargo, no hemos detectado un aumento en la expresión de la chaperona GRP78 en células HeLa tratadas con N-fMLP (Figura II-10). Para conocer el grado de implicación de las caspasas 4 y 8 en la apoptosis mediada por N-fMLP, decidimos utilizar los inhibidores de las caspasas 4 (z-LEVD-fmk) y 8 (z-IETD-fmk) además del inhibidor general de caspasas z-VAD. La eficiencia de los inhibidores de caspasa-4 (Figura II-10B) y caspasa-8 (Figura II-10C) se comprobó mediante Western blot. Asimismo, se confirmó que la inhibición de caspasa-8 previene la formación del fragmento p20 de BAP31 (Figura II-10C). Ademas, la preincubación con los inhibidores de caspasas inducen una disminución significativa en el porcentaje de apoptosis en las células tratadas con N-fMLP (Figura II-10D). En conjunto estos datos sugieren que la muerte inducida en células HeLa por el N-fMLP involucra una respuesta apoptótica mediada por caspasas y la activación de la cascada de señalización PERK/ATF4/ CHOP característica del estrés de RE y la respuesta UPR.

A pesar de que el inhibidor de la arginasa nor-NOHA puede disminuir el porcentaje de muerte en un 60\% para la línea celular HeLa (Figura II-9), hay un porcentaje de células que mueren por mecanismos independientes de la actividad arginasa. En base a estas observaciones quisimos determinar si limitando la actividad de la ARG1 contenida en el N-fMLP mediante el inhibidor nor-NOHA, éramos capaces de detectar la activación de la ruta PERK (Figura II-11). Cultivamos las células HeLa con el N-fMLP en presencia o ausencia de nor-NOHA. A las 24 horas analizamos la activación de las proteínas PERK, CHOP, caspasa-4, caspasa-8 y su sustrato Bap31, caspasa-3 y su sustrato PARP-1. Observamos que la activación por fosforilación de PERK (p-PERK) y la consecuente regulación positiva de CHOP sólo se 
A

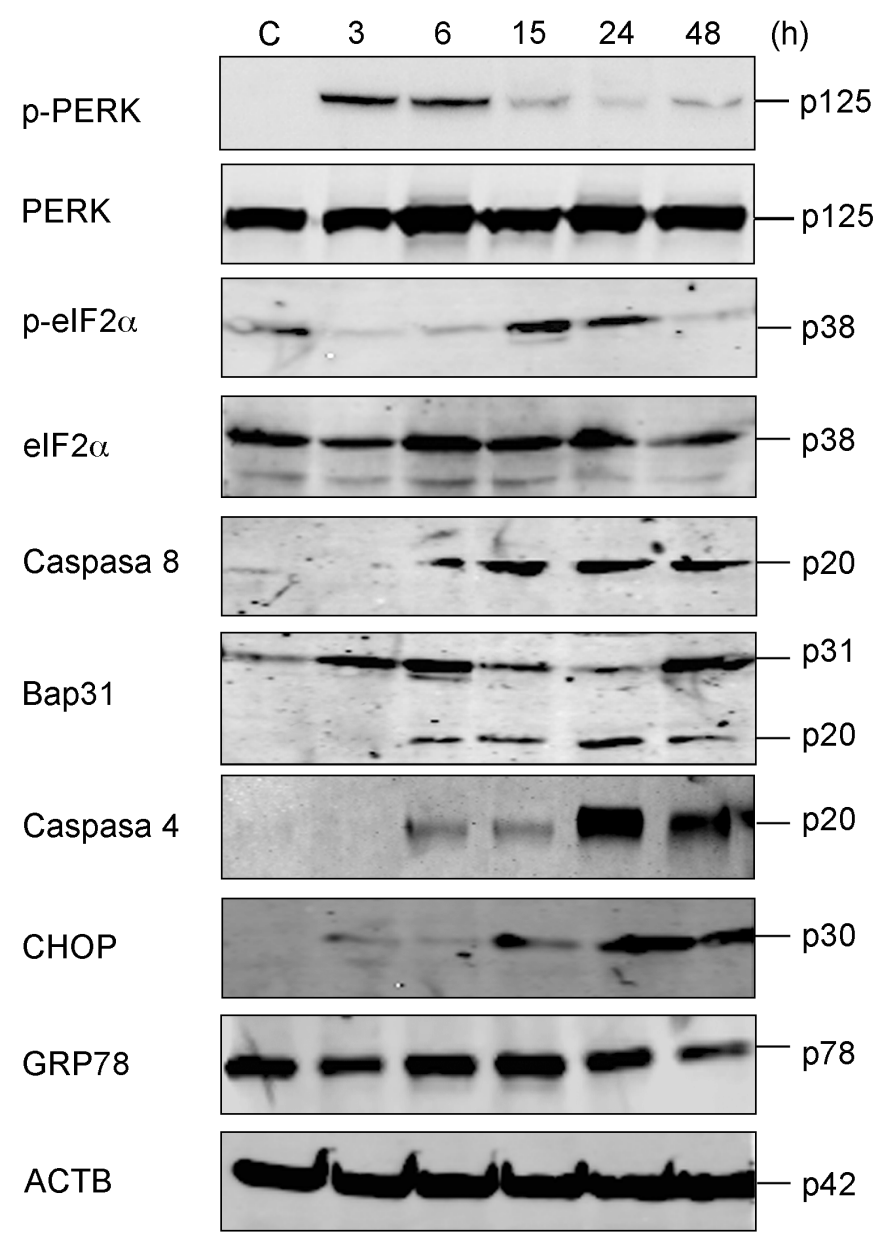

B

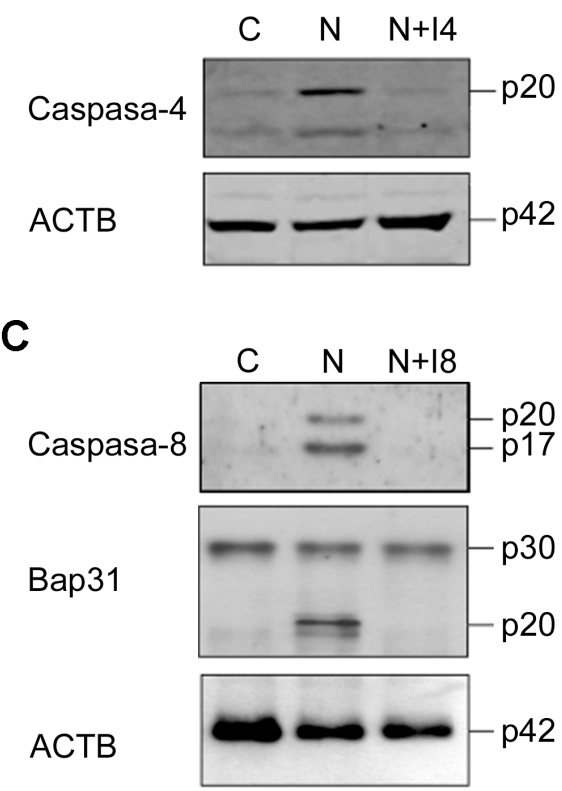

D

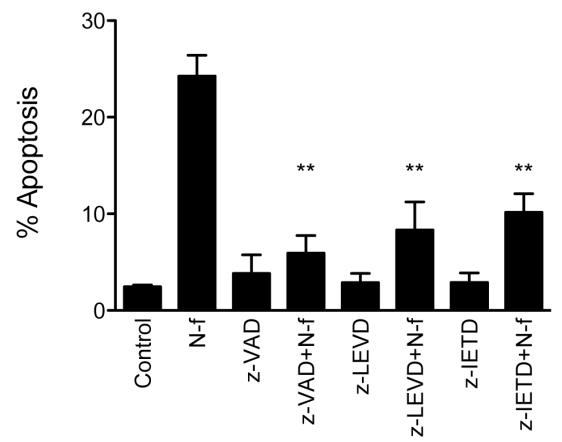

Figura II-10. Neutrófilos activados inducen apoptosis en células tumorales por activación de señales de estrés de RE. (A) $1 \times 10^{7}$ neutrófilos fueron estimulados con $100 \mathrm{nM}$ de fMLP, el sobrenadante fue cocultivado con la línea celular HeLa durante 48 horas. En los tiempos indicados se realizaron extractos proteicos que fueron analizados por Western blot. Los datos corresponden a la media \pm SD de al menos tres experimentos independientes. Para determinar si la apoptosis inducida por neutrófilos activados era inhibida por los inhibidores de caspasas 4 y 8, las células HeLa fueron pre-tratadas durante 1 hora con $20 \mu \mathrm{M}$ z-LEVD-fmk (inhibidor de caspasa-4) y con $100 \mu \mathrm{M}$ z-IETD-fmk (inhibidor de caspasa-8). Transcurrido el pretratamiento, fueron co-cultivadas durante 24horas con el sobrenadante de $1 \times 10^{7}$ neutrófilos estimulados con $100 \mathrm{nM}$ de fMLP (N-f). Las muestras fueron analizadas por Western-blot utilizando anticuerpos específicos para caspasa 4 (B) y caspasa 8 y Bap31 (C). Se utilizó la ATCB como control de carga en cada pocillo. Los resultados mostrados son representativos de tres experimentos independientes. (D) Se determinó el porcentaje de apoptosis mediante la tinción de anexina-V por citometría de flujo. Los valores representados corresponden a las medias \pm S.D. de tres experimentos ejecutados de manera independiente. ** $\mathrm{p}<0,01$. N: células HeLa co-cultivadas con 1x10 neutrófilos estimulados con 100 nM de fMLP; I4: $20 \mu \mathrm{M}$ z-LEVD-fmk; I8: $100 \mu \mathrm{M}$ z-IETD-fmk

observa en las células tratadas con el N-fMLP sin el inhibidor nor-NOHA. Las caspasas-4 y 8 involucradas en la apoptosis mediada por señales de estrés de RE también se activan sólo en las células tratadas con N-fMLP sin el inhibidor nor-NOHA. A pesar de que la caspasa-8 no se activa en las células tratadas con fMLP/nor-NOHA, si observamos la activación de la caspasa-3 y la inactivación por escisión de su sustrato PARP-1 en las células tratadas con fMLP 
con o sin nor-NOHA (Figura II-11). Nuestros resultados indican que el tratamiento de células HeLa con fMLP induce la activación de caspasas-3, 4 y 8, pero al inhibir la actividad arginasa con nor-NOHA es la caspasa-3 la encargada de dirigir la cascada proteolítica que conduce a la muerte celular independiente de la ARG1.

\section{5. La disminución de la L-Arg por la ARG1 de neutrófilos activados, no afecta a células proliferativas no tumorales}

La utilización y desarrollo de enzimas que puedan catabolizar aminoácidos u otros metabolitos necesarios para el crecimiento tumoral constituye una estrategia atractiva para el tratamiento del cáncer. Sobretodo cuando las deficiencias metabólicas entre células tumorales y células normales pueden ser utilizadas como método selectivo. Para determinar si el sobrenadante que resulta de la activación de neutrófilos con fMLP tiene algún tipo de efecto en células proliferativas no tumorales como las células endoteliales de la vena de cordón umbilical humano (HUVEC). Las células HUVEC fueron co-cultivadas con N-fMLP y evaluamos el porcentaje de células apoptóticas a lo largo de 48 horas de tratamiento (Figura II-12). Observamos un porcentaje de muerte no superior al 7\%, menos de la mitad del observado

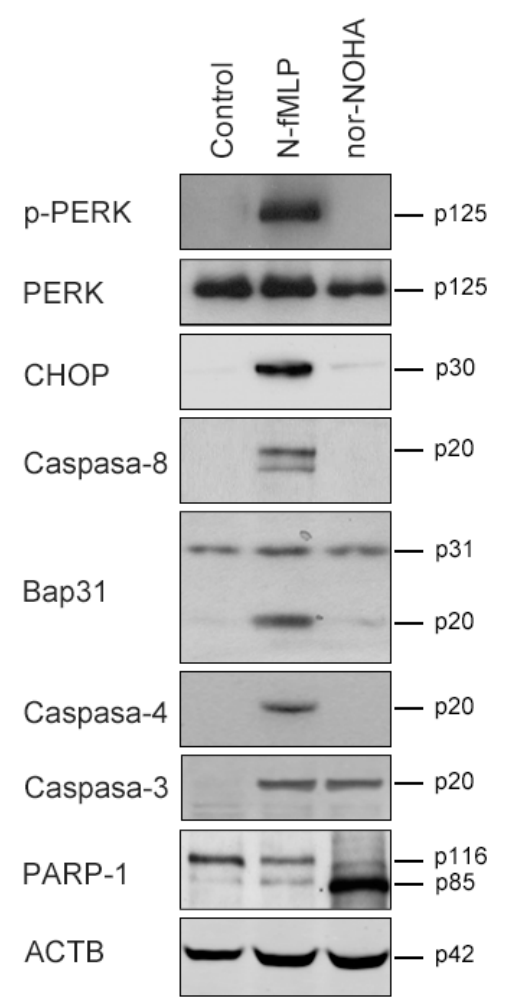

Figura II-11. La ARG1 exocitada por neutrófilos activados induce apoptosis en células tumorales por activación de señales de estrés de RE. $1 \times 10^{7}$ neutrófilos fueron estimulados con 100 nM de fMLP, el sobrenadante (N-fMLP) fue cocultivado con la línea celular HeLa en presencia o ausencia del inhibidor nor-NOHA $(50 \mu \mathrm{M})$ durante 24 horas. Se realizaron extractos proteicos que fueron analizados por Western blot. con los anticuerpos indicados. Los datos corresponden a la media \pm SD de al menos tres experimentos independientes. en las líneas tumorales estudiadas (Figura II-9). La muerte celular fue totalmente inhibida con el inhibidor de ARG1 nor-NOHA (Figura II-12). Nuestros resultados sugieren que la utilización de neutrófilos activados con fMLP podría ser una estrategia interesante para el tratamiento de tumores auxotrofos para L-Arg ya que no afecta la proliferación de células epiletiales no tumorales. 


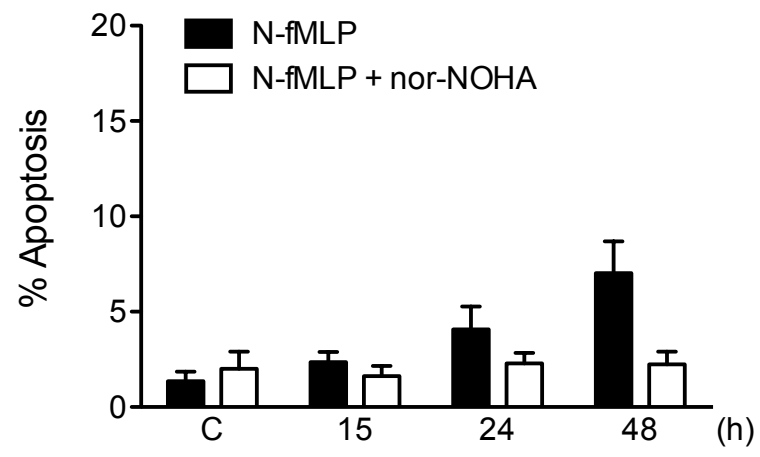

Figura II-12. Neutrófilos activados inducen menos apoptosis en células proliferativas no tumorales que en células tumorales. 1 x $10^{7}$ neutrófilos fueron estimulados con $100 \mathrm{nM}$ de fMLP, el sobrenadante fue cocultivado con las células HUVEC en presencia o ausencia del inhibidor nor-NOHA $(50 \mu \mathrm{M})$ durante 48 horas. Posteriormente las muestras se analizaron por citometría de flujo mediante la tinción de anexina- $\mathrm{V}$, en comparación con el control de células incubadas durante 48 horas con el sobrenadante de los neutrófilos en reposo. Los datos corresponden a la media \pm SD de al menos tres experimentos independientes. 

Discusión 



\section{La ausencia de $L$-Arg en células $T$ humanas induce autofagia como respuesta citoprotectora al estrés del retículo endoplásmico}

La L-Arg es un aminoácido no esencial involucrado en varios sistemas biológicos que incluyen al sistema inmune ${ }^{39}$. Estudios in vitro e in vivo demuestran que la ausencia de L-Arg no solo bloquea la proliferación de células $\mathrm{T}$, sino que también induce cambios moleculares que incluyen la disminución de la expresión de la cadena CD3 $\zeta$ del receptor de células T (TCR) y la producción de ciertas citoquinas como IFN $\gamma$, IL-5 e IL-10208. La regulación negativa de la cadena $\mathrm{CD} 3 \zeta$, como única consecuencia molecular relacionada directamente con la ausencia de L-Arg, no explica la incapacidad de las células T para proliferar después de la estimulación con PHA+IL-2 en ausencia de L-Arg. Los datos publicados hasta el momento en cuanto al efecto de la L-Arg sobre la proliferación de las células T humanas, se han limitado a describir la disminución de la expresión de la cadena CD3 $\zeta$ del TCR y la parada del ciclo celular en $\mathrm{G}_{0} / \mathrm{G}_{1}$ por la disminución de la expresión de la ciclina 3 y cdk $4^{51,59}$. Sin embargo, no se han explicado los mecanismos que permiten a las células $T$ permanecer hasta 5 días en cultivo en ausencia de L-Arg sin que se observe un aumento significativo de la muerte celular. Nuestros resultados indican que la ausencia de L-Arg induce autofagia como mecanismo de supervivencia en células $\mathrm{T}$, manteniendo un estado no proliferativo que puede revertirse restableciendo los niveles de L-Arg. Además estos resultados se confirman porque al inhibir la autofagia, las células mueren por apoptosis en solo 48 horas.

La deficiencia de aminoácidos puede activar la quinasa GCN2, un sensor nutricional, a través de la acumulación de tRNAs no cargados. Al activarse por fosforilación GCN2 desencadena rutas de señalización que permiten a las células adaptarse a las nuevas condiciones nutricionales ${ }^{218}$. Estudios en levaduras han revelado que no sólo la restricción de aminoácidos puede inducir la fosforilación de GCN2, sino que señales de estrés ambiental como la exposición a altas concentraciones de $\mathrm{NaCl}$ pueden inducir rápidamente la acumulación de tRNAs no cargados como tRNA ${ }_{i}^{\text {Met }}$, $\mathrm{tRNA}^{\mathrm{Cys}}$ y tRNA ${ }^{\mathrm{Arg}}$, coincidiendo con la fosforilación de GCN2 y de eIF2 $\alpha^{209}$. Las células no poseen reservorios de aminoácidos, por lo que dependen de los niveles intracelulares o de la biosíntesis para cumplir con sus necesidades nutricionales. Los tRNAs son los intermediarios entre el DNA y las proteínas, cada aminoácido posee un 
tRNA específico el cual sólo puede transferir un único aminoácido a la vez; el proceso se completa reutilizando los tRNA ${ }^{276}$. Estudios previos muestran que la restricción de la L-Arg tienen un efecto marcado en el crecimiento de levaduras con la deleción en el gen GCN2. Además en levaduras normales se puede detectar una disminución del 50\% de los tRNA ${ }^{\operatorname{Arg}}$ cargados con sólo 10 minutos de restricción de L-Arg ${ }^{277}$. La acumulación de los tRNA ${ }^{\operatorname{Arg}}$ no cargados es capaz de inducir la activación de GCN2 y la posterior fosforilación de eIF2 $\alpha^{209}$. En base a estas evidencias, suponemos que en células $\mathrm{T}$ la ausencia de L-Arg induce la fosforilación de la quinasa GCN2 por la acumulación de tRNA ${ }^{\operatorname{Arg}}$ no cargados.

La activación de GCN2 induce la fosforilación del residuo Ser $^{51}$ del factor de transcripción eIF2 $\alpha$ en ausencia de L-Arg. Estudios previos han demostrado que el eIF2 $\alpha$ fosforilado es un inhibidor competitivo de eIF2B que altera la formación del complejo eIF2GTP-Met-tRNAi e inhibe el inicio de la traducción ${ }^{278}$, por lo tanto la fosforilación de GCN2 y eIF2 $\alpha$ puede estar evitando la formación del complejo eIF2-GTP-Met-tRNAi e inhibiendo la síntesis global de proteínas en células T. Estas suposiciones pueden corroborarse con la disminución en la expresión de la cadena $\mathrm{CD} 3 \zeta$ y la regulación negativa de las proteínas de membrana CD2, CD3e, CD5, CD11A y CD45. Nuestros resultados indican que la restricción de un sólo aminoácido puede inhibir la síntesis de proteínas de membrana en células $\mathrm{T}$ posiblemente por la activación de eIF2 $\alpha$. La activación de GCN2 y la consecuente fosforilación de eIF2 $\alpha$ por la ausencia de L-Arg en células T, induce un aumento en la expresión de la proteína ATF4. El factor de transcripción ATF4 regula el inicio de la transcripción de una amplia gama de genes involucrados en el metabolismo y transporte de aminoácidos, en el estatus oxidativo, energético y en la autofagia ${ }^{93,279,280}$. Durante la restricción de nutrientes, la activación de ATF4 regula la expresión de genes involucrados en la autofagia como Atg16L1, LC3, Atg12, Atg3 y Beclin-1 281,282. En células T cultivadas en ausencia de LArg hemos observado que la activación de ATF4 induce la expresión de Atg12. Atg12 es la primera proteína ubiquitina-like en expresarse en la maquinaria autofágica, se une a Atg5 y Atg16L para dar al inicio de un proceso autofágico ${ }^{283}$. Se conoce que tanto la formación del complejo terciario eIF2 $\alpha$-GTP-Met-tRNAi como la activación de la ruta GCN2/eIF2 $\alpha / A T F 4$ son necesarias en la inducción de la autofagia mediada por la restricción de aminoácidos ${ }^{281}$. Además la inhibición de GCN2 por RNA de interferencia inhibe la autofagia mediada por IFN- $\boldsymbol{\gamma}^{284}$. En nuestro modelo de estudio tras la inhibición de la expresión de GCN2 seguimos detectando la fosforilación de eIF2 $\alpha$. Este factor de iniciación de la transcripción no solo puede ser fosforilado por GCN2 sino que también puede ser fosforilado por otras quinasas 
como PERK, PKR y HRI ${ }^{92}$. A pesar de que inicialmente no hemos detectado la activación de estas quinasas en células $\mathrm{T}$ cultivadas en ausencia de L-Arg, cuando silenciamos GCN2 observamos la activación de la quinasa PERK involucrada en la respuesta UPR. Suponemos que al inhibir la expresión de GCN2, es la quinasa PERK la encargada de fosforilar eIF2 $\alpha$ y desencadenar la cascada de señalización que da lugar a la degradación de LC3-II y SQSTM1/ p62. Estos resultados sugieren que la fosforilación de GCN2 no es un paso crítico para la inducción de la autofagia en ausencia de L-Arg ya que cuando disminuye la expresión de GCN2, su papel putativo en la fosforilación de eIF2 $\alpha$ puede llevarse a cabo por rutas alternativas, como la vía PERK, que de otro modo permanece inactiva. Estudios posteriores podrían enfocarse en estudiar la importancia de la ruta eIF2 $\alpha$ /ATF4 bien sea mediante el silenciamiento de los mismos o de sus quinasas activadoras, GCN2 o PERK. Las rutas alternativas para la activación de la vía eIF2 $\alpha / A T F 4$ puede ser esencial para el inicio de la autofagia en ausencia de L-Arg.

La expresión del TCR, y en especial de la cadena $\mathrm{CD} 3 \zeta$, es un paso crítico en la regulación de la respuesta inmune ${ }^{60}$. El factor de necrosis tumoral (TNF), una potente citoquina pro-inflamatoria, induce la regulación negativa de la cadena $\mathrm{CD} 3 \zeta$ en células $\mathrm{T}$ activadas. El tratamiento con TNF no altera los niveles del mRNA/CD3 $\zeta$, pero si induce la degradación de la proteína tanto por la vía proteasomal como por la vía lisosomal ${ }^{227}$. La ausencia de L-Arg en células T no induce una regulación negativa del mRNA/CD3 $\zeta^{208}$, pero sí de los niveles de la proteína. Sin embargo, hasta el momento no se ha descrito el mecanismo o mecanismos responsables de la degradación $\mathrm{CD} 3 \xi$ en ausencia de L-Arg. Nuestros resultados demuestran que la degradación de la cadena $\mathrm{CD} 3 \zeta$ en células T por la ausencia de L-Arg se debe a la activación de la vía proteasomal. Sin embargo, al contrario de lo que se observa con el tratamiento con el TNF, la inactivación de la ruta lisosomal no bloquea la degradación del CD3 $\zeta$. Se conoce que la distribución y la cantidad de complejos TCR/CD3 en la membrana plasmática se mantiene gracias al equilibrio entre la síntesis y secreción de nuevos polipéptidos, así como por la internalización, reciclado y degradación de los ya existentes ${ }^{285}$. Los ligandos del TCR/CD3 pueden estimular tanto la internalización y degradación del receptor. Una vez interiorizado el TCR/CD3 puede ser reciclado o degradado. En la síntesis de novo todas las cadenas del TCR/CD3 son ensambladas en el RE y transportadas a través del Golgi hacia la membrana plasmática, cuando no se ensamblan correctamente son rápidamente degradadas ${ }^{286}$. La exportación de los complejos TCR/CD3 desde el retículo endoplasmático y su transporte a la superficie celular requiere la producción concomitante y montaje de las cadenas $\alpha \beta$ del TCR 
y las cadenas $\varepsilon \gamma$ y $\delta \varepsilon$, así como los dimeros $\zeta-\zeta$ del CD3. Las cadenas que no son ensambladas son rápidamente degradadas en el RE o en el citoplasma ${ }^{226,287}$. La vida media de las diversas subunidades del complejo TCR/CD3 en la membrana plasmática difieren en gran medida: siendo mayor de $20 \mathrm{~h}$ para las cadenas $\gamma \delta \varepsilon$ del complejo $\mathrm{CD}^{285} \mathrm{y}$ menor de $4 \mathrm{~h}$ para la cadena CD3 $\zeta^{288}$. Algunas de estas subunidades son internalizadas y recicladas hacia la superficie celular, mientras que otras se degradan. Al contrario de las demás cadenas $\gamma \delta \varepsilon$ del CD3 que se expresan en exceso, la cadena $\mathrm{CD} 3 \zeta$ se expresa en menor cantidad y es un factor limitante para el ensamblaje del TCR/CD3 ${ }^{288}$. Se conoce que la cadena $\mathrm{CD} 3 \zeta$ contiene un motivo de internalización, por lo puede ser continuamente internalizado y reciclado ${ }^{289}$. Dadas las características de la cadena $\mathrm{CD} 3 \zeta$, esta puede ser una de las primeras proteínas internalizadas tras la activación de células T, ya que la estimulación con PHA estimula la internalización del TCR/CD $3{ }^{290}$. Al internalizarse, la cadena $\mathrm{CD} 3 \zeta$ puede ser dirigida al RE para el ensamblaje del complejo TCR/CD3, pero debido a los cambios producidos en la homeostasis del RE por la ausencia de L-Arg y al bloqueo de la síntesis general de proteínas por la fosforilación eIF2 $\alpha$ observadas en la presente Tesis, suponemos que el complejo TCR/CD3 no puede formarse y en consecuencia la cadena $\mathrm{CD} 3 \zeta$ es rápidamente degradada por la vía proteasomal.

El RE es un organelo esencial para el control de la calidad y la síntesis de proteínas. Perturbaciones en el funcionamiento del RE por la disminución de los niveles de glucosa o aminoácidos, la desregulación del flujo de $\mathrm{Ca}^{2+}$, posibles infecciones virales o hipoxia, inducen a la acumulación de proteínas desplegadas en el lumen del RE y el inicio de la respuesta de proteínas desplegadas (UPR). La respuesta UPR se inicia por la activación de las quinasas IRE1 $\alpha$, PERK y ATF6 residentes en la membrana del RE ${ }^{81}$. En células T hemos observado que la ausencia de un único aminoácido, la L-Arg, es capaz de inducir señales de estrés de RE. La ausencia de L-Arg induce la activación de la ruta IRE1 $\alpha$ de la respuesta UPR, posiblemente por la acumulación de proteínas desplegadas en el RE. La activación de la región RNAsa de IRE1 $\alpha$ induce escisión la de una secuencia de 26 nucleótidos pertenecientes al mRNA inmaduro de XBP1 o XBP1u. El mRNA maduro de XBP1 (XBP1s) codifica un potente factor de transcripción que se transloca al núcleo para la activación de genes involucrados en el plegado de proteínas que se encuentran en el lumen del RE y para la activación de la maquinaria de degradación asociada al RE (ERAD) ${ }^{291}$. Nuestros resultados concuerdan con lo esperado para la activación del XBP1s en células T por la ausencia de L-Arg, observamos un aumento en la expresión de EDEM1, proteína de la maquinaria ERAD, conforme detectamos el XBP1s. La maquinaria ERAD es una de las vías activadas por la respuesta UPR para 
contrarrestar el estrés de RE. Su principal función es eliminar proteínas mal plegadas del lumen del RE que generan agregados tóxicos para la célula110. Las proteínas que no alcanzan su conformación nativa son reconocidas por la maquinaria ERAD y retro-translocadas hacia el citoplasma, poli-ubiquitinadas y degradadas mediante el proteasoma ${ }^{241}$. Nuestros resultados sugieren que en células T la ausencia de L-Arg puede inducir la activación de la maquinaria ERAD por XBP1 y del proteasoma como mecanismo downstream de la respuesta UPR. Además la activación del proteasoma interviene en la regulación negativa de la cadena $\mathrm{CD} 3 \xi$, observada tras la ausencia de L-Arg.

La función inicial de la respuesta UPR es inducir la degradación de las proteínas desplegadas en el lumen del RE mediante la activación del proteasoma o de la autofagia ${ }^{86,292,293}$. Cuando se induce estrés de RE por restricción de nutrientes, o por el tratamiento con tunicamicina, se observa la activación de la ruta IRE1 $\alpha / \mathrm{JNK}$ y el consecuente flujo autofágico como mecanismo de supervivencia ${ }^{229,231}$. La proteína Beclin-1 es el ortólogo de mamífero del Atg6 en levaduras y componente esencial para la formación del autofagosoma. Mediante screening de dos híbridos en levaduras se identificó a Beclin-1 como una proteína que interactuaba con proteínas de la familia Bcl-2 ${ }^{294}$. La interacción entre Bcl-2 y Beclin-1 se lleva a cabo exclusivamente en la superficie del RE. De ese modo la capacidad de Bcl-2 para inhibir la autofagia mediante su unión a Beclin-1 es particularmente sensible a las alteraciones en la homeostasis del $\mathrm{RE}^{200}$. La inducción de la autofagia como mecanismo de supervivencia bajo condiciones de estrés de RE es un evento ampliamente estudiado en la literatura ${ }^{86,295-298}$. Nuestros resultados aportan nuevos datos ya que la ausencia de L-Arg podría ser catalogada como un agente desencadenante de estrés del RE, con la capacidad de inducir la activación de la ruta IRE1 $\alpha$, la fosforilación de JNK y la consecuente escisión del complejo Bcl-2/Beclin-1 por la fosforilación de Bcl-2, al igual que otros conocidos inductores de estrés de RE como la ceramida $^{299}$ o la tunicamicina ${ }^{231}$.

La activación de la autofagia en respuesta a la omisión de un sólo aminoácido ha sido estudiada en células CHO (Chinese hamster ovary) y en células hepáticas de rata 236,306-308. Inicialmente se describió en hepatocitos de rata un grupo de aminoácidos (L-Leu, L-Gln, LHis, L-Pro, L-Met, L-Trp, L-Tyr), cuya restricción individual o combinada, tenía la capacidad de inducir autofagia en la misma medida que la restricción total de aminoácidos ${ }^{307}$. Estudios con células CHO clasificaron los aminoácidos según su capacidad para inducir la degradación del LC3-II. Como resultado se obtuvieron tres grupos de aminoácidos en donde L-Arg, L-Leu, LLys y L-Met se clasificaron como fuertes activadores de la autofagia; los aminoácidos L-Gln, L- 
His, L-Phe, L-Thr, L-Trp, L-Tyr y L-Val como activadores débiles y los aminoácidos L-Ala, LAsn, L-Asp, L-Cys, L-Glu, L-Gly, L-Iso, L-Pro, L-Ser no ejercían ningún efecto en cuanto a la degradación del LC3-II ${ }^{236}$. En nuestro modelo de estudio, la cuantificación del flujo autofágico en respuesta a la omisión de un solo aminoácido nos permitió determinar el requisito mínimo nutricional para la inducción de la autofagia en células T. Identificamos un grupo de aminoácidos (L-Arg, L-His, L-Leu, L-Met, L-Phe, L-Trp y L-Tyr) como reguladores directos de la degradación del LC3-II, mientras que los demás aminoácidos no parecían tener ningún efecto. Al igual que en células $\mathrm{CHO}$, los aminoácidos L-Arg y L-Met inducen una mayor degradación del LC3-II eque el resto de aminoácidos. Podría esperarse que la deficiencia de LMet sea un estímulo suficiente para generar cambios en el metabolismo celular, ya que es un elemento limitante para el inicio de la traducción de proteínas ${ }^{309}$. Sin embargo, el aminoácido L-Tyr, clasificado como un inductor débil de la autofagia en células $\mathrm{CHO}^{236}$, en células T no sólo es un potente activador de la autofagia, sino que también induce el splicing alternativo de XBP1, al igual que L-Arg y L-Met. Suponemos que los aminoácidos L-Met y L-Tyr inducen la activación de la ruta IRE1 $\alpha$ de la respuesta UPR y probablemente por las mismas rutas que la L-Arg en cuanto a la activación de la autofagia.

En condiciones nutricionales óptimas como abundancia de aminoácidos, glucosa y factores de crecimiento, el complejo mTORC1 bloquea la autofagia mediante la inhibición de la quinasa ULK1. Cuando disminuyen los niveles de aminoácidos, factores de crecimiento o aumenta la relación AMP/ATP, se inhibe la actividad del complejo mTORC1 permitiendo que aumente la actividad de la quinasa ULK1 dando inicio a la formación del autofagosoma ${ }^{171}$. Además, la inhibición de Akt, quinasa que se encuentra upstream de mTORC1, puede conducir a la inhibición del complejo mTORC1 y activar la autofagia ${ }^{179,300 . ~ E n ~ c o n c o r d a n c i a ~ c o n ~ e s t a s ~}$ observaciones la ausencia de L-Arg en células T induce la inhibición de la fosforilación de Akt, del complejo mTORC1 y de su sustrato $\mathrm{p} 70^{\mathrm{S} 6 \mathrm{~K}}$. Podemos inferir que la ausencia de L-Arg regula negativamente la ruta Akt/mTORC1 y promueve el inicio del proceso autofágico. Sin embargo, serían necesarios más estudios para determinar los mecanismos involucrados en la regulación negativa de la ruta de señalización de mTORC1 por la ausencia de un sólo aminoácido, la L-Arg. Por otra parte, existen rutas adicionales a la ruta mTORC1 con la capacidad de regular la autofagia. Entre ellas se encuentra la ruta MAPK-ERK1/2, siendo especialmente importante en la activación de la autofagia después del estrés de RE ${ }^{168,301,302}$. Sin embargo, nuestros resultados indican que en células $T$ la autofagia inducida por la ausencia de L-Arg depende en mayor grado de la ruta JNK que de la ruta MAPK-ERK1/2, puesto que al utilizar el inhibidor de MAPK U0126, aún podemos detectar la conversión de LC3-I a LC3-II. 
La activación de la autofagia en células T inducida por la ausencia de L-Arg es un proceso que favorece la supervivencia celular ante señales de estrés de RE. Este proceso puede mantenerse durante periodos prolongados, sin que se observe un aumento significativo en la apoptosis, y se invierte una vez que los niveles de L-Arg vuelven a la normalidad. Sin embargo, al bloquear la autofagia con inhibidores farmacológicos o genéticos, las células T mueren por apoptosis en un periodo de 24 horas. Observamos que al inhibir la autofagia se desencadena una respuesta apoptótica caracterizada por la expresión de CHOP, la activación de las caspasas 4 y 8 , además de la escisión de Bap31. Tanto CHOP como las caspasas 4 y 8 han sido reportados como integrantes claves de la apoptosis mediada por estrés de $\mathrm{RE}^{303-305}$.

En conjunto nuestros resultados indican que la ausencia de L-Arg induce estrés de RE en células $\mathrm{T}$ y que estas señales pueden ser detectadas y canalizadas tanto por sensores nutricionales como GCN2, como por las quinasas de la respuesta UPR, IRE1 $\alpha$ y PERK en sustitución de GCN2. Estas quinasas son las encargadas de desencadenar mecanismos adaptativos comola autofagia, para restaurar la homeostasis del RE (Figura I-21).

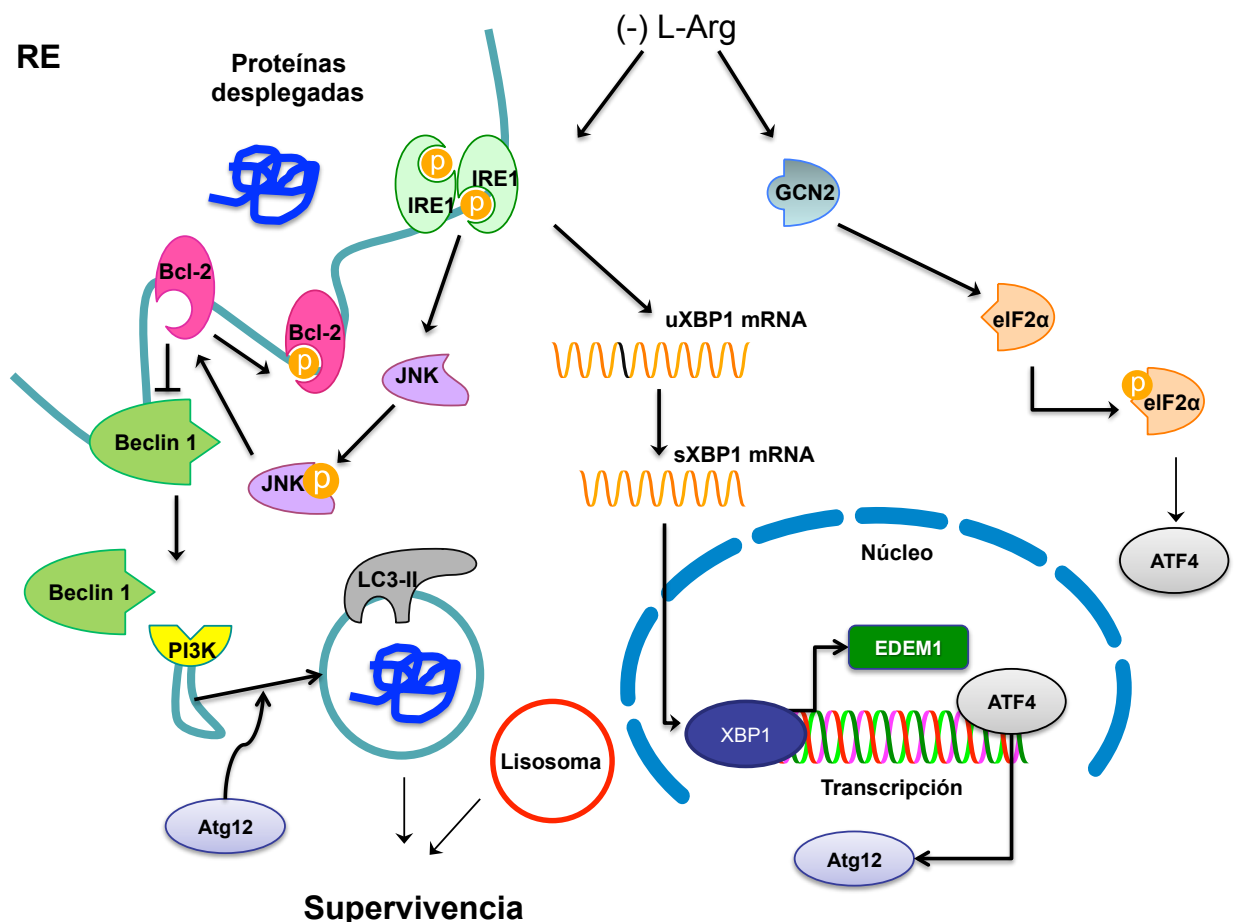

Figura I-21. Modelo esquemático de la autofagia inducida por estrés de RE en ausencia de L-Arg en células T. La ausencia de L-Arg induce la activación de la región RNAsa de IRE1a, el cual procesa el mRNA de XBPl cortando una secuencia de 26 nucleotidos y dando lugar al factor de transcripción XBP1s. XBP1s induce la transcripción de genes como EDEM1 involucrados en la maquinaria ERAD. Adicionalmente la ausencia de L-Arg induce la activación de GGN2 el cual fosforila eIF2a e induce la expresión de ATF4. ATF4 esta involucrado en la expresión de genes iniciadores de la autofagia como ATG12. Por otra parte la activación de IRE1 induce la fosforilación de JNK, el cual promueve la disociación del complejo Bcl-2/Beclin-1 en la membrana del RE mediante la fosforilación de Bcl-2. El Beclin-1 libre inicia la formación del autofagosoma y la supervivencia celular. 



\section{Participación de la arginasa I en la muerte de células tumorales mediada por neutrófilos}

Las alteraciones en el metabolismo celular constituyen una característica casi universal en muchos tipos de células cancerosas. Muchos tumores presentan deficiencias en la síntesis o reciclaje de uno o más aminoácidos, forzando a la dependencia de la disponibilidad extracelular de los mismos para satisfacer las demandas biosintéticas. Por lo tanto, una modalidad de tratamiento con alta selectividad para células tumorales sería la degradación sistémica de aminoácidos esenciales para el tumor, resultando en la muerte celular de las células tumorales con un efecto mínimo en las células normales ${ }^{245}$. Sin embargo, las enzimas heterólogas han tenido una utilidad limitada en el tratamiento de neoplasias malignas ya que pueden provocar respuestas adversas como el shock anafiláctico y la inactivación enzimática mediada por anticuerpos. La única excepción notable es la L-asparaginasa II de Escherichia coli, que ha sido aprobado por la FDA para el tratamiento de primera línea para la leucemia linfoblástica aguda (LLA) infantil ${ }^{247,310}$. Otra excepción, la constituye la asparaginasa de la planta Emvinia chrysanthemi, que se utiliza conjuntamente con otros medicamentos para el tratamiento de pacientes de LLA que han tenido algún tipo de reacción alérgica a medicamentos similares, tales como L-asparaginasa amidohidrolasa de Merck\&CO (Elspar $\left.{ }^{\circledR}\right)$ o PEG-L-asparaginasa (Oncaspar $)^{311}$.

El uso de enzimas humanas puede ofrecer un nuevo enfoque para el desarrollo de terapias oncológicas, ya que pueden presentar una reducida inmunogenicidad y presentar una mayor estabilidad en condiciones fisiológicas. La ARG1 cataboliza la L-Arg a L-ornitina y urea, disminuyendo los niveles de L-Arg disponibles. Los neutrófilos humanos expresan grandes cantidades de ARG1, lo que podría ser perjudicial para algunas células tumorales auxótrofas para L-Arg. Estudios previos han demostrado que líneas tumorales con deficiencia en la expresión de la enzima ASS son auxotrofas para L-Arg, y la ausencia de este aminoácido puede inducir una parada en el ciclo celular y la posterior muerte celular por apoptosis ${ }^{312,313}$. Nuestros resultados indican que tanto la proteína recombinante GST-ARG1, como el extracto de proteínas totales de neutrófilos (EPT-N) y el sobrenadante del exocitado de neutrófilos inducido por fMLP (N-fMLP) pueden inducir apoptosis en líneas tumorales en las que se observa una disminución de la proliferación por la actividad de la ARG1 de neutrófilos. Además hemos observado que líneas de ovario, pulmón, piel, mama, páncreas y riñón son 
especialmente sensibles a la actividad de la ARG1 de neutrófilos. En las líneas celulares más sensibles a la actividad de la ARG1, el inhibidor específico de la ARG1 nor-NOHA, era capaz de disminuir el porcentaje de apoptosis, indicando que la actividad arginasa es un factor importante en cuanto a la muerte celular mediada por neutrófilos. Nuestros resultados aportan información relevante en la identificación de tipos tumorales sensibles a la restricción de LArg. Esta información puede servir para diseñar terapias específicas en donde se utilicen enzimas humanas que regulen la disponibilidad de L-Arg.

Estudios anteriores han demostrado que la ausencia de arginina en el medio de cultivo por la acción de la arginina deiminasa (ADI) de Mycoplasma arginini, induce una parada del ciclo celular en $G_{1}$, lo que conlleva a una eventual muerte celular ${ }^{255,314,315}$. Sin embargo, el agotamiento de L-Arg por la enzima recombinante humana ARG1 induce una parada del ciclo celular en fase $\mathrm{G}_{2} / \mathrm{M}$ ó $\mathrm{S}$ en líneas celulares de carcinoma hepatocelular sin inducción de apoptosis, ya que no se observa un aumento significativo de la fracción sub-G ${ }_{1}^{316}$. En contraste con estos hallazgos, nuestros resultados indican que la actividad ARG1 de neutrófilos da lugar a la activación de una respuesta apoptótica en las líneas celulares COLO205, MCF7, SKMEL-5, NCI-H522, OVCAR-3, PC3, 786-O, SF268, BxPC3, HeLa, en las que se observó inicialmente una disminución de la proliferación celular. Por lo tanto, la actividad arginasa y la consecuente disminución de L-Arg puede causar una parada en el ciclo celular o apoptosis en función de las características genéticas del tumor y de sus necesidades nutricionales.

En el capítulo anterior observamos que las células T eran capaces de inducir autofagia como mecanismo de supervivencia ante la deficiencia de L-Arg y podían mantenerse 5 días en cultivo, sin más de un $10 \%$ de apoptosis. Por el contrario, en las células tumorales sensibles a la actividad de la ARG1 estudiadas en este apartado, el co-cultivo con N-fMLP induce un 25\% de apoptosis tan sólo 24 horas después del inicio del tratamiento. Se conoce que la muerte celular inducida por el tratamiento con ADI-PEG20 ó con rhARG1 en células tumorales puede observarse tras 3 ó 6 días de tratamiento ${ }^{253,317,318}$. Sin embargo, el mecanismo mediante el cual la restricción de un sólo aminoácido como la L-Arg puede inducir muerte celular no está del todo claro. Nuestros resultados indican que la actividad de la ARG1 de neutrófilos, liberada por la activación con fMLP, induce muerte celular por apoptosis, mediante la activación de proteínas involucradas en la respuesta UPR como PERK, ATF4 y CHOP. Se conoce que la fosforilación del factor de transcripción eIF2 $\alpha$ a través de PERK puede inducir apoptosis por la regulación positiva de la expresión de ATF4 y $\mathrm{CHOP}^{100}$. La expresión de CHOP se considera un marcador de estrés de RE, ya que en condiciones normales suele permanecer a 
niveles bajos mientras que aumenta su expresión durante el estrés de RE. Aunque se desconoce el mecanismo exacto mediante el cual CHOP induce apoptosis mediada por estrés de RE, células $\mathrm{CHOP}^{-/}$son resistentes a la muerte celular mediada por compuestos que inducen la liberación de $\mathrm{Ca}^{2+}$ del $\mathrm{RE}^{303}$. En células HeLa co-cultivadas con N-fMLP también observamos una fuerte activación de la caspasa-4 a las 24 horas del tratamiento, una vez que ya se han desencadenado las señales de muerte como la fragmentación de Bap31 y la expresión de CHOP. Lo que nos sugiere que esta cisteín-proteasa podría contribuir a la respuesta apoptótica mediante la potenciación de la misma y no como una caspasa iniciadora. Estos resultados concuerdan con los publicados por Nieto-Miguel y colaboradores (2007) en los que la activación de la caspasa-4 en células tratadas con edelfosina, no es el resultado de un acontecimiento inicial, sino que se presenta como un fenómeno tardío que tiene lugar en la cascada de señalización apoptótica tras la formación del apoptosoma ${ }^{134}$. El tratamiento con neutrófilos activados en células HeLa provocó la activación de la caspasa- 8 a las 6 horas de tratamiento. También observamos la fragmentación temprana de la proteína integral de membrana de RE Bap31 por la caspasa-8, conduciendo a la generación de un fragmento de 20 $\mathrm{kDa}$ (p20) se ha relacionado con la conducción de señales proapoptóticas entre el RE y la mitocondria, induciendo la liberación del $\mathrm{Ca}^{2+}$ del $\mathrm{RE}$ y su consiguiente incorporación en la mitocondria, lo que tiene como consecuencia la ruptura de la membrana mitocondrial y la liberación del citocromo $c$ al citosol ${ }^{319}$. Al inhibir la ARG1 presente en N-fMLP observamos que los marcadores de estrés de RE como PERK fosforilado o CHOP dejan de detectarse, al igual que las caspasas 4, 8 y la ruptura de su sustrato Bap31. Sin embargo, podemos detectar la activación de la caspasa-3 y la ruptura de su sustrato PARP-1. La caspasa-3 es una cisteínproteasa efectora que es procesada a su forma activa por las caspasas 8,9 y 10, además de la granzima $B^{320,321}$. Suponemos que tras inhibir la actividad arginasa con nor-NOHA son las caspasas 9 ó 10 las encargadas de dirigir la muerte inducida por neutrófilos activados. En conjunto, nuestros resultados indican que la muerte inducida por el sobrenadante del exocitado de neutrófilos inducido por fMLP, depende en gran medida de la actividad de la ARG1, y que esta muerte parece estar desencadenada por señales de estrés de RE dirigida por la ruta PERK de la respuesta UPR.

Con respecto a la utilización de enzimas que degraden la L-Arg, actualmente existen ensayos clínicos con las enzimas recombinantes ADI-PEG20 (Polaris Pharmaceuticals, Inc.) para el tratamiento del carcinoma hepatocelular, cáncer de pulmón de células pequeñas, cáncer de próstata, cáncer de mama metastásico, melanoma metastásico, leucemia mieloide aguda y linfomas no-Hodgkin's. Además, existe otro estudio en fase I llevado por la compañía 
biotecnológica BCT (Bio-Cancer Treatment International Limited) en el que se está utilizando la enzima recombinante humana ARG1 (rhARG1-BCT100) en pacientes con leucemia refractaria (información disponible en www.clinicaltrials.gov). Estos estudios tienen en común la administración intravenosa de la enzima recombinante ADI-PEG20 ó rhARG1, resultando en la disminución de los niveles de L-Arg en el suero de los pacientes tratados. La L-Arg es un aminoácido importante para el correcto funcionamiento del sistema inmune y para la activación y proliferación de células $\mathrm{T}^{48,322-324}$. Sin embargo, en presencia de ARG1, las células T pueden aumentar hasta 5 veces la incorporación de L-citrulina para producir L-Arg a través del ciclo de la urea. Si los niveles de L-citrulina son suficientes, las células T pueden mantener la expresión de la cadena CD3ל y la proliferación celular ${ }^{325}$. Se conoce que las células $\mathrm{T}_{\mathrm{H}} 1$ juegan un papel importante en la inmunidad anti-tumoral. Esta población de células T puede actuar directamente sobre la proliferación de células tumorales mediante la liberación de IFN$\gamma$, TNF- $\alpha$ y componentes de gránulos citolíticos, como indirectamente a través de la activación y expansión de las células $\mathrm{T}$ citotóxicas, lliberadoras de moléculas citotóxicas como las granzimas y perforinas ${ }^{326}$. Al disminuir los niveles de L-Arg en sangre, se bloquea el papel benéfico de las células $\mathrm{T}$ en la batalla contra la proliferación de células tumorales. A diferencia de las terapias establecidas con enzimas que catabolizan la L-Arg, la ARG1 de neutrófilos se encuentra localizada en gránulos intracelulares y puede ser movilizada tras la activación celular $^{13}$. La exocitosis de gránulos en neutrófilos está estrechamente regulada por la maquinaria SNARE, evitando la liberación de moléculas nocivas sin una estimulación específica ${ }^{267,268,327}$. Hemos observado que los neutrófilos humanos pueden liberar hasta un 25\% de la ARG1 contenida en los gránulos intracelulares tras la estimulación con fMLP. Esta liberación es suficiente para inducir apoptosis en células tumorales en un periodo de 24 horas. Nuestros datos indican que la ARG1 contenida en los gránulos intracelulares de los neutrófilos humanos es capaz de inducir apoptosis en células tumorales posiblemente a través de la privación de L-Arg, sin embargo, la inhibición de la actividad arginasa no suprime completamente la apoptosis. Los neutrófilos humanos poseen otros componentes citotóxicos como las proteasas, S100A8/A9 (calprotectina) y especies reactivas de oxígeno que pueden estar contribuyendo a la destrucción de las células tumorales cuando se inhibe la ARG1328,329.

Aunque nos hemos centrado en la supuesta acción antitumoral de la ARG1, existen evidencias sobre la participación de la actividad arginasa en la inmunosupresión mediada por el por el reclutamiento de células MDSCs y neutrófilos en el microambiente tumoral $52,330,331$. Además los neutrófilos activados generan especies reactivas de oxígeno que pueden inducir mutaciones en genes específicos que favorecen la transformación de las células normales ${ }^{332,333}$. 
Se conoce que los neutrófilos constituyen una de las poblaciones celulares mayoritarias en el infiltrado de células inflamatorias en muchos modelos de cáncer. Estudios recientes han demostrado que señales específicas como el TGF- $\beta$ (transforming growth factor- $\beta$ ) inducen la formación de un fenotipo pro-tumorigénico ó N2 en los neutrófilos asociados a tumores, capaz de promover el crecimiento tumoral y la supresión de la respuesta inmune antitumoral $^{70,334}$. Sin embargo, también existe un fenotipo antitumoral ó N1 que puede inducir apoptosis en las células tumorales a través de Fas-ligando, especies reactivas de oxígeno o por la citotóxicidad celular mediada por anticuerpos ${ }^{335-337}$.

Por lo tanto, a pesar de que la ARG1 y la presencia de los neutrófilos en el microambiente tumoral pueden actuar como una espada de doble filo en la carcinogénesis, utilizando los conocimientos actuales sobre el metabolismo de la L-Arg en células T y la manipulación de la infiltración y degranulación de los neutrófilos en el microambiente tumoral, se puede definir en qué circunstancias la enzima ARG1 puede ser utilizada como supresor del crecimiento tumoral. La elucidación de mecanismos que regulen la secreción de la ARG1 sin inducir las propiedades pro-tumorales de los neutrófilos podría establecer un nuevo enfoque para el tratamiento del cáncer. 



\section{Conclusiones}

1. La ausencia de L-Arg induce en células T humanas estrés del retículo endoplásmico y la activación de la respuesta de proteínas desplegadas a través de la quinasa IRE1 $\alpha$.

2. En respuesta al estrés del retículo endoplásmico mediado por la ausencia de L-Arg, las células $\mathrm{T}$ activan la autofagia mediante la vía de señalización IRE1 $\alpha / \mathrm{JNK}$ como mecanismo de supervivencia.

3. No sólo la deficiencia de L-Arg, sino también de L-Met ó L-Tyr induce en células T el procesamiento del mRNA de XBP1 y la activación del flujo autofágico.

4. La arginasa I de neutrófilos bloquea la proliferación e induce apoptosis en líneas tumorales de mama, melanoma, ovario, cuello uterino, pulmón, riñón, próstata y páncreas.

5. La arginasa I de neutrófilos puede ser liberada por exocitosis mediante la estimulación con fMLP.

6. La muerte mediada por el exocitado de neutrófilos activados con fMLP induce la activación de la ruta PERK/ATF4/CHOP de la respuesta UPR en células HeLa, y la muerte celular por apoptosis. Está muerte celular depende en gran medida de la actividad arginasa y está mediada por la activación de marcadores de estrés de retículo endoplásmico como CHOP, caspasa-4, caspasa-8 y Bap31. 



\section{Bibliografía}

8.Morris SM. Arginine: beyond protein. Am J Clin Nutr. 2006;83(2):508S-512S.

9.Morris SM. Arginine metabolism: boundaries of our knowledge. J Nutr. 2007;137(6 Suppl 2):1602S-1609S.

10.Ikemoto $\mathrm{M}$, Tabata $\mathrm{M}$, Miyake $\mathrm{T}$, et al. Expression of human liver arginase in Escherichia coli. Purification and properties of the product. Biochem J. 1990;270(3):697-703.

11.Kim PS, Iyer RK, Lu KV, et al. Expression of the liver form of arginase in erythrocytes. Molecular Genetics and Metabolism. 2002;76(2):100-110.

1.Wu G, Meininger CJ, Knabe DA, Bazer FW, Rhoads JM. Arginine nutrition in development, health and disease. Curr Opin Clin Nutr Metab Care. 2000;3(1):5966.

2.Barbul A. Arginine: biochemistry, physiology, and therapeutic implications. JPEN J Parenter Enteral Nutr. 1986;10(2):227238.

3.Suchner U, Heyland DK, Peter K. Immunemodulatory actions of arginine in the critically ill. Br J Nutr. 2007;87(S1):S121S132. doi:10.1079/BJN2001465.

4.Hibbs JB, Taintor RR, Vavrin Z, Rachlin EM. Nitric oxide: a cytotoxic activated macrophage effector molecule. Biochemical and Biophysical Research Communications. 1988;157(1):87-94.

5.Bogdan C. Nitric oxide and the immune response. Nat Immunol. 2001;2(10):907916. doi:10.1038/ni1001-907.

6.Wu G, Pond WG, Flynn SP, Ott TL, Bazer FW. Maternal dietary protein deficiency decreases nitric oxide synthase and ornithine decarboxylase activities in placenta and endometrium of pigs during early gestation. J Nutr. 1998;128(12):2395-2402.

7.Morris SM. Arginine metabolism in vascular biology and disease. Vasc Med. 2005;10 Suppl 1:S83-7.

12.Sica A, Bronte V. Altered macrophage differentiation and immune dysfunction in tumor development. Journal of Clinical Investigation. 2007;117(5):1155-1166. doi: 10.1172/JCI31422.

13.Munder M, Mollinedo F, Calafat J, et al. Arginase I is constitutively expressed in human granulocytes and participates in fungicidal activity. Blood. 2005;105(6): $2549-2556$. doi:10.1182/ blood-2004-07-2521.

14.Jacobsen LC, Theilgaard-Mönch K, Christensen EI, Borregaard N. Arginase 1 is expressed in myelocytes/ metamyelocytes and localized in gelatinase granules of human neutrophils. Blood. 2007;109(7):30843087. doi:10.1182/blood-2006-06-032599.

15.Jenkinson $\mathrm{CP}$, Grody WW, Cederbaum SD. Comparative properties of arginases. Comparative Biochemistry and Physiology Part B: Biochemistry and Molecular Biology. 1996;114(1):107-132. doi: 10.1016/0305-0491(95)02138-8.

16.Ming X-F, Rajapakse AG, Yepuri G, et al. Arginase II Promotes Macrophage Inflammatory Responses Through Mitochondrial Reactive Oxygen Species, Contributing to Insulin Resistance and Atherogenesis. J Am Heart Assoc. 2012;1(4):e000992. doi:10.1161/JAHA. 112.000992 . 
17.Soberón G, Tarrab R, Placios R. Urea biosynthesis. An experimental model for the study of the integration of a metabolic cycle during biological evolution. A review. Bol Estud Med Biol. 1969;26(1):15-33.

18.Shantz LM, Levin VA. Regulation of ornithine decarboxylase during oncogenic transformation: mechanisms and therapeutic potential. Amino Acids. 2007;33(2):213-223. doi:10.1007/ s00726-007-0531-2.

19.Kung JT, Brooks SB, Jakway JP, Leonard LL, Talmage DW. Suppression of in vitro cytotoxic response by macrophages due to induced arginase. J Exp Med. 1977;146(3):665-672.

20.Alderton WK, Cooper CE, Knowles RG. Nitric oxide synthases: structure, function and inhibition. Biochem J. 2001;357(Pt 3):593-615.

21.Kone BC, Kuncewicz T, Zhang W, Yu Z-Y. Protein interactions with nitric oxide synthases: controlling the right time, the right place, and the right amount of nitric oxide. American Journal of Physiology - Renal Physiology. 2003;285(2):F178-F190. doi:10.1152/ ajprenal.00048.2003.

22.Humm A, Fritsche E, Mann K, Gohl M, Huber R. Recombinant expression and isolation of human L-arginine: glycine amidinotransferase and identification of its active-site cysteine residue. Biochem J. 1997;322:771-776.

23.Regunathan S, Reis DJ. Characterization of arginine decarboxylase in rat brain and liver: distinction from ornithine decarboxylase. J Neurochem. 2000;74(5): 2201-2208.

24.Efron D, Barbul A. Role of arginine in immunonutrition. I Gastroenterol. 2000;35 Suppl 12:20-23.

25.Okamoto Y, Okano K, Izuishi K, Usuki H, Wakabayashi H, Suzuki Y. Attenuation of the systemic inflammatory response and infectious complications after gastrectomy with preoperative oral arginine and omega-3 fatty acids supplemented immunonutrition. World J Surg. 2009;33(9):1815-1821. doi: $10.1007 /$ s00268-009-0140-1.

26.Barbul A, Wasserkrug HL, Yoshimura N, et al. High arginine levels in intravenous hyperalimentation abrogate posttraumatic immune suppression. J Surg Res. 1984.

27.Wu G. Amino acids: metabolism, functions, and nutrition. Amino Acids. 2009;37(1):117. doi:10.1007/s00726-009-0269-0.

28. Efron DT, Barbul A. Arginine and immunonutrition: a reevaluation. Nutrition. 2000;16(1):73-74.

29.Nath J, Powledge A. Modulation of human neutrophil inflammatory responses by nitric oxide: studies in unprimed and LPS-primed cells. J Leukoc Biol. 1997;62(6):805-816.

30.Stechmiller JK, Childress B, Porter T. Arginine immunonutrition in critically ill patients: a clinical dilemma. Am J Crit Care. 2004;13(1):17-23.

31.Heyland DK, Novak F, Drover JW, Jain M, Su $X$, Suchner U. Should immunonutrition become routine in critically ill patients? A systematic review of the evidence. JAMA. 2001;286(8):944-953.

32.Lorente JA, Landín L, De Pablo R, Renes E, Liste D. L-arginine pathway in the sepsis syndrome. Crit Care Med. 1993;21(9):1287-1295.

33.Duke T, South M, Stewart A. Activation of the L-arginine nitric oxide pathway in severe sepsis. Arch Dis Child. 1997;76(3): 203-209.

34.Brenner T, Fleming TH, Rosenhagen $\mathrm{C}$, et al. L-arginine and asymetric dimethylarginine are early predictors for survival in septic patients with acute liver failure. Mediators Inflamm. $2012 ; 2012: 210454$. d o i : $10.1155 / 2012 / 210454$. 
35.Ochoa JB, Strange J, Kearney P, Gellin G, Endean E, Fitzpatrick E. Effects of Larginine on the proliferation of $\mathrm{T}$ lymphocyte subpopulations. JPEN J Parenter Enteral Nutr. 2001;25(1):23-29.

36. Munder M, Eichmann K, Modolell M. Alternative metabolic states in murine macrophages reflected by the nitric oxide synthase/arginase balance: competitive regulation by $\mathrm{CD} 4+\mathrm{T}$ cells correlates with Th1/Th2 phenotype. J Immunol. 1998;160(11):5347-5354.

37.Munder M. Arginase: an emerging key player in the mammalian immune system. $\mathrm{Br} J$ Pharmacol. 2009;158(3):638-651. doi: 10.1111/j.1476-5381.2009.00291.x.

38.Corraliza IM, Campo ML, Soler G, Modolell M. Determination of arginase activity in macrophages: a micromethod. I Immunol Methods. 1994;174(1-2):231-235.

39.Bronte V, Zanovello P. Regulation of immune responses by L-arginine metabolism. Nat Rev Immunol. 2005;5(8):641-654. doi: 10.1038/nri1668.

40.Currie GA. Activated macrophages kill tumour cells by releasing arginase. Nature. 1978;273(5665):758-759.

41. Bruch-Gerharz D, Schnorr O, Suschek C, et al. Arginase 1 Overexpression in Psoriasis. The American Journal of Pathology. 2003;162(1):203-211. doi:10.1016/ S0002-9440(10)63811-4.

42. Waddington SN. Arginase in glomerulonephritis. Kidney Int. 2002;61(3):876-881. doi:10.1046/j. 1523-1755.2002.00236.x.

43. Corraliza I, Moncada S. Increased expression of arginase II in patients with different forms of arthritis. Implications of the regulation of nitric oxide. J Rheumatol. 2002;29(11):2261-2265.

44.Zea AH, Culotta KS, Ali J, et al. Decreased expression of CD3zeta and nuclear transcription factor kappa B in patients with pulmonary tuberculosis: potential mechanisms and reversibility with treatment. J Infect Dis. 2006;194(10): 1385-1393. doi:10.1086/508200.

45.Morris CR, Poljakovic M, Lavrisha L, Machado L, Kuypers FA, Morris SM. Decreased arginine bioavailability and increased serum arginase activity in asthma. Am J Respir Crit Care Med. 2004;170(2):148-153. doi:10.1164/rccm. 200309-1304OC.

46.Rouzaut A, Subirá ML, de Miguel C, et al. Co-expression of inducible nitric oxide synthase and arginases in different human monocyte subsets. Apoptosis regulated by endogenous NO. Biochim Biophys Acta. 1999;1451(2-3):319-333.

47.Pesce JT, Ramalingam TR, Mentink-Kane $\mathrm{MM}$, et al. Arginase-1-Expressing Macrophages Suppress Th2 CytokineDriven Inflammation and Fibrosis. PLoS Pathog. 2009;5(4):e1000371. doi:10.1371/ journal.ppat.1000371.

48.Wanasen N, Soong L. L-arginine metabolism and its impact on host immunity against Leishmania infection. Immunol Res. 2008;41(1):15-25. doi:10.1007/ s12026-007-8012-y.

49.Lee A-H, Iwakoshi NN, Glimcher LH. XBP-1 regulates a subset of endoplasmic reticulum resident chaperone genes in the unfolded protein response. Molecular and Cellular Biology. 2003;23(21):7448-7459.

50.El-Gayar S, Thüring-Nahler H, Pfeilschifter J, Röllinghoff M, Bogdan C. Translational control of inducible nitric oxide synthase by IL-13 and arginine availability in inflammatory macrophages. J Immunol. 2003;171(9): 4561-4568.

51.Rodriguez PC, Zea AH, Culotta KS, Zabaleta J, Ochoa JB, Ochoa AC. Regulation of T cell receptor CD3zeta chain expression by L-arginine. Journal of Biological Chemistry. 2002;277(24):21123-21129. doi:10.1074/jbc.M110675200.

52. Rodriguez PC, Ochoa AC. Arginine regulation by myeloid derived 
suppressor cells and tolerance in cancer: mechanisms and therapeutic perspectives. Immunol Rev. 2008;222:180-191. doi:10.1111/j. 1600-065X.2008.00608.x.

53.Weiss A, Wiskocil RL, Stobo JD. The role of T3 surface molecules in the activation of human T cells: a two-stimulus requirement for IL 2 production reflects events occurring at a pre-translational level. J Immunol. 1984;133(1):123-128.

54.Clevers H, Dunlap S, Terhorst C. The transmembrane orientation of the epsilon chain of the TcR/CD3 complex. Eur J Immunol. 1988;18(5):705-710. doi: 10.1002/eji.1830180508.

55.Clayton LK, D'Adamio L, Howard FD, et al. CD3 eta and CD3 zeta are alternatively spliced products of a common genetic locus and are transcriptionally and/or post-transcriptionally regulated during T-cell development. Proceedings of the National Academy of Sciences. 1991;88(12): 5202-5206. doi:10.1073/pnas.88.12.5202.

56.Latour S, Veillette A. Proximal protein tyrosine kinases in immunoreceptor signaling. Current opinion in immunology. 2001.

57. RL, Samelson LE. Complex complexes: signaling at the TCR. Immunity. 1996;5(3):197-205.

58.Penna D, Müller S, Martinon F, Demotz S, Iwashima M, Valitutti S. Degradation of ZAP-70 following antigenic stimulation in human T lymphocytes: role of calpain proteolytic pathway. J Immunol. 1999;163(1):50-56.

59.Rodriguez PC, Quiceno DG, Ochoa AC. Larginine availability regulates $T$ lymphocyte cell-cycle progression. Blood. 2007;109(4):1568-1573. doi: 10.1182/blood-2006-06-031856.

60.Baniyash M. TCR zeta-chain downregulation: curtailing an excessive inflammatory immune response. Nat Rev Immunol. 2004;4(9):675-687. doi:10.1038/nri1434.
61.Kropf P, Baud D, Marshall SE, et al. Arginase activity mediates reversible $\mathrm{T}$ cell hyporesponsiveness in human pregnancy. Eur J Immunol. 2007;37(4): 935-945. doi:10.1002/eji.200636542.

62.Bernard A, Kasten M, Meier C, et al. Red blood cell arginase suppresses Jurkat ( $\mathrm{T}$ cell) proliferation by depleting arginine. Surgery. 2008;143(2):286-291. doi: 10.1016/j.surg.2007.07.037.

63.Palomero Rodríguez MA, García-Navas R, Laporta Báez Y, et al. Relationship between arginase activity and the storage time of packed red blood cells. Rev Esp Anestesiol Reanim. 2012.

64.Lewis CE, Pollard JW. Distinct role of macrophages in different tumor microenvironments. Cancer Research. $2006 ; 66(2): 605-612$. d o i : 10.1158/0008-5472.CAN-05-4005.

65.Greten TF, Manns MP, Korangy F. Myeloid derived suppressor cells in human diseases. Int Immunopharmacol. 2011;11(7):802-807. doi:10.1016/j.intimp. 2011.01.003.

66.Huang B, Pan P-Y, Li Q, et al. Gr-1+CD115+ immature myeloid suppressor cells mediate the development of tumorinduced $\mathrm{T}$ regulatory cells and $\mathrm{T}$-cell anergy in tumor-bearing host. Cancer Research. 2006;66(2):1123-1131. doi: 10.1158/0008-5472.CAN-05-1299.

67.Raychaudhuri B, Rayman P, Ireland J, et al. Myeloid-derived suppressor cell accumulation and function in patients with newly diagnosed glioblastoma. 2011.

68.Srivastava MK, Zhu L, Harris-White M, et al. Myeloid suppressor cell depletion augments antitumor activity in lung cancer. PLoS ONE. 2012;7(7):e40677. doi: 10.1371/journal.pone.0040677.

69.Fridlender ZG, Albelda SM. Tumorassociated neutrophils: friend or foe? Carcinogenesis. 2012;33(5):949-955. doi: $10.1093 /$ carcin/bgs123. 
70.Fridlender ZG, Sun J, Kim S, et al. Polarization of tumor-associated neutrophil phenotype by TGF-beta: "N1" versus "N2" TAN. Cancer Cell. 2009;16(3):183-194. doi:10.1016/j.ccr. 2009.06.017.

71.Scott L, Lamb J, Smith S, Wheatley DN. Single amino acid (arginine) deprivation: rapid and selective death of cultured transformed and malignant cells. Br J Cancer. 2000;83(6):800-810. doi:10.1054/bjoc.2000.1353.

72.Wheatley DN, Campbell E, Lai PBS, Cheng PNM. A rational approach to the systemic treatment of cancer involving medium-term depletion of arginine. Gene Ther Mol Biol. 2005;9:33-40.

73.Shen LJ, Beloussow K, Shen WC. Modulation of arginine metabolic pathways as the potential anti-tumor mechanism of recombinant arginine deiminase. CANCER LETTERS. 2006.

74.Ott PA, Carvajal RD, Pandit-Taskar N, et al. Phase I/II study of pegylated arginine deiminase (ADI-PEG 20) in patients with advanced melanoma. Invest New Drugs. 2013;31(2):425-434. doi:10.1007/ s10637-012-9862-2.

75.Delman KA, Brown TD, Thomas M. Phase I/ II trial of pegylated arginine deiminase (ADI-PEG20) in unresectable hepatocellular carcinoma. J Clin Oncol. 2005.

76.Ni Y, Schwaneberg U, Sun Z-H. Arginine deiminase, a potential anti-tumor drug. CANCER LETTERS. 2008;261(1):1-11. doi:10.1016/j.canlet.2007.11.038.

77.Barbosa-Tessmann IP. Activation of the Human Asparagine Synthetase Gene by the Amino Acid Response and the Endoplasmic Reticulum Stress Response Pathways Occurs by Common Genomic Elements. Journal of Biological Chemistry. 2000. doi:10.1074/jbc.M000004200.

78.Zhang P, McGrath BC, Reinert J, et al. The GCN2 eIF2 $\alpha$ kinase is required for adaptation to amino acid deprivation in mice. Molecular and Cellular Biology. 2002;22(19):6681-6688. doi:10.1128/ MCB.22.19.6681-6688.2002.

79.Hay N. Upstream and downstream of mTOR. Genes E Development. 2004;18(16):19261945. doi:10.1101/gad.1212704.

80.Ma Y, Hendershot LM. ER chaperone functions during normal and stress conditions. Journal of Chemical Neuroanatomy. 2004;28(1-2):51-65. doi: 10.1016/j.jchemneu.2003.08.007.

81.Bartoszewski R, Brewer JW, Rab A, et al. The unfolded protein response (UPR)activated transcription factor $\mathrm{X}$-boxbinding protein 1 (XBP1) induces microRNA-346 expression that targets the human antigen peptide transporter 1 (TAP1) mRNA and governs immune regulatory genes. J Biol Chem. 2011;286(48):41862-41870. doi:10.1074/ jbc.M111.304956.

82.Tsang KY, Chan D, Bateman JF, Cheah KSE. In vivo cellular adaptation to ER stress: survival strategies with double-edged consequences. Journal of Cell Science. 2010;123(Pt 13):2145-2154. doi:10.1242/ jcs.068833.

83.Kadowaki H, Nishitoh H, Ichijo H. Survival and apoptosis signals in ER stress: the role of protein kinases. Journal of Chemical Neuroanatomy. 2004;28(1-2):93100. doi:10.1016/j.jchemneu.2004.05.004.

84.Hetz C, Martinon F, Rodriguez D, Glimcher LH. The unfolded protein response: integrating stress signals through the stress sensor IRE1 $\alpha$. Physiological Reviews. 2011;91(4):1219-1243. doi: 10.1152/physrev.00001.2011.

85.Hollien J. Evolution of the unfolded protein response. Biochim Biophys Acta. 2013;1833(11):2458-2463. doi:10.1016/ j.bbamcr.2013.01.016.

86.Lee H, Noh JY, Oh Y, et al. IRE1 plays an essential role in ER stress-mediated aggregation of mutant huntingtin via the inhibition of autophagy flux. Human 
Molecular Genetics. 2011;21(1):101-114. doi:10.1093/hmg/ddr445.

87.Gardner BM, Walter P. Unfolded proteins are Ire1-activating ligands that directly induce the unfolded protein response. Science. 2011;333(6051):1891-1894. doi: 10.1126/science.1209126.

88.Chen Y, Brandizzi F. IRE1: ER stress sensor and cell fate executor. Trends in Cell Biology. 2013. doi:10.1016/j.tcb. 2013.06.005.

89.Uemura $\mathrm{A}, \mathrm{Oku} \mathrm{M}$, Mori $\mathrm{K}$, Yoshida $\mathrm{H}$. Unconventional splicing of XBP1 mRNA occurs in the cytoplasm during the mammalian unfolded protein response. Journal of Cell Science. 2009;122(Pt 16):2877-2886. doi:10.1242/ jcs.040584.

90.Sriburi R, Jackowski S, Mori K, Brewer JW. XBP1: a link between the unfolded protein response, lipid biosynthesis, and biogenesis of the endoplasmic reticulum. The Journal of Cell Biology. 2004;167(1):35-41. doi:10.1083/jcb. 200406136.

91. Yan W, Frank CL, Korth MJ, et al. Control of PERK eIF2alpha kinase activity by the endoplasmic reticulum stress-induced molecular chaperone P58IPK. Proc Natl Acad Sci USA. 2002;99(25):15920-15925. doi:10.1073/pnas.252341799.

92.Donnelly N, Gorman AM, Gupta S, Samali A. The eIF2 $\alpha$ kinases: their structures and functions. Cell Mol Life Sci. 2013;70(19): 3493-3511. doi:10.1007/ s00018-012-1252-6.

93.Kilberg MS, Shan J, Su N. ATF4-dependent transcription mediates signaling of amino acid limitation. Trends in Endocrinology \& Metabolism. 2009;20(9): 436-443. doi:10.1016/j.tem.2009.05.008.

94.Kepp O, Galluzzi L, Giordanetto F, et al. Disruption of the PP1/GADD34 complex induces calreticulin exposure. Cell Cycle. 2009;8(23):3971-3977.
95.Oyadomari S, Mori M. Roles of CHOP/ GADD153 in endoplasmic reticulum stress. Cell Death Differ. 2004;11(4):381389. doi:10.1038/sj.cdd.4401373.

96.Cullinan SB, Diehl JA. PERK-dependent activation of Nrf2 contributes to redox homeostasis and cell survival following endoplasmic reticulum stress. I Biol Chem. 2004;279(19):20108-20117. doi: 10.1074/jbc.M314219200.

97.Cullinan SB, Zhang D, Hannink M, Arvisais E, Kaufman RJ, Diehl JA. Nrf2 is a direct PERK substrate and effector of PERKdependent cell survival. Molecular and Cellular Biology. 2003;23(20):7198-7209.

98.Li M, Baumeister P, Roy B, et al. ATF6 as a transcription activator of the endoplasmic reticulum stress element: thapsigargin stress-induced changes and synergistic interactions with NF-Y and YY1. Molecular and Cellular Biology. 2000;20(14):5096-5106.

99.Liu L, Qi X, Chen Z, et al. Targeting the IRE1 $\alpha /$ XBP1 and ATF6 arms of the unfolded protein response enhances VEGF blockade to prevent retinal and choroidal neovascularization. The American Journal of Pathology. 2013;182(4):1412-1424. doi:10.1016/ j.ajpath.2012.12.020.

100.Teske BF, Wek SA, Bunpo P, et al. The eIF2 kinase PERK and the integrated stress response facilitate activation of ATF6 during endoplasmic reticulum stress. Mol Biol Cell. 2011;22(22):4390-4405. doi: 10.1091/mbc.E11-06-0510.

101. Yoshida H, Matsui T, Yamamoto A, Okada T, Mori K. XBP1 mRNA is induced by ATF6 and spliced by IRE1 in response to ER stress to produce a highly active transcription factor. Cell. 2001;107(7): 881-891.

102.Hetz C. The unfolded protein response: controlling cell fate decisions under ER stress and beyond. Nat Rev Mol Cell Biol. 2012;13(2):89-102. doi:doi:10.1038/ nrm3270. 
103.Harding HP, Zhang Y, Bertolotti A, Zeng H, Ron D. Perk is essential for translational regulation and cell survival during the unfolded protein response. Mol Cell. 2000;5(5):897-904.

104.Hollien J, Weissman JS. Decay of endoplasmic reticulum-localized mRNAs during the unfolded protein response. Science. 2006;313(5783):104107. doi:10.1126/science.1129631.

105.Kroemer G, Mariño G, Levine B. Autophagy and the Integrated Stress Response. Mol Cell. 2010;40(2):280-293. doi:10.1016/ j.molcel.2010.09.023.

106.Sitia R, Braakman I. Quality control in the endoplasmic reticulum protein factory. Nature. 2003;426(6968):891-894. doi: 10.1038 / nature02262.

107.Kang S-W, Rane NS, Kim SJ, Garrison JL, Taunton J, Hegde RS. Substrate-specific translocational attenuation during ER stress defines a pre-emptive quality control pathway. Cell. 2006;127(5):9991013. doi:10.1016/j.cell.2006.10.032.

108.Oyadomari S, Yun C, Fisher EA, et al. Cotranslocational degradation protects the stressed endoplasmic reticulum from protein overload. Cell. 2006;126(4): 727-739. doi:10.1016/j.cell.2006.06.051.

109.Calì T, Galli C, Olivari S, Molinari M. Segregation and rapid turnover of EDEM1 by an autophagy-like mechanism modulates standard ERAD and folding activities. Biochemical and Biophysical Research Communications. 2008;371(3):405-410. doi:10.1016/j.bbrc. 2008.04.098

110.Kincaid MM, Cooper AA. ERADicate ER Stress or Die Trying. Antioxidants $\mathcal{E}$ Redox Signaling. 2007;9(12):2373-2387. doi:10.1089/ars.2007.1817.

111.Zhang W-J, Hanisch S, Kwaaitaal M, Pedersen C, Thordal-Christensen H. A component of the Sec61 ER protein transporting pore is required for plant susceptibility to powdery mildew. Front
Plant Sci. 2013;4:127. doi:10.3389/fpls. 2013.00127.

112. Crawshaw SG, Cross BCS, Wilson CM, High $\mathrm{S}$. The oligomeric state of Derlin-1 is modulated by endoplasmic reticulum stress. Mol Membr Biol. 2007;24(2):113120. doi:10.1080/09687860600988727.

113. Ye Y, Shibata Y, Yun C, Ron D, Rapoport TA. A membrane protein complex mediates retro-translocation from the ER lumen into the cytosol. Nature. 2004;429(6994): 841-847. doi:10.1038/nature02656.

114.Schrader EK, Harstad KG, Matouschek A. Targeting proteins for degradation. Nat Chem Biol. 2009;5(11):815-822. doi: 10.1038/nchembio.250.

115.Pickart CM, Eddins MJ. Ubiquitin: structures, functions, mechanisms. Biochimica et Biophysica Acta (BBA) Molecular Cell Research. 2004;1695(1-3): 55-72. doi:10.1016/j.bbamcr.2004.09.019.

116.Li W, Ye Y. Polyubiquitin chains: functions, structures, and mechanisms. Cell Mol Life Sci. 2008;65(15):2397-2406. doi: $10.1007 / \mathrm{s} 00018-008-8090-6$.

117.Pickart CM. Mechanisms underlying ubiquitination. Annu Rev Biochem. 2001;70:503-533. doi:10.1146/ annurev.biochem.70.1.503.

118.Qin L, Wang Z, Tao L, Wang Y. ER stress negatively regulates $\mathrm{AKT} / \mathrm{TSC} / \mathrm{mTOR}$ pathway to enhance autophagy. Autophagy. 2010;6(2):239-247.

119.Tabas I, Ron D. Integrating the mechanisms of apoptosis induced by endoplasmic reticulum stress. Nature Cell Biology. 2011;13(3):184-190. doi:10.1038/ ncb0311-184.

120.Vaeteewoottacharn K, Kariya R, Matsuda K, et al. Perturbation of proteasome function by bortezomib leading to ER stress-induced apoptotic cell death in cholangiocarcinoma. J Cancer Res Clin Oncol. 2013;139(9):1551-1562. doi: 10.1007/s00432-013-1473-6. 
121.Tatsuta T, Hosono M, Miura Y, et al. Involvement of ER stress in apoptosis induced by sialic acid-binding lectin (leczyme) from bullfrog eggs. Int $J$ Oncol. 2013;43(6):1799-1808. doi: 10.3892/ijo.2013.2128.

122.Ghavami S, Yeganeh B, Stelmack GL, et al. Apoptosis, autophagy and ER stress in mevalonate cascade inhibition-induced cell death of human atrial fibroblasts. Cell Death and Disease. 2012;3:e330. doi: 10.1038/cddis.2012.61.

123.Shiraishi H, Okamoto $\mathrm{H}$, Yoshimura A, Yoshida H. ER stress-induced apoptosis and caspase-12 activation occurs downstream of mitochondrial apoptosis involving Apaf-1. Journal of Cell Science. 2006;119(Pt 19):3958-3966. doi:10.1242/ jcs.03160.

124.Tait SWG, Green DR. Mitochondria and cell d e a th: outer membrane permeabilization and beyond. Nat Rev Mol Cell Biol. 2010;11(9):621-632. doi: $10.1038 /$ nrm 2952.

125.Shamas-Din A, Brahmbhatt H, Leber B, Andrews DW. BH3-only proteins: Orchestrators of apoptosis. Biochim Biophys Acta. 2011;1813(4):508-520. doi: 10.1016/j.bbamcr.2010.11.024.

126.Rodriguez D, Rojas-Rivera D, Hetz C. Integrating stress signals at the endoplasmic reticulum: The BCL-2 protein family rheostat. Biochim Biophys Acta. 2011;1813(4):564-574. doi:10.1016/ j.bbamcr.2010.11.012.

127.Dey S, Baird TD, Zhou D, Palam LR, Spandau DF, Wek RC. Both transcriptional regulation and translational control of ATF4 are central to the integrated stress response. J Biol Chem. 2010;285(43):33165-33174. doi: 10.1074/jbc.M110.167213.

128.Puthalakath H, O'Reilly LA, Gunn P, et al. ER stress triggers apoptosis by activating BH3-only protein Bim. Cell. 2007;129(7):1337-1349. doi:10.1016/ j.cell.2007.04.027.
129.Wei MC, Zong W-X, Cheng EH, et al. Proapoptotic BAX and BAK: a requisite gateway to mitochondrial dysfunction and death. Science. 2001;292(5517):727730. doi:10.1126/science.1059108.

130.Buytaert E, Callewaert G, Vandenheede JR, Agostinis P. Deficiency in apoptotic effectors Bax and Bak reveals an autophagic cell death pathway initiated by photodamage to the endoplasmic reticulum. Autophagy. 2006;2(3):238-240.

131.Woehlbier U, Hetz C. Modulating stress responses by the UPRosome: a matter of life and death. Trends Biochem Sci. 2011;36(6):329-337. doi:10.1016/j.tibs. 2011.03.001.

132.Gajate C, Matos-da-Silva M, Dakir E-H, Fonteriz RI, Alvarez J, Mollinedo F. Antitumor alkyl-lysophospholipid analog edelfosine induces apoptosis in pancreatic cancer by targeting endoplasmic reticulum. Oncogene. 2012;31(21):2627-2639. doi:10.1038/onc. 2011.446 .

133.Upton J-P, Austgen K, Nishino M, et al. Caspase-2 cleavage of BID is a critical apoptotic signal downstream of endoplasmic reticulum stress. Molecular and Cellular Biology. 2008;28(12):39433951. doi:10.1128/MCB.00013-08.

134.Nieto-Miguel T, Fonteriz RI, Vay L, Gajate C, Lopez-Hernandez S, Mollinedo F. Endoplasmic Reticulum Stress in the Proapoptotic Action of Edelfosine in Solid Tumor Cells. Cancer Research. 2007;67(21):10368-10378. doi: 10.1158/0008-5472.CAN-07-0278.

135.Dejeans N, Tajeddine N, Beck R, et al. Endoplasmic reticulum calcium release potentiates the ER stress and cell death caused by an oxidative stress in MCF-7 cells. Biochemical Pharmacology. 2010;79(9):1221-1230. doi:10.1016/j.bcp. 2009.12.009.

136.Han D, Lerner AG, Vande Walle L, et al. IRE1alpha kinase activation modes control alternate endoribonuclease outputs to determine divergent cell 
fates. Cell. 2009;138(3):562-575. doi: 10.1016/j.cell.2009.07.017.

137.Han X, Zhou J, Zhang P, et al. IRE1 $\alpha$ dissociates with BiP and inhibits ER stress-mediated apoptosis in cartilage development. Cell Signal. 2013;25(11): 2136-2146. doi:10.1016/j.cellsig. 2013.06.011.

138.Ding W-X, Yin X-M. Sorting, recognition and activation of the misfolded protein degradation pathways through macroautophagy and the proteasome. Autophagy. 2008;4(2):141-150.

139.De Duve C, Pressman BC, Gianetto R, et al. Tissue fractionation studies. 6 . Intracellular distribution patterns of enzymes in rat-liver tissue. Biochemical Journal. 1955;60(4):604.

140.De Duve C, Wattiaux R. Functions of lysosomes. Annu Rev Physiol. 1966;28:435-492. doi:10.1146/ annurev.ph.28.030166.002251.

141.Codogno P, Meijer AJ. Autophagy and signaling: their role in cell survival and cell death. Cell Death Differ. 2005;12:1509-1518. doi:10.1038/sj.cdd. 4401751.

142.Mizushima N, Klionsky DJ. Protein turnover via autophagy: implications for metabolism. Annu Rev Nutr. 2007;27:1940. doi:10.1146/annurev.nutr. 27.061406.093749.

143.Dunn WA Jr. Autophagy and related mechanisms of lysosome-mediated protein degradation. Trends in Cell Biology. 1994;4(4):139-143. doi: 10.1016/0962-8924(94)90069-8.

144.Wang Y, Singh R, Xiang Y, Czaja MJ. Macroautophagy and chaperonemediated autophagy are required for hepatocyte resistance to oxidant stress. Hepatology. 2010;52(1):266-277. doi: 10.1002/hep.23645.

145.Tooze SA, Yoshimori T. The origin of the autophagosomal membrane. Nature Cell
Biology. 2010;12(9):831-835. doi:doi: 10.1038/ncb0910-831.

146.Boya P, Reggiori F, Codogno P. Emerging regulation and functions of autophagy. Nature Cell Biology. 2013;15(7):713-720. doi:10.1038/ncb2788.

147.Mizushima N, Ohsumi Y, Yoshimori T. Autophagosome formation in mammalian cells. Cell Struct Funct. 2002;27(6):421-429.

148. Klionsky DJ. Autophagy: from phenomenology to molecular understanding in less than a decade. Nat Rev Mol Cell Biol. 2007;8(11):931-937. doi:10.1038/nrm2245.

149. Massey AC, Zhang C, Cuervo AM. Chaperone-mediated autophagy in aging and disease. Curr Top Dev Biol. 2006;73:205-235. doi:10.1016/ S0070-2153(05)73007-6.

150. Yorimitsu T, Klionsky DJ. Autophagy: molecular machinery for self-eating. Cell Death Differ. 2005;12 Suppl 2:1542-1552. doi:10.1038/sj.cdd.4401765.

151.Klionsky DJ. The molecular machinery of autophagy: unanswered questions. Journal of Cell Science. 2005;118(Pt 1):718. doi:10.1242/jcs.01620.

152.Mizushima N, Noda T, Yoshimori T, et al. A protein conjugation system essential for autophagy. Nature. 1998;395(6700):395398. doi:10.1038/26506.

153.Mizushima $N$, Sugita $H$, Yoshimori $T$, Ohsumi Y. A new protein conjugation system in human. The counterpart of the yeast Apg12p conjugation system essential for autophagy. J Biol Chem. 1998;273(51):33889-33892.

154.Kabeya Y. LC3, a mammalian homologue of yeast Apg8p, is localized in autophagosome membranes after processing. The EMBO Journal. 2000;19(21):5720-5728. doi:10.1093/ emboj/19.21.5720. 
155.Kuma A, Matsui M, Mizushima N. LC3, an autophagosome marker, can be incorporated into protein aggregates independent of autophagy: caution in the interpretation of LC3 localization. Autophagy. 2007;3(4):323-328.

156.Tanida I, Ueno T, Kominami E. LC3 conjugation system in mammalian autophagy. The International Journal of Biochemistry \& Cell Biology. 2004;36(12): 2503-2518. doi:10.1016/j.biocel. 2004.05.009.

157.Pankiv S, Clausen TH, Lamark T, et al. p62/ SQSTM1 binds directly to Atg8/LC3 to facilitate degradation of ubiquitinated protein aggregates by autophagy. Journal of Biological Chemistry. 2007;282(33):24131-24145. doi:10.1074/ jbc.M702824200.

158.Bjørkøy G, Lamark T, Johansen T. p62/ SQSTM1: a missing link between protein aggregates and the autophagy machinery. Autophagy. 2006;2(2):138139.

159.Puissant A, Auberger P. AMPK- and p62/ SQSTM1-dependent autophagy mediate Resveratrol-induced cell death in chronic myelogenous leukemia. Autophagy. 2010;6(5):655-657. doi: 10.4161/auto.6.5.12126.

160.Petiot A, Ogier-Denis E, Blommaart EF, Meijer AJ, Codogno P. Distinct classes of phosphatidylinositol 3'-kinases are involved in signaling pathways that control macroautophagy in HT-29 cells. J Biol Chem. 2000;275(2):992-998.

161.Matsunaga K, Saitoh T, Tabata K, et al. Two Beclin 1-binding proteins, Atg14L and Rubicon, reciprocally regulate autophagy at different stages. Nature Cell Biology. 2009;11(4):385-396. doi: 10.1038/ncb1846.

162.He C, Levine B. The Beclin 1 interactome. Current Opinion in Cell Biology. 2010;22(2):140-149. doi:10.1016/j.ceb. 2010.01.001.
163.Ravikumar B, Imarisio S, Sarkar S, O'Kane CJ, Rubinsztein DC. Rab5 modulates aggregation and toxicity of mutant huntingtin through macroautophagy in cell and fly models of Huntington disease. Journal of Cell Science. 2008;121(Pt 10):1649-1660. doi:10.1242/ jcs.025726.

164. Young ARJ, Chan EYW, Hu XW, et al. Starvation and ULK1-dependent cycling of mammalian Atg9 between the TGN and endosomes. Journal of Cell Science. 2006;119(Pt 18):3888-3900. doi:10.1242/ jcs.03172.

165.Rusten TE, Stenmark H. How do ESCRT proteins control autophagy? Journal of Cell Science. 2009;122(Pt 13):2179-2183. doi:10.1242/jcs.050021.

166.Stroupe C. Autophagy: cells SNARE selves. Curr Biol. 2011;21(18):R697-9. doi: 10.1016/j.cub.2011.08.017.

167.Behrends C, Sowa ME, Gygi SP, Harper JW. Network organization of the human a utophagy system. Nature. 2010;466(7302):68-76. doi:10.1038/ nature09204.

168.Shinojima N, Yokoyama T, Kondo Y, Kondo S. Roles of the Akt/mTOR/p70S6K and ERK1/2 signaling pathways in curcumin-induced autophagy. Autophagy. 2007;3(6):635-637.

169.Loewith R, Jacinto E, Wullschleger S, et al. Two TOR complexes, only one of which is rapamycin sensitive, have distinct roles in cell growth control. Mol Cell. 2002;10(3):457-468.

170.Zoncu R, Efeyan A, Sabatini DM. mTOR: from growth signal integration to cancer, diabetes and ageing. Nat Rev Mol Cell Biol. 2011;12(1):21-35. doi:10.1038/ nrm3025.

171.Jung $\mathrm{CH}$, Ro S-H, Cao J, Otto NM, Kim D-H. mTOR regulation of autophagy. FEBS Letters. 2010;584(7):1287-1295. doi: 10.1016/j.febslet.2010.01.017. 
172.Hosokawa N, Hara T, Kaizuka T, et al. Nutrient-dependent mTORC1 Association with the ULK1-Atg13FIP200 Complex Required for Autophagy. Mol Biol Cell. 2009;20(7): 1981-1991. doi:10.1091/ mbc.E08-12-1248.

173.Sarkar S. Regulation of autophagy by mTOR-dependent and mTORindependent pathways: autophagy dysfunction in neurodegenerative diseases and therapeutic application of autophagy enhancers. Biochem Soc Trans. 2013;41(5):1103-1130. doi: 10.1042/BST20130134.

174. Meijer AJ. Amino acid regulation of autophagosome formation. Methods $\mathrm{Mol}$ Biol. 2008;445:89-109.doi: 10.1007/978-1-59745-157-4_5.

175.Nicklin P, Bergman P, Zhang B, et al. Bidirectional Transport of Amino Acids Regulates mTOR and Autophagy. Cell. 2009;136(3):521-534. doi:10.1016/j.cell. 2008.11.044.

176.Jewell JL, Russell RC, Guan K-L. Amino acid signalling upstream of mTOR. Nat Rev Mol Cell Biol. 2013;14(3):133-139. doi: $10.1038 /$ nrm3522.

177.Efeyan A, Zoncu R, Chang S, et al. Regulation of mTORC1 by the Rag GTPases is necessary for neonatal autophagy and survival. Nature. 2013;493(7434):679-683. doi:10.1038/ nature11745.

178.Lopiccolo J, Blumenthal G, Bernstein W, Dennis P. Targeting the PI3K/Akt/ mTOR pathway: Effective combinations and clinical considerations. Drug Resistance Updates. 2008;11(1-2):32-50. doi:10.1016/j.drup.2007.11.003.

179.Degtyarev M, De Mazière A, Orr C, et al. Akt inhibition promotes autophagy and sensitizes PTEN-null tumors to lysosomotropic agents. The Journal of Cell Biology. 2008;183(1):101-116. doi: 10.1083/jcb.200801099.
180.Yang Q, Inoki K, Kim E, Guan KL. TSC1/ TSC2 and Rheb have different effects on TORC1 and TORC2 activity. Proceedings of the National Academy of Sciences. 2006;103(18):6811-6816. doi:10.1073/ pnas.0602282103.

181.Inoki K, Li Y, Zhu T, Wu J, Guan K-L. TSC2 is phosphorylated and inhibited by Akt and suppresses mTOR signalling. Nature Cell Biology. 2002;4(9):648-657. doi:10.1038/ncb839.

182.Zhou J, Liao W, Yang J, et al. FOXO3 induces FOXO1-dependent autophagy by activating the AKT1 signaling pathway. Autophagy. 2012;8(12):1712-1723. doi: $10.4161 /$ auto. 21830 .

183.Inoki K, Zhu T, Guan K-L. TSC2 mediates cellular energy response to control cell growth and survival. Cell. 2003;115(5): 577-590.

184.Liang J, Shao SH, Xu Z-X, et al. The energy sensing LKB1-AMPK pathway regulates p27kip1 phosphorylation mediating the decision to enter autophagy or apoptosis. Nature Cell Biology. 2007;9(2):218-224. doi:10.1038/ ncb1537.

185.Sarkar S, Korolchuk VI, Renna M, et al. Complex inhibitory effects of nitric oxide on autophagy. Mol Cell. 2011;43(1): 19-32. doi:10.1016/j.molcel.2011.04.029.

186.Criollo A, Senovilla L, Authier H, et al. The IKK complex contributes to the induction of autophagy. The EMBO Journal. 2010;29(3):619-631. doi:10.1038/ emboj.2009.364.

187.Tasdemir E, Maiuri MC, Galluzzi L, et al. Regulation of autophagy by cytoplasmic p53. Nature Cell Biology. 2008;10(6):676687. doi:10.1038/ncb1730.

188.Papandreou I, Lim AL, Laderoute K, Denko NC. Hypoxia signals autophagy in tumor cells via AMPK activity, independent of HIF-1, BNIP3, and BNIP3L. Cell Death Differ. 2008;15(10): 1572-1581. doi:10.1038/cdd.2008.84. 
189.Skupin A, Falcke M. The role of IP3R clustering in $\mathrm{Ca} 2+$ signalinG. Genome Inform. 2008;20:15-24.

190. Majerus PW. Inositol phosphate biochemistry. Annu Rev Biochem. 1992;61:225-250. doi:10.1146/annurev.bi. 61.070192.001301.

191.Sarkar S, Floto RA, Berger Z, et al. Lithium induces autophagy by inhibiting inositol monophosphatase. The Journal of Cell Biology. 2005;170(7):1101-1111. doi: 10.1083/jcb.200504035.

192.Williams RSB, Cheng L, Mudge AW, Harwood AJ. A common mechanism of action for three mood-stabilizing drugs. Nature. 2002;417(6886):292-295. doi: $10.1038 / 417292 a$.

193.Williams A, Sarkar S, Cuddon P, et al. Novel targets for Huntington's disease in an mTOR-independent autophagy pathway. Nat Chem Biol. 2008;4(5):295305. doi:10.1038/nchembio.79.

194.Parys JB, Decuypere J-P, Bultynck G. Role of the inositol 1,4,5-trisphosphate receptor/Ca2+-release channel in autophagy. Cell Commun Signal. $2012 ; 10(1): 17$. d o i : 10.1186/1478-811X-10-17.

195.Gordon PB, Holen I, Fosse M, Røtnes JS, Seglen PO. Dependence of hepatocytic autophagy on intracellularly sequestered calcium. Journal of Biological Chemistry. 1993;268(35):26107-26112.

196.Ganley IG, Wong P-M, Gammoh N, Jiang X. Distinct autophagosomal-lysosomal fusion mechanism revealed by thapsigargin-induced autophagy arrest. Mol Cell. 2011;42(6):731-743. doi: 10.1016/j.molcel.2011.04.024.

197.Salminen A, Kaarniranta K, Kauppinen A. Beclin 1 interactome controls the crosstalk between apoptosis, autophagy and inflammasome activation: impact on the aging process. Ageing Res Rev. 2013;12(2):520-534. doi:10.1016/j.arr. 2012.11.004.
198.Zhong Y, Wang QJ, Li X, et al. Distinct regulation of autophagic activity by Atg14L and Rubicon associated with Beclin 1-phosphatidylinositol-3-kinase complex. Nature Cell Biology. 2009;11(4): 468-476. doi:10.1038/ncb1854.

199.Fimia GM, Stoykova A, Romagnoli A, et al. Ambra1 regulates autophagy and development of the nervous system. Nature. 2007;447(7148):1121-1125. doi: 10.1038 /nature05925.

200.Ciechomska IA, Goemans GC, Skepper JN, Tolkovsky AM. Bcl-2 complexed with Beclin-1 maintains full anti-apoptotic function. 2009;28(21):2128-2141. doi: 10.1038/onc. 2009.60 .

201.Abrahamsen H, Stenmark H, Platta HW. Ubiquitination and phosphorylation of Beclin 1 and its binding partners: Tuning class III phosphatidylinositol 3kinase activity and tumor suppression. FEBS Letters. 2012;586(11):1584-1591. doi:10.1016/j.febslet.2012.04.046.

202.Cabaner C, Gajate C, Macho A, Muñoz E, Modolell M, Mollinedo F. Induction of apoptosis in human mitogen-activated peripheral blood T-lymphocytes by the ether phospholipid ET-18-OCH3: Involvement of the Fas receptor/ligand system. Br J Pharmacol. 1999;127(4):813825.

203.Chomczynski P, Sacchi N. Single-step method of RNA isolation by acid guanidinium thiocyanate-phenolchloroform extraction. Anal Biochem. 1987;162(1):156-159. doi:10.1006/abio. 1987.9999.

204.Bradford MM. A rapid and sensitive method for the quantitation of microgram quantities of protein utilizing the principle of protein-dye binding. Anal Biochem. 1976;72:248-254.

205.Myc A, Pizzolo JG, Dygulski K, Melamed MR. Increase in acridine orange (ao) fluorescence intensity of monocytes cultured in plastic tissue culture plates as measured by flow cytometry. Cytometry. 1992;13(1):103-107. 
206.Eng KE, Panas MD, Hedestam GBK, McInerney GM. A novel quantitative flow cytometry-based assay for autophagy. Autophagy. 2010;6(5):634641. doi:10.4161/auto.6.5.12112.

207. Burbach BJ, Medeiros RB, Mueller KL, Shimizu Y. T-cell receptor signaling to integrins. Immunol Rev. 2007;218(1):6581. doi:10.1111/j.1600-065X.2007.00527.x.

208.Zea AH, Rodriguez PC, Culotta KS, et al. LArginine modulates CD3zeta expression and $\mathrm{T}$ cell function in activated human T lymphocytes. Cell Immunol. 2004;232(1-2):21-31. doi:10.1016/ j.cellimm.2005.01.004.

209.Zaborske JM, Narasimhan J, Jiang L, et al. Genome-wide Analysis of tRNA Charging and Activation of the eIF2 Kinase Gcn2p. J Biol Chem. 2009;284(37): $25254-25267$. d o i : 10.1074 / jbc.M109.000877.

210.Schneider U, Schwenk HU, Bornkamm G. Characterization of EBV-genome negative "null" and " $\mathrm{T}$ " cell lines derived from children with acute lymphoblastic leukemia and leukemic transformed non-Hodgkin lymphoma. Int J Cancer. 1977;19(5):621-626.

211.Sudduth-Klinger J, Schumann M, Gardner P, Payan DG. Functional and immunological responses of Jurkat lymphocytes transfected with the substance P receptor. Cell Mol Neurobiol. 1992;12(5):379-395.

212.Hinnebusch AG. Translational regulation of GCN4 and the general amino acid control of yeast. Annu Rev Microbiol. 2005;59:407-450. doi:10.1146/ annurev.micro.59.031805.133833.

213.Marina S Gorbatyuk OSG. The Molecular Chaperone GRP78/BiP as a Therapeutic Target for Neurodegenerative Disorders: A Mini Review. Journal of genetic syndrome $\mathcal{E}$ gene therapy. $2013 ; 4$ ( 2 ). d o i : 10.4172/2157-7412.1000128.
214.Scheuner D, Song B, McEwen E, et al. Translational Control Is Required for the Unfolded Protein Response and In Vivo Glucose Homeostasis. Mol Cell. 2001;7(6):1165-1176. doi:10.1016/ S1097-2765(01)00265-9.

215.Xu C. Endoplasmic reticulum stress: cell life and death decisions. Journal of Clinical Investigation. 2005;115(10):2656-2664. doi:10.1172/JCI26373.

216.Schröder M, Kaufman RJ. ER stress and the unfolded protein response. Mutation Research/Fundamental and Molecular Mechanisms of Mutagenesis. 2005;569(1-2):29-63. doi:10.1016/ j.mrfmmm.2004.06.056.

217. Hamanaka RB, Bennett BS, Cullinan SB, Diehl JA. PERK and GCN2 contribute to eIF2alpha phosphorylation and cell cycle arrest after activation of the unfolded protein response pathway. $\mathrm{Mol}$ Biol Cell. 2005;16(12):5493-5501. doi: 10.1091/mbc.E05-03-0268.

218.Romano PR, Garcia-Barrio MT, Zhang X, et al. Autophosphorylation in the activation loop is required for full kinase activity in vivo of human and yeast eukaryotic initiation factor 2alpha kinases PKR and GCN2. Molecular and Cellular Biology. 1998;18(4):2282-2297.

219. Chen JJ, London IM. Regulation of protein synthesis by heme-regulated eIF-2 alpha kinase. Trends Biochem Sci. 1995;20(3): 105-108.

220.Hirota M, Kitagaki M, Itagaki H, Aiba S. Quantitative measurement of spliced XBP1 mRNA as an indicator of endoplasmic reticulum stress. J Toxicol Sci. 2006;31(2):149-156.

221.Samali A, FitzGerald U, Deegan S, Gupta S. Methods for Monitoring Endoplasmic Reticulum Stress and the Unfolded Protein Response. International Journal of Cell Biology. 2010;2010(11):1-11. doi: 10.1074/jbc.M505784200.

222.Lazar C, Macovei A, Petrescu S, BranzaNichita N. Activation of ERAD Pathway 
by Human Hepatitis B Virus Modulates Viral and Subviral Particle Production. Ryu W-S, ed. PLoS ONE. 2012;7(3):e34169. doi:10.1371/ journal.pone.0034169.s002.

223.Kosmaoglou M, Kanuga N, Aguila M, Garriga P, Cheetham ME. A dual role for EDEM1 in the processing of rod opsin. Journal of Cell Science. 2009;122(24):44654472. doi:10.1242/jcs.055228.

224.Chen X, Yin XM. Coordination of autophagy and the proteasome in resolving endoplasmic reticulum stress. Vet Pathol. 2011;48(1):245-253. doi: $10.1177 / 0300985810385154$

225.Craiu A, Gaczynska M, Akopian T, et al. Lactacystin and clasto-lactacystin betalactone modify multiple proteasome beta-subunits and inhibit intracellular protein degradation and major histocompatibility complex class I antigen presentation. J Biol Chem. 1997;272(20):13437-13445.

226.Ouchida R, Yamasaki S, Hikida M, et al. A Lysosomal Protein Negatively Regulates Surface $\mathrm{T}$ Cell Antigen Receptor Expression by Promoting CD3 $\zeta$-Chain Degradation. Immunity. 2008;29(1):3343. doi:10.1016/j.immuni.2008.04.024.

227.Ersek B, Molnar V, Balogh A, et al. CD3 Chain Expression of Human $\mathrm{T}$ Lymphocytes Is Regulated by TNF via Src-like Adaptor Protein-Dependent Proteasomal Degradation. The Journal of Immunology. 2012;189(4):1602-1610. doi: 10.4049/jimmunol.1102365.

228. Breckenridge DG, Germain M, Mathai JP, Nguyen M, Shore GC. Regulation of apoptosis by endoplasmic reticulum pathways. Oncogene. 2003;22(53):86088618. doi:10.1038/sj.onc.1207108.

229.Ding W-X, Ni H-M, Gao W, et al. Linking of Autophagy to Ubiquitin-Proteasome System Is Important for the Regulation of Endoplasmic Reticulum Stress and Cell Viability. The American Journal of Pathology. 2007;171(2):513-524. doi: 10.2353/ajpath.2007.070188.
230. Yorimitsu T. Endoplasmic Reticulum Stress Triggers Autophagy. Journal of Biological Chemistry. 2006;281(40):30299-30304. doi:10.1074/jbc.M607007200.

231.Ogata M, Hino SI, Saito A, et al. Autophagy Is Activated for Cell Survival after Endoplasmic Reticulum Stress. Molecular and Cellular Biology. 2006;26(24):9220-9231. doi:10.1128/ MCB.01453-06.

232.Paglin S, Hollister T, Delohery T, et al. A Novel Response of Cancer Cells to Radiation Involves Autophagy and Formation of Acidic Vesicles. Cancer Research. 2001.

233.Han J, Burgess K. Fluorescent Indicators for Intracellular pH. Chem Rev. 2010;110(5): 2709-2728. doi:10.1021/cr900249z.

234.Darzynkiewicz Z. Flow cytometric methods for RNA content analysis. Methods. 1991;2(3):200-206. doi:10.1016/ S1046-2023(05)80062-3.

235.Xi G, Hu X, Wu B, et al. Autophagy inhibition promotes paclitaxel-induced apoptosis in cancer cells. CANCER LETTERS. 2011;307(2):141-148. doi: 10.1016/j.canlet.2011.03.026.

236.Shvets E, Fass E, Elazar Z. Utilizing flow cytometry to monitor autophagy in living mammalian cells. Autophagy. 2008;4(5):621-628.

237.Mizushima N, Yoshimori T, Levine B. Methods in Mammalian Autophagy Research. Cell. 2010.

238. Meijer AJ, Codogno P. Regulation and role of autophagy in mammalian cells. The International Journal of Biochemistry $\mathcal{E}$ Cell Biology. 2004;36(12):2445-2462. doi: 10.1016/j.biocel.2004.02.002.

239. Urano F. Coupling of Stress in the ER to Activation of JNK Protein Kinases by Transmembrane Protein Kinase IRE1. Science. 2000;287(5453):664-666. doi: $10.1126 /$ science. 287.5453 .664 . 
240.Kang R, Zeh HJ, Lotze MT, Tang D. The Beclin 1 network regulates autophagy and apoptosis. Cell Death Differ. 2011;18(4):571-580. doi:10.1038/cdd. 2010.191.

241.Schröder M. Endoplasmic reticulum stress responses. Cell Mol Life Sci. 2007;65(6): 862-894. doi:10.1007/s00018-007-7383-5.

242.Rutkowski DT, Kaufman RJ. A trip to the ER: coping with stress. Trends in Cell Biology. 2004;14(1):20-28. doi:10.1016/ j.tcb.2003.11.001.

243.Meijer AJ, Gustafson LA, Luijken JJ, et al. Cell Swelling and the sensitivity of autophagic proteolysis to inhibition by amino acids in isolated rat hepatocytes. Eur J Biochem. 1993;215(2):449-454. doi: 10.1111/j.1432-1033.1993.tb18053.x.

244.Cairns RA, Harris IS, Mak TW. Regulation of cancer cell metabolism. Nat Rev Cancer. 2011;11(2):85-95. doi:10.1038/ nrc2981.

245.Fu Y-M, Meadows GG. Specific amino acid dependency regulates the cellular behavior of melanoma. J Nutr. 2007;137(6 Suppl 1):1591S-1596Sdiscussion 1597S-1598S.

246. Müller $H$. Use of L-asparaginase in childhood ALL. Critical Reviews in Oncology/Hematology. 1998;28(2):97-113. doi:10.1016/S1040-8428(98)00015-8.

247.Lorenzi PL, Llamas J, Gunsior M, et al. Asparagine synthetase is a predictive biomarker of L-asparaginase activity in ovarian cancer cell lines. Molecular Cancer Therapeutics. 2008;7(10):31233128 . d o i : 10.1158/1535-7163.MCT-08-0589.

248. Cooney DA, Handschumacher RE. Lasparaginase and L-asparagine metabolism. Annu Rev Pharmacol. 1970;10:421-440. doi:10.1146/ annurev.pa.10.040170.002225.

249.Cellarier E, Durando X, Vasson MP, et al. Methionine dependency and cancer treatment. Cancer Treat Rev. 2003;29(6): 489-499.

250.Fu Y-M, Yu Z-X, Li Y-Q, et al. Specific amino acid dependency regulates invasiveness and viability of androgen-independent prostate cancer cells. Nutr Cancer. 2003;45(1):60-73. doi:10.1207/ S15327914NC4501_8.

251.Shanware NP, Mullen AR, DeBerardinis RJ, Abraham RT. Glutamine: pleiotropic roles in tumor growth and stress resistance. J Mol Med. 2011;89(3):229236. doi:10.1007/s00109-011-0731-9.

252.Wasa M, Bode BP, Souba WW. Adaptive regulation of amino acid transport in nutrient-deprived human hepatomas. Am J Surg. 1996;171(1):163-169. doi: 10.1016/S0002-9610(99)80093-2.

253.Ensor CM, Holtsberg FW, Bomalaski JS, Clark MA. Pegylated arginine deiminase (ADI-SS PEG20,000 $\mathrm{mw}$ ) inhibits human melanomas and hepatocellular carcinomas in vitro and in vivo. Cancer Research. 2002;62(19): 5443-5450.

254.Bowles TL, Kim R, Galante J, et al. Pancreatic cancer cell lines deficient in argininosuccinate synthetase are sensitive to arginine deprivation by arginine deiminase. Int $J$ Cancer. 2008;123(8):1950-1955. doi:10.1002/ijc. 23723.

255.Gong H, Zölzer F, Recklinghausen von G, Havers W, Schweigerer L. Arginine deiminase inhibits proliferation of human leukemia cells more potently than asparaginase by inducing cell cycle arrest and apoptosis. Leukemia. 2000;14(5):826-829.

256.Hernandez CP, Morrow K, Lopez-Barcons LA, et al. Pegylated arginase I: a potential therapeutic approach in $\mathrm{T}$ ALL. Blood. 2010;115(25):5214-5221. doi: 10.1182/blood-2009-12-258822.

257. Wheatley DN, Scott L, Lamb J, Smith S. Single amino acid (arginine) restriction: growth and death of cultured HeLa and 
human diploid fibroblasts. Cell Physiol Biochem. 2000;10(1-2):37-55.

258.Balkwill F, Mantovani A. Inflammation and cancer: back to Virchow? The Lancet. 2001;357(9255):539-545. doi:10.1016/ S0140-6736(00)04046-0.

259.Murdoch C, Muthana M, Coffelt SB, Lewis $\mathrm{CE}$. The role of myeloid cells in the promotion of tumour angiogenesis. Nat Rev Cancer. 2008;8(8):618-631. doi:doi: $10.1038 /$ nrc2444.

260.Shoemaker RH. The NCI60 human tumour cell line anticancer drug screen. Nat Rev Cancer. 2006;6(10):813-823. doi:10.1038/ nrc1951.

261.Witko-Sarsat V, Rieu P, Descamps-Latscha B, Lesavre P, Halbwachs-Mecarelli L. Neutrophils: molecules, functions and pathophysiological aspects. Lab Invest. 2000;80(5):617-653.

262.Tenu JP, Lepoivre M, Moali C, Brollo M, Mansuy D, Boucher JL. Effects of the new arginase inhibitor $\mathrm{N}$ (omega)hydroxy-nor-L-arginine on NO synthase activity in murine macrophages. Nitric Oxide. 1999;3(6):427-438. doi:10.1006/ niox.1999.0255.

263.Mollinedo F. Human neutrophil granules and exocytosis molecular control.Inmunología. 2003;22(4):340-358.

264.Borregaard N, Cowland JB. Granules of the human neutrophilic polymorphonuclear leukocyte. Blood. 1997;89(10):3503-3521.

265.Ivanov AI. Exocytosis and endocytosis. Methods in Molecular Biology. 2008;440.

266.Martín-Martín B, Nabokina SM, Blasi J, Lazo PA, Mollinedo F. Involvement of SNAP-23 and syntaxin 6 in human neutrophil exocytosis. Blood. 2000;96(7): 2574-2583.

267.Mollinedo F, Calafat J, Janssen H, et al. Combinatorial SNARE complexes modulate the secretion of cytoplasmic granules in human neutrophils. J Immunol. 2006;177(5):2831-2841.
268.Herrero-Turrión MJ, Calafat J, Janssen H, Fukuda M, Mollinedo F. Rab27a regulates exocytosis of tertiary and specific granules in human neutrophils. The Journal of Immunology. 2008;181(6): 3793-3803.

269.Lacy P. Mechanisms of Degranulation in Neutrophils. Allergy, Asthma \& Clinical Immunology. 2006;2(3):98. doi:10.1056/ NEJM200007273430407.

270.Thomas CG, Spyrou G. ERdj5 Sensitizes Neuroblastoma Cells to Endoplasmic Reticulum Stress-induced Apoptosis. Journal of Biological Chemistry. 2008;284(10):6282-6290. doi:10.1074/ jbc.M806189200.

271.Kim R, Emi M, Tanabe K, Murakami S. Role of the unfolded protein response in cell death. Apoptosis. 2006;11(1):5-13. doi: 10.1007/s10495-005-3088-0.

272.Han J, Back SH, Hur J, et al. ER-stressinduced transcriptional regulation increases protein synthesis leading to cell death. Nature Cell Biology. 2013;15(5):481-490. doi:10.1038/ ncb2738.

273. Yamaguchi $H$, Wang $H-G$. CHOP is involved in endoplasmic reticulum stress-induced apoptosis by enhancing DR5 expression in human carcinoma cells. J Biol Chem. 2004;279(44):4549545502. doi:10.1074/jbc.M406933200.

274.Lee AS. The ER chaperone and signaling regulator GRP78/BiP as a monitor of endoplasmic reticulum stress. Methods. 2005;35(4):373-381. doi:10.1016/j.ymeth. 2004.10.010.

275.Li J, Lee AS. Stress induction of GRP78/BiP and its role in cancer. Curr Mol Med. 2006;6(1):45-54.

276.Jakubowski H. Quality control in tRNA charging. Wiley Interdiscip Rev RNA. 2012;3(3):295-310. doi:10.1002/wrna. 122.

277.Zaborske JM, Wu X, Wek RC, Pan T. Selective control of amino acid 
metabolism by the GCN2 eIF2 kinase pathway in Saccharomyces cerevisiae. BMC Biochem. 2010;11:29. doi: 10.1186/1471-2091-11-29.

278.Krishnamoorthy T, Pavitt GD, Zhang F, Dever TE, Hinnebusch AG. Tight Binding of the Phosphorylated Subunit of Initiation Factor 2 (eIF2 $\alpha$ ) to the Regulatory Subunits of Guanine Nucleotide Exchange Factor eIF2B Is Required for Inhibition of Translation Initiation. Molecular and Cellular Biology. 2001;21(15):5018-5030. doi:10.1128/ MCB.21.15.5018-5030.2001.

279. Yang X. ATF4, the Osteoblast Accumulation of Which Is Determined Posttranslationally, Can Induce Osteoblastspecific Gene Expression in Nonosteoblastic Cells. Journal of Biological Chemistry. 2004;279(45):47109-47114. doi:10.1074/jbc.M410010200.

280.Rzymski T, Milani M, Singleton DC, Harris AL. Role of ATF4 in regulation of autophagy and resistance to drugs and hypoxia. Cell Cycle. 2009;8(23):38383847.

281.B'chir W, Maurin A-C, Carraro V, et al. The eIF2 $\alpha$ /ATF4 pathway is essential for stress-induced autophagy gene expression. Nucleic Acids Res. 2013;41(16):7683-7699. doi:10.1093/nar/ gkt563.

282.Rzymski T, Milani M, Pike L, et al. Regulation of autophagy by ATF4 in response to severe hypoxia. Oncogene. 2010;29(31):4424-4435. doi:10.1038/onc. 2010.191.

283.Fujita N, Itoh T, Omori H, Fukuda M, Noda $\mathrm{T}$, Yoshimori T. The Atg16L Complex Specifies the Site of LC3 Lipidation for Membrane Biogenesis in Autophagy. Mol Biol Cell. 2008;19(5):2092-2100. doi: 10.1091/mbc.E07-12-1257.

284.Fougeray S, Mami I, Bertho G, Beaune P, Thervet E, Pallet N. Tryptophan depletion and the kinase GCN2 mediate IFN- $\gamma$-induced autophagy. The Journal of
Immunology. 2012;189(6):2954-2964. doi: 10.4049/jimmunol.1201214.

285.Alcover A, Alarcón B. Internalization and intracellular fate of TCR-CD3 complexes. Crit Rev Immunol. 2000;20(4): 325-346.

286.Dasgupta JD, Cemach K, Dubey DP, Yunis EJ, Amos DB. The role of class I histocompatibility antigens in the regulation of T-cell activation. Proc Natl Acad Sci USA. 1987;84(4):1094-1098.

287.Dietrich J, Kastrup J, Lauritsen JPH, Menné C, Bülow von F, Geisler C. TCR $\zeta$ is transported to and retained in the Golgi apparatus independently of other TCR chains: implications for TCR assembly. Eur J Immunol. 1999;29(5):1719-1728.

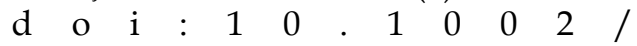
(SICI)1521-4141(199905)29:05<1719::AID -IMMU1719>3.0.CO;2-M.

288. Ono S, Ohno H, Saito T. Rapid turnover of the CD3 zeta chain independent of the TCR-CD3 complex in normal $\mathrm{T}$ cells. Immunity. 1995;2(6):639-644.

289.San José E, Borroto A, Niedergang F, Alcover A, Alarcón B. Triggering the TCR complex causes the downregulation of nonengaged receptors by a signal transduction-dependent mechanism. Immunity. 2000;12(2):161-170.

290.Martin EP, Arnaud J, Alibaud L, et al. Molecular mechanisms in the TCR (TCR alpha beta-CD3 delta epsilon, gamma epsilon) interaction with zeta 2 homodimers: clues from a "phenotypic revertant" clone. Int Immunol. 1999;11(7): 1005-1015.

291.Plongthongkum N, Kullawong N, Panyim S, Tirasophon $\mathrm{W}$. Ire1 regulated XBP1 mRNA splicing is essential for the unfolded protein response (UPR) in Drosophila melanogaster. Biochemical and Biophysical Research Communications. 2007;354(3):789-794. doi:10.1016/j.bbrc. 2007.01.056.

292.René L Vidal CH. Crosstalk between the UPR and autophagy pathway 
contributes to handling cellular stress in neurodegenerative disease. Autophagy. 2012;8(6):970. doi:10.4161/auto.20139.

293.Kouroku Y, Fujita E, Tanida I, et al. ER stress (PERK/eIF $2 \alpha$ phosphorylation) mediates the polyglutamine-induced LC3 conversion, an essential step for autophagy formation. Cell Death Differ. 2006;14(2):230-239. doi:10.1038/sj.cdd. 4401984.

294.Liang XH, Kleeman LK, Jiang HH, et al. Protection against Fatal Sindbis Virus Encephalitis by Beclin, a Novel Bcl-2Interacting Protein. Journal of .... 1998.

295.Pu Y, Bassham DC. Links between ER stress and autophagy in plants. Plant Signal Behav. 2013;8(6). doi:10.4161/psb.24297.

296.Matsumoto H, Miyazaki S, Matsuyama S, et al. Selection of autophagy or apoptosis in cells exposed to ER-stress depends on ATF4 expression pattern with or without CHOP expression. Biol Open. 2013;2(10):1084-1090. doi:10.1242/bio. 20135033.

297.Mahoney E, Lucas DM, Gupta SV, et al. ER stress and autophagy: new discoveries in the mechanism of action and drug resistance of the cyclin-dependent kinase inhibitor flavopiridol. Blood. 2012;120(6):1262-1273. doi:10.1182/ blood-2011-12-400184.

298. Velentzas PD, Velentzas AD, Mpakou VE, et al. Detrimental effects of proteasome inhibition activity in Drosophila melanogaster: implication of ER stress, autophagy, and apoptosis. Cell Biol Toxicol. 2013;29(1):13-37. doi:10.1007/ s10565-012-9235-9.

299.Pehar M, Jonas MC, Hare TM, Puglielli L. SLC33A1/AT-1 protein regulates the induction of autophagy downstream of IRE1/XBP1 pathway. Journal of Biological Chemistry. 2012;287(35):29921-29930. doi:10.1074/jbc.M112.363911.

300.Takeuchi H, Kondo Y, Fujiwara K, et al. Synergistic Augmentation of Rapamycin-Induced Autophagy in
Malignant Glioma Cells by Phosphatidylinositol 3-Kinase/Protein Kinase B Inhibitors. Cancer Research. 2005.

301.Oh S-H, Lim S-C. Endoplasmic reticulum stress-mediated autophagy/apoptosis induced by capsaicin (8-methyl-Nvanillyl-6-nonenamide) and dihydrocapsaicin is regulated by the extent of c-Jun NH2-terminal kinase/ extracellular signal-regulated kinase activation in WI38 lung epithelial fibroblast cells. J Pharmacol Exp Ther. 2009;329(1):112-122. doi:10.1124/jpet. 108.144113.

302.Ellington AA, Berhow MA, Singletary KW. Inhibition of Akt signaling and enhanced ERK1/2 activity are involved in induction of macroautophagy by triterpenoid B-group soyasaponins in colon cancer cells. Carcinogenesis. 2006;27(2):298-306. doi:10.1093/carcin/ bgi214.

303.Nishitoh H. CHOP is a multifunctional transcription factor in the ER stress response. J Biochem. 2012;151(3):217-219. doi: $10.1093 / \mathrm{jb} / \mathrm{mvr} 143$.

304.Hitomi J, Katayama T, Eguchi Y, et al. Involvement of caspase-4 in endoplasmic reticulum stress-induced apoptosis and Abeta-induced cell death. The Journal of Cell Biology. 2004;165(3): 347-356. doi:10.1083/jcb.200310015.

305.Jimbo A, Fujita E, Kouroku Y, et al. ER stress induces caspase-8 activation, stimulating cytochrome $\mathrm{c}$ release and caspase-9 activation. Experimental Cell Research. 2003;283(2):156-166.

306.Kanazawa T, Taneike I, Akaishi R, et al. Amino acids and insulin control autophagic proteolysis through different signaling pathways in relation to mTOR in isolated rat hepatocytes. J Biol Chem. 2004;279(9):8452-8459. doi:10.1074/ jbc.M306337200.

307.Mortimore GE, Wert JJ, Adams CE. Modulation of the amino acid control of hepatic protein degradation by caloric 
deprivation. Two modes of alanine coregulation. J Biol Chem. 1988;263(36): 19545-19551.

308.Mortimore GE, Pösö AR, Kadowaki M, Wert JJ. Multiphasic control of hepatic protein degradation by regulatory amino acids. General features and hormonal modulation. J Biol Chem. 1987;262(34): 16322-16327.

309.Pestova TV, Kolupaeva VG, Lomakin IB, et al. Molecular mechanisms of translation initiation in eukaryotes. Proc Natl Acad Sci USA. 2001;98(13):7029-7036. doi: 10.1073/pnas.111145798.

310.Dinndorf PA, Gootenberg J, Cohen MH, Keegan P, Pazdur R. FDA Drug Approval Summary: Pegaspargase (Oncaspar(R)) for the First-Line Treatment of Children with Acute Lymphoblastic Leukemia (ALL). The Oncologist. 2007;12(8):991-998. doi: 10.1634/theoncologist.12-8-991.

311.Keating GM. Asparaginase Erwinia chrysanthemi (Erwinaze ${ }^{\circledR}$ ): A Guide to Its Use in Acute Lymphoblastic Leukemia in the USA. BioDrugs. 2013;27(4):413-418. doi:10.1007/ s40259-013-0051-4.

312.Dillon BJ, Prieto VG, Curley SA, et al. Incidence and distribution of argininosuccinate synthetase deficiency in human cancers. Cancer. 2004;100(4): 826-833. doi:10.1002/cncr.20057.

313. Wheatley DN, Kilfeather R, Stitt A, Campbell E. Integrity and stability of the citrulline-arginine pathway in normal and tumour cell lines. CANCER LETTERS. 2005;227(2):141-152. doi: 10.1016/j.canlet.2005.01.004.

314.Gong H, Zölzer F, Recklinghausen von G, et al. Arginine Deiminase Inhibits Cell Proliferation by Arresting Cell Cycle and Inducing Apoptosis. Biochemical and Biophysical Research Communications. 1999;261(1):10-14. doi:10.1006/bbrc. 1999.1004
315.Noh E-J, Kang S-W, Shin Y-J, et al. Arginine deiminase enhances dexamethasoneinduced cytotoxicity in human Tlymphoblastic leukemia CCRF-CEM cells. Int J Cancer. 2004;112(3):502-508. doi:10.1002/ijc.20435.

316.Lam TL, Wong GKY, Chong HC, et al. Recombinant human arginase inhibits proliferation of human hepatocellular carcinoma by inducing cell cycle arrest. CANCER LETTERS. 2009;277(1):91-100. doi:10.1016/j.canlet.2008.11.031.

317.Hsueh EC, Knebel SM, Lo W-H, Leung Y-C, Cheng PN-M, Hsueh C-T. Deprivation of arginine by recombinant human arginase in prostate cancer cells. $J$ Hematol Oncol. 2012;5:17. doi: 10.1186/1756-8722-5-17.

318.Kuo MT, Savaraj N, Feun LG. Targeted cellular metabolism for cancer chemotherapy with recombinant arginine-degrading enzymes. Oncotarget. 2010;1(4):246-251.

319.Breckenridge DG, Stojanovic M, Marcellus $\mathrm{RC}$, Shore GC. Caspase cleavage product of BAP31 induces mitochondrial fission through endoplasmic reticulum calcium signals, enhancing cytochrome $\mathrm{c}$ release to the cytosol. EMBO Rep. 2006;7(9):880-885. doi:10.1038/sj.embor.7400779.

320.Brauns SC, Dealtry G, Milne P, Naudé R, Van de Venter M. Caspase-3 activation and induction of PARP cleavage by cyclic dipeptide cyclo(Phe-Pro) in HT-29 cells. Anticancer Res. 2005;25(6B):41974202.

321.Goping IS, Barry M, Liston $\mathrm{P}$, et al. Granzyme B-induced apoptosis requires both direct caspase activation and relief of caspase inhibition. Immunity. 2003;18(3):355-365.

322.Potenza MA, Nacci C, Mitolo-Chieppa D. Immunoregulatory Effects of L-Arginine and Therapeutical Implications. curr drug targets immune endocr metabol disord. $2001 ; 1(1): 67-77 . \quad$ d o i : $10.2174 / 1568008013341811$. 
323.Evoy D, Lieberman MD, Fahey TJ, Daly JM. Immunonutrition: the role of arginine. Nutrition. 1998;14(7-8):611-617.

324. Raber P, Ochoa AC, Rodriguez PC. Metabolism of L-Arginine by MyeloidDerived Suppressor Cells in Cancer: Mechanisms of $\mathrm{T}$ cell suppression and Therapeutic Perspectives. Immunol Invest. 2012;41(6-7):614-634. doi: 10.3109/08820139.2012.680634.

325. Bansal V, Rodriguez P, Wu G, et al. Citrulline Can Preserve Proliferation and Prevent the Loss of CD3 Chain Under Conditions of Low Arginine. JPEN J Parenter Enteral Nutr. 2004;28(6): $423-430$. d o i : $10.1177 / 0148607104028006423$.

326.Dobrzanski MJ. Expanding roles for CD4 T cells and their subpopulations in tumor immunity and therapy. Front Oncol. 2013;3:63. doi:10.3389/fonc.2013.00063.

327.Mollinedo F, Martín-Martín B, Calafat J, Nabokina SM, Lazo PA. Role of vesicleassociated membrane protein-2, through Q-soluble N-ethylmaleimide-sensitive factor attachment protein receptor/Rsoluble N-ethylmaleimide-sensitive factor attachment protein receptor interaction, in the exocytosis of specific and tertiary granules of human neutrophils. J Immunol. 2003;170(2): 1034-1042.

328.Dallegri F, Ottonello L, Ballestrero A, et al. Tumor cell lysis by activated human neutrophils: analysis of neutrophildelivered oxidative attack and role of leukocyte function-associated antigen 1. Inflammation. 1991;15(1):15-30.

329.Nakatani Y, Yamazaki M, Chazin WJ, Yui S. Regulation of S100A8/A9 (calprotectin) binding to tumor cells by zinc ion and its implication for apoptosis-inducing activity. Mediators Inflamm. 2005;2005(5): 280-292. doi:10.1155/MI.2005.280.

330.Kong YY, Fuchsberger M, Xiang SD, Apostolopoulos V, Plebanski M. Myeloid derived suppressor cells and their role in diseases. Curr Med Chem. 2013;20(11):1437-1444.

331.Gregory AD, Houghton AM. Tumorassociated neutrophils: new targets for cancer therapy. Cancer Research. $2011 ; 71$ ( 7 ): $2411-2416$. d o i : 10.1158/0008-5472.CAN-10-2583.

332.Weitzman SA, Weitberg AB, Clark EP, Stossel TP. Phagocytes as carcinogens: malignant transformation produced by human neutrophils. Science. 1985;227(4691):1231-1233.

333.Tamatani T, Turk P, Weitzman S, Oyasu R. Tumorigenic conversion of a rat urothelial cell line by human polymorphonuclear leukocytes activated by lipopolysaccharide. Jpn J Cancer Res. 1999;90(8):829-836.

334.Mishalian I, Bayuh R, Levy L, Zolotarov L, Michaeli J, Fridlender ZG. Tumorassociated neutrophils (TAN) develop pro-tumorigenic properties during tumor progression. Cancer Immunol Immunother. 2013;62(11):1745-1756. doi: $10.1007 /$ s00262-013-1476-9.

335.Piccard H, Muschel RJ, Opdenakker G. On the dual roles and polarized phenotypes of neutrophils in tumor development and progression. Critical Reviews in Oncology/Hematology. 2012;82(3):296309. doi:10.1016/j.critrevonc. 2011.06.004.

336. Chen Y-L, Chen S-H, Wang J-Y, Yang B-C. Fas ligand on tumor cells mediates inactivation of neutrophils. I Immunol. 2003;171(3):1183-1191.

337.Hubert P, Heitzmann A, Viel S, et al. Antibody-dependent cell cytotoxicity synapses form in mice during tumorspecific antibody immunotherapy. Cancer Research. 2011;71(15):5134-5143. doi:10.1158/0008-5472.CAN-10-4222. 